Portland State University

PDXScholar

\title{
Building on the Strengths of Indigenous Knowledge to Promote Sustainable Development in Crisis Conditions from the Community Level: The Case of Palestine
}

Jehad Yousif Alayasa

Portland State University

Follow this and additional works at: https://pdxscholar.library.pdx.edu/open_access_etds

Part of the Public Affairs Commons, and the Public Policy Commons Let us know how access to this document benefits you.

\section{Recommended Citation}

Alayasa, Jehad Yousif, "Building on the Strengths of Indigenous Knowledge to Promote Sustainable Development in Crisis Conditions from the Community Level: The Case of Palestine" (2012). Dissertations and Theses. Paper 121.

https://doi.org/10.15760/etd.121

This Dissertation is brought to you for free and open access. It has been accepted for inclusion in Dissertations and Theses by an authorized administrator of PDXScholar. Please contact us if we can make this document more accessible: pdxscholar@pdx.edu. 
Building on the Strengths of Indigenous Knowledge to Promote Sustainable Development in Crisis Conditions from the Community Level:

The Case of Palestine

by

Jehad Yousif Alayasa

A dissertation submitted in partial fulfillment of the requirements for the degree of

\author{
Doctor of Philosophy \\ in \\ Public Affairs and Policy
}
Dissertation Committee:
Phillip Cooper, Chair
Ronald Tammen
Claudia M. Vargas
Jennifer Allen
Veronica Dujon

Portland State University

(C)2012 


\begin{abstract}
This study began focused on the use of traditional knowledge in promoting sustainable development in crisis conditions. Presented the question: How have successful community- level sustainable development efforts undertaken under crisis conditions drawn upon indigenous knowledge to achieve positive outcomes? The study is a cross case analysis. The three cases addressed in this study have explained some of the ways that indigenous knowledge has played significant positive roles in promoting sustainable development for communities living under crisis conditions in Palestine. Indigenous knowledge community based patterns indicated significant focus on strengths of local culture, social cohesion, the integration process, and special advantages for policy implementation from the community level as key components of sustainable development in crisis conditions.

The study contributes to theory by analyzing common elements from the case studies and providing a set of testable propositions, grounded in those successful experiences that can be a starting point for building theory. Practically, the study has generated lessons that sustainable development policy implementers and decision makers can learn from when addressing sustainable development in different crisis conditions contexts.
\end{abstract}




\section{Dedication}

I lovingly dedicate this dissertation to: My children Sondos, Salsabeel, Mohammed and Istabraq who inspired me to overcome many challenges. I also dedicate the work to my Professors who guided me to meet my educational goals. And to my family, and my friends who supported me. 


\section{Acknowledgments}

My warm and sincere thanks are due to my advisor professor Phillip Cooper; for his sincere support, encouragement and thoughtful guidance. Professor Cooper's commitment to his students is distinguished. He is the one who worked hard and patiently with me during the course work and the dissertation work to make it successful. During this scientific journey, I learned the best academic skills from Professor Cooper.

I am also truly and deeply thankful to my dissertation committee members, professor Claudia Maria Vargas, professor Ronald Tammen, professor Jennifer Allen, and professor Veronica Dujon, for their helpful discussions and feedback that improved the quality of the work.

My deep thanks are also due to the Hatfield school of government administrative staff: Professor Ronald Tammen, the director of the school; professor David Kinsella; Betty Lewis; Becky Fidler; and Megan Loos, who over five years solved problems and made every thing easy for me. Their professional support indeed allowed me to focus on academic challenges.

I would like to thank all Hatfield School of Government's students, especially my cohort, for their continuous support especially during my first year.

Finally, my thanks, appreciations and regards are due to the Open Society Foundations and U.S. Aid for their generous sponsorship for the PFDP program that allowed me and many other students to have this opportunity. 


\section{Table of Contents}

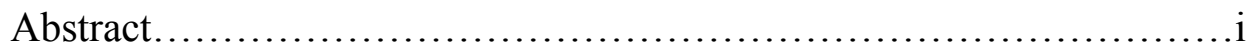

Dedication.......................................................

Acknowledgments.............................................ii

List of Figures..............................................

Chapter1

Introduction...........................................................

Chaper 2

The Literature of Sustainable Development in Crisis Conditions: .........54

The Need for more Attention to Indigenous Knowledge and Community Action

Chapter 3

Organic (Baladi), Extra Virgin Olive Oil Producing Project...............104

in Bani-Zaid Al-Sharkiya Community: "We Treat Olive Tree As we Treat our Children"

Chapter 4

Social and Economic Empowerment of Rural. 154

Women in the West Bank Women's Club's, Rural Women's Development

Association, and the Palestinian Agricultural Relief Committees

Chapter 5

Sulha Committees: An Indigenous Pattern of Conflict.

Resolution, The Case of Central Sulha Committee in the District of Jenin in the West Bank

Chapter 6

Cross Case Analysis: Lessons on the Use of Indigenous

Knowledge in Sustainable Development

References

Appendices

Appendix A

Appendix B.

Appendix C.

Appendix D 


\section{List of Figures}

Figure (1) Number of countries that have credit unions,.................184 number of unions, and number of its members 


\section{CHAPTER 1: INTRODUCTION}

This study focuses on efforts to implement sustainable development in crisis conditions. As the World Commission on Environment and Development, better known as the Brundtland Commission, explained in its seminal report (1987), the core problem for sustainable development is the need to integrate social development, economic development, and environmental protection to ensure "development that meet the needs of the present without compromising the ability of the future generations to meet their own needs" (World Commission on Environment and Development 1987, p. 8, Cooper and Vargas 2004, p. 3). And as that report and subsequent studies indicate, too often the social development dimension of the living triangle has been ignored or dramatically undervalued as those involved in development have concentrated on economic development and environmental protection (World Commission on Environment and Development 1987). In addition to the important ongoing problem of lack of focus on social aspects, sustainable development is particularly important and especially challenging in crisis conditions that include war, terrorism, and civil disorder and their aftermath (Cooper and Vargas 2008, World Bank 2003). This research specifically considers the challenges of sustainable development in the Palestinian context with sensitivity to the need for the integration of all three elements of the living triangle and with concern for the special challenges presented by efforts to achieve sustainable development in crisis conditions.

For reasons that will be addressed in the discussion to come, this research focuses on successful efforts in the field of sustainable development in this difficult setting in 
Palestine, with particular attention to the contributions of indigenous knowledge as a promoter of sustainable development under crisis at the community level. The research addresses three case studies from three different policy domains which include: (i) conflict resolution in Palestinian communities; (ii) social and economic empowerment of rural women in Palestinian communities; (iii) protecting natural resources and the adaptation of organic farming in Palestinian communities.

This chapter explains the problem that is the focus of the research, the purpose and importance of the study, the research question, methodology, anticipated findings, and the contributions to theory and practice of the study.

Problem definition: Inadequate Attention to the Role of Indigenous Knowledge, the Lack of Attention to the Social Dimension of Sustainable Development, the Crisis Condition Challenge, and Gaps in Policy Implementation Literature

An examination of the existing literature and practice of post conflict development and even the literature of sustainable development generally evidence a number of difficulties that shape the research question and the research design that have been used to address it. They include the continuing problem of ensuring that social development is considered in addition to the economic and environmental dimensions, the tendency to focus on an inadequate stability and reconstruction approach to postconflict development (Cooper and Vargas 2008), a need for attention to policy successes as compared to a policy failure approach, the need for attention to community level efforts, and, of particular importance for this study, the lack of careful consideration of the role of indigenous knowledge in post-conflict sustainable development. While 
chapter two will present the literature in greater depth, it is important to note at this point some of the key elements that together comprise the problem that this research will address.

\section{Lack of Attention to Social Development Dimension of Sustainable Development}

The World Commission on the Environment and Development Report (1987), commonly known as the Brundtland Commission Report, defined sustainable development as: "development that meet the needs of the present without compromising the ability of the future generations to meet their own needs" (p. 8). It stressed throughout the document that sustainable development defined in this way cannot be achieved without a balanced integration of economic development, social development, and environmental protection. To the degree that discussions since the 1972 Stockholm conference had focused almost completely on debates between advocates of economic development and environmentalists, they would not lead to sustainable development. Although this definition based on the three elements has guided sustainable development rhetoric, the warnings of the Brundtland Commission have not been adequately heeded and the tendency has been to return to the same unproductive economics versus environment debate.

Although the Agenda 21 document that was the report of the Rio Earth Summit emphasized the three elements, there was growing evidence that the social aspects had not been adequately addressed and in too many areas were not even considered. It was primarily for that reason that the 1995 Copenhagen conference on development and the resulting Copenhagen Declaration and Program of Action (commonly known as the 
Copenhagen Social Accords) were needed and why the common commitments made in Copenhagen contained specific targets in the social development dimension (United Nations 1995). In an effort to press for serious treatment of the social dimension, the Copenhagen accords included performance goals in each of the areas of the report (United Nations 1995). It also led to the development of a unit in the UN secretariat to support implementation of the Copenhagen accords (United Nations 1995, p. 4).

The UN also moved to ensure greater visibility for the kind of goals presented in the Copenhagen accords with the development of the Millennium Goals that were initially issued in 2000 (See United Nations 2005). Once again, at the Johannesburg conference in 2002, the delegates sought to underscore the critical importance of integrated attention to the three elements and called for progress on meeting the goals. When it was clear that those goals were slipping, the UN moved to revise the Millennium Goals, but keep them before the international community (United Nations 2005-2010.) Sustainable Development in Crisis Conditions: Reconstruction and Stabilization is Not

\section{Sustainable Development}

It is important to make clear that there has not been sufficient attention in the literature to sustainable development in crisis conditions, and particularly nations that is in or emerging from periods of serious violence or civil disorder. And, as Cooper and Vargas make clear, where there has been attention to crisis conditions, the model of development that has been used, in what literature there is and in policymaking by donor nations, is the model of "stability and reconstruction" that was applied in Japan and Germany after WWII (Cooper and Vargas 2008, pp. 28-35). (See also Special Inspector 
General for Afghanistan Reconstruction 2010, UNEP 2007, UNDP 1999, World Bank 2009, UNDP 2009/2010, Cooper and Vargas 2008).

The reconstruction and stability model was applied successfully in Japan and Germany for certain reasons related to the context of both countries, including the industrial structures both countries had before WWII but even that success was not measured by the standards of sustainable development. More important, the United States, the implementer of that model at that time, used enormous administrative, technical and fiscal resources to stabilize and reconstruct the two countries (Ibid.). Using the same model (focusing on economic growth and stability and security) in different recent crisis conditions (see for example the UNDP 2004a, The Special Inspector General for Afghanistan Reconstruction 2010) has not been providing sustainable outcomes in part because reconstruction is different from sustainable development and also because the circumstances of contemporary countries and conflicts are very different from those examples (Ibid).

A major part of the problem is the continuing tendency to use borrowed models, like the Germany and Japan models, to very different situations without adequate consideration of the differences and limitations of these original models. Cooper and Vargas argue that there is no one model that fits all contexts and that context always counts. In sustainable development there is "no one-plan- way to utopia" and it is "not a simple one - size plan fits all plan for an ideal society" (Cooper and Vargas 2004, p. 4, p. 17). But even though it has long been known that borrowing models of development 
from other countries has many problems, that has been the approach to post-conflict development programs (Cooper and Vargas 2008, p. 33).

Many developing countries (see for example UNDP 2004b) have been attempting to apply what they seem to assume are advanced and superior policy models that have brought successes in western contexts. Unfortunately these models did not show the same successes in the new context (Al-Omary 2006). For example, Al-Omary argues that Jordan's experience in E-Government has been trying to imitate experiences applied in the U.S.A. and the U.K without taking into consideration differences such as legal issues related to information privacy. Far more important even than institutional and legal differences however, are cultural differences.

Vargas (2000) pays attention to the challenge of "cultural mediation" that policy implementers face when they work in different cultural contexts. Cultural mediation is a process that goes beyond words translation and pays more attention to cultural and crosscultural issues that policy implementers need to know. Cultural mediation becomes necessary when it comes to sensitive cultural issues such as indigenous values (Vargas 2000, p. 3). In this regard, translating models to another language does not meet the challenge of cultural issues or address cultural differences that take place not only among peoples and communities but also among institutions that have organizational cultures in addition to being part of the larger anthropologic culture in which they operate (Cooper and Vargas 2004).

Even if policies are culturally sensitive and appropriate to the crisis context, there is still the fact that policy implementation is a critical challenge by itself, which had 
contributed to what policy scholars call the implementation gap (Pressman and Wildavsky $1973,1979,1984)$, a gap between policy design and policy implementation, that appears after policies are adopted when so much attention is on the design effort (See Cooper and Vargas, 2004, p. 2). The situation in many parts of the world such as Iraq, Afghanistan, and Palestine is very different from the post-WWII situation in Japan or Germany. The situation that Palestine confronts as it looks to development is made more complex by a continuing legacy of international conflict, occupation, and continuing internal political conflict (World Bank, 2003). Thus, it is key to use a sustainable development approach and not simply to think in terms of reconstruction or stabilization (Cooper and Vargas 2008, pp. 28-35).

The Gap in Policy Implementation Literature: the Focus on Strengths Versus Weaknesses and Policy Failure

Attention to the policy implementation gap goes back to the late 1960s and early 1970s rise of contemporary policy studies. The literature that came from it has tended to focus on policy failures (Pressman and Wildavsky 1973, 1979, 1984). Pressman and Wildavsky argue that the field of public policy has an "implementation gap" that usually appears either when implementers start converting policy ideas and designs into action through the implementation process or where by intention or simple inaction no implementation takes place. Additionally, Cooper and Vargas (2004) argue that the problem in policy process is not because of lack of policy designs and ideas but involves a complex set of challenges that arise during implementation and a lack of attention or adequate response to them. Public policy scholars and practitioners consider the stage of 
policy implementation, among other stages, as a serious challenge (Cooper and Vargas 2004, p. 13).

Like the policy failure bias in the implementation literature generally, the crisis and post conflict conditions literature has often viewed developing countries from a deficit model, ranging from discussion about how to economically and politically stabilize and reconstruct such countries to assertions that they are failed states. Even in the mainline sustainable development literature in the years since the Brundtland Commission Report and Agenda 21, there has been a common emphasis in international reports on weaknesses and failures rather than successes. For example, the Arab Human Development Report, (United Nations 2004-2010) and the Human Development Report about Palestinian Territories (2009/2010) address very critical topics such as freedoms, human insecurity, equality, gender issues, and social cohesion in terms of highlighting problems and weaknesses without telling what the solutions could be. In this regard, good recommendations are not enough to solve problems. What we need is a set of research that focuses on strengths and provides applicable solutions that leads change in development practices. (Cooper and Vargas 2008, p. 20).

COMMUNITY LEVEL FOCUS AND INDIGENOUS KNOWLEDGE: TWO KEY COMPONENTS WITH PROMISE FOR SUSTAINABLE DEVELOPMENT IN CRISIS CONDITIONS

This study considers indigenous knowledge and community level policy implementation as two key components of sustainable development. Indigenous knowledge- based development patterns are most likely implemented from the 
community level. In this regard, community level is proposed to have advantages in crisis conditions while indigenous knowledge is proposed to significantly promote positive outcomes for communities in crisis conditions.

\section{Community Level Analysis Advantage in Crisis Conditions}

Research in conflict contexts often focuses at the nation-state level or the national political process rather than penetrating into the actual operations of society. In some areas the political feasibility (Cooper and Vargas 2004) problems are so great that continuing to focus at that level may mean an inability to move beyond intense political arguments to get at important problems and real successes at the community level. Also, it is at the community level where indigenous knowledge often manifests itself and where it is used to find responses to important challenges. Community level analysis is a component that has too often been neglected as serious elements of sustainable development in crisis conditions even if they are occasionally mentioned.

Political feasibility, briefly defined as very frequently a serious challenge to efforts to understand or to do sustainable development in crisis conditions (Cooper and Vargas 2004, ch. 7). These political challenges make it extremely difficulty to break out of the clashes at the national level and to get other scholars to do so in order to allow effective research. It is because of those difficulties that a community perspective promises to offer an alternative and useful level of analysis for understanding sustainable development in such conditions as one finds in Palestine.

Political Division, Polarization, and Stress: Common Elements in the Crisis Conditions $\underline{\text { Context }}$ 
In the Palestinian context, the two major political parties (Hamas and Fatah) have been competing over development programs and projects and have been using development issues for their political agendas (UNDP Report about Palestinian Territories 2009/2010, ch. 9). Difficulties in using development support effectively, particularly the question of where money should come from and go to or who gets what and why, is negatively affected by another critical issue that characterizes the Palestinian Authority's state of governance; that is the lack of a well developed rule of law system (UNDP 2009/2010).

The Palestinian authority is not a sovereign state. Many different laws and administrative systems have governed Palestinian territories. Some of them have been applied by the Israeli occupation and some were borrowed from Jordan, Egypt and the ancient Ottoman Turks administrative systems (Palestinian national Authority 2002). Besides these administrative resources, the PNA has been trying additional modern (Western) development models that are basically based on cost-benefit analysis (Ma'an Development Center 2009). George Kurzom, a Palestinian expert in the development field argues that international development partners force these models on Palestine. Therefore the kind of model applied in a development program or project has most often not been derived from people's needs but it has depended upon who paid for it (Ma'an Development Center 2009, p. 10).

Therefore, addressing development issues from a national governmental level might not lead to acceptance of findings or actions, especially when it comes to some culturally sensitive issues such as successes and failures. In crisis conditions, such as the 
situation in Iraq, Afghanistan, and Palestine, political bias, political division and polarization, political stress, and lack of accountability are common conditions. These conditions create difficulties for researchers who try to address sensitive issues such as policy failures or even any kind of policy evaluation. Formal agencies in such conditions become more cautious about releasing information under the justification of protecting the national security of the country (see for example UNDP 2009/2010, ch. 3). Moreover, the lack of accountability and cooperation between levels of governance that accompanies crisis conditions often lead to corruption and bribery which in turn lead to lack of trust in the information provided by national agencies and officials (see for example Special Inspector General for Afghanistan Reconstruction 2010, p. 33).

The advantage of community level analysis, in contrast, is that it enables the researcher to interview, survey or observe the story and action of people in their communities, especially in policy implementation studies. Researchers who address their questions from a community level do not have to worry much about the cooperation among governance levels because they are interested in the story of the people in their day-to-day lives rather than in political leadership or parties. In fact the researcher has more opportunity than at the national level to reach the information they want to know and get answers to the research question away from political bias or polarization.

Community level analysis has an additional advantage in that it enables the researcher to reach the marginalized sectors such as women, the poor, children and people with special needs. Therefore, this study focuses on community level analysis.

The Role of Indigenous Knowledge and Community Action 
Indigenous knowledge, also known as traditional knowledge and local knowledge, is often seen as "the basis for local-level decision making in agriculture, health care, food preparation, education, natural-resource management, and a host of other activities in rural communities" (Warren 1991, p. 3). Literature that addresses indigenous knowledge (which will be discussed in depth in chapter two), for example Warren (1991), Weeramantry (2002), Pye-Smith, and Feyerabend (1994), highlights characteristics that help us to understand what indigenous knowledge means and what distinguishes it from knowledge that has been developed through contemporary scientific research methods. Warren defines indigenous as:

Patterns of knowledge that are simple and acceptable by local culture, that is orally transmitted, holistic that includes rights of the individual, groups, the village and rights of the eco system, has inclusive and collective trends, spiritual and rooted in traditional wisdom and religion, rurally and ecologically centered, tested by long-term experience, rooted in the historical culture of communities, practices and patterns differ from one context to another (1991, pp. 3-6).

This study considers each of these elements in the selection of cases studies and in the analysis as criteria for deciding which cases represent indigenous knowledge based patterns, that this chapter will address further in a later section.

Indigenous knowledge was seen in the past as "backward, uncivilized, not scientific, and anti-development" (see World Bank 1993, p. 4). This view has changed more recently, as development agencies, researchers, and donors, including the World Bank, started to pay more attention to the role of indigenous knowledge in supporting sustainable development (Ibid.) Part of the attention came from the recognition of the importance of culture in development and as the international sustainable development 
agreements stressed the importance of paying attention to the impact of development on cultures as well as the need to include excluded groups in development decisions (see Cooper and Vargas 2004, Ch. 9). The United Nations Development Program Arab Human Development Report 2002 said:

Culture and values are the soul of development. They provide its impetus, facilitate the means needed to further it, and substantially define people's vision of its purposes and ends. Culture and values are instrumental in the sense that they help to shape people's daily hopes, fears, ambitions, attitudes and actions, but they are also formative because they mould people's ideals and inspire their dreams for a fulfilling life for themselves and future generations. There is some debate in Arab countries about whether culture and values promote or retard development. Ultimately, however, values are not the servants of development; they are its wellspring (United Nations Development Program and the Arab Fund for Economic and Social Development 2002, p. 8).

Although this research focuses on the strengths of indigenous knowledge and its role in promoting sustainable development, there can also be negative impacts from indigenous knowledge on development, with special focus on culturally sensitive issues that might present obstacles to sustainable development. This problem will be discussed in the literature review chapter of the study (see Ch. 2).

While there is some recognition in the sustainable development literature that indigenous knowledge can and should play an important role in sustainable development (World Bank 1993), very little has actually been done with this subject in the literature beyond that general point. Moreover, the evidence of preliminary research suggests that indigenous knowledge is playing a role on the ground in very useful ways in Palestine even in these difficult times. Further discussion will be provided in chapter two about the relationship between indigenous knowledge and sustainable development and how this 
research can help to fill the gap in the literature about how and why it can be so important to successful sustainable development efforts.

\section{THE RESEARCH PROBLEM STATEMENT}

What has been said to this point indicates that the problem that requires research attention is that in the development literature and even in some sustainable development literature, there is a lack of focus on the social dimension in the living triangle, a lack of focus on successes rather than weaknesses as documented in the policy implementation literature, a need for more attention to action at the community level in communities in crisis conditions, and perhaps most important of all, a lack of studies that address the role of indigenous knowledge in sustainable development.

\section{THE PURPOSE OF THE STUDY: ATHEORETICAL AND PRACTICAL RESPONSE}

\section{TO THE PROBLEM}

The purpose of the study is to understand the dynamics that contribute to successful sustainable development efforts in crisis conditions with particular attention to the role of indigenous knowledge. It will address each of the elements of the research problem identified above. It will address the role of indigenous knowledge as an active component of sustainable development in communities living under crisis. The study pays particular attention to social development as a fully integrated element in sustainable development. It will focus on successful efforts rather than policy failures and uses a community level view.

Theoretically, the study aims to fill in sustainable development literature gaps in all of these areas, but with a focus on indigenous knowledge. The World Bank 
Conference about Indigenous Knowledge and Sustainable Development in (1993) introduced indigenous knowledge as a key factor for creating successful sustainable development outcomes. However, indigenous knowledge is still not significantly addressed in the sustainable development literature and this study seeks to make a contribution in that area. A multiple case study approach used in this study generated propositions about and lessons learned from the role of indigenous knowledge in sustainable development that can be tested in the future and tried by development practitioners in the field. The study aims to explore particularly how indigenous knowledge can be used in crisis conditions.

It seeks to add to the literature knowledge of ways of ensuring the integration of the social dimension of sustainable development that is too often still not adequately considered, even though it has been clear since at least the report of the Brundtland Commission that it is essential. The purpose here is to emphasize the importance of integrating the social dimension with the other two dimensions of sustainable development, the environmental dimension and the economic dimension even in the most challenging conditions. The international literature, (United Nations1972, the World Commission on Environment and Development Report 1987, United Nations 1992, United Nations 1997, United Nations 2002), indicates that the focus is still too often on the environmental and economic dimensions of sustainable development. Unfortunately, the so-called Social Summit in Copenhagen 1995 addressed social issues independently of and not really with integration with the other dimensions. It led to the creation of a unit in the UN secretariat for social development separate from the sustainable 
development unit. Still the problem of inadequate treatment of the social dimension exists.

The other gap that the study aims to address is in the implementation literature (Pressman and Wildavsky 1983, Cooper and Vargas 2004), and particularly the need for attention to problems of implementation in crisis conditions. That literature has too often in the past focused on policy failures. There is need to look at strengths and successes in order to learn not just why policy fails but how it can succeed. Craig Mortenson's works, Three Cups of Tea (2006) and Stones into Schools (2009), provide inspiring examples about how focusing on strengths of indigenous communities can solve sensitive problems even in crisis and complicated conditions (see chapter two).

As to theory and practice, the study aims to generate a list of propositions about how indigenous knowledge based practices in Palestine play a positive role in sustainable development that can be used in other Palestinian communities, in the region, and in other regions around the world. The study should be useful to non-governmental organizations (NGOs), research institutions and governmental agencies, as partners in development, including the organizations with which the author had been and will be affiliated. As to theory, the propositions go beyond very general comments in the literature and provide a focus for testing ideas in future research that can lead to a useful body of theory about the role indigenous knowledge can play in sustainable development.

\section{RESEARCH QUESTION}

The effort to address these gaps in the literature and challenges in practice lead to an important research question. The study addresses the following research question: 
How have successful community- level sustainable development efforts undertaken under crisis conditions drawn upon indigenous knowledge to achieve positive outcomes? This question consists of four components: community level analysis, strengths and successes, crisis conditions, and most important for this study, the role of indigenous knowledge in sustainable development.

\section{Community Level Analysis: the Story of People Living Under Crisis}

Community level analysis is an opportunity to listen to people's story; the story of those who are on the ground who are participants or real clients of development. The community level is also the place where one can most readily observe evidence of legitimacy granted by the people to development programs and practices (see Easton 1965, 1958). Community level research is also a useful way of building on and learning from success. Works that addressed sustainable development (see Cooper and Vargas 2004, Pye-Smith and Feyerabend 1994) indicate that policy success can better be understood from a community perspective as compared to broad national perspectives (Chapter two addresses this literature further). And, as noted earlier, it is also a perspective that can allow the researcher to avoid getting entangled in national or international political issues.

\section{Learning from Successes}

As it is stated in the question, the research considers successful cases. This perspective helps to get at lessons about the way that indigenous knowledge can be used to accomplish successful sustainable development programs. The emphasis here is on 
what works. This approach avoids the policy failure bias in the implementation literature noted earlier (see Pressman and Wildavsky 1983).

\section{Challenges of Crisis Conditions}

Regarding sustainable development in crisis conditions, probably the critical question is how to approach and how to accomplish sustainable outcomes. In crisis contexts such as Iraq, Afghanistan, and Palestine, because governments in these countries are either weak or overwhelmed with security concerns, sustainable development is a serious challenge. However, sustainable development is a key to a positive future for both national and international developers. There is still a tendency to focus on rebuilding, stability and security as a guiding approach for development. As noted earlier, however, economic stability and security cannot alone meet the needs. That requires a sustainable development approach. The warfare context (weak economy, lack of stability, refugees, lack of security, environmental disasters) needs more attention to social and environmental issues than has been addressed in many of the efforts to this point. The crisis context is also a useful place to observe what indigenous knowledge can contribute.

Indigenous Knowledge (IK): Why it is Important to Sustainable Development

Indigenous knowledge plays a key role in local culture. Indigenous knowledge usually is present in one way or another (World Bank 1993) but it is important to go beyond this obvious point to get at what difference it makes. In rural communities in many parts of the world and particularly in developing countries, people still live in ways that are grounded in traditional patterns and practices derived from local culture that have 
been in place over generations. Moreover, local culture, morals, and religious doctrines are usually respected and play a critical role in indigenous communities. Therefore, indigenous leadership and institutions, such as tribal leaders, tribe and village committees and councils, elders, and indigenous institutions are available and active in such contexts (World Bank 1993).

Furthermore, it is important to say that indigenous leadership is most often voluntary in nature. Elders, religious leaders, and other socially respected people usually volunteer their time, effort, and money to manage their communities' needs. The lack of resources and governmental structure in many developing countries, and particularly those in crisis conditions, also encourages both indigenous leaders and their communities to find alternatives derived from the local culture. These indigenous leaders are also often people who are connected to the natural resources in the community.

There is another aspect that distinguishes indigenous communities. It is the fact that knowledge is most often transmitted orally from one generation to another. Knowledge is often grounded in generations of experience and is reinforced by experience over time. These factors help indigenous people to promote trust in their leadership who seek in turn to enhance social cohesion (UNDP 2009/2010). In brief, indigenous knowledge context is well known to local people, socially cohesive, collectively- driven, and very connected to the environment-land, animals, forests, rivers, lakes and so on. These factors set indigenous knowledge up to play a critical role in sustainable development. However, the fact that indigenous knowledge and practices are 
usually known only locally and often in oral traditions makes a study like this necessary and potentially useful.

\section{ANTICIPATED RESEARCH FINDINGS}

The research is not a hypothesis testing study, but work that is designed to produce propositions that can be tested in other cases and contexts and can be a basis for theory building. At the outset, however, there were some expectations about what in general terms at least the research was likely to find. This section discusses some of those anticipated findings. These included the likelihood that the study would shed light on how indigenous knowledge helps to integrate the elements of sustainable development, provide evidence that its use tends to build legitimacy in the community, that it uses and builds on trust, and that it promotes self-reliance in development. Indigenous Knowledge Characteristics and Sustainable Development: How the

\section{$\underline{\text { Integration Occurs }}$}

Among the many areas of life in which indigenous knowledge plays a role two major areas are obviously important to sustainable development. They are natural resources management and dispute resolution with obvious impacts on social cohesion (see definition of social cohesion in section 3). As Wolf et al. explain, IK is "simple, oral, intuitive/holistic, slow/ inclusive, spiritual, rurally and ecologically centered and tested by long- term experience" (Wolfe et al 1991, p. 6). Indigenous practices, according to Wolfe's definition and characteristics, are not at odds with the local culture of communities but central to it. Therefore, the integration process between environmental development (voluntary care about natural resources, land water, trees, etc), social 
development (level of decision making, respect, trust and social cohesion), and economic development (developing whatever resources available to provide sustainable life for the people) are highly likely to be demonstrated through the suggested case studies of this research. The anticipated evidence is that indigenous practices have been successfully implemented in the Palestinian communities over generations at least in terms of the integration of the three elements of sustainable development. Indigenous Knowledge is Legitimate and Provides Legitimacy

Legitimacy is a concept that still raises debate among social science scholars, particularly legal, and social scholars (see chapter two of this study). Building on Easton's (1963) account of legitimacy, accumulating support and energy from the people through past decisions and reinforcement of new decisions, indigenous knowledge appears from existing evidence to enjoy legitimacy in itself and can lend legitimacy to policy actions ( Pye-Smith, et al 1994, Mortenson 2009, Weeramantry 2000). One of the cases that is investigated in this research, the Sulha committees (an indigenous pattern of conflict resolution), has a very recognizable legitimacy among Palestinian communities. The "Birzeit Informal Justice System Study" (2006) indicates that among every ten dispute cases in Palestinian communities, eight of them are resolved by Sulha committees while only two of them might go to courts or might be solved by the dispute parties themselves. The results of this study indicate the state of legitimacy that indigenous Sulhas have in the communities.

The role of indigenous leadership and institutions in their communities can be expected to emphasize that indigenous knowledge is not only legitimate but also provides 
legitimacy to policy actions that are important in development projects and programs. In the three cases selected to be investigated in this study, indigenous leaders are key partners with either governmental agencies or NGOs who trust indigenous practices to solve complicated problems. According to this kind of partnership, the study would like to show that people's participation in and support of development actions increases when indigenous leadership and institutions approve or show acceptance of these actions. The Power of Indigenous Knowledge in Crisis Conditions: the Power of Trust

In crisis conditions, indigenous institutions could be an acceptable and trusted alternative to weak governments, war agents, NGOs with political agendas, and occupiers. People in crisis conditions need fast response to problems that cannot wait until stability and security becomes complete on the ground. In this regard, indigenous answers to such problems come from the communities that live the crisis situation. This study could help to determine whether and how trust might be the important factor that encourages communities to choose indigenous leadership and practices to respond to their problems. In such a complex condition, it is not easy for people to give legitimacy (acceptance, participation, support and trust) to these other parties who have political positions such as supporting one party or political group against the other (World Bank 1993, Cooper and Vargas 2008, p. 22).

Lack of trust and tension over development to achieve political goals has been taking place between Fatah and Hamas for a long time. Hamas claims that Fatah uses development to advance international agenda, the United States and Israel's, while Fatah claims that Hamas uses development to advance radical agenda, Iran's, (UNDP 
2009/2010, ch. 4). This situation may help to explain why Palestinian communities prefer indigenous practices and trust indigenous institutions to solve their problems and sustain their lives.

Indigenous Knowledge-Based Patterns of Development Promotes Self-Reliance Model of Development

One of the significant findings to which the primary data point is the fact that indigenous knowledge promotes self-reliance in development based on social cohesion and trust (further discussion about these terms will be in chapter two of the study) which is necessary in crisis conditions. Besides the need for a careful management and protection of natural resources, people living in crisis conditions need public safety, which can be supported by cultural patterns that promotes social cohesion. Classical definitions of social cohesion have emphasized individuals' membership in the community, through shared attitudes, and behaviors.

Social cohesion is a required environment for developing a kind of selfreliance model of sustainable development. In crisis conditions people also suffer from a trust crisis due to insecurity and an ambiguous and unstable political and economic situation (see The World Bank 2003, Cooper and Vargas 2008, ch. 5). The simplicity and familiarity of indigenous patterns of interaction and leadership start from the inside of communities and easily reach peoples' needs. Another factor might be the immediate response of indigenous institutions and leaders to communities' problems. The fast response might be related to two factors: the voluntary dimension of indigenous institutions and leadership, and the trust that people have in these institutions and leaders. 
Indigenous development process are local patterns, and more important, driven by leaders who deeply care about their communities. These characteristics are demonstrated by respect and acceptability that indigenous institutions have in their communities. As a response to this the respect, indigenous leaders serve two main goals for the current and future generations. They pass on to current and future generations their knowledge about respecting the environment (land, water, trees and plants) and their care to social cohesion of their communities. These goals represent key factors to the integration process in sustainable development. All these factors support a kind of self-reliance model of development in which indigenous practices use available cultural resources to sustain people's lives. Finally, the study set out to develop a set of testable propositions that, if confirmed, may form the foundation for a new indigenous knowledge-based model of sustainable development in crisis conditions.

SIGNIFICANCE OF EXPECTED FINDINGS, IMPORTANCE OF THE STUDY, AND THEORETICAL AND PRACTICAL VALUE

These findings and indeed the thesis and propositions that come out of the study contribute to building theory and improving practice. The concluding chapter, which provides the cross-case analysis and the propositions that flow from it indicates more specifically the contributions and possible future research directions. Importance and Theoretical Value of the Study

This study is important because, unlike studies that approach sustainable development from economic or environmental perspective, it approaches sustainable development with emphasis on the integration process criteria with special focus on the 
too often missing or inadequately considered social dimension and perhaps, more important it takes steps beyond the current literature on development in the context of crisis conditions. As the chapters that follow show, these case studies show successes of development action based on the integration of the three parts of sustainable development. The study also adds additional evidence to critique development models that challenges reconstruction and economic stability as standered models of development in crisis conditions. The reconstruction and stability model, which was successfully applied in Japan and Germany on the aftermath of WWII, has failed to achieve sustainable development in crisis conditions such as Afghanistan, Iraq and Palestine(See for example: UNEP 2007, UNDP 2009/2010, the Special Inspector General for Afghanistan Reconstruction Report 2010). The cases studied here indicate a much more effective approach based on sustainable development driven by indigenous knowledge.

Additionally, the study generates a set of testable propositions about the contributions of indigenous knowledge that can provide focused for further research on ways to creating models that can help explain the process of sustainable development in crisis conditions. Because crisis conditions present complex contexts and extremely challenging conditions, there is a need to new-grounded frameworks and models that interpret actions, interactions and human processes (see Creswell 2007, p. 63). This study shows that indigenous knowledge is one component that can lead to successes in sustainable development outcomes in crisis conditions. 
The study is also important because it helps to address gaps in the literature on policy implementation as it focuses on the strengths of communities in promoting sustainable development in crisis context as compared to the emphasis in the literature on failures (see Pressman and Wildavsky 1973, 1979,1984). In policy implementation in developing countries, the study contributes propositions derived from the local cultures about what can help to enhance implementation success. Additionally, the findings of this study contribute to what might in the future be a new model that interprets how indigenous knowledge-based development patterns function in crisis conditions. Such a model, if developed, will contribute to understanding the complexity of crisis conditions as well as how to move forward from that situation.

\section{Practical Value}

In general, the case studies and the analysis that comes from them provide lessons to be learned in the field of policy implementation and also suggest lessons for program or project design. The key lesson to be learned, apart from the specific propositions and the analysis that supports them, is the art of building on community strengths and successes. The study has promise in terms of helping both developers and communities who receive and participate in development in terms of improving sustainable development outcomes.

Developers and governments may consider indigenous knowledge-based institutions as partners of sustainable development. The study might help to change the stereotypical view about indigenous knowledge as an old, out of date, primitive and antidevelopment culture. The study suggests ways to reinforce and enable communities to 
trust their capacities in improving their living, depending on their own resources. The analysis provides lessons in how the integration among the three pillars of sustainable development can be accomplished successfully. That can encourage development groups and project managers to pay more attention to the gap in social impacts of development actions. As indigenous knowledge-based development patterns studied here show positive, simple and cheap applicability, the findings from this study suggest ways to reduce the cost of development actions and might show how simple, little, and few can give sustainable results.

Governments like the PNA as well as national and international developers may consider indigenous knowledge as a source of social cohesion and civil peace. The findings of the study may be used as a guide in designing sustainable development workshops, training courses, and education in schools and universities. There are also several specific practical lessons that come from the case studies that can be used. For example, the study shows the potential for use of indigenous ways of doing organic farming and the use of indigenous plants in healing and health promotion. It is clear that the study offers findings that link theory and practice.

\section{STUDY DESIGN AND RESEARCH STRATEGY}

This study provides a multiple case study analysis in three policy domains of successful, community-based, sustainable development efforts in which indigenous knowledge appeared at the beginning of the work to have played a significant role. They were carefully chosen to be useful as individual case studies to address the research question, but also to allow cross-case analysis to enhance the likelihood of producing 
useful and more generalizable findings that lead to propositions concerning the uses of indigenous knowledge in sustainable development efforts in crisis conditions that can both contribute to the literature and provide the foundation for future empirical testing.

This study uses a qualitative research method. Sustainable development in crisis conditions is a challenging process that has not sufficiently been addressed in in-depth research. The general purpose of the study, in brief, is not to measure any model but rather to explain how successful sustainable development efforts function in an extremely complex context such as crisis conditions and with respect to the role of indigenous knowledge. In sum, the multiple case analyses can provide a foundation for the building of grounded theory. The following sub-sections will discuss in details the rationale why qualitative design is appropriate to this study, the strategies that were followed to conduct the study and the challenges that the research expected to face at the beginning of the research process.

\section{$\underline{\text { Rationale for Selecting Qualitative Design }}$}

Yin (2003) argues that the type of research question is the most important condition to identify the type of research to be conducted. Berg (2007) states that "quality refers to the what, how, why, when and where of a thing-its essence and ambience" (Berg 2007, p. 3). For many reasons, qualitative research design is a suitable one for this study. First, the nature of the research question is explanatory. It examines how successful community level sustainable development efforts have drawn upon indigenous knowledge to achieve positive outcomes. This means that we examine successful indigenous-based case studies so that we may have a good chance to provide 
evidence to answer the research question building on the cases positive features and strengths. The case studies are proposed to generate lessons and themes for learning in terms of future theory building and improved practice.

Second, the purpose of the research is one that fits a qualitative analysis rationale. Creswell (2003) argues that qualitative approaches should be used if a concept or phenomenon needs to be understood because little research has been done on it; the topic is new, the topic has never been addressed with a certain sample or group of people, or existing theories do not apply with a certain sample or group under study. The study addresses the gap in policy implementation literature in terms of building on strengths and successes rather than weaknesses. In this regard, Cooper and Vargas (2004), Pressman and Wildavsky (1973) argue that the gap in public policy literature is not in designs and ideas but in converting these ideas into actions. Studies that address pattern and practices from a strengths and successes perspective are very few particularly in crisis conditions context. Additionally, studies that address indigenous knowledge issues are extremely rare compared to the rich environment of indigenous knowledge in developing countries like Palestine.

The third reason that qualitative design is suitable for the study is that the research is a community- based one and therefore the researcher is looking forward to conducting action research. Berg (2007) defines action research as research that "focuses on methods and techniques of investigation that take into account the study of population's history, culture, interactive activities and emotional lives" (Berg 2007, p. 224). These factors are taken into consideration with the intention of being able to then apply the 
results of the research to improve the lives of those involved. These characteristics look to be fitting well in community-based analysis. Berg also argues that the purpose of action research is to empower communities, encourage them to reflect, learn and change. The work on this study is setting the ground for future action in Palestine. This research is very committed to creating nonviolent social change based on sustainable practices.

\section{Grounded Theory Approach}

This study is not testing a particular model or established claim in the literature, but rather is, in the tradition of grounded theory a proposition (testable hypothesis) generating study (Glaser and Strauss 1967, Creswell 2007). Creswell argues that grounded theory "should be grounded in data from the field especially in the actions, interactions and social processes of the people" (Creswell 2007, p. 63).

Glaser and Strauss (1967) state that, in grounded theory, researchers "generate conceptual categories or their properties from evidence, then the evidence from which the category emerged is used to illustrate the concept" (p. 23). These conceptual categories can then be explored in other comparison groups, which may support the categorical concept or suggest modifications to make it more generalizable. The authors also state that "theory generation doesn't require lots of cases. One case could be used to generate conceptual categories and a few more cases used to confirm the indication" (p. 30). The grounded theory approach aims at generating testable propositions that can be developed into hypothesis in another research (Glaser and Strauss 1967, p. 30).

Creswell (2007) argues that grounded theory study is important "to move beyond description and to generate or discover a theory. A key idea is that this theory- 
development does not come off the shelf, but rather is generated or grounded in data from participants who have experienced the process" (Creswell 2007, p. 63). Since sustainable development processes in crisis conditions have no complete theory, the study is interested in developing new theoretical propositions, shaped by participants in the field and data collected from the field, for further research that can give deep explanation to the actions, interactions and social processes that take place in the context of the study. Creswell (2007) adds that grounded theory approach is good when "a theory is not available to explain a process. The literature may have models available, but they were developed and tested on samples and populations other than those of interest to the qualitative research. Theories also might be present but incomplete or they do not address potentially valuable variables of interest to the researcher" (Creswell 2007, p. 66). The propositions seek to present explanations as to the way indigenous knowledge can contribute to successful sustainable development which requires the integration among the three pillars of sustainable development, social, environmental and economic development.

\section{Level of Analysis}

The study will address the research question from the community level. Community level analysis, compared to national or governmental level of analysis, is preferred in this research because of the political bias, polarization and sometimes contradiction that might influence the information resources if the research addresses national or governmental level. In a politically and economically unstable context, governmental units are usually weak and controlled by the state of conflicts taking place 
in the context. Furthermore, in such a context, reaching national levels of analysis such as ministries and heads of agencies is not easy. In comparison, community level research is an advantage because it can provide a better sense of what is actually taking place on the ground even in these difficult conditions.

\section{Grounded Theory Approach: the Need to Generate Propositions}

The researcher was committed to going beyond the single case to a multi- case approach which can give a deeper and wider picture of the subject matter than a singlecase approach. It reduces the danger of idiosyncratic findings and allows for more generalizable results than a single case. The single case approach is suitable when the researcher is interested in understanding the case itself; this is called intrinsic case approach (Creswell 2007, p. 75, Stake 2006, p. 8).

The literature of multiple case study analysis, led by Stake (2006), argues that each individual case of a study should share common characteristics that serve the purpose of shaping and explaining the quintain (Stake 2006, p. 6). The quintain, as Stake explains it, is more than a phenomenon, a condition, a project or a program. The quintain is an umbrella that bounds together educational context, political context, cultural context, relevant research and history (Stake 2006, p. 5). The multi-cases of the study together makes up the quintain and contribute to explaining its complexity. Stake describes the relationship between the quintain and the cases as a relationship between pieces and a whole (Stake 2006, p. 7). However the researcher should keep a balance so as not to be pulled more toward the pieces or the whole. 
In the case of examining the relationship between indigenous knowledge and sustainable development in Palestine, the quintain might be the role of indigenous knowledge in promoting sustainable development in a conflict context, and how pieces (cases represented by the project addressed in the study) function or perform in the whole quintain. As the role of indigenous knowledge in crisis conditions has not been adequately researched and there is complexity in understanding it, a multi-case approach is most likely to explain more deeply than a single case approach. The cases of the study are culturally diverse but connected to the same indigenous knowledge based quintain. Although the selected cases have been living the same political, social and economic context, they are expected to provide enough explanation, and answer the research question.

\section{$\underline{\text { Criteria of Case Selection }}$}

This research used a number of criteria to select case studies that would address the research question and allow the researcher to get enough and well organized data to answer the research question. These are (i) cases that indicate integration of the missing social dimension of sustainable development (ii) cases that have success indicators. (iii) Cases that represent community level and (iv) cases that are based on indigenous knowledge patterns of development. For this study, success is indicated in cases that indicate a level of legitimacy (Easton 1965) in terms of support and regard of local communities. Success also means that the case shows sustainable and positive outcomes to local communities, integrative of all the three elements of sustainable development living triangle. Also, success cases would suggest that the project provides the 
sustainable development progress based on participants' opinions. Finally, success means that the case provides sustainable responses to critical problems (for example, natural resources management and critical conflicts).

The following section will identify the characteristics and boundaries of each case and their applicability to the criteria mentioned above. The three cases presented in this document represent three policy domains, as it will be discussed in the next section. However, there were some other cases that might have been chosen, but were not selected because they do not represent indigenous knowledge or focus on the community level and also do not include marginalized sectors in Palestinian society. In this regard, although sustainable development is an inclusive approach to development that includes everyone as well as integrates the three dimensions of development, it should also pay attention to marginalized people (see for example Cooper and Vergas 2004, Cooper and Vargas 2008). For example, development institutions in Palestine, such as the Ma'an Center and the Palestinian Agricultural Association Union, as leading institutions in development, have implemented many programs under the efforts of promoting democracy and human rights. Although these topics are important, the two centers have implemented these programs in partnership with the universities, law schools, other NGOs and some governmental agencies. The programs are more involved with elite communities, are not integrative of the three elements, and do not indicate the use of indigenous knowledge.

Other cases that have addressed marginalized communities were either single events or projects that showed some success for a short period of time, but have stopped 
for some reason. For example, the researcher had reviewed a case that addresses the role of Sulha Committees in education. An example of a single event was a case in which Sulha committees have succeeded in pushing the government to build schools for some communities that did not have high schools for girls. Such events do not represent a continuous pattern, rather it is a one or two times reaction to a problem. It is an interesting case, but not one that meets all of the key elements of this research. Another case that has been excluded is the "Bee and Honey Projects for Poor Women" implemented by the Palestinian Agricultural Association Union. The project did not continue, although it showed success indicators and it used an indigenous knowledge based pattern. In comparison, in addition to the fact that they meet the selection criteria, the cases selected for this study continue to indicate success and sustainable outcomes and they are expected to provide enough data to answer the research question.

Finally, it is important to say that the three cases are selected from the West Bank geographical area. This excludes cases from the Gaza Strip. That is first because it is very difficult for those who live in the West Bank to go to Gaza without permission from Israeli forces, which is almost impossible. Second, because of the political division between the two parts of the country; with Gaza is controlled by Hamas and the West Bank by the PNA. This means that it is not feasible to study events across those boundaries at this time.

\section{Description of Cases}

The three cases represent three different selected policy domains that are important in crisis conditions: conflict resolution and social cohesion, natural resources 
and environmental management, women's empowerment and gender issues. These policy domains are important by themselves but they are also at the core of sustainable development principles (see Cooper and Vargas 2004, Sen 1999).

In crisis conditions people usually struggle over scarce natural resources including food production in order to survive. Because war and other kinds of conflict are harmful to the environment and natural resources, management of these resources and protecting the environment, based on available patterns and that function well in such conditions, is a critical policy domain too (Cooper and Vargas 2008, ch. 2).

The three policy domains represented by the three selected cases also meet with the declared sustainable development principles developed by the international agreements on sustainable development such as the environmental protection principle, the principle of balance and integration, the right to development principle, the decentralization principle, the partnership principle, the family principle, the livable community principle, the health and wellness principle, the poverty eradication principle, the culture sensitivity principle among others (See Cooper \& Vargas 2004, pp. 28-60).

Moreover, the cases are "theoretically chosen" (see Croswell 2007, p. 64) to compensate the lack of focus on the social dimension of sustainable development. The three cases are: (i) the Sulha Committee in the Northern Districts of the West Bank, (ii) the Organic Farming Project in the Bani-Zaid Al-Sharkiya Community in the West Bank, (iii) the Social and Economic Empowerment of Palestinian Women's Program, the Rural Women Co-operatives in the West Bank. 
Case one: the Jenin Central Sulha Committee in Northern districts of the West Bank known as (JCSC). This addresses conflict resolution and building social cohesion. The committee consists of five to eight indigenous leaders (usually older people) who are socially respected and influential in their communities. Sulha Committees are present in almost all Palestinian villages, towns, refugee camps and cities; they have been socially and politically active in the Palestinian communities over many generations. The Sulha Committee in Northern district is a central committee that co-operate with minor secondary committees available in most Palestinian communities. The committee is specialized in solving issues that cannot be solved locally by the secondary committees and the issues that are considered extremely complicated such as killing crimes, and conflicts that take place among villages and big tribes in the district (See Institute of Law in Birzeit University 2006). The committee consists of (6-8) members, usually elders who are nationally well known, trusted and respected in their local communities and in the Palestinian society. The members volunteer their time, money and effort to resolve conflicts within and sometimes outside the district. They usually act immediately when a conflict in the region starts. They start negotiating with the parties to reduce the tensions and agree on temporary solutions, they also continue investigating and negotiating until they reach a compromise. Moreover, the committee acts at the time peace is settled to create more social cohesion in the society. Sulha committees in Palestine work in partnership with the national police, district governors, the Palestinian Legislative Council members, lawyers, district courts and political parties (See Institute of Law in Birzeit University 2006). 
In terms of time boundaries, the study covers the committee indigenous conflict dispute process (patterns of Sulha conflict dispute) that have been functioning in the area since 1987 until 2010. This period of time allows the researcher to compare two stages of crisis conditions of the Palestinian people; before the PNA and after its control over the Palestinian territories. Between 1987 and 1994, Palestinian communities lived under direct control of Israeli military forces during occupation. There were no government or local governmental agencies allowed in the territories, but some Palestinian administrators received their orders from a military administration that controlled each Palestinian district. Therefore, indigenous knowledge- based committees were considered an acceptable alternative to conflict resolution issues during the occupation.

Between 1994 and 2010, the Palestinian authority (PNA) was established but lacked complete sovereignty under the Oslo Agreement and the Wye River Memorandum (See Government of Israel and Palestinian Liberation Organization 1995a, 1995b, and Government of Israel and Palestinian national Authority 2002). The PNA has been overwhelmed with politics issues (security requirements, negotiations, struggle with the Islamic opposition) and moreover lack of economic freedom because the Palestinian territories' economy, as well as most issues, have been controlled by Israel. This situation has created a weak form of governance and sometimes an absence of the PNA in civil life. This also encouraged Palestinian communities to consider indigenous alternatives to sustain the most important aspect in the fabric of civil life, social cohesion. The researcher is interested in exploring the role of such indigenous patterns of conflict resolution in building sustainable social cohesion in Palestinian communities and 
society in general. Additionally, the researcher is interested in explaining why and when people select this indigenous process to solve their problems. Interviews focused on committee members, some of their clients who experienced critical conflict issues, police representatives, lawyers, and judges who are relevant to committee activities. Clients are important to interview to explore how people look at Sulha committees, and probably enrich the data by their experience. Police officers and other relevant formal representatives are important to explore the nature of partnerships with Sulha committees and their role in promoting or weakening the rule of law.

In terms of applicability of the selection criteria, the term Sulha is an indigenous term that means agreement (desired by all parties) that leads to removing abhorrence creating love and tolerance among people. Sulha committees indigenous process have been successfully used in creating and supporting a sort of social cohesion in the Palestinian society over generations (Institute of Law in Birzeit University 2006). These patterns represent the power of indigenous knowledge at the community level, because Sulha process has been used over generations in almost every Palestinian community. The fact that Sulha Committees are socially active in conflictive situations is another advantage of selecting it as a case study. By improving and protecting social cohesion, these committees, in fact, especially integrate the social dimension of sustainable development with economic and environmental development by providing a socially safe environment for economic and environmental development. That is to say that the preventive and constructive role that these committees play protects the economy and the environment of local communities. If these committees do not respond "quickly" in 
crisis conditions, the alternative might be lack of security and loss of property and destruction of public natural resources (Institute of Law in Birzeit University2006).

Although the case does not directly touch on environmental issues, the advantage is that it represents a strong focus on the social and the economic dimension. The economic dimension is measured by using an inexpensive indigenous (socially acceptable) alternative of conflict resolution compared to how much it would cost communities if nothing were done if Sulha Committees did not exist. The researcher's observations indicate that critical cases that failed to be solved immediately by Sulha committees have ended up with many victims (direct killing, injuries, burning of houses, destroying businesses and farms, removing people from their towns and so on). These effects often occurred at the time before the PNA and even after (See also Institute of Law in Birzeit University 2006). Social cohesion generated by the Sulha process indeed protects the well living of communities. Communities, instead of focusing money and effort on conflict (fighting and revenge), they focus on the health and education of their people.

Case Two: Organic farming Project in the Bani-Zaid Al-Sharkiya Community in the West Bank. This case involves food production policy domain as a priority for people living under crisis. This policy domain also includes interests in natural resources management, environmental issues, and health issues related to organic (Baladi) farming. The term Baladi in Arabic means that it is organic, but it is also part of the indigenous heritage on crops and practices farming on crop production. 
The case addresses the Bani-Zaid Al-Sharkiya Community, which has a population of 5500 people living in two small villages, the Mazari Al-Nobani village and the Arora village. The community is located in the middle rural mountainous area $(20 \mathrm{~km}$ to the north of Ramallah city) in the West Bank. The Bani- Zaid community has been developing and producing organic olive oil in partnership with and The Palestinian Agricultural Relief Committees (PARC) since 2004. Locally, the project is managed and implemented by the Bani Zaid Al-Sharkiya Cooperative that represents farmers who practice Baladi olive oil. The project is based on the traditional way of organic farming practiced in Palestine for hundreds of years (See Ma'an Center for development 2009). Because of the mountainous geography of the two villages, the only natural resource that people in Bani-Zaid community live on is olive trees farming.

Interviews were conducted with eight founding leaders of the Bani-Zaid AlSharkiya Cooperative in addition to the director and the advisor of the project, farmers who benefit from the project and volunteers who implement most of the actions. This case meets the selection criteria because it addresses the integration of the three areas of sustainable development. It also operates at the community level, is based on the indigenous heritage of organic (Baladi) farming in the selected community. The BaniZaid Cooperative is recognized to be one of the leading national cooperatives producing organic extra virgin olive oil and exporting it to foreign markets, which depends on indigenous the Baladi farming practices. Additionally, the project has helped families in Bani-Zaid community to expand new farms and cultivate new areas of land; this success reduced the level of poverty in the area (See Ma'an Development 2009) and definitely 
has had its impacts on people's health. Part of the project's success is farmer's strong commitment to anti- chemical (no chemical spraying) policy. Instead, farmers use indigenous methods of treatment such as garlic mix and hot pepper mix in spraying and treating diseases. Farmers also have practiced natural ways of fighting flies that attack olive leaves and fruits by growing a kind of indigenous (Carob) trees which sends a kind of smell that keeps flies away. (Azeza Thahir, 2010).

The primary indicators of this case show a clear integration among the three dimensions of sustainable development. Besides the environmental issue, the case represents a concern for family level economic situation. Indigenous Baladi farming is practiced at the family level so that all family members play a role in making a living to support the family. However the basic role in Baladi farming is played by women who are usually responsible for technical practices such as selecting, classifying and saving Baladi seeds and plants to be used for next farming season. They are also responsible for preparing treatment mix and treating diseases (Azeza Thahir 2010). This active role of women, from a sustainable development view, indicates consideration of the social dimension of sustainable development.

Case Three: The Social and Economic Empowerment of Palestinian Rural Women in the West Bank. This program addresses the empowerment of poor women through improving poor women's social and economic opportunities. It particularly assists women living in rural areas in different villages in the West Bank to support their families and build a kind of social women's clubs. Through these clubs, women manage their social and economic needs. The program addresses 6,722 women members in 12 
rural women cooperatives located in different villages in the West Bank. The economic purpose of the program is to encourage women to save money through their cooperatives and in partnership with the Palestinian Agriculture Development Association and its international partners. The women cooperatives then lend members small loans to start their own small businesses. The program was started in 2005 to be a continuous leading program in empowering poor women; one of the program's aims is to create a network of women's clubs who join the program in the future (The Palestinian Agricultural Association 2010).

Socially, the program targets empowering women. It aims to help them to be more organized, active in their communities, to participate collectively in national events, and to raise their voices in a variety of areas. Furthermore, the program addresses environmental issues through educating women about recycling, house gardens management, childcare, literacy, and social leadership. The program increased the number of members and women's cooperatives in different areas of the West Bank, established new economic projects and childcare centers, it also established 270 new house gardens and developed 580 already established gardens, helped 543 women who were school drop outs who left school in an early age because of early marriage to go back to school and get a high school certificate. Also, the project includes campaigns to educate rural families (men and women) about the dangers of family violence especially violence against females (The Palestinian Agricultural Association 2010). There are many indicators that the case represents the purpose of integration the three aspects of sustainable development, social, economic and environmental. Interviews cover 
women's clubs leaders, members, and the project director and any other relevant implementers.

\section{Data Collection}

Data collection depended basically on semi-structured interviews. However, the study also used site visits so that the research team could collect site observations about the cases to prepare for the interviews and enrich the discussion. Additionally the study analyzed existing data as a secondary strategy before the interviews. Existing data include projects records, cooperatives' documents, lists, agreements, and meetings documents. The following sub-sections will detail data collection strategies.

Characterizing the Suggested Cases: The research team started collecting more information about the cases and why they represent successful examples in implementing sustainable development in the Palestinian context. Characterization depended on data from local agencies records, NGOs records and reports, site visits, and available literature. This strategy insured that the cases meet the key criteria of case selection. The problems that the cases address are key issues from a sustainable development perspective. Once the cases were finally approved according to the previous criteria, interviews were started.

\section{The Role of the Research Team}

One of the challenges that faced this research team is that it was limited in time. The research needed to be conducted within 13 months. In this regard, the political and security situation on the ground were important issues but not insurmountable ones. In many cases, people who live in the North of the West Bank cannot easily (because of the 
continuous closure of areas and the many checkpoints that separate districts) go to the South and visa versa. It was easier for those who live in the same geographical area to collect information (interview people) in the same geographical area. Additionally, there was the cultural challenge of gender. Females usually prefer to talk to females and males prefer to talk to males when interviewed. Therefore, the researcher worked with a research team to overcome these challenges.

The research team consisted of two, one male and one female research assistants supervised by the researcher. One of them lives in the North and the other lives in the South. Their role was limited to making the pre-site visits and doing the interviews. The researcher was responsible for the follow-up interviews, the analysis, and the writing. The two assistants are specialized in the field of development. The first is a male expert who holds a master degree in environmental studies and works for local NGOs. The second is a female master student in the field of social studies who works for local NGOs too. The purpose behind choosing a male and a female was solving any sensitive issues that might have appeared concerning cultural and religious sensitivity such as male meeting females or female meeting males. The team did the interviews and the site visits as designed by the researcher. However, the researcher participated through Skype as much as was possible. The interviews were saved on computer files and sent to the researcher. For confidentiality, the two research assistants signed a confidentiality commitment. Both persons participated in all the interviews for each case, except when there was some sensitivity as mentioned above.

\section{$\underline{\text { Interviews }}$}


Different types of in-depth interviews were the major tools for collecting the research data. First, the interviews with indigenous leaders were semi-structured in format. This format is probably the most appropriate with respect to the nature of the cases as age and literacy are sensitive issues. Moreover, the semi-structured format enables the research team to reorder the questions during the interview, flexibly word the questions, adjust the language and explain when necessary and add or delete items.

The second stage of interviews was with recipients of the projects. This include people who experienced solving critical problems by Sulha Committee, farmers who experienced Baladi farming, and members of women's clubs. Also, in this phase, the team interviewed directors of projects and representatives of groups relevant to the cases.

The third and last type of interviews were follow up interviews conducted over the phone or Skype service with key participants to address some questions that needed further investigation before starting the analysis. Such interviews increase the validity of the data and give the researcher an extra opportunity to understand any ambiguous issues as well as to make sure that all questions have been covered. The follow up interviews were also used to ask some participants about other participants' opinions. This technique is important when there is some contradiction of opinions over a certain issue; for example the role of Sulha committees (indigenous dispute resolution patterns) in promoting the rule of law society from the perspective of indigenous leaders and from the perspective of police officers and judges.

Researcher's Observations and Participation in the Field 
As the study was expected to develop an action research agenda for the future, the researcher and the research team needed to spend enough time observing some communities' development practices such as collecting crops and the collective pressing that farmers of the Bani-Zaid Cooperative practice. This work will continue after the current study. Ongoing participation in actions will improve trust between the researcher and the communities and improve the process of learning that goes through the research time and beyond. Participation also enables the researcher to decide who within the cases can participate in the action research and how to go forward. Participants in action research could not only participate in research as interviewees, but they could also take part in future research and also participate in some publications. After conducting the research and writing the report, the researcher is planning to share the results with the communities represented in the three cases and specialized NGOs, in terms of networking among and NGOs, and governmental agencies.

\section{Data Analysis}

In general the researcher used two strategies of analysis, case-by-case analysis and cross-case analysis. However, each process consisted of three steps. First, the data were organized into categories. During this step, the researcher processed the raw data and organized it into major categories. This step is called the open coding and coding data into primary themes (Creswell 2007). Each category consists of first, "causal conditions" for example what factors caused success of indigenous knowledge-based practices in creating sustainable solutions to a certain problem. Second, "strategies" which are actions that people take in respond to such a practice. Third, "intervening 
conditions" which are broad and specific situational factor that influences people's responses. Finally, “consequences," are outcomes from using these kind of practices (Creswell 2007, pp. 64-65).

The second step is reducing or "condensing" the data into themes where similarities, differences and patterns' regularities start to make sense. Third, the research addressed the need for organizing data into tables, figures and findings that are discussed in the study. In this step, the researcher was about to recognize and report frequency indicators, count codes and characterize patterns (Creswell 2007, p. 148), develop propositions and prepare findings that contribute to developing model characteristics, concepts and relations. The cross-case analysis was then carefully developed to connect the pieces the three cases pieces into a whole picture that reflects an answer to the research question.

\section{$\underline{\text { Cross- Cases Analysis }}$}

The cross-case analysis is necessary when the approach is a multi-case one. Cross-case analysis enables the researcher and the reader to find what is common across cases besides what is unique about each case (Stake 2006, pp. 39-40). Finding common perspectives and themes across cases helps the researcher to understand the complexity of the quintain and consequently to report comparative findings to the reader. Finding comparable themes between the selected cases might explain the question of how indigenous knowledge is related to sustainable development in Palestine whereas finding differences might explain the question of why these differences happen and what are the strengths of each case that might generate lessons to be learned. 
Lijphart (1971) pays attention to the importance of selecting "comparable cases" which means cases that share similar characteristics. Having similar characteristics among cases allows the establishment of relationships among variables while different variables are controlled (Lijphart 1971). Hence addressing the research question(s) at the community level and through multi-communities allows the researcher to avoid being stuck with certain variables, if it is from a single case, and also avoid the lack of information a researcher might face a single case approach. A multi-case approach also can compensate from the lack of information, which is a common problem in conflict contexts where the state is either a failed or a weak one and releasing information and finding the rich kind of resources is a sensitive issue.

Triangulation within multi-cases is a double advantage. In a triangulation technique, the researcher uses multi-sources of information (interviews, documents, observations, personal notes and visual sources). Triangulation across cases can improve the validity of the study as the researcher uses the same techniques with each case (Stake 2006, pp. 35-36). Triangulation is also a good technique to find comparable variables across cases.

\section{CONCERNS OF VALIDITY AND RELIABILITY}

Yin (2009) categorizes validity into three types; construction validity, internal validity and external validity. For the advantages discussed in the previous section of the proposal, the researcher is following a purposeful strategy in selecting the cases. The concern of construction validity is a mater of subjectivity in the selection and collection of data (Yin 2009, pp. 41-44). However this concern was addressed by the careful 
definition of each case (defining cases' characteristics and how do they fit in the quintain. Moreover, triangulation is another technique to avoid subjectivity in gathering data.

Internal validity is another type of concern in the case study approach in general. This concern is more common in experimental research and casual relationships between variables. The researcher needs to be sure that $\mathrm{X}$ variable is the only cause for $\mathrm{Y}$ result and there is no $\mathrm{Z}$ variable that influences the relationship and which has not been taken into consideration (Yin 2009, p. 43). However, in a multi-case approach, each case opens a new window of investigation from which the researcher benefits during the investigation. The third type of validity is external validity; a concern that deals with generalizability of the study's results to the population or other cases in other contexts. Again, case study research is not a statistical approach. The research, in a case study is interested in learning, understanding, and interpreting a complex quintain, and at the end, developing propositions that contribute to theory building or refining. Therefore, the multi- case approach is more likely to improve external validity than a single- case approach.

Finally, reliability is a serious challenge in a case study approach. The question here is "if another researcher does the same research, will she or he find the same results? Creswell 2007, p. 76).” This is one of the challenging questions in social sciences in general and in qualitative research in particular; simply because human nature is different. For example, an interviewee might explain his/her experience but change his/her perspective later according to new factors that influenced his/her understanding of the issue. However, the researcher worked to reduce errors of reliability by using study 
protocols and case study data organization. Additionally, triangulation technique reduces errors of reliability.

\section{OTHER CHALLENGES}

The cases for this research study were manageable however there were some other concerns that were considered. While the multiple case study may improve validity and reliability, it might also create many variables that increase the complexity of viewing and understanding the whole picture that consists of many pieces. The challenge here is to connect the many variables (similar or different) in a way that makes sense. There is another concern that might come from losing depth investigation when looking at (5-6) cases at the same time. The problem is how to keep a balanced focus on the pieces and the whole (Creswell 2007, p. 76). The use of three cases was enough, but not too much.

Compared to quantitative research and some other qualitative research, case study research, particularly multi-case approach can cost more time, effort and money. Yin (2009) pays attention to the concern of time in case-study research and the possibility of producing a massive and unreadable report (Yin 2009, p. 15). However, effort and money costs might be overcome by using modern technology in doing telephone or online (Skype) interviews. In this regard, identifying clear case boundaries such as time, place, events, processes and key players helps to address the problem of spending more effort and time in case study research and indeed is what made this research feasible.

Finally, it is important to recognize that Palestinian territories formally includes the Gaza Strip, but for political reasons (the political division between Hamas and Fatah) 
and because of the occupation limitations, West Bankers are not allowed to enter Gaza; therefore Gaza's communities are excluded from the research. However, the propositions developed from the analysis of these cases can be tested there, in other areas of the region, and in other countries. It is the researcher's hope that they will be tested in those contexts.

\section{CONCLUSION}

This chapter has presented the problem of the study, the research question, its importance and objectives and the research strategy and design. This research has identified a variety of propositions that indicate the way in which indigenous knowledge can be used to promote sustainable development for communities in crisis conditions. These propositions form a theoretical body that explains the influence of indigenous knowledge on implementing sustainable development actions in crisis conditions. The second chapter will review the relevant literature that indicates what the literature says about the elements of the research and the core question, but also indicates more fully the gaps that need to be addressed. Those gaps were mentioned briefly in this chapter but require more thorough development.

Chapters three to five will present the three cases. Each chapter will discuss the narrative story of the case then the analysis of the case. Chapter six is a cross-case analysis that will present lessons learned from the cases in the form of a set of propositions derived from the study that are subject to testing in further research and that can be used in theory-building efforts to better understand the role of indigenous knowledge in sustainable development in crisis conditions. It will conclude with a 
discussion about further research that the study suggests on the light of the propositions and related questions that were encountered during the current research. 


\section{CHAPTER 2: THE LITERATURE OF SUSTAINABLE DEVELOPMENT IN CRISIS CONDITIONS: THE NEED FOR MORE ATTENTION TO INDIGENOUS KNOWLEDGE AND COMMUNITY ACTION}

This chapter presents what the literature says about sustainable development in crisis conditions, and what the gaps and, which needs are have not been sufficiently addressed. Additionally, it explores what the sustainable development literature considers the role of indigenous knowledge is in development. There are four critical areas to consider in order understanding the need for this study, and the gaps in these literatures, that it expects to address. They include (i) the core literature of sustainable development (ii) the challenges of sustainable development implementation in crisis conditions, (iii) The importance of community perspectives and the challenge of crisis conditions, and (iv) the emerging literature on the role of indigenous knowledge in building successful sustainable development.

The first important gap in the literature is the insufficient integration of the social dimension with the two other dimensions of sustainable development, economic dimension and environmental dimension. Although, key many works in the literature (World Commission on Environment and Development 1983, United Nations 1995, United Nations 2000, United Nations 2002) emphasized the integration process, still implementation, as the Millennium Goals report for 2011 indicates that the integration process has not yet been sufficient and needs more effort (United Nations 2011, p. 5).

In addition, the challenges of implementing sustainable development in crisis conditions are even more serious than in ordinary conditions. As the following 
discussion indicates, there is insufficient research that addresses sustainable development in crisis conditions particularly at the community level. Given the core concern that sustainable development depends upon support and creativity at the local level, there is a need to further consider that perspective.

Another key concern with the literature is the tendency to focus on policy implementation or policy failures as compared to strengths and successes. While it is important to know about successful efforts, it is also important to address the other side of the scale. While there many literatures that focus on failures and weaknesses, there are lesser materials that address lessons that could be learned from success.

The final relevant literature that this chapter presents is related to the role of indigenous knowledge in promoting sustainable development in crisis conditions. International development institutions have emphasized the role of indigenous knowledge in development, but while there is an emerging set of materials that consider the likely importance of indigenous knowledge, there is a lack of studies that go beyond the general commentaries to address the role of indigenous knowledge in practice in sustainable development.

THE CONTINUING PROBLEM OF INTEGRATING SOCIAL DEVELOPMENT IN SUSTAINABLE DEVELOPMENT

Although the discussion of development and environmental protection reaches well back in time, the move to what is now understood as sustainable development began with the Stockholm Declaration which came from the Stockholm Conference of 1972 and continued until 1987 when the Brundtland Commission developed the which is today the 
internationally accepted definition of sustainable development which emphasized the need to integrate economic development, social development, and environmental protection. The tendency has been for groups, countries, and international institutions to move back to focusing on the debate between environmentalists and economists, often omitting social development and not really integrating the other elements. The efforts at international conferences, starting with the Rio Earth Summit in 1992 has been to work to integrate the pieces. Still, there is a tendency in the literature and in practice to focus on the environment or economic development, but not to integrate all three elements. It is important to understand the effort to make that happen, but the pattern shows that still more attention is needed to integrate and in particular to ensure that the social development part is included.

Anti-pollution and Environmental Management Dominates Early Action in What Would be Sustainable Development.

During the 1960s and early 1970s, the world saw an increased concern about the environment. Environmental activists and scientists, such as Rachel Carson, "started to educate the public and policy makers about the importance of regulating toxic chemicals, particularly pesticides and herbicides" (Cooper and Vargas 2004, p. 24). The interest in environmental problems continued through the 1980s and in fact was fueled by major incidents such as the Chernobyl nuclear disaster, oil spills around the world, and Love the Canal disaster.

Furthermore, during the late 1970s and through the 1980s, the world saw an increasing interest in environmental management; especially about the nonrenewable 
resources such as oil and metals (Cooper and Vargas 2004, p. 24). Oil and metals, because of the increasing demand, were not only major pollution causing sources but were also used in huge amounts and wastefully as the industrial movement had been dramatically increasing. The debate continued between economists. However, the United Nations convened a Conference on the Human Environment that became known as the as Stockholm Conference that tried to deal with that tension between the two. Stockholm Conference of 1972: An International Start Toward Sustainable Development

The United Nations Conference on the Human Environment held in 1972 (United Nations 1972) in Stockholm, Sweden marked the first great international meeting on how human activities were harming the environment and putting humans at risk but also talked about the right of people in developing countries to move forward to improve their lives through economic development and the need to respect important social values. During a 1971 preparatory meeting for this conference, developed nations expressed concern about the environmental consequences of increasing global development, while nations that were still developing raised their own continuing need for economic development (United Nations 1972). At the same time, they insisted that they had a right to develop which includes the right to use their resources to improve their standard of living. The Stockholm declaration emphasized all of these elements, including the right to development with special concern for the needs of developing countries. Among the principles of the Stockholm Declaration were the following:

Man has the fundamental right to freedom, equality and adequate conditions of life, in an environment of a quality that permits a life of dignity and well being, and he bears a solemn responsibility to protect and 
improve the environment for present and future generations. In this respect, policies promoting or perpetuating apartheid, racial segregation, discrimination, colonial and other forms of oppression and foreign domination stand condemned and must be eliminated. (Principle 1)

The environmental policies of all States should enhance and not adversely affect the present or future development potential of developing countries, nor should they hamper the attainment of better living conditions for all . . .. (Principle 11)

States have, in accordance with the Charter of the United Nations and the principles of international law, the sovereign right to exploit their own resources pursuant to their own environmental policies, and the responsibility to ensure that activities within their jurisdiction or control do not cause damage to the environment of other States or of areas beyond the limits of national jurisdiction. (Principle 22)

The conference heightened awareness of the global nature of environment problems and set in motion events that led to the general acceptance of the idea that we would later come to know as "sustainable development" as a means of realizing the developmental needs of all people without sacrificing the earth's capacity to sustain life (United Nations 1972).

Out of the Stockholm Conference, the United Nations Environmental Program (UNEP) was formed with a mandate to promote the idea of environmentally centered development. Based in Nairobi, Kenya, UNEP provided the UN with an agency to examine the world's growing environmental and development problems with a view to making recommendations to national governments and international bodies on appropriate actions. Eventually the work of the UNEP helped launch, among other things, the International Environmental Educational Program (IEEP) in 1975 and the World Conservation Strategy in 1980 (UN Documents 2011). The parts of sustainable 
development were there, but the emphasis in the years after Stockholm and the work of UNEP was focused on the environment rather than all three elements. However, development agencies tended to emphasize economic development (United Nations 1972, Cooper and Vargas 2004, p.11).

The Nairobi Conference of 1982: Several Steps Backward

This international environmental conference held in Nairobi, Kenya, marked the midpoint between the Stockholm UN Conference on the Human Environment of 1972, and the Rio UN Conference on Environment and Development of 1992. It was supposed to be a tenth anniversary of Stockholm and rededication. The Nairobi Conference was much smaller than the other two principal conferences, but was an opportunity to review progress since the 1972 Stockholm conference. The Nairobi Declaration (1982) in its second and fourth principle focused on the gap of implementation of the Stockholm principles and Action Plan. Principle four posed on the "threats to the environment that are aggravated by poverty as well as by wasteful consumption patterns: both can lead people to over-exploit their environment. The International Development Strategy for the Third United Nations Development Decade and the establishment of a new international economic order are thus among the major instruments in the global effort to reverse environmental degradation" (United Nations 1982, p. 2). This principle considers poverty as a social problem to threat the environment at a time when globalization has expanded the gap in the world between the rich and the poor.

The second principle indicates the implementation gap of Action Plan since the Stockholm conference of 1972. It states: 
However, the Action Plan has only been partially implemented, and the results cannot be considered as satisfactory, due mainly to inadequate foresight and understanding of the long-term benefits of environmental protection, to inadequate co-ordination of approaches and efforts, and to unavailability and inequitable distribution of resources. For these reasons, the Action Plan has not had sufficient impact on the international community as a whole. Some uncontrolled deterioration, deforestation, soil and water degradation and desertification are reaching alarming proportions, and seriously endanger the living conditions in large parts of the world. Diseases associated with adverse environmental conditions continue to cause human misery. Changes in the atmosphere - such as those in the ozone layer, the increasing concentration of carbon dioxide, and acid rain-pollution of the seas and inland waters, careless use and disposal of hazardous substances and the extinction of animal and plant species constitute further grave threats to the human environment. (United Nation1982, p. 2).

The Nairobi Conference was supposed to recommit the United Nations members' commitment to Stockholm principles and the Action Plan and recommended many actions to respond to the environmental threats. However, the support of the U.S., which had been so important to Stockholm, had turned to opposition with the election of Ronald Reagan. The conference was a disappointment and the future of the Stockholm ideas was in doubt (Cooper and Vargas 2004, p. 26). It did not assure anyone of anything except that something dramatic had to be done or the whole movement toward sustainable development would be dead.

The Brundtland Commission Report: The Founding Document of Sustainable Development Demands Integration of All Three Parts

The report of the World Commission on Environment and Development, commonly known as the Brundtland Commission Report, after its chair, Gro Harlem Brundtland, is a cornerstone in sustainable development international literature and the 
foundation for international conferences and agreements starting with the Rio Earth Summit in 1992. It developed the internationally accepted common definition of sustainable development and clearly emphasized the critical need to integrate the three elements of sustainable development in development efforts.

On December 1983, Gro Harlem Brundtland, the Prime Minister of Norway, was asked by Morese SP Strong, the Secretary General of the UNEP, to chair a special independent commission, the World Commission on Environment and Development known as the WCED with a formal mission to re-examine critical environmental and development problems of the world and formulate realistic proposals to address them (World Commission on Environment and Development 1983).

A second formally stated goal was to strengthen international cooperation on environmental and development issues. And, finally, the commission was to raise the level of understanding and commitment to sustainable development on the part of individuals, organizations, businesses and governments (World Commission on Environment and Development 1983). In one of the important "calls for actions" the report states:

This commission believes that people can build a future that is more prosperous, more just, and more secure. Our report is not a prediction of ever increasing environmental decay, poverty and hardship in ever more decreasing resources. We see instead the possibility for a new era of economic growth, one that must be based on policies that sustain and expand the environmental resource base...We have the power to reconcile human affairs with the natural laws and to thrive in the process. (See World Commission on Environment and Development 1983, p. 9)

For three years the commission conducted public meetings in diverse regions 
throughout the world to get a broad perspective of environment and development issues. These hearings proved invaluable and resulted in more than 10,000 pages of testimony. The commission's work concluded in 1987 with the publication of its report entitled "Our Common Future", (commonly known as the Brundtland Report) (World Commission on Environment and Development 1987), which outlined a path for global sustainable development and served a key role in bringing sustainable development into the public eye world-wide.

The Brundtland Commission is important in the sustainable development literature for two reasons: First, it launched the first and most common definition of the concept sustainable development. Second, it emphasized the importance of the integration of the three elements of sustainable development. The commission define sustainable development as "development that meets the needs of the present without compromising the ability of future generations to meet their own needs" (World Commission on Environment and Development 1987, p. 8). In order to do that, the report stressed that the integration of the three elements is critical and harshly criticizes the tendency by some to stress economic development and others to focus almost exclusively on the environment with little attention to social development.

There is another reason why the Brundtland Commission Report is considered a cornerstone in the sustainable development debate. It is because the commission spent three years travelling and collecting hearings and perspectives from not only governments leaders, scientists, and experts but also perspectives and from citizens' groups, thousands of individuals, farmers, young people, industrialists and tribal people 
and leaders (World Commission on Environment and Development 1987, Ch. 1). This realistic and diverse perspective, precisely reflects the present and future needs and challenges of different sectors, pressed for producing a more integrated report than before with special focus on social challenges such as poverty and food security, and suggesting new integrated approaches to meet these challenges among others. The single most important argument, though, was that none of this could happen without consideration of all three parts of sustainable development.

The Rio Earth Summit and Agenda 21: Global Agreement on Key Principles of Sustainable Development

A two-year effort of preparatory meetings culminated in the Earth Summit in Rio de Janeiro, June 1992. This marked the third meeting of world leaders to discuss environmental and development issues and was substantially larger than its precursor the Stockholm Conference held, 20 years earlier. It produced a set of commitments in the form of the Rio Declaration and the program of action known as Agenda 21 that sought to integrate all the three elements as the Brundtland Commission had expressed (United Nations1992).

The Earth Summit was larger not only in the level of participation by the nations of the world, but also in the scope of issues it sought to address. Over 100 heads of state and government attended the Earth Summit and 170 nations sent delegations. As part of the Earth Summit, national leaders had an opportunity to sign international conventions on climate change and biodiversity, a "Declaration of Environment and Development" and an Agenda for the 21st Century known as (ㅁgenda 21), which sought to establish a 
concerted effort to educate people about the state of both the environment and development, and to assist them in making decisions that could lead to sustainable development.

Agenda 21 in sum is a program of action for a sustainable future for the human community and a first step towards ensuring that the world will become a more "just", secure and prosperous habitat for all humanity. Agenda 21 called on all countries of the world to undertake a comprehensive process of planning and action to attain sustainability (United Nations 1992).

In addition to a global agenda, this document also detailed a role for cities and counties. Chapter 28 of Agenda 21 (known as Local Agenda 21) states: "Local authorities construct, operate and maintain economic, social and environmental infrastructure, oversee planning processes, establish local environmental policies and regulations, and ....as the level of government closest to the people, they play a vital role in educating, mobilizing and responding to the public to promote sustainable development" (United Nations 1992, ch.28).

The Rio conference was to incorporate the social dimension more fully in the aftermath of the Brundtland Commission Report. As it happens, the politics of the event also caused indigenous groups to press for a more serious and careful hearing of their concerns. The Summit was the first serious event to actually work at integration after more than two decades of thinking only in environmental or economic terms. It was clear after Rio that although the language of Agenda 21 moved in the right direction, most countries were not integrating the social dimension and the international institutions were 
continuing to stress either economy or environment or both, but not the social element. Agenda 21 was an attempt, but after that things drifted back into the old direction. It was this fact that promoted the effort to ensure that Copenhagen would be a "Social Summit." The Copenhagen Declaration and Program of Action: Stressing Inclusion of Social

\section{Development}

The Copenhagen Summit of 1995 came as a respond to the lack of integration of the social dimension in sustainable development implementation. For example, the "contradiction" between expansions of prosperity in some places in the world and the expansion of "unspeakable" poverty in other places, among many other social problems, had not been addressed (World Summit for Development 1995, p. 5). The focus was still on environment and economics and not all three parts.

In March 1995, at the World Summit for Social Development, held in Copenhagen, Governments reached a new consensus on the need to put people at the centre of development. The Social Summit was the largest gathering ever of world leaders at that time. It promised to make the conquest of poverty, the goal of full employment and the promotion of social integration intervening. At the end of the Summit, governments adopted the Copenhagen Declaration, the Ten Commitments, and the Program of Action of the World Social Summit (United Nations 1995). In the opening of the declaration, the report states:

For the first time in history, at the invitation of the United Nations, we gather as Heads of State and Government to recognize the significance of social development and human well being for all and to give to these goals the highest priority both now and into the twenty-first century (United Nations 1995, p. 1). 
This declaration's principle, as well as all other principles of the summit, assured that the sustainable development process should be human centered process.

The summit also agreed on a set of measurable social goals that nations and governments should meet by the beginning of the $21^{\text {st }}$ century. Some of the most challenging goals are:

Directing the economy to meet human needs more effectively as human being are at the centre of development with a focus on the family as a basic unit of society; assuring equity and promoting equitable distribution of income for the present generation; insuring that vulnerable persons and groups are included in social development, reaffirming the right of self-determination of all people especially people under foreign occupation; recognizing the rights of indigenous people to purse their economic and social development; empowering women worldwide to strengthen their capacity; and promoting democracy, human dignity, social justice, solidarity, ensuring tolerance, nonviolence and nondiscrimination with full respect of diversity within and between societies (United Nations 1995, pp. 10-11).

There were more specific goals with percentage improvements concerning poverty, education, health care, and other social issues. The general principles and specific goals are challenging because they need a high level of collaboration between all levels of governance between and among nations.

It was the first time that such goals with measures for the social development part of sustainable development were agreed to on the international level and more importantly, the participants sign a set of commitment besides the Program of Action of the summit in order to achieve these goals:

We Heads of State and Government are committed to a political, economic, ethical and spiritual vision for social development based on human dignity, human rights, equality, respect, peace, democracy, mutual responsibility and cooperation, and full respect for the various religious and ethical values and cultural backgrounds of people. Accordingly, we 
will give the highest priority in national, regional and international policies and actions to the promotion of social progress, justice and the betterment of the human condition, based on full participation by all (United nations 1995, p. 5).

One of the important procedures to implement the goals of the summit was the composition of the Commission for Social Development (CSD) as part of the United Nations Economic and Social Council. The commission was formed to coordinate with other United Nations bodies relevant to the summit and prepare for follow-up conferences (United Nations 1995, p. 122).

The Copenhagen Summit emphasized that social development should be fully integrated with all development actions based on the principle of considering human beings at the center of sustainable development. In order to insure the integration and the comprehensive implementation, the Declaration of Program of Action required the United Nations to do a follow up and assessment of the outcomes of the Summit and the outcomes of other recent and planned United Nations conferences related to social development. These are: the Global Conference on Sustainable Development of Small Island Development States, held at Bridgetown, Barbados in 1994; the International Conference on Population and Development held in Cairo in 1994; the International Conference on Women held in Beijing in 1995; and the International Conference on Human Settlement (Habitat II), held in Istanbul in 1996 (The United Nations 1995, p. 121). In addition, the Rio +5 and the Copenhagen +5 follow up reports are key events to implementation of the commitment made at these conferences because they stress the failure, particularly of most economically advanced countries, to follow through on their 
commitments. That also led to changes in goals and laid the foundation to what became the Millennium Goals.

Agenda 21, the report and commitments of the Rio Earth Summit, emphasized the inclusion of the social dimensions, but when progress was assessed five years later (The United Nations1997), a number of gaps were identified particularly with regard to social equity and poverty. In other words, the Rio +5 Report found a lack of serious implementation of Agenda 21 with respect to the social as well as the other dimensions (Cooper and Vargas 2004, pp. 28-29). However, even before then, the need for more attention to the social development dimension led to, largely because of that lack of inclusion of the social dimension, the Copenhagen Social Summit which produced a series of commitments with specified goals.

Johannesburg: An Emphasis on Integration of the Three Elements Still Needed

Beginning in April 2001, preparation for the World Summit for Sustainable Development (WSSD) to be held in Johannesburg, South Africa took place at the local, national, sub-regional, regional and global levels. Negotiations occurred addressing not only Agenda 21, but also confronting new critical issues the world was facing in the 21 st century with globalization. Held in August 2002 in Johannesburg, South Africa, the World Summit on Sustainable Development (WSSD) marked the 10-year anniversary of the 1992 Earth Summit, the United Nations Conference on Environment and Development in Rio de Janeiro, Brazil. WSSD presented an opportunity for governments, United Nations' agencies, multilateral financial institutions, NGOs, and civil society to re-strengthen their global commitment towards sustainable development 
(United Nations 2002, p. 74).

Despite the many collective efforts such as World Summit for Social Development 1995; Report of the International Conference on Financing for Development 2002; Doha Ministerial Conference 2001, that have taken place between the time of Rio Earth Summit held in 1992 and Johannesburg (WSSD) Summit held in 2002, the WSSD summit had to face many challenges, particularly regarding the social dimension such as poverty eradication, reducing the gap between developing countries and developed countries and the poor and the rich worldwide, changing consumption and production patterns, in addition to many environmental challenges. However, globalization and its negative impacts on developing countries have been recognized to be a key challenge that faces the world (United Nations 2002, pp. 2-3). Globalization was recognized, despite the many focus on integration of the three elements in sustainable development, to exclude more people from development and increase the gap between the rich and the poor even within developed countries. The Summit report states that:

Globalization has added a new dimension to these challenges. The rapid integration of markets, mobility of capital and significant increases in investment flows around the world has opened new challenges and opportunities for the pursuit of sustainable development. But the benefits and costs of globalization are unevenly distributed, with developing countries facing special difficulties in meeting this challenge (United Nations 2002, p. 3).

The report of the conference explored and expanded discussion of all three parts of sustainable development, but acknowledged that the goals and principles set in Rio and in Copenhagen had not been met. The report discussed the negative effects such as 
structural adjustment of economies that had serious social consequences. It discussed several social development issues that still needed to be stressed like the importance of sensitivity to cultural differences in understanding of the family and community.

The Johannesburg Summit was trying to move sustainable development efforts in the right direction and pushing well beyond where efforts had been in many respects. However, the report made clear that much had not been done despite many promises. The Millennium Goals: A Stress on Sustainable Development Performance in the New Century

In addition to organizing world summits and conferences on development, the United Nations, in 2000, launched eight development goals known as (the Millennium Goals) to be achieved by 2015 as part of the follow up reports in order to watch the implementation of the international conferences commitments since Copenhagen Summit. The Millennium Development Goals were derived from the United Nations Millennium Declaration, adopted by 189 nations and at least 25 international NGOs (see the United Nations Millennium Declaration 2000). To monitor progress towards the Millennium Development Goals, data has been created and provided by specialized agencies within their area of expertise. They are drawn from national statistics provided by governments to the international statistical system of the United Nations Statistics Division and the statistical offices of the various international organizations and adjusted for comparability (see for example United Nations 2005).

Since 2005, the United Nations have started publishing an annual report (See United Nations Millennium Goals Reports Website 2012) about how the world nations 
are progressing and achieving the Millennium Goals up to the date. "The Millennium Goals are: goal one, eradicating extreme poverty and hunger. Goal two, achieve universal primary education. Goal three, promote gender equality and empower women. Goal four, reduce child morality. Goal five, improve mental health. Goal six, combat HIV/AIDS, malaria and other diseases. Goal seven, ensure environmental sustainability. Goal eight, develop a global partnership for development" (United Nations 2005, pp. 45). Based on data provided by a large number of international organizations within and outside the United Nations system, the annual reports present the most comprehensive global assessment of progress to date. The total figures in the reports provide an overview of regional progress under the eight goals and are a convenient way to track advances over time.

Despite the progress that occurs every year towards achieving the Millennium Development Goals, the latest United Nations Report of (2011) indicates that the world is failing to reach the most vulnerable sectors. Although many countries have demonstrated that progress is possible and indeed achieved some progress, still efforts need to be intensified. "They must also target the hardest to reach: the poorest of the poor and those disadvantaged because of their sex, age, ethnicity or disability. Disparities in progress between urban and rural areas remain daunting" (United Nations 2011, p. 4).

The report also indicates that despite the progress, there are some critical challenges toward achieving the goals by 2015 . For example, "being poor, a female or living in a conflict zone increases the probability that a child will be out of school" (United Nations 2011, p. 17). "Forests are disappearing rapidly in South America and Africa... the limits 
for sustainable water resources are already exceeded in Western Asia and North Africa...Poor rural populations remain at a disadvantage in accessing clean drinking water" (United Nations 2011, pp. 48-53).

In conclusion, much of the sustainable development literature even from the perspective of the international agreements to keep all three parts in balance has shifted from focusing on the economic dimension, as if economic is sustainable to focusing on the environmental dimension, as if green is sustainable. Although the continuing efforts in the international agreements and in the structure of the UN to force integration, the tendency continues to drift back to the separation, in contrast to some key works such as the World Summit for Social Development (1995) and the Millennium Goals (2000) address the social dimension of development. Still the integration process among the three dimensions, social, environmental and economic, is the key challenge and might continuous to be when it comes to implementation and also because sustainable development is a dynamic and continues process. In many cases, environmentalists and economic advocates have the tendency to redefine the concept of sustainable development the same as sustainability to reinforce their interests and ignore the social dimension except in some limited rhetoric.

\section{$\underline{\text { Sustainability Versus Sustainable Development: A Continuing Problem for Integration }}$}

In recent years there has been a growing tendency for policymakers and scholars to use the term sustainability instead of sustainable development. It may seem as if that is just a short version of the same thing, but it is not. It is a way for those who previously have focused on either environment or economic development to continue to do that 
while appearing to be committed to sustainable development. The problem with the concept of "sustainability" is not only that there is no clear definition of the concept, but it is also used to refer to sustainable development when it often is used in a very different way (See Diesendorf 2000, p.3). Thus, for those focused on environment, the term sustainability is a way to focus on conservation of the environment over the long term, but not necessarily to deal with either economic development or social development. For those who talk about economic sustainability, they often are referring to the ability to continue a certain kind of market behavior over time rather than being concerned about either the environment or social development.

THE CHALLENGE OF SUSTAINABLE DEVELOPMENT IMPLEMENTATION: THE POLICY FAILURE APPROACH AND THE LACK OF ATTENTION TO STRENGTHS VERSUS WEAKNESSES

Implementation of sustainable development is a complex process. This complexity, among other challenges, has caused many works in the field of sustainable development implementation to focus overwhelmingly on failure instead of successes. This section discusses the problem in policy failures approach or what Cooper and Vargas (2004) call the policy implementation gap, and the need to focus on the cultural strengths of communities as part of cultural feasibility in the sustainable development policy implementation process.

\section{The Complexity of the Implementation Process}

The challenge of sustainable development implementation is not only due to challenges of sustainable development integration, as discussed in the previous section, 
but also due to challenges of the way we understand the implementation process of public policy from the literature. The most important point here is to avoid the focus on policy failure that has been so important in the implementation literature. Also that literature often does not pay attention to cultural differences (see Mazamanian and Sabatier 1983).

It is important to take into account that sustainable development is for everyone and it is an integrated public-private process that involves many different players. Public policy implementation is, by definition, a complex process. Daniel Mazamanian and Paul Sabatier (1983) define the policy implementation process as "the carrying out of a basic policy decision, usually incorporated in a statute but which can also take the form of important executive orders or court decisions. Ideally that decision identifies the problem(s) to be addressed, stipulates the objective(s) to be persuaded in a variety of ways, structures the implementation process" (Mazamanian and Sabatier 1983, p. 20). This definition indicates the complexity of the process that integrates decision-making and responds to problems that should be addressed through different ways structured by objectives. Additionally, the implementation process involves many players from politically different decision makers, interest groups, public institutions and public servants (who usually implement the policy) to target groups and stakeholders who are supposed to participate and benefit from the policy.

The problem is that most of the literature focuses on why policy does not work and uses examples where policy failed (see Pressman and Wildavsky 1973, 1979, 1983). Sometimes it even looks for how people deliberately made it fail. For example, Eugene Bardach (1977), in his volume The Implementation Game, also emphasizes on the 
complexity of the implementation process of public policy. He argues that policy implementation is a process of responding to changes in political, organizational and technical environments. Accordingly, the process can "best" be understood as one that involves a complicated interaction between government institutions, actors, and the particular characteristics of substantive policy areas (Bradach 1977, see also Nakamura and Smallwood 1980). Bardach concludes that "the character and degree of many implementation problems are inherently unpredictable. Even the most robust policy, one that is well designed to survive, the implementation process will tend to go awry" (Bardach 1977, p. 5). However, what he focuses on in his book is a series of games that people use to block implementation. Yet the complexity of the implementation process explains a good deal about why implementing integrated sustainable development actions is always challenging even if no one is deliberately trying to stop it. This is what Phillip Cooper and Claudia Maria Vargas (2004) call the "the implementation gap" that exists between policy designs and the lack of action (Cooper and Vargas 2004, p. 13). The Implementation Gap: Focus on Failure Adds to the Problem

Cooper and Vargas (2004) like others who have written about policy implementation argue that the problem in policy process is not because of lack of policy designs and ideas but it is a matter of lack of action (Pressman and Wildavsky, 1983, Nakamura and Smallwood 1980, Mazmanian and Sabatier 1983). Public policy scholars and practitioners have considered the stage of policy implementation as a serious challenge for decades and it has been a dominant part of the literature from the outset. Pressman and Wildavsky $(1973,1979,1984)$ argued that the field of public policy has an 
implementation challenge that usually appears either when implementers start converting policy ideas and designs into action through the implementation process or where by intention or simple inaction no implementation takes place.

Additionally, most of the attention in the literature has been to understand policy failure rather than building on success (see Mazmanian and Sabatier 19981). Van Meter and van Horn, in their critique to public policy approaches, argue that " they (public policy approaches) added to our understanding to public policy process, yet neither tells us a great deal about how policy decisions are transformed into public services: they tell us little about the application or implementation of public policy. They have not given sufficient attention to the linkages between policy and performance" (Van Meter and Van Horn 1975, p. 447). The point here is that studies usually focus on policy failures and weaknesses rather than learning from successes.

Part of the implementation challenge is the need to avoid focusing so much on weaknesses versus strengths. There has been a long-term debate among policy implementation scholars over conceptualization and approaches to policy implementation (Sabatier Jenkins -Smith 1993). Unfortunately, most of the works in the policy implementation field (see, for example, Pressman and Wildavsky 1973, 1979) address weaknesses in policy implementation but few works tell us what to do or help implementers to build on strengths (see Cooper and Vargas 2004, Vargas 2002). 
Mortenson $^{1}$ (2007, 2008) and Pye-Smith, Borrini Feyerabend, and Richard Sandbrook (1994) are some of whose works have focused on learning from the strengths of communities in sustaining their lives and community ways. Pye-Smith et al.(1994) address successful case studies that focus on communities' strengths in sustaining their livings and developing their capacities in difficult conditions; often poverty and lack of resources. In most of these cases, communities developed a bottom-up approaches to implementing sustainable development actions that depend on "local implementation structures" (Sabatier1986, p. 32). Local individuals and leaders played a critical role in the implementation process. Pye Smith et al. selected their cases as successful cases of communities that organized and acted to meet their local needs (food, income, health and housing), while carefully managing their natural resources in a sustainable way (Pye Smith et al 1994, p. 171). The point here is that learning from strengths and successes makes a difference. A key lesson was the fact that governments, in these cases, gave local communities enough freedom to manage their environmental resources and use their indigenous skills and patterns, and their indigenous associations in the implementation process without interference from the central government and using effective partnership with external individuals and institutions (see Pye Smith et al.1994, pp. 171-180).

11 Although Mortenson's work and Central Asia Institute's efforts have been recently criticized by the 60 Minutes program produced on April 16 $6^{\text {th }}$ 2011, the evidence is clear that he has worked with dozens of communities to address a host of complex problems in one of the most conflict-ridden parts of the world. For more details, see CAI website https://www.ikat.org/ 
Greg Mortenson (2006, 2009), in his two volumes Three Cups of Tea and Stones into Schools, built on the role of culture in implementing development in one of the most difficult tribal communities in both Pakistan and Afghanistan. Mortenson and the Central Asia Institute that he created, focused on building schools to educate girls in Pakistan and Afghanistan, while they addressed a culturally sensitive issue, implemented policies and programs respectful of the culture and based on the communities' indigenous customs and leadership. The point here is that respecting the local culture of a certain target group makes an important difference in the implementation process. Implementation can be successful if implementers pay enough attention to culturally sensitive issues; and it might fail if implementers ignore local culture structures such as the role of elders, religion, and customs. In this regard, Cooper and Vargas (2004) argue that cultural principles are important not only because policies fail when they do not respect cultural sensitivities of beneficiaries but also because resistance to change can be based on cultural norms (Cooper and Vargas 2004, p. 373).

\section{The Challenge of Cultural Feasibility}

Thus the policy implementation literature and practice needs to meet the challenge of cultural feasibility (Cooper and Vargas 2004, ch9). Cultural Feasibility emphasizes questions that should be raised when decision-making and policy implementation are in action. Cultural feasibility raises two critical questions: "First, what are the impacts of proposed policy on different ethno-cultural groups? Second, has the policy engaged the diverse cultures available to take advantage of their knowledge and traditions, especially indigenous cultures?” (Cooper and Vargas 2004, p. 372). 
In developing countries, cultural feasibility is a double challenge. International NGOs, as key players in development policy implementation in developing countries, also bring their own cultures to the context. International NGOs are not only different in culture from each other but also different from the culture of national NGOs and local communities' cultures. However, sustainable development experience has overtime proved that paying attention to cultural sensitivities and involving indigenous cultures in policy making and policy implementation leads to successful results (Cooper and Vargas 2004, 361-362).

Regarding the role of culture in development, Vargas (2002) addresses important concepts in policy implementation field, addressing topics such as culturally sensitive issues (honesty, trust) and ethical issues in implementing policies in the refugee service delivery context, gender empowerment in policy implementation, and the importance of cultural interpretation and cultural mediation in building partnerships, and trust-based policy implementation process. While this discussion cites some examples of focus on success and on the importance of culture, most of the literature on implementation does not. There needs to be much more work on these two points.

The debate focusing on strengths and successes versus weaknesses and failure in policy implementation studies poses another important question, regarding differences in implementation at the community level compared to the national level. The question here is which level might provide positive sustainable development outcomes in crisis conditions? 
COMMUNITY LEVEL ANALYSIS VERSUS NATIONAL FOCUS: AN IMPORTANT DIFFERENCE IN PERSPECTIVE

Selecting the appropriate level of analysis to be applied in the appropriate context is a crucial issue in sustainable development implementation. The question that this section raises is: which level (community versus national) should scholars and implementers focus to achieve successful sustainable development? The literature has not given enough attention to a focus on the community and that includes the sustainable development literature.

Some policy implementation studies addressed the advantages and disadvantages of what is called "top-down approaches" (which usually depends on central decision making and national bureaucrats) of policy implementation versus "bottom-up approaches" (usually more flexible in involving stakeholders in decision- making and depends on their local structures) (see, for example, Sabatier1986). While top-down approaches are suitable for large governmental programs when there is a piece of legislation structuring the implementation process and funds are controlled by central rules. Bottom-up approaches are preferred when there is no dominant piece of legislation but rather a large number of actors without "power dependency" and with dynamics of different local situations (Sabatier1986, p. 37).

Sabatier (1986) indicates that the top-down approaches are criticized because they ignore or underestimate the abilities of local bureaucrats and target groups to effectively implement activities for their own purposes. At the same time bottom-up approaches are 
criticized because they often overestimate local abilities to deal with complex processes (Sabatier 19986, p. 30).

However, from a sustainable development perspective, the simple answer for this debate is that the context always counts (Cooper and Vargas 2004). As Cooper and Vargas (2004) put it, "sustainable development is not a one-plan-way to utopia... and is not tied to a physical planning model" (pp. 4-5). Successful policies, programs and projects, at the end, get its legitimacy not only from legislation and laws but also from a large participation, regard and support from the targeted people or communities (Easton 1989). Regarding this study, the context is in crisis conditions where the role of the state is precisely, weak if not absent. In such situation, empowering communities is important for sustainable development.

The Community Perspective and the Challenge of Politics of Crisis Conditions

The level of analysis is a serious challenge in crisis conditions because of complex politics. Cooper and Vargas (2004) argue that political feasibility is one of the important elements (See Cooper and Vargas, the feasibility framework, specifically political feasibility, ch. 7) in policy implementation success that leads to sustainable outcomes. Political feasibility is interested in the question whether policy makers and implementers have the political will to do what they want to do, and if yes, do they have the power to do it (Cooper and Vargas 2004, p. 255).

Political feasibility is influenced by three major factors: First, intergovernmental relations; this means how policy decision making takes place and flows among the different levels of governance, and how collaborative are the levels when it comes to 
implementation. Second, participation or what is called participatory democracy. This factor relies on involving stakeholders, especially the "less visible" (women, the poor and people with special needs), in the policy process and moreover empowering them (Cooper and Vargas 2004,). Internationally, in non-democratic countries, the interest is also on the rule of law, human rights, and freedoms (Cooper and Vargas 2004, pp. 284285). Third, consideration of the politics of NGOs is crucial. For many reasons, NGOs these days are considered key factors in international, national and local governance. NGOs are major players in many developing countries as contractors and grant receivers in national politics and public administration in developed countries. They work in difficult and stressful internal conditions as they rely on volunteer staffs; management of volunteers is different from paid staffs in terms of transparency and accountability (Cooper and Vargas 2004, p. 290). Implementers therefore should pay attention to the question of which level is politically feasible. The problem for implementation is that almost all of these parts are either missing or very weak in countries that are in crisis conditions.

Most of the literature that addresses sustainable development is focused on projects that are conducted from the national level and the international level. Part of this stems from attention to the national level from the Rio Earth Summit on. For example the Millennium Goals reports $(2005,2006,2007,2008,2009,2010,2011)$ are an international effort at collecting national data from different countries about improvement toward achieving the goals. However, little attention has been paid to sustainable development from the community level. Mortenson $(2006,2009)$ and Pye-Smith et al 
(1994) are examples, from a few works, that addressed sustainable development in crisis and difficult conditions at the community level. Mortenson's works succeeded to challenge the lack of Pakistani and Afghani government's attention to the critical issue of educating girls in conservative tribal communities. However Mortenson succeeded in managing building hundreds of schools with the help of local communities and their indigenous leadership.

The Wealth of Communities (1994), by Pye-Smith et al., is a book on community stories where local environmental, social and economic problems were solved locally (Pye Smith et al.1994, p. 183). Lessons could be learned from its stories in which governments, especially in difficult conditions of poverty and lack of resources, gave enough freedom to local communities to make decisions and implement actions to sustain their living and whatever available resources.

The final factor that influences political feasibility is political will (Cooper and Vargas 2004). What any policy proposal needs to assure in this regard is creating common political commitment from decision-makers and implementers. Political will is a serious challenge in regimes in crisis conditions which may be authoritarian or that in many cases suffer from corruption. In some cases, there is little effective governance from the top. In brief, understanding the political picture of the context helps implementers to decide on which level of analysis (governmental agencies, nongovernmental organizations national level, local level, or community level) is feasible and can provide sustainable outcomes. Crisis conditions politics is an extraordinary challenge in terms of selecting a feasible level of analysis. The need for community level 
sustainable development implementation is in the focus here and should be addressed in further research.

\section{IMPLEMENTING SUSTAINABLE DEVELOPMENT UNDER CRISIS}

\section{CONDITIONS: CONTEXT COUNTS}

As noted above, crisis conditions, especially wars, civil disorder, and terrorism, create extraordinary challenges to sustainable development efforts. As the World Bank Report (2003) Breaking the conflict Trap: Civil War and Development Policy argues, “war retards development but conversely development retards war"(World Bank 2003, p. 9). This means that development leads countries to become progressively safer from violent conflict, and makes subsequent development easier. On the other hand, where development fails, countries are at high risk of becoming caught in a "conflict trap" in which war exhausts and destroys the economy and increases the risk of further conflicts (World Bank 2003, p. 1).

The report further states: "Civil wars particularly attract less attention but their influence goes across borders in terms of creating regional insecurity and instability, sends refugees across borders, forces regional and sometimes international powers to take a position in the conflict" (see World Bank 2003, pp. 4-5; ch3). The report concludes that the attitude of "it is not our problem" sometimes taken by the international community is mistaken, therefore, sustainable development is a key factor in war crisis conditions in general and war conditions in particular; yet the question is how to approach sustainable development in such conditions. 
In most crisis conditions cases, the international reports and other literature, (for example, UNDP 2009/2010; Special Inspector General for Afghanistan Reconstruction 2010; UNEP 2007) address development from a security, economic stability and reconstruction perspective. However, sustainable development, according to the feasibility framework (see Cooper and Vargas 2004) and also by definition (see The World Commission on Environment and Development 1987), is different from stability, security and reconstruction although these are important elements for development (Cooper and Vargas, 2008, Ch. 1). For example, the Special Inspector General for Afghanistan Reconstruction (2010), known as the SIGAR Report, indicates that security and economic growth are still considered the key factors of development in Afghanistan. Yet spending billions of dollars on building stability and security, although they are important factors, have not provided sustainable outcomes to the Afghani society.

Secretary of States Hillary Clinton declared a new approach for implementing development in Afghanistan that includes increasing partnerships with developing countries to design and implement development projects and decreasing the reliance on private contractors to develop, execute and evaluate projects. This approach is still focused on security, economic stability and reconstruction attitude (Special Inspector General for Afghanistan Reconstruction 2010, p. 4). Moreover, the report itself is not designed from a sustainable development perspective. SIGAR was assessing whether U.S investments in reconstruction projects and programs in the security, governance, and development sectors are resourced to achieve the conditions that would allow the United States to meet its goal to begin withdrawing troops from Afghanistan in the summer of 
2011 (Special Inspector General for Afghanistan Reconstruction 2010, p. 4). Neither the report nor the "new approach" of addressing development in Afghanistan focuses on sustainable development; still the focus continues to be security and economic stability; this approach does not sufficiently answer questions of sustainable development. Cooper and Vargas explain why these are problems in so many ways (2008, Ch. 1), but more research needs to be done on how to do sustainable development successfully in crisis conditions.

\section{THE ROLE OF IDIGENOUS KNOWLEDGE IN SUSTAINABLE DEVELOPMENT:}

\section{POSITIVE WORDS BUT NOT MUCH RESEARCH}

There have been several times during the history of sustainable development when governments and scholars have said it is important to include indigenous knowledge, but very little detailed research has been done on the subject that helps us to know why it is important for sustainable development or how it works. To understand the role of indigenous knowledge in sustainable development, it is important to understand how interest in indigenous knowledge developed in the international sustainable development literature and events, what is the definition and characteristics of indigenous knowledge and why it is important, which role can indigenous knowledge play in sustainable development efforts, and finally the concerns about the limitations of indigenous knowledge that have been raised.

Indigenous Knowledge in the International Sustainable Development Literature

Historically, indigenous peoples have been socially and economically discriminated against and culturally marginalized by the process of economic 
modernization and development. Over the past three decades, however, policymakers, development planners, and the public in general have become increasingly aware of the important role that the traditional knowledge of indigenous peoples can play in the promotion of sustainable development (see United Nations 1995, p. 10).

The significance of traditional knowledge for sustainable development was recognized in the Brundtland Commission's report, Our Common Future (1987), and at the Earth Summit in Rio de Janeiro in 1992. In fact indigenous groups demanded an opportunity to participate at Rio. It is also incorporated in the Agenda 21 documents of the United Nations and the International Convention on Biodiversity (see for example United Nations 1992, pp. 227-229, World Commission on Environment and Development 1987, ch. 4). On December 1992, the United Nations declared 1993 as the International Year for the World's Indigenous Peoples with a view to strengthening international co-operation for the solution of problems faced by indigenous communities in such areas as human rights, the environment, development, education, and health (United Nations1992, p. 127).

The World Bank Shows Special Interest in Indigenous Knowledge. The World Bank was the first multilateral development institution to establish a special policy for the treatment of indigenous peoples in internationally funded development projects. This policy dates back to the early 1980s, when the bank became involved in funding several projects that affected the lands and welfare of relatively marginalized and highly vulnerable indigenous tribes in the South American Amazon. The bank policy called for: "the recognition, demarcation, and protection of indigenous peoples' lands, and the 
providing of culturally appropriate social services, especially to protect and maintain their health" (World Bank 1993, p. 3).

In the late 1980s the bank reviewed its project experience in this area and, in 1991 issued a revised policy. This new policy extends the definition of indigenous peoples to reflect the much broader range of social and legal definitions and situations in bank member countries. Some of the earlier protective measures are maintained, but the new policy also stresses the need to promote the informed participation of indigenous peoples and their sharing in the social and economic benefits of development projects (World Bank 1993, p. 4).

In September 1993 a conference was organized as part of the World Bank's activities for the UN International Year of the World's Indigenous People. A major purpose of the conference was to bring together a small number of indigenous peoples from around the world to educate Bank staff on issues relating to traditional knowledge and sustainable development (World Bank1993). The conference explored critical questions such as: "What is the role of traditional knowledge in sustainable development? What are the contributions that traditional knowledge can make to health and environment programs? How can traditional institutions be used to increase participation in the development process? How can the Bank and other donor agencies improve their performance in planning development projects with indigenous peoples?" The September 1993 conference was only a first step in addressing these issues and did not cover all of the significant cultural and development concerns relating to the large scope of 300 million of indigenous people living in 70 countries all over the world (World 
Bank1993).

Although the international literature and events about indigenous knowledge raised important questions about the role of indigenous knowledge in sustainable development, it did not clearly define the concept in a way that enables researchers to identify what is within indigenous knowledge and what is not. It can be challenging to do that work because of the large scope of indigenous cultures, different from each other, that are spread all over the world nations and societies. In fact, there is currently no clear agreed upon definition of indigenous knowledge, however operational definitions and identifying indigenous knowledge characteristics can help for the purpose of research.

\section{Operational definition of Indigenous Knowledge: It is Better Understood by its}

Characteristics. It is important to say that the term "indigenous people" in the Palestinian context is a little bit different from the meaning of the term as it is used in Western contexts such as the United States, Canada and Australia. That is because, compared to indigenous peoples living in these countries, Palestine is an occupied country in which people are still struggling for independence and national identity. The term in Western contexts is used to refer to native people who are conquered by colonial forces and who are still living in their indigenous communities within the modern societies in these countries (see United Nations 2008, pp. 7-9). This situation is different from the situation in Palestine. Even so, some observers might find similarities between these situations.

The word indigenous will be used in the research to mean traditional patterns of life that have been in existence for a long period of time in the community, the country, 
or the region. Here the research is addressing the indigenous (traditional) knowledge used in Palestinian local communities as a basic part of development practices that takes place in these communities. Because of their nature, it is often not possible to know just how far back in time an indigenous practice goes. That fits with the usage in the international literature.

Indigenous Knowledge Key Characteristics. The United Nations Resource Kit on Indigenous Peoples' Issues (2008) states that: “the most fruitful approach is to identify rather than attempt to define, indigenous peoples in a specific context. Indigenous peoples' representatives themselves have taken the position that no global definition is either possible or desirable. Identification is a more constructive and pragmatic process" (United Nations 2008, p. 9). In this regard, the United Nations identify some common characteristics for indigenous such as people who usually have poor representation and participation in political life, lack of access to social services, and exclusion from national decision-making even on matters that might affect their livings and their future. Additionally, indigenous people and their pattern of development are recognized in their historical and spiritual deep connection to their lands, territories and natural resources, which in many cases distinguish their identity and sustain their lives (United Nations2008, p. 9).

As discussed in chapter one, indigenous knowledge could be better understood by identifying and understanding its characteristics, as compared to contemporary scientific knowledge characteristics, and the culture of the community(s) that believe and practice such type of knowledge. Warren (1991) argues that IK is better understood when it is 
compared to scientific knowledge (modern knowledge developed by universities, research institutions and scholars). He gives another operational definition to indigenous knowledge. He defines it as: "it is the basis for local-level decision making in agriculture, health care, food preparation, education, natural-resource management, and a host of other activities in rural communities" (Warren 1991, p. 6). This definition identifies rural communities as the context where IK takes place.

One of the distinguishing dimensions of indigenous knowledge is the spiritual sphere and epistemology of the people who believe and practice indigenous knowledge. For example, indigenous knowledge in African communities such as the Xhosa in South Africa considers that "the holistic nature of the interrelationship between nature, human beings and the supernatural is foundational" (Breidlid 2009, p. 141). Consequently, indigenous knowledge systems (social patterns, ecological patterns, economical practices, science and technology) in these communities are influenced, if not derived from, the communities' worldviews including religious beliefs and cultural views.

Chivaura (2006) argues that:

[T] he difference between African and European worldviews concerning earth and heaven is related to differences in their attitudes towards the material and spiritual. Africans regard them as compatible...the danger of adopting the European worldview to solve African problems is therefore obvious. It is hostile to our worldview and idea of development. African development can only be truly achieved through an African worldview (Chivaura in Breidlid2009, p. 141).

Chivaura's argument raises the question of the capability and flexibility of indigenous knowledge to integrate and exchange knowledge with scientific models of development. The limitations and shortcomings of indigenous knowledge will be discussed later in this 
chapter; however, this study argues that integration of indigenous knowledge with scientific models, by paying enough attention to the concept of cultural mediation (Vargas 2000), is possible and could provide sustainable solutions for development problems in crisis conditions.

Indigenous knowledge and Legitimacy. Another dimension that is important to discuss is legitimacy of indigenous knowledge. In politics, legitimacy is the popular acceptance of a governing law or régime as an authority (Dahl1971). Robert Dahl differentiates between legitimacy and authority. Whereas "authority" denotes a legal power in an established government, the term "legitimacy" refers to a system of government where in "government" denotes "sphere of influential". Dahl argues that legitimacy can be explained as a "reservoir"; so long as the water is at a given level, political stability is maintained, if it falls below the required level, political legitimacy is endangered (Dahl 1971, 122-125).

Easton (1957) explains how political systems and their policies gain legitimacy by getting support and "energy" from the people. Easton argues that outputs (good decisions and policies) that tend to satisfy the day-to day demands of members which can work as supporting mechanisms. Another mechanism of support, Easton considers, is politicization; a process of accumulating support through past decisions and reinforcement of new decisions (Easton1957, p. 10). When both mechanisms and many other political attachments are rooted "institutionalized", the system will be claimed to have legitimacy. Easton concludes that the process of politicization "effectively sums up 
the way in which legitimacy is created and transmitted in a political system" (Easton 1957 p. 10).

Indigenous Knowledge and Trust. The question whether indigenous knowledge has the power of trust in crisis conditions is a key question because crisis conditions is a context of uncertainty and lack of resources, including confidence in governments and policy implementers. Trust is a "slippery" concept that is hard to define because it is based on attitudes and it is a multi-dimensional concept. Most of the literature (see for example Uslaner 2001, Gambetta 1998, Trudy 1997) that address trust deals with the concept in terms of questions such as: how it matters? Why it matters? When it matters? What are its levels? What are its types, conditions, elements and descriptions etc?

One of the influential descriptions of the concept of trust is Uslaner's (2001). He states that "trust is the chicken soup of social life. It brings us all sorts of good things, from willingness to get involved in our communities to higher rates of economic growth and, ultimately, to satisfaction with government performance, to making daily life more pleasant" (Uslaner 2001, p. 1).

Niklas Luhmann cited in Gambetta (1998) defines trust as " an attitude that allows for risk taking decision" (p. 103). The author argues that the development of trust and distrust depends on personal experience. He also considers confidence as a key element of trust building; "lack of confidence and the need for trust may form a vicious circle. A system, economic, legal or political, requires activities in situations of un-certainty or risk. At the same time, the structural and operational properties of such system may 
erode confidence and thereby undermine one of the essential conditions of trust" (Gambetta1998, p. 103).

Indigenous patterns of development usually come as an accumulative heritage of knowledge that a generation passes from one to the other. It is also built on the set of ethics and culture and religion that distinguishes communities. This cohesion between knowledge and practices distinguishes indigenous knowledge based- patterns of agriculture, natural resources management, conflict dispute and social cohesion. An additional factor that might be considered as a key success factor is its simplicity to be applicable in communities when it is familiar to the culture. Although most of indigenous knowledge principles are not written in books or documents, they form a kind of oral, well known knowledge to the community and agreed on principles and practices (The World Bank1993).

Indigenous Knowledge and Sustainable Development. The World Bank (1998) indicates that indigenous knowledge represents an important component of global knowledge on development issues. "IK is an underutilized resource in the development process. Learning from IK, by investigating first what local communities know and have, can improve understanding of local conditions and provide a productive context for activities designed to help the communities" (World Bank1998, p. 1). The World Bank, as a leading development institution, has recently recognized the importance of cultural issues including indigenous knowledge in development, particularly sustaining lives of communities and reducing poverty (World Bank1998). 
Many World Bank studies (World Bank 1993, World Bank 1998) have addressed the potential power of indigenous knowledge in development. The World Bank is interest in indigenous knowledge is also, as Cooper and Vargas (2004) note, recognized part of cultural feasibility, as that concept is presented in the international common commitments from Agenda 21 on, a key element in sustainable development policy implementation. Cultural feasibility raises two critical questions: "First, what are the impacts of a proposed policy on different ethno-cultural groups? Second, has the policy engaged the diverse cultures available to take advantage of their knowledge and traditions, especially indigenous cultures?" (Cooper and Vargas2004, p. 373; see also Vargas2000). The culture sensitivity principle is important not only because policies fail when they do not respect cultural sensitivities of beneficiaries but also because resistance to change can be based on cultural norms.

There is a lack of case studies that address the relationship between indigenous knowledge and sustainable development in developing countries although the context is rich in diverse cases. There is a good deal of general discussion and some individual studies, but more is needed. Moreover, there is lack of attention in the literature on how indigenous knowledge is used and what differences it makes to sustainable development. The Wealth of Communities (1994) by Pye-Smith et al. is one of the few works that addresses this relationship. The work is a collection of cases from diverse contexts especially from poor countries. The cases generate lessons about how poor people were able to sustain development and improve their lives using simple indigenous approaches and partnerships. The book addresses the theme of learning through cross-case analysis, 
learning from the people and the theme of cultural mediation and interpretation.

Interestingly enough, the book addresses sustainable development from a community level where people got the chance to tell their interesting stories about their experiences in sustaining their lives.

Indigenous knowledge is proposed, in this study, to play the role of a mediator that can provide integrated sustainable development outcomes in crisis conditions. This study addresses the question: how have successful community-level sustainable development efforts undertaken under crisis conditions drawn upon indigenous knowledge to achieve positive outcomes? The study will add to this literature a set of propositions to guide further research and sustainable development practices.

The Status of Indigenous Knowledge as a System of Knowledge. The validity and importance of indigenous knowledge as a knowledge system could be defended by examples and case studies, however, IK, compared to scientific knowledge, is still not recognized by many institutions worldwide under the justification that it is not published in books and models are not scientifically examined (World Bank 1993). In this regard, the question for many people in the community would be: If indigenous knowledge outcomes are valid from the perspective of its communities, why should its validity be questionable by outsiders? Even so, there is a general agreement among international bodies that indigenous knowledge is important, but there is still not enough research to get beyond that general assertion.

In conclusion, it is important to say that sustainable development works in a context and the context is represented by the culture of the people and the organizations 
working with the people. The collective trend of IK- based practices should be important to modern sustainable development efforts (Weeramantry 2002). Criticizing modern law that protects individual's interests, Weeramantry argues that absolute freedom of contract and ownership of properties are devastating to the environment. In contrast, indigenous "wisdom" is more collective and sustainable in focusing on groups' rights (the village's and communitiy rights) as well as the environment's rights. He claims that indigenous and traditional ways of living and interacting provided guidance on how to build sustainable development in the modern day. In the same regard, individualism is a subject of criticism by Garrett (1998). He argues that "individualism is cherished because it produces freedoms, but the gift is conditional: the more the population exceeds the carrying capacity of the environment, the more freedoms must be given up" (Garrett 1998, p2). Competitive individualism would be helpless to prevent the social disaster. So, complete freedom is a tragedy. The fact that cultural contexts are different counts a great deal in development policy implementation. Despite that, indigenous knowledge has some limitations that might be important to discuss and pay attention to in the next section.

$\underline{\text { Some Possible Negative Impacts of Indigenous Knowledge }}$

Traditional societies used to be described as "rigid, anti-change and antidevelopment and exclusionary" (World Bank 1993, p. 3). Probably the basic issue of this claim however is the role of women in patriarchic or male-dominated societies (See UNDP2005, pp. 13-14, see ch.4 of UNDP 2009). There are important challenges in this area and part of this research explores those challenges. The findings also indicate, 
however, that indigenous knowledge can be and has been used to meet sustainable development goals in these areas.

Traditional custom- based exclusion is one of the examples of an area in which there have been challenges concerns gender biases. In some traditional communities, women have historically been excluded in terms of power and decision -making, while in others they have been key decision-makers in traditional societies. The World Bank (2000a) in its report named Voices of the Poor: Crying out for Change states that traditions and customs play a role in classifying gender role in "poor" communities (World Bank 2000a, pp. 142-144). For example in Indonesia, researchers indicate that in many traditional communities "community means men only...women groups every where confirm women are neither invited nor expected to attend the village meetings...some of them may attend the general village meetings, women's expected role is generally that of silent observers or servers of tea and refreshment" (World Bank 2000a, p. 143). Similarly, in one of the traditional communities in Bolivia, researchers state that "if women go to a meeting, they do not give their opinion...community decisions are the rights and responsibilities of men folks" (World Bank 2000a, p. 142).

In other traditional communities, females are excluded from education. Again, the Voices of the Poor: Can Anyone Hear Us addresses the issue from the perspective of family security (World Bank 2000b). The report states that there is discrimination against girls, compared to boys, in education rights because of early marriage. A girl from a traditional community in Nigeria said: "my brother completed primary school and went to college. I look forward to getting married someone" (World Bank 2000b, p. 
209); marriage in this case is assumed to count for the security of the girl. Another case from South Africa states that "it is wasting money to educate girls because they will marry and join another family" (World Bank 2000b, p. 209).

The UNDP, in the Arab Human Development Report (2009), raises the problem of early "child" marriage of girls in many Arab communities especially traditional ones such as communities in Mauretania, Somalia, Yemen, and Sudan (see statistics in UNDP2009, p. 81). The report indicates that among other reasons, "security" of girls (to be secured with her husband from harassment or any immoral behaviors) is a main reason for early marriage. Early marriage is also reported as a critical cause of other social problems such as increasing the rate of divorce and family break down and family violence (UNDP2009, pp. 78-82). In this regard, it is important to remember that violence against women is a world -wide phenomenon and not limited to one society or community. (UNDP2009, p. 79) indicates that "around the world, one in three women will be raped, beaten, forced into sex or otherwise assaulted in her lifetime".

However, early marriage has positively changed (increasing the age) in Arab countries because of the extraordinary efforts of women activists and human rights organizations that lobbied hard to change the marriage law in many countries. Some of these organizations were influenced by catastrophic cases such as the Yemeni child bride (Nojood Ali) who escaped from her husband, who was three times her age, and went to the nearest court and sued for divorce justice justice. Accordingly the Yemeni government, under public and law activists, was forced to increase marriage age of girls from 15 years old to 18 years old (see the details in UNDP 2009, p. 82). Also, stigma 
against women in traditional or male-oriented communities is a serious social problem that is part of the difficulty and often comes with stereotyping (UNDP 2009, p. 82). World Bank Report (2000b), Voices of the Poor: Can Anybody Hear Us, investigate the issue of traditional gender norms in many poor countries and recorded women's opinions about the sources of gender stigma. The report indicates that stigma might come from "common proverbs, traditional stories, customs and every day practice" (World Bank 2000b, p. 178).

Women's "inferiority" is used to justify discrimination and abuse (see for example UNDP2009, pp. 80-83) in the household and in society at large and power inequity is reflected and reinforced by traditional and modern laws and institutional practices. A woman's extra-household bargaining power with legal authorities, society, and the market impacts her intra-household bargaining power too. In this regard, it is important to say that traditional communities are not the only ones that discriminate against women; and there may be more variables that negatively affect the issue of gender stigma and social exclusion such as poverty and the nature of political regime that rules the society (World Bank 2000c, p. 136).

So it is clear that gender biases that have long been part of a culture can pose barriers to successful sustainable development. However, as this research shows, traditional knowledge can also be used to address some of the problems that have been caused by those cultural biases. The case studies and the cross-case analysis address these questions very directly.

Religion Versus Custom-Based Exclusion. Mixing what is from religion with 
what is from customs is another area in which there can be challenges to successful sustainable development in contexts where indigenous knowledge is important is religion. Religion-based exclusion, for the purpose of this discussion, could be classified into two dimensions: (i) exclusion confronted by religious minorities (because of their religion) from outside their communities and (ii) exclusion (based on religion) of some sectors, such as women who are excluded within their communities. However, there are two cautions that should be taken into account when discussing religion-based exclusion. These are first, distinguishing what is from religion from what is from custom especially in traditional tribal communities, and second, paying attention to other variables, besides religion, that might mix with the religious issue and cause exclusion such as race or language.

The World Bank (2000a) indicates that ethnic minorities, including religious groups, face exclusion and discrimination worldwide, however, this is not limited to traditional societies (p. 139). Indigenous people in Ecuador, Hindus in Bangladesh, Protestants in Ethiopia, Muslim communities in India struggle at the community level and the state level to get their rights and not be excluded and marginalized (p. 139). For example, in Bangladesh, Hindu minority do not receive enough flood relief from the state like Muslims who live in the same village; however, Hindus cannot protest for their rights because of fear from Muslims (World Bank 2000a , p. 141). Being isolated from higher level of decision-making might cause these minorities and communities to partially self-isolate themselves from other communities and the society in general (World Bank2000a, p. 142). 
Exclusion, especially against women, in some traditional communities might base on people's interpretation and understanding of their religious texts. Here there is the caution of mixing what is from a religious text and what is from traditional customs or local interpretation. For example, early marriage in many Muslim communities is claimed to be based on Islamic rules. Although Islam encourages marriage in general and, like other religions, prohibits sex relationships outside marriage, there is no Islamic text (Quran or Hadith $\left.{ }^{2}\right)$ that calls for early marriage. Thus early marriage is spread in traditional communities as a custom. In many traditional communities, families compete and feel proud if they get all their daughters married at an early age. Therefore, the Islamic text is misinterpreted to serve a rationale for social custom in these communities.

These two examples show that it is important to be aware when using traditional knowledge and determine whether it poses challenges to sustainable development. However, this discussion also shows that indigenous knowledge can also be a very important resource. This study explores just how that works in the chapters that follow.

\section{CONCLUSION}

This chapter presents a literature review on sustainable development, sustainable development implementation in crisis conditions from the community level, and the role of indigenous knowledge in the sustainable development literature including the possible negative impacts of some traditional practices. This study adds to the few studies that address sustainable development in crisis conditions. It also adds to the small amount of

\footnotetext{
${ }^{2}$ Hadeath is all authentic oral speeches, statements and sayings; written statements and actions that Prophet Mohammed did or situations and actions that he was asked about but did not deny by not saying anything about it. The most authentic Hadeath books in Islamic history are Saheeh Al-Bukhari and Saheeh Muslim.
} 
literature that has focused on strengths and successes from sustainable development work at the community level. The study also adds to the very few studies that address the role of indigenous knowledge in promoting sustainable development particularly in crisis conditions. It recognizes the need to be alert to challenges, but it clear adds to the very general discussion of indigenous knowledge in the literature. The individual case analysis and the cross-case analysis provide contributions to a number of these. 


\section{CHAPTER 3: ORGANIC (BALADI), EXTRA VIRGIN OLIVE OIL PRODUCING PROJECT IN BANI-ZAID AL-SHARKIYA COMMUNITY: "WE TREAT THE OLIVE TREE AS WE TREAT OUR CHILDREN"}

\section{INTRODUCTION}

This first of three case studies addresses a successful story of a Palestinian rural community; Bani-Zaid Al-Sharkiya. It is a community of 5639 people living in two small villages (Mazari Al-Nobani and Arora) located $20 \mathrm{~km}$ to the North of Ramallah city. The community has vey few resources; basically olive and grapes trees. Farmer leaders of this community succeeded in developing an agricultural community cooperative named Bani-Zaid Al-Sharkiya Cooperative for Organic Olive Oil that, as the chapter will explain, succeeded in promoting sustainable development economically, socially and environmentally. Bani-Zaid Al-Sharkiya Cooperative has implemented the first certified organic farming project in Palestine in partnership with the Palestinian Agricultural Relief Committees (PARC), Reef Company for Export, Fair Trade Association, French- Palestinian Coordination Association and other national and international NGOs. The core success of this case is that it represents sustainable development policy implementation from the community level, with focus on strengths of local indigenous culture in crisis conditions.

The project implemented by Bani-Zaid Cooperative faced and successfully addressed a number of challenges with respect to the elements of the sustainable development implementation feasibility framework presented by Cooper and Vargas (2004) presented in chapter 2. Technically, the founders of the cooperative started from 
zero and moved forward to repairing an old house to be the cooperative building, to building a new location for the cooperative, to establishing a new olive presser owned by the cooperative, to establishing a small bank for saving and credit, to currently planning for building a compost factory in the future. More important for this study, however, they employed lessons and values from indigenous culture to address technical challenges they faced in both their agricultural work and their business management efforts. Administratively, the project started under the umbrella of PARC until farmers got trained and then elected their administrative leadership.

Legally, they got the cooperative registered in PNA Ministry of Interior Affairs as a local non-profit organization and kept working with respect to Palestinian legal system. Fiscally, the administrative team has been effective in obtaining grants, in receiving strong returns from the sales of their products, and in creating, budgeting for, and managing their "saving and credit bank." However, there is the challenge of cash flow, given the time that farmers have to wait between the time when they deliver their crop to the export company and the time to get paid. They have to wait for 90 days until the cargos gets marketed in Europe, that is because the exporter cannot pay before marketing (Al-Qadi 2011).

Politically, the cooperative is registered as an independent NGO and according to its internal rules accepts any farmer regardless of political belief, race religion or sex. The Cooperative has avoided political involvement as much as possible except in the form of representing the interests of farmers and the local community with NGOs, international 
donors and institutions, and where necessary the national government. Like any project that operates in the crisis conditions that characterize this area, critical power remains in the hands of the Israeli Occupation who restrict access to land. The biggest risks could be the take-over of the farmland, restrictions on access to it, or blocking international funds. However, implementing the project from the community level lowers the potential political risk from the occupation side.

Ethically, the project addresses a poor rural community that has very few resources except olive agriculture and inclusiveness is key to success. The olive oil business is family based where the whole family (men, women and children) work together and benefit together (Zabin 2011, Reskallah 2011, Al-Qadi 2011). Finally, cultural feasibility is the secret of success behind the project. Indigenous culture has not only provided sustainable solutions to critical problems, but has also reinforced traditional patterns of development that replaced harmful and non-sustainable patterns.

This chapter consists of two sections: (i) The narrative part of the case that discusses how the project started and developed and why it is considered a successful case, (ii) the analytic section that discusses how the case answers the research questions with focus on the questions elements: sustainable development success and strengths of the case, community level advantages, crisis conditions challenges and how indigenous knowledge based patterns meet them, and finally the section concludes by discussing how indigenous knowledge contributes to promoting sustainable development in crisis conditions. 
THE STORY OF SUCCESS OF THE ORGANIC FARMING OLIVE OIL PROJECT IN BANI-ZAID AL-SHARKIYA COMMUNITY

The story of this cooperative starts from the loss of traditional methods to the crisis in olive oil farming to the creation of the cooperative. The story then focuses on the development of that cooperative and its accomplishments to date all of which trace to the ability of the people involved to reconnect with their indigenous knowledge and practices.

Farming before the Project, Baladi Equals Organic: From Baladi Farming to Destructive $\underline{\text { Agricultural Practices }}$

Before 1948, Palestinian land was very productive and fertile, largely because people did not know about chemicals and were used to applying what is called Baladi farming (Kurzom 2001, p. 9). Baladi farming is an indigenous (traditional) pattern of farming that depends on locally developed seeds and plants (taken from the best fruits and trees and reserved for next season). Those indigenous seeds and plants have survived in the local environment for many generations because they were traditionally treated by natural fertilizers (animal's remains) and free from chemical pesticides. Baladi farming depends on using labor more than machinery in plowing and other farming treatments (Kurzom 2001 p. 9, Dager 2011). In the process, it employed people more than technology and depended on family and community cooperation more than individual capital investments and equipment. 
George Kurzom (2001) argues that modern agriculture, borrowed from Israel and other countries destroyed the land with chemicals and diminished the local kinds of seeds and plants that used to grow and produce well in Palestine. After 1948, Palestinian farmers borrowed what has been called modern patterns of agriculture, including using machines but also using dangerous chemicals in fertilizing the land and spraying the crops. These patterns emphasized mass production, which presumably means more money, but at the expense of human health and sustainability of planting kinds. Over time, chemicals destroyed the soil and indigenous Baladi planting materials and practices (Dager 2011). Moreover, farmers who were fascinated by increasing their production and making more money imported what has been called genetically improved seeds to produce more crops regardless of future impacts on the land and the environment. These seeds and plants grow well when certain chemical fertilizers and sprays are used intensively with which consequently damaged the soil and reduced its productivity over time (Kurzom 2001, Dager 2011). This kind of mass production agriculture also consumes large quantities of water, a very scarce and valuable resource in the area.

\section{The Tradition Was Overwhelmed, but the Roots Survived to Seed a New Project}

Some Palestinian farmers continued to use Baladi farming and to some extent protected their farms and their traditional kinds of seeds and plants (Dager 2011). These farmers formed the core of the recent return to Baladi farming nowadays in the West Bank. With the help of many international, national and local NGOs these farmers renewed and reinforced the traditional Baladi farming patterns under a new name called 
"organic farming". Said Dager, a Palestinian expert in Baladi farming and the current advisor of the Organic Farming Project managed and implemented by Bani Zaid ASharkiya Cooperation, argues that Baladi farming is a form of organic farming. However Baladi farming, according to Dager, should follow some recently required procedures imposed by international markets, as well as using the traditional Baladi farming practices. The new requirements must be met if the product is to be certified by international bodies as organic. The new procedures that have been added are testing samples in laboratories and using modern stainless steal containers (in the case of olive oil) to store the products as compared to the traditional pattern which used clay jars in storing olive oil, which was very safe and healthy, but could not contain big amounts of oil (Dager 2011).

The Eight interviewees, all members of Bani-Zaid Al-Sharkiya Cooperative (S Al-Qadi 2011, Masri 2011, Zabin 2011, Al-Zabin 2011, Rizkallah 2011, M Al-Qadi 2011, Qadi 2011, Bakir 2011), agreed that traditional Baladi farming is a form of organic farming (the name that NGOs and exporters use), but in contemporary international markets, formal certification as organic product is needed which requires laboratory testing and on-site inspections. Farid Rizkallah, a 65 years old farmer from Bani -Zaid community, says: "Baladi is organic. As our ancestors taught us, we can recognize Baladi products from its smell, taste and color that all assures high quality because no chemicals are added" (Rizkallah 2011). 
Said Dager, the advisor of the Organic Farming Project, is an agricultural engineer who is interested in research and practice of Baladi farming. He states that "in 1996, he talked to the PNA minister of agriculture at that time about returning to baladi farming and the importance of adopting a formal policy in that regard by the ministry of agriculture. The minister replied that "it is silly, we need to increase the product no matter what" (Dager 2011). Now Dager is "glad and proud" that hundreds or may be thousands of farmers in Palestine are returning to baladi farming especially in a strategic product like olive oil, and recognize the difference between Baladi versus chemically based patterns.

\section{Olive Tree is an Economic Source and Cultural Symbol}

For thousands of years, olive trees were a symbol of Palestinians identity and a key part of their culture and economy (Oxfam 2010 p. 4). An Oxfam report entitled The Road to Olive Farming: Challenges to Developing the Economy of Olive Oil in the West Bank demonstrates that "the majority of Palestinian farmers are at least partially dependent on olive cultivation...[I]n a good year, the olive oil sector contributes over $\$ 100$ million income annually to some of the poorest communities" (Oxfam 2010, p. 4). Indeed, the report states that:

Currently, $45 \%$ of agricultural land in the West bank and Gaza Strip is planted with around 10 million olive trees... As olive cultivation in the West bank tends to be low input traditional plantations, with low use of chemicals, it is more environmentally sustainable than the intensive olive cultivation often practiced in other olive oil producing countries especially in Europe (Orfam 2010, p. 7). 
In terms of income and job opportunities, the olive oil sector, according to (Oxfam 2010) provides income and employment for around 100,000 olive oil producing families who $80 \%$ of them are small- medium scale farmers that own about 25 dunums in size. Additionally thousands of families who do not own land benefit from the olive harvest season as share-croppers who contribute labor during the collection season and receive a share of the crop (usually third) in return (Oxfam 2010,p. 6).

The report concludes that the serious challenge, after the occupation and settlers who take or destroy farms, is marketing skills and meeting the requirements of foreign markets. However, olive oil sector in the Palestinian territories can double if certain policies are carefully implemented such as organizing farmers, improving marketing (access to external markets) and adoption of appropriate agricultural practices (Oxfam 2010 p. 20).

Start of the Project: The Depression of Olive Oil Market (2000-2004) and the Search for $\underline{\text { Alternative Markets }}$

Because of the tradition and role of olive growing, a depression in prices was enough to trigger creative responses. That gave rise to active efforts to find alternative market through collective will and in partnership with local NGOs. The response started by small group efforts of eight farmers who started the nucleus of what is now called Bani-Zaid Al-Sharkia Cooperative for Producing Organic Olive Oil. However, BaniZaid Cooperative experience has inspired many neighboring communities who 
established organic farming cooperatives and developed partnership with Bani-Zaid Cooperative.

The Second Intifada: Crisis Conditions Creates Alternatives. Once the aftermath of the second Intifada that started in 2000 , the Palestinian olive oil market faced the worst crisis in marketing (local and regional) in decades (M Al-Qadi 2011). The only markets at that time were local markets in the West bank and Gaza Strip, exporting (legally and illegally) to Israel, and exporting limited amounts to some Arab countries through the Jordanian market. Because of the closure of Palestinian territories that separated districts from each other by hundreds of checkpoints, farmers could not reach their local markets in cities, refugee camps, and other towns that do not produce olive oil. Additionally, reaching the Arab markets, Israeli market and Gaza market became impossible.

Accordingly, hundreds of tons of olive oil were accumulated in farmer's houses for three years without selling any of it. Because olive oil loses its quality over time, farmers had no choice but to sell it in local (if accessible) markets for a very cheap price $(\$ 1.30)$ per kilogram that is less than production cost (M. Al-Qadi 2011, Rizkallah 2011).

Consequently, farmers individually started searching for other alternative markets through national NGOs that are well connected to the European NGOs. Active farmers (Al-Qadi 2011) made many visits to NGOs in Ramallah city and discussed their problems with heads of these NGOs. Similar visits were made to the Ministry of Agriculture. The leading NGO that played the key role in negotiating on behalf of individual farmers at that time is Palestinian Agricultural Relief Committees (PARC). The PARC decided to 
make these farmers' efforts a focus of effort. The main goal of negotiations and discussions (Dager 2011) was to find sustainable solutions for olive oil marketing problem not short- term relief efforts.

In the Summer 2003, PARC started networking with international NGOs, such as the French Association for Supporting the Palestinian People, and some Palestinian private companies working in international export. The negotiations resulted in opening an opportunity for exporting Palestinian olive oil under organic conditions through two private exporting Palestinian companies called Reef Company (RC) and Kan'an Company (KC). Both of them work in exporting food products and already have legal permits to export through Israeli ports. While PARC took responsibility for networking with local farmers to explore their capacities to meet international market requirements, $\mathrm{RC}$ and $\mathrm{KC}$ started exploring the conditions and the possibility of exporting Palestinian olive oil to the European market (Al-Qadi 2011, Dager 2011).

Mahmoud Al-Qadi, a Palestinian farmer who started the "campaign of searching for alternative marketing" and now head of Bani-Zaid Al-Sharkiya Cooperative and coordinator of the project states that:

When we first started talking to PARC representatives, we were hopeless, but we kept visiting them and asking them to help, then they told us about the idea of organic farming... first we did not know what it mean but later we knew that they are talking about something that we already know and practice since generations. Now with our will and hard working, we export organic extra virgin olive oil to the European market and the American market (M AlQadi 2011). 
It seems that part of the success, at first, was that Palestinian farmers had already experienced the tradition of organic farming. Additionally, the crisis conditions that farmers were facing, as well as all Palestinian people, pushed them to keep searching for alternatives and also to organize their efforts to meet the new market requirements.

Challenges at the Beginning, Eight Farmers Started. In October 2004, eight Palestinian farmers led by Mahmoud Al-Qadi started the project of Organic Olive Oil with support and help from PARC. The key was to reinvigorate the tradition of Baladi farming but adapt enough to meet current conditions. They started applying the conditioned required by the European market to produce organic certified extra virgin olive oil. The conditions of this "organic extra virgin" were to produce chemical free, tested for not more than 0.8 acidity (this is the standard of the World Olive Oil Council) and certified by special NGOs to meet these requirements (M Al-Qadi 2011). Testing used to take place in European countries through importers and in Palestine through private exporters, Kan'an Company, Reef Company and The Fair Trade Association.

The major challenge was persuading farmers with the new idea of collective pressing and also trusting private companies who would market the crop in European markets first, then pay for farmers after 90 days of taking their crops. The 90 days waiting before payment was $\mathrm{RC}$ and $\mathrm{KC}$ conditions because, according to them, they “cannot pay before marketing" (Al-Qadi 2011). Collective pressing means that pressing the product should be daily in order to improve the quality. "The more the crop is stored (in hot weather) the more it loses its quality (M Al-Qadi 2011)". Therefore, one farmer 
cannot press his product alone because the amount will be very small. They had to overcome this problem by mixing the product of all farmers together and press it in a "collective pressing" in a daily base during the season and receive a standard share for each farmer. This means that farmers whose olive crop produces more oil per weight unit should receive a standard share per weight unit (usually kilogram). M Al-Qadi considers that collective pressing was a serious challenge because every farmer believes that his crop is higher in quality than others, so why should he or she receive a standard share of oil (every four kilograms of olive crop receives one kilogram of oil) if his crop produces better oil than others (M Al-Qadi 2011). Community cooperation was essential.

The first successful season was in 2004 when the 8 farmers produced 4.5 tons of extra virgin organic olive oil that met the standers of the European market. The lab test proved that the product quality was better than the organic certification requirements; acidity rate was about 0.24 (M Al-Qadi 2011). The 8 farmers who participated in this study responded that the secret of their success and overcoming challenges, especially at the beginning, was their collective work to solve problems. All of them agree that mixing products, despite the fact that some products might be higher in quality than others, and collecting crops together, pressing crops together, and testing together, were the key factors that they could produce demanded amounts, under required conditions and at the right time (M.S Al-Qadi 2011, Masri 2011, Zabin 2011, Alzabin 2011, Rizkallah 2011, Alqadi 2011, Qadi 2011, Bakir 2011). 
Establishing Bani-Zaid Alsharkiya Cooperation and Getting the Organic Olive Oil Project Formally Certified and Branded

Until 2005, all activities of the project were implemented under the umbrella of the mother NGO (PARC) who adopted the farmers and facilitated their connection with the European NGOs and market players. One of the conditions, to expand and turn farmers of Bani-Zaid Al-Sharkiya community's activities into a formal project, was to establish a cooperation with an administrative body that could take over responsibilities from PARC and start direct networking with other local, national and international NGOs and private companies. The 8 farmers have no experience in international marketing; therefore, they had to take training workshops through PARC in order to be able to take over responsibilities and overcome future challenges and sustain the project.

On 6/6/2005, the 8 farmers established Bani Zaid Al-Sharkiya Cooperative for Organic Farming. Immediately the number of farmers who joined the cooperation increased to 31 members. A month later, with collective financial and labor support from members, Mahmoud Al-Qadi and other volunteers members worked hard to repair an old house owned by one of the members to use it as the cooperative building instead of renting facilities specifically for a headquarters for the project. This was a requirement to get the cooperation formally registered by Ministry of Interior Affairs. They also worked on creating a system of rules that organize membership and activities (M Al-Qadi 2011, Zabin 2011, Rizkallah 2011). The cooperation, according to its rules, would accept any applicants "committed" to the rules and goals of the cooperation regardless of their 
political background, religion, race or sex (M Al-Qadi 2011). The cooperation was legally authorized by PNA.

Development of the Project and Key Accomplishments

In October 2005, Bani-Zaid Al-Sharkiya Cooperative applied to get an international certificate, as the first organic farming cooperative in Palestine, from the Egyptian Institution for Organic Farming and other Italian institutions specialized in organic farming. Mahmoud Al-Qadi, chair of the cooperative, and his administrative team, with the help of PARC advisors, wrote the proposal in Palestine. The proposal succeeded and the cooperative was certified; so the cooperative became the first formal organic farming producer. After this certificate, many communities in the West Bank (M Al-Qadi 2011) approached Bani-Zaid Al-Sharkiya Cooperative to learn about organic farming. In the aftermath of Bani-Zaid Al-Sharkiya' successful experience with organic farming, farmers groups started to form new cooperatives especially communities that have never had agricultural cooperatives under the title of "organic farmers". In this regard, the eight interviewees (all are members in Bani Zaid-Al-Sharkiya Cooperative) who participated in this case study agreed that their cooperation has built partnerships and coordinated and exchanged experience with other co-operatives in different districts. Now there are about fifty cooperatives in different districts of the West Bank that work on organic farming especially olive oil.

New Partnerships: Indigenous Leaders Adapt New Techniques. In September 2005, Banizaid Al-Sharkiya Cooperative proposed for a grant from the French Ministry of 
Agriculture to improve the quality of organic olive oil and improve the administrative skills of the cooperation leaders. Particularly the proposal addressed the process of pressing (building new stores, buying new stainless steel containers for storing, reengineering the village presser building and providing new cleaning processer to be added to the presser. The proposal got $\$ 102$ thousand and the cooperative implemented the plan successfully (M Al-Qadi 2011). The purpose of this plan was to help the cooperative and its administrative body to adapt new skills and techniques that qualify them to be a leading cooperative in organic olive oil production.

Part of the French grant was spent on the administrative development of the project. Mahmoud Al-Qadi (chair of the Cooperative) and the four administrative team members (secretary, treasury, vice chair, and activities coordinator) had training workshops organized by PARC and other national NGOs. M Al-Qadi states that:

They had to adapt new techniques such as writing reports, budgeting, preparing for meetings, building partnerships and networking with other co-operations and agencies; all these activities were serious challenges because we had no administrative experience. Because we have a strong will and determination to change our difficult life, we could adapt the new skills and move forward (M AlQadi 2011).

Abdallah Al-Zabin (treasury of the cooperative) is a 55 years old farmer who has no experience in finance. He was elected to run the treasury of the cooperative because he is the one who has a small business in the village. Al-Zabin says: "I accepted to run money issues because I consider it Amana (honesty) and honor to serve my community. Other members volunteer their effort and labor to do harder things, I volunteer less than them" (Al- Zabin 2011). 
Saving and Credit Bank, Borrowed from indigenous Women Tradition. In 2008, Bani-Zaid Cooperative, with the help of PARC, established "the bank of savings and credit" to respond to financial needs of members who need loans but more importantly met a religious challenge. The idea is borrowed from an indigenous tradition called Jamiyya that used to take place within old generations of Palestinian women. Groups of old women used to establish Jamiyyas where they pay a certain amount of money (JD usually 20-100) each month and should be given to one member each month by lottery or by emergent needs (for further information about saving and credit in Palestine, see chapter 4 of this study).

Under Sharia' law (The Quran, Bakarah 276, Al Emran 130-132), interest is illegal. The notion of taking loans with interests from regular banks is strongly rejected in traditional (usually religious) communities especially the elders (M Al-Qadi 2011). In this regard Hatim Salem Zabin (60 years old and a father of 12 children) states:

I can't take loans from regular banks because it is Haram (illegal according to Islamic rules). How come I start a new business or pay my children's marriage expenses or build a house from illegal money; God will not put Baraka (good results) in my business or what ever I do from Haram money. Interests have destroyed many businesses and even nations. We agreed on the saving and credit idea to avoid loans from banks. We don't want to feed our children from Haram (Zabin 2011).

The saving and credit bank gets money from national and international donors, membership fees. And gives small easy- repaid loans (up to \$7000) without interest for farmers who want to start small businesses or improve their families' life. For example loans were given to members who want to pay education expenses for their children, 
build or repair their houses, pay for marriage expenses in the family, or start a small business. The condition for eligibility is that borrowers should be members of the cooperation, pay the monthly JD 20 (\$14) fees, and usually donate, for one time, about $1 \%$ to $2 \%$ of the loan to the cooperative. This money goes for development of the cooperative and daily expenses. They also sign an agreement about the period of repaying the loan, which goes up to 10 years. The "bank" so far gave about $\$ 25.000$ as small loans to 15 members (M Al-Qadi 2011).

Getting the Fair Trade Certificate. In 2009, the cooperative had started a partnerships with Fair Trade Development Center in Bethlehem University who supervises Palestinian NGOs and private companies that apply for the fair trade international certificate. This certificate is given from the International Fair Trade Association (IFAT) also called World Fair Trade Organization (WFTO) which is the global representative of (350) international organizations committed to fair trade (see WFTO website 2011).

Fair Trade is a trading partnership, based on dialogue, transparency and respect that seek greater equity in international trade. It contributes to sustainable development by offering better trading conditions to, and securing the rights of, marginalized producers and workers - especially in the South. Fair Trade organizations have a clear commitment to fair trade as the principal core of their mission. They, backed by consumers, are engaged actively in supporting producers, awareness raising and in campaigning for changes in the rules and practice of conventional international trade. They can be recognized by the WFTO logo (WFTO 2011, p. 1)

The WFTO principles are: (i) to be committed to building relationships between producers and consumers with focus on fair prices for both (ii) to be committed to not using children (less than 18 years old) in their labor force (iii) to be committed to 
democracy and accountability (iv) to be committed to providing capacity and working effectively with the local community and paying attention to the marginalized sectors without discrimination (v) and to be committed to protecting the environment (see WFTO 2011).

To meet the fair trade principles, the cooperative members, through partnership with other local NGOs and the village council, volunteered for local community public service. They volunteered labor and expenses of repairing classrooms in the local schools and managing many local parties and celebrations of rewarding for academic excellence in local schools. They also opened new local farming roads. In an important step towards achieving more accountability and trust in the cooperative, the administrative body has elected a committee for Nazaha (accountability) that consists of three indigenous (known as honest and respectful) leaders who are not members in the cooperative to watch and advise the administrative body of the cooperative and facilitate their connection to the local community. As local elders, the three Nazaha Committee members are also known in good experience in Baladi farming and its benefits to the land and olive trees; therefore, they usually share this experience with the cooperative members, visitors and training workshops. The Nazaha committee has the right to attend the cooperative meetings, review its financial status and advice the board in decision making (M Al-Qadi 2011).

\section{The Current Situation and Future Planning}


In Fall/Summer olive season 2011, M Al-Qadi, head of Bani-Zaid Cooperative, stated that "so far the project is sustainable, we are still in the beginning of the season and so far we pressed 25 tons of extra virgin organic olive oil. We expect a good harvest this year, about 35-40 tons, because people cultivated more land and planted more olive trees since the project started" (M Al-Qadi 2011). In good seasons, when the demand in international markets is good, the price of a kilogram of organic extra virgin olive oil reaches Sh30 (about \$8.5). Products that cannot find their way to international market or do not meet the organic conditions have to be locally marketed for a maximum price of Sh16 (about \$4). The good price that olive oil product gets in international market, in addition to the cheap cost of Baladi farming are the key reasons why farmers cultivated more olive trees and established olive oil co-operations in many rural communities.

Because of successes and accomplishments achieved by Bani-Zaid Cooperative, three other agricultural neighboring co-operations have recently negotiated with BaniZaid Cooperative to benefit from their experience and form a small organic (Baladi) farmers union. In October 2011, the four cooperatives, Bani Zaid Al-Shakiya Cooperative, Abood Cooperative, Farkha Cooperative and Dair Assodan Cooperative, signed agreement and formed The Organic Farmers Union in Ramallah. The mission of this union is to "emphasize the idea of organic farming in the region and coordinate among the four communities to improve the role of the cooperatives in their communities. The union is open for other organic farming cooperatives to join" (AlQadi 2011). Establishing such a union may strengthen the idea of organic farming in other 
districts and also strengthen the financial situation of farmers through expanding the saving and credit borrowing opportunities.

To enforce the objective of promoting organic farming in the region, supporters of the idea (M Al-Qadi (2011), Rizkallah (2011), and Bakir (2011) argue that the priorities of the new union must overcome two challenges: (i) building a new olive presser designed to meet the requirement of organic conditions; such a presser should be owned and run by the union, and (ii) building a compost factory also owned and run by the union. The eight interviewees who participated in this case study agreed that building a new presser and compost factory that belong to the farmers will reduce production expenses and encourage more farmers to turn to organic farming and join the union or other co-operatives. Additionally, a compost factory will solve significant environmental problem and found the right place to process home trash and animals' remains.

Challenges. Despite the successful story that this case reflects, there are still serious challenges with respect to the role of PNA in policy regulation; particularly in allowing some kind of chemical pesticides to enter the Palestinian market and to be used in chemically- based agricultural patterns. Six interviewees (out of eight) consider that the PNA is not doing anything to help and protect farmers who turn to Baladi farming. On the contrary, PNA, according to them, allows some kinds of dangerous and even forbidden pesticides to enter the Palestinian market. For example Zabin (2011) and F AlQadi (2011) agrees that some farmers who try to turn to organic farming lose their opportunity because their farming practicies are influenced by their neighbors' choice to 
heavily use pesticides. "They (neighbors) do not want to work hard, they want fast solutions," to kill grass that grows between olive trees. When they sent their samples of olive oil, for the first time, to test before they applied to join the Cooperative, their samples showed high acidity (Zabin 2011, and F Al-Qadi 2011).

Mahmoud Al-Qadi, the head of the Cooperative argues that the PNA should apply some regulation on importing and selling pesticides. Without a regulation role from the PNA, organic farming will struggle hard before turning into a national or even local (limited to some districts) policy. "There are some people who benefit from chemicals market and do not want any change, they do not care about peoples' health" (M Al-Qadi 2011).

The issue of regulation (initiating new laws and rules) is not only legal and administrative challenge, but it is also a political challenge. The PNA administrative agricultural agencies, according to what this case tells, are not open to learn from successful stories because of lack of professional staff (Dager 2011) and also because of political limitations. Politicians, not experts, who cannot professionally deal with administrative regulations, run some of these agencies. Moreover, the Israeli occupation policies keep the Palestinian territories' economy, especially in agriculture, connected to and dependent on the Israeli economy. Additionally, the internal division between West Bank and Gaza has added more political pressure on the PNA. The following analytic section will discuss how indigenous knowledge -based patterns in this case contribute to sustainable development outcomes. 


\section{ANALYSIS OF THE BEN ZID COOPERATIVE CASE: INDIGENOUS KNOWLEDGE CONTRIBUTIONS TO SUSTAINABLE DEVELOPMENT}

The narrative story of this case has told us that traditional practices of olive trees cultivation can meet with contemporary understanding of sustainable development based on the living triangle. Bani Zid Cooperative was established to build on, renew and develop indigenous patterns of agriculture especially olive tree cultivation that has a special significance in Palestinian local culture. This analytic section seeks to understand how this successful community- level sustainable development effort undertaken under crisis conditions has drawn upon indigenous knowledge to achieve positive outcome. First the section analyzes the strengths and successes of indigenous knowledge based patterns of development implemented by Bani-Zaid Cooperative. Second, it discusses the advantages of implementing development efforts from the community level as it indicated by the case. Third, it discusses the challenges of crisis conditions and how indigenous knowledge -based patterns succeed to meet these challenges. Finally, the section summarizes the contribution of indigenous knowledge efforts

Strengths and Successes of Indigenous knowledge -Based Patterns: The Collective Will $\underline{\text { Counts for Sustainable Development }}$

The selection criteria for the three cases of the study are that development efforts use indigenous knowledge- based patterns and that the case shows strengths in promoting sustainable development. This section explores and explains these strengths as following: (i) strengths of indigenous knowledge- based patterns from the participants' 
perspective, (ii) promoting sustainable solutions for critical problems, (iii) integration among the three elements of sustainable development, (iv) indicating sustainable positive outcomes for local communities and (v) indicating legitimacy, support and consideration of local communities.

Strength and Success from the Perspective of Participants. The eight participants in the study consider that the project is successful and has important strengths that bring sustainable and positive outcomes for local communities. Farid Rizkallah, member of the administrative board of Bani-Zaid Cooperative, considers that the Cooperative has played a key role in lobbying PNA and national and international NGOs to improve Bani-Zaid Al-Sharkiya's community life. For example, Rizkallah states that "the community council regularly invites leaders of the cooperative to discuss community matters, they listen to us and take our advice. They know we are ready to help and act" (Rizkallah 2011). This environment of trust is at the heart of success of the project especially in the social dimension.

In 2008, the Cooperative's members volunteered to implement a campaign to repair local schools of the community including building new classrooms, building safety walls around schools, painting, gardening and overall cleaning. Care about public institutions, especially education and health institutions, is a basic element in local Palestinian culture especially rural communities like Bani Zaid. The Cooperative also organizes frequent medical campaigns and check up days, including health and check ups for children, elders, women, and children such as dental hygiene tests, blood tests and 
other services that are not covered by public health services. Some of these activities are either free or completely or partially sponsored by national NGOs (Al-Qadi 2011). National NGOs such as Palestinian The Health Relief (PHR) usually sponsor health check ups or send doctors and nurses to communities who have local organizations that volunteer their time and effort to offer these services besides offering the appropriate place for these activities and services. This active role of the Cooperative not only improves the health of the poor people, children, pregnant women and elders, but also promotes a kind of healthy social partnership between the Cooperative, the community and local and national NGOs and sponsors.

Implementing projects under crisis conditions is an extraordinary challenge because the demand of services usually exceeds available or accessible resources and after the conflict there is little infrastructure available even if there are some resources found (see Cooper and Vargas 2008, ch5). Even so, The Bani-Zaid Cooperative, in partnership with the local council, frequently provided leadership in distributing benefits that come from national and international NGOs to people who are in need in the community. For example, in 2007, the Cooperative brought and implemented "bees project" a (20 bees cells) that was distributed to 20 poor families in Bani-Zaid community. They also implemented a sheep- raising project distributed to 25 poor families. They sponsored, with a grant from the Spanish-Palestinian Cooperation Association, a project to digg wells for rainfall collection for farmers who were able to cultivate new 10 donoms (1donom=1000square meters) of mountainous land (Rezkalla 2011, M Al-Qadi 2011, Zabin 2011, Qadi 2011). 
All these small projects and services improved the economic situation for the Bani-Zaid community and reduced poverty (M Al-Qadi 2011). Such grants and projects will be difficult to come to Bani-Zaid community or any community without having a "title", an organization formally registered and with an established administrative body, that show readiness to take responsibility and carefully implement a project or a program.

The Integration Process. This study emphasizes the critical importance of the integration among the three elements of sustainable development as the core of a sustainable development process. The project was basically created to solve an economic problem: that was marketing olive oil crops at a good price. However, the leadership of the cooperative succeeded to adapt social and environmental actions that have made the project sustainable. Particularly, the integration of social actions have increased the community's regard and support to the role of the Cooperative in the community, and consequently sustained the project.

In the social dimension and as part of the local community care about education, the cooperative has, since 2007, adapted managing a recognition and appreciation celebration to reward local schools in academic excellence. During this festival all local agencies and institutions and community people, especially elders and indigenous leaders, are invited to reward students who have excelled in academic performance of especially those who graduate and get distinguished scores in the Tawjihi (the national high school) certificate. In many cases prizes are provided by the cooperative and some private businesses in the community (M Al-Qadi 2011). The management of this 
celebration promotes voluntary work in the community especially among the young generation who in turn expected to participate in voluntary campaign such as cleaning the village or repairing schools buildings. The celebration also encourages and pays attention of local businesses to sponsor and support local public schools.

Moreover, Bani Zaid community, among neighboring communities, became well known to national NGOs because of many partnerships that connected the community with other Ramallah district institutions and national NGOs. The cooperative's building became a center of training where members of administrative boards from other communities' co-operatives, who implemented a variety of local activities with the help of volunteers from Bani-Zaid Cooperative, come to participate in training workshops. Some cooperatives' boards came to recieve training on how to meet fair trade requirements and benefit from Bani-Zaids Cooperative's experience. Workshops about bee treatment were also held in the cooperative building (Masri 2011, Rizkallah 2011, M Al-Qadi 2011).

In fact, the hard work that the Bani-Zaid Cooperative did to meet the requirements for fair trade certification principles (see WFTO 2011), led to more integration among the three dimensions of sustainable development. Working with the local community institutions, targeting the marginalized people (the poor, women, children) by the cooperative's activities, such as health care campaigns, cleaning campaigns, repairing school buildings, fundraising for school, encouraging protecting the environment through organic farming in both cultivation and home gardens, are examples of the integration 
process. According to most of the interviewees, (Masri 2011, Qadi 2011, M. S Al-Qadi 2011, Rizkallah 2011) the project has had a recognizable effect on the new generation in the community who started to see the good economic impact of cultivating more olive trees and therefore return to farming; the price of olive oil is now at least three times better than the price before the cooperative. Farid Rezkallah, a father of seven children some of who are college students, states that "My son who is a university student, during olive harvesting season, he works with me; he saves the academic year tuition (about JD1000) from his work" (Rizkallah 2011).

The indigenous patterns that farmers use in producing Baladi olive oil reflect their care about the environment and natural resources. All participants agreed that indigenous patterns such as using compost from animal remains, using animals instead of tractors in plowing, protecting soil from erosion by using stones walls, removing wild plants from the land by hands instead of spraying and covering trees root with these plants, and collecting olive crops by hands are all environmentally friendly patterns and protect the land over time. M Al-Qadi significantly mentioned that farmers uses natural ingredients such as garlic, hot pepper and Kurrass (an indigenous spicy plant) mixed together to treat flies and ants that attack olive products during the season of collection. If flies and ants reach ripe olive crops, it can pock olives and oil leaks out (Al-Qadi 2011). Seven participants mentioned that they used this mixture and solved the problem of flies and ants. This pattern was also proved in treating insects that attack vegetables (Thahir 2010). In the indigenous tradition, these are traditional practices, but in contemporary language these practices would be referred to as integrated pest management. Reduced 
use of chemicals and use of traditional patterns of fertilization and cultivation help build soil structure and health. They also removed health threats from the farmers and their families. As used, these practices are producing strong yields of pure and very healthy olive oil.

Dealing with Religious Challenges. One of the critical problems that the project had to overcome is the religious limitation of borrowing from regular banks. Many religious people, especially the elders, do not believe in borrowing from banks that deals with interests (M. Al-Qadi 2011, see also p.11 of this chapter). Those who believe in this religious rule not only consider interest as illegal but they also consider that when dealing with interest, God will Yamhak (ruin) their businesses and any thing on which they invest money (see Ibn Katheer p120, the Quran, Al-Bakara 276). To solve the problem, AlQadi (2011) states, the leadership of the cooperative adopted the idea of saving and credit (discussed in the narrative part of this chapter); a unit (bank) that saves from members monthly fees (usually JD20 a month), grants from national and international NGOs. Those who took loans from the savings and credit unit (Masri 2011, Zabin 2011, M. S Alqadi 2011, Rizkallah 2011) explain that their approach has contributed to their religious tranquility and also economic comfort towards borrowing from the cooperative rather than a regular bank.

Another critical challenge that the project overcame, at the very beginning of the project, is the collective pressing of olive crops. This process is key to producing high quality olive oil because the more the crop is stored (before pressing) the lower the 
quality will be. Therefore farmers have to gather their daily crops, estimate the amount (weight) for each farmer, then mix it and press it together. Later when they sell the oil in a unified price, every farmer is supposed to take the price of his share minus all expenses. Technically, this process is important because the presser will not open for one farmer with small amount or separate small amounts. At an even more fundamental level, this process also responded to a need to build trust, cooperation, and community among the farmers. Working as a community and community building has traditionally been a key dimension in sustaining communities where individuals recognizes themselves and their interests through the community interest and development (M Al-Qadi 2011).

Moreover, the owner of the presser, supervised by some of the cooperative members, usually do a complete clean up process and a special measurement of water temperature, according to the advice of community elders, for the hours of pressing for organic farmers. Organic crop pressing usually starts every day during the season at 7:00pm and ends around 2:00 am the next day (M Al-Qadi (2011). As Mahmoud AlQadi indicates, "if farmers couldn't overcome the challenge of collective pressing, the project could have failed, we (the eight farmers) showed the example that it is possible". Now hundreds of farmers bring their daily products, press it together and store it.

In many indigenous (traditional) communities, decision -making goes beyond the matter of individual rights to the matter of collective benefits. In the example of collective pressing, if each individual would consider only his rights, because he or she considers that his crop is in a high quality category and thus deserves better share, the 
project might not have succeeded. Therefore when individuals reach a compromise of their personal views to the benefit of the group, the result was successful. The nature of collective decision- making that in which individual rights are conceded to benefit the collective community will be addressed in the third case of this study in chapter five.

\section{Indigenous Knowledge Provides Legitimacy Needed for Sustainable Development.}

Stakeholders' acceptance regarding development activities is a key factor in a sustainable development process. This study considers Easton's (1987) account of legitimacy as support, regard and "energy" that people give to policy makers. Policy makers will also get legitimacy from their successful policy actions and decisions (see chapter two of this study). On the one hand, the increasing number of people who apply to join the cooperative and the increasing number of people who cultivate more land and plant more olive trees indicates that the community is supporting the project. The cooperative started with eight members, now it has more than one hundred members (M Al-Qadi 2011).

Beyond that, the project got the support and the respect of people in the BaniZaid community and people in other communities because it addresses a national and cultural symbol (olive trees) in the Palestinian history and culture (Masri 2011, Al-Qadi 2011, Dager 2011, Zabin 2011). In fact Bani-Zaid has no other natural resources but olive trees because of the mountainous topograpgy of the area. Therefore, preserving and sustaining this resource successfully increases implementers' legitimacy. 
All respondents agreed that the active role that the cooperative plays in bringing more projects through networking with NGOs, helping the local agencies in decision making, and lobbying and acting in social and political life indicates that the cooperative decisions and actions provide legitimacy to both the project and the Cooperative. Most of the participants (Masri 2011, Al-Zabin 2011, S Al-Qadi 2011, Bakir 2011) indicate that the Cooperative succeeded in keeping some distance from local political powers (Hamas an Fatah) that could be difficult by playing the role of an "independent mediator" between both of them. This position increased acceptability of the cooperative and its activities in the community. The state of independence might be understood as a negative position in a context where politics plays a critical role in social and economic and may be even environmental arena. Sometimes an individual has to take a political position in order to get what he or she wants at the local political system. However, this case indicates that success in policy implementation from the community level in crisis conditions is an extraordinary challenge that needs implementers to stay in a politically balanced position in order to avoid political exclusion (see pages 28-29 of this chapter).

A majority of respondents (seven of them) including the director of the project prefers this balanced position; staying away from political polarization. The question of the effects of politics (political polarization and fragmentation in the territories) on development was raised in chapter three of the UNDP report about Palestinian Territories (UNDP report about Palestinian Territories 2099/2010, chapter 3). This is a topic that needs to be examined in further research. 
Additionally, when the cooperative decided to seek, in partnership with Bethlehem University, the Fair Trade Certificate, Mahmoud Al-Qadi and his administrative team built on previous decisions; that they should work with the local community to perform some social public services such as repairing school buildings, rewarding students' academic excellence and organizing dental cleaning and health care check up days (M Al-Qadi 2011). Later the fair trade requirements came to reinforce the social role of the cooperative in the community.

Community Level Advantages: What can Policy Makers and Policy Implementers Learn?

This section answers the question whether implementing the project from the community level is part of its success and what are the advantages of implementing it from the community level compared to the national level. In this regard, it is important to remember that this project started small, expanded over time, and is likely to expand and improve in the future. Moreover, the project has transferred the Bani-Zaid experience to about fifty other communities in the West Bank; similar co-operations and organic projects have started in these communities with different levels of success.

The Palestinian Agricultural Relief Committees (PARC) has a policy of empowering communities and community groups with the intention that projects implemented from the community level should be implemented from start to finish as much as possible, by and within the community (see PARC Strategic Objectives on PARC 2010). This means that jobs, materials used, machinery and supporting activities implemented in a project (such as training) should come from the community unless it is 
unavailable there (Dager 2011, M Al-Qadi 2011). The Bani-Zaid Cooperative implemented this policy successfully. For example, in 2006 they spent a (\$7000) grant that came from international NGOs through PARC on designing and buying agricultural tools (ladders, small olive boxes, compost expenses and labor and training etc.) in local stores and with flexible contracts. Every farmer can choose his preferred local store or workshop to design and buy his tools (for example M Al-Qadi 2011, Zabin 2011, Rizkallah 2011). These practices benefit others in the community who may not be directly involved in the cooperative or in olive farming. It also helps to integrate different groups within the community.

Similarly, the cooperative spent a $\$ 102,000$ grant provided by the French government to repair the current village presser, building the new building of the cooperative and building new healthy stores for the collective crop of olive oil that needs to be exported. All these activities and tasks were implemented within the community and by using the local labor force (Bakir 2011). These flexible and community based projects are difficult to implement (Dager 2011) at the national level because the government usually has unified contracts and methods of implementation. Additionally, the government usually uses its staff who may not know the community and its needs.

Managing Political Exclusion. Under crisis conditions challenges, implementing such projects at the national level might be subject of corruption or political exclusion or fall victim to political clashes like the ongoing Hamas and Fatah debate. This debate means that people who are considered Hamas or supporting Hamas agenda might be, informally, 
excluded from PNA projects or project that are implemented through it especially those sponsored by international NGOs. There is no formal policy in this direction but it depends on the PNA bureaucracy who most likely belongs to or support Fatah party. The same thing happens to Fatah members and supporters in the Gaza Strip which is governed by Hamas. Political exclusion has taken place deeply in the West Bank and Gaza in the aftermath of the Hamas takeover of Gaza in June 2007.

In this regard Mahmoud Al-Qadi, as the head of the cooperative, states that "we do not have this political debate of Hamas and Fatah in our work, we only care about good, honest, active, and hard working producers without discrimination, we have members from Hamas and others from Fatah, we even never noticed that we care about the political background of beneficiaries, we would feel shame to do that for our community members (M Al- Qadi 2011)". The successful management of the issue of political exclusion is a key factor in promoting sustainable outcomes in the Bani-Zaid community. Many other communities that failed to manage political exclusion, failed to get people's support and respect of their cooperative and consequently lost many projects sponsored by independent NGOs (M Al-Qadi 2011). The lesson to be learned here is that community based implementation brings more benefits to the community itself and probably reduces political exclusion.

Promoting Social Cohesion. Implementing projects such as this case study at the community level promotes social cohesion. Most of the project's tasks, such as administrative and training work, repairing and cleaning, advising new members and 
organizing health care days and school celebrations, are implemented by volunteers; however the benefit, socially, economically and environmentally, belongs to the volunteers as well as the community as a whole (M A-Qadi 2011). All respondents indicated that they have had more social cohesion within the Bani-Zaid community and among the neighboring communities because of the project. The cooperative has also played a key role in creating a stronger social network and a variety of partnerships at several levels inside and outside of the community. The cooperative has also built good relationships with international partners. Its leadership usually welcomes foreign visitors, such as representatives of international NGOs from France, Italy, Spain, Switzerland and other countries. Those representatives usually come to follow up and support the Organic Farming Project or other projects sponsored by foreign NGOs or agencies and implemented by the Bani-Zaid Cooperative (Al-Qadi 2011).

Social cohesion has in turn created an environment of trust within the community. For example, the cooperative does not ask members to bring any (cosigner) to take a loan from the savings and credit bank. M Al-Qadi says that "we do not ask for a cosigners they (lenders) are members of the cooperative, they volunteer with the cooperative, they have been working with us for many years, we trust them and they trust us. We have never experienced any problem, all lenders repay their loans regularly according to the plan they liked" (M Al- Qadi 2011).

The process of collective pressing is another example of trust. Farmers usually bring their daily products around 7:00 pm, there is a person (named Mahmoud Al- 
Zabin, member of the cooperative) who is responsible for weighing the crops and recording who brought how much. While farmers go home, Al-Zabin supervises the pressing process and records each farmer's amount of olive oil based on the amount he brought that day (Al-Zabin 2011, M Al-Qadi 2011).

Additionally, implementing the project using community workers and tools has also created an environment of trust between the cooperative, local agencies and local businesses, and people in the community. The project opened job opportunities (most likely seasonal) for families who do not own land but work for oil shares, traders, food stores and small restaurants, small industrial workshops, labor forces who work in the presser, and others who work in loading and downloading. At the end of the season, the project brings about $\$ 250.000$ to 3,000.000 cash money to the community (M Al-Qadi 2011). The lesson to be learned here is that community based project (depending on community capacities and decisions) implementation promotes social cohesion and trust in these communities, these are two key elements of sustainable development especially in crisis conditions.

\section{Crisis Conditions: What Counts to Meet the Challenges}

Developers working under crisis conditions (see for example Special Inspector General for Afghanistan Reconstruction 2010, section 3) worry about the question whether they put their money in the right place at the right time or not. Breaking the Conflict Trap: Civil War and Development Policy Report addresses the relationship between development and civil war: "war retards development and conversely 
development retards war" (World Bank 2003, p1). For poor and marginalized communities especially those under occupation, stopping war might not be in their hands. Therefore the remaining choice is to deal with development in order to reduce the negative effects of war and crisis conditions even as it continues around them. Indeed, the literature indicates that efforts at sustainable development really cannot wait until the conflict ends (Cooper and Vargas 2008, p. 26).

In the case of Palestine, neither international donors or the PNA nor Palestinian communities have the authority to stop the Israeli occupation. Moreover, the political division between the West Bank and Gaza is also a critical challenge that, up to the moment of writing this dissertation, Palestinians failed to deal with probably because of outside political powers. Yet the question is how to protect development under such long- term crisis conditions. Indeed some development projects, implemented through PNA, were stopped on the aftermath of the 2005/2006 elections that brought Hamas to power (see UNDP about Palestinian Territories 2009/2010, chapter 3).

Protecting Scarce Resources. In crisis conditions, after physical protection and life, safety, and protection of resources (healthy food, clean water and air among others) will come next on the list of people's needs. People need food, water and shelter. In the case of Palestine, land is a scarce resource that Palestinian communities struggle hard to protect from being taken by the illegal Israeli settlers or the Israeli government for military purposes. Land represents a food security resource for many communities in Palestine. However, “Around 40 percent of the West Bank is effectively off- limits to 
Palestinians, or access is highly restricted, due to settlements, outposts, bypass roads, military bases, closed military areas and areas Israel has declared as being nature reserves" (Oxfam 2010, p. 19). Therefore sustainable development projects in this context must, if they are to be successful, take into consideration the availability and accessibility of resources such as land, water, accessibility to outside markets and flow of money from outside to the national market.

The research team asked the interviewees about the top priorities or needs of their community with regard to this project. Two participants stated that their top need is security and safety for their families. The rest of them (six out of eight) answered that they need to cultivate the "only resource" for the community so that they can produce food and also reduce the possibility of their land being taken. For example, Ali Masri, a 65 year old farmer and member in Bani-Zaid Cooperation, states:

We don't have any resources in this village but these mountains; the blessing is that these mountains are suitable for growing olive trees. The more trees we plant the more we protect the land from being stolen by settlers...we have planted thousands of donoms, otherwise they will take it. Other communities who do not plant olive trees raise the risk of having their land being stolen. Additionally, I feed my families (eight children) from this land (Masri 2011).

The land provides a kind of food security and sustainable economic resource for rural communities. It also represents a cultural symbol of their existence. Dager (2011), from his long experience as an agricultural engineer, considers that "there can be no sustainable development in rural communities and may be not even for a nation as a whole without the land" (Dager 2011). However, for some communities like in Palestine, land is an exceptionally important resource. 
Self Reliance is the Key to Food Security. Said Dager, the advisor of the project and an expert in community agricultural implementation, considers that food security is a key challenge in crisis conditions. If communities and nations do not own (produce) their food, they cannot move forward in development (Dager 2011). He argues that development in Palestine cannot be sustainable from the national level because the PNA relied much on international aid. International aid controls the PNA's political position. Therefore, according to Dager, communities are more flexible to build self-reliant models of sustainable development in crisis conditions "because they know what to do and how to do it for themselves...in the past, the PNA had implemented some development projects on agricultural land, which was a strategic mistake that threatens our food security because it focused on chemically based mass production. Communities like and support what they do for themselves" (Dager 2011). From a sustainable development perspective, self -reliance is a requirement for sustainable development.

The research team explored the respondents' opinion about the role of the Organic Farming Project in building a kind of self-reliance model of development. All respondents stated that the Project positively changed their life in terms of increasing their income, improved the families' health, contributed to educational purposes, and improved their families' standard of living. Dager (2011) believes that crisis conditions are the right conditions to empower communities and strengthen their self- capacity. Baladi farming is one of the projects that create self- reliance based sustainable development. He adds: "from my experience as an agriculture engineer, the PNA has 
received hundreds of millions of grants but very little has been used to develop selfreliance models of development" (Dager 2011).

The Role of the State in Development is Limited in Crisis Conditions. This case study indicates that the role of the state (PNA) in crisis conditions is very limited. The eight respondents pointed out that the ministry of agriculture did not give them any support or advice. However, some of them mentioned that the local council cooperates with the cooperative in many aspects including decision making and planning (Bakir 2011, Masri 2011, Zabin 2011, Alzabin 2011,Rizkallah 2011, M. S Al-Qadi 2011, Qadi 2011). M Al-Qadi argues that if the project had been implemented by the PNA agencies (usually the ministry of agriculture) there would be three sorts of challenges: "(i) the project will not be implemented the way people in the community like and support, (ii) there might be some lack of finance due to corruption and lack of accountability, and (iii) there might be obstacles from the side of the occupation because it will be considered as a national policy that might need agreements" (M Al-Qadi 2011). These concerns seem to be valid in crisis conditions more than any other times because the role of the state is usually weak or not functioning well due to wars, civil disorder, or lack of political and economic stability. Nonetheless, in crisis conditions, the national state or authority is rarely concerned about environmental issues because in many cases the purpose of the state and even the international community is to build political and economic stability and security. As Cooper and Vargas have explained, the focus on stability and reconstruction has very often been part of the problem rather than part of an effective way forward (Cooper and Vargas 2008, ch1). The lesson to be learned here is that in 
crisis conditions, communities have more flexibility to care about their economic, social and environmental life than the state. That is, in such conditions, "weak", states arepolitically and economically limited by outside agendas and administratively poor to reach people's needs. However, community based institutions may need empowerment from the state, especially in legal feasibility, and some administrative training in order to overcome technical and administrative challenges such as networking and negotiating with international donors.

Indigenous Knowledge: A Key Player in Sustainable Development

This case study provides evidence that indigenous knowledge-based patterns can serve sustainable development purposes and more important, can revive techniques, derived from the indigenous culture, and adapt them to meet complex contemporary challenges. The agricultural pattern (Baladi Farming) used in the case project has been used and developed since thousands of years in Palestine. Farmers of Baniz-Zaid Cooperative had to adopt new techniques such as establishing a title (the cooperative with an administrative body) to be able to negotiate and network with national and international NGOs. Abd Al-Rahman Zabin, a 52 year old farmer from the Bani Zaid community, briefs on the project's matching between indigenous knowledge and modern requirements of the market:

I learned Baladi farming from my father when I was 10 years old. Baladi farming focuses basically on quality. In the past, we had no labs to test acidity but I can recognize Baladi products from its color, its smell and of course from its taste. Now we adopted testing in the lab, collective pressing and storing, using aired boxes instead of natural cloth bags, stainless steal big containers instead of 
clay small containers so that we can produce mass amounts with high quality that pleases the international market. We also adapted a savings and credit bank for Halal (interest free) loans, so we can strengthen our economic needs within the religious and cultural limitations (Zabin 2011).

When the research team asked the respondents to define Baladi farming, they demonstrated basic things such as chemical-free farming. But some of them (Rezkallah 2011, M Al-Qadi 2011, Dager 2011) raised a key social advantage of Baladi farming; that it promotes social justice. Dager (2011) says that "Baladi products are healthy, chemical free, with high quality and affordable in price in the Palestinian market, compared to chemically treated products. Therefore, poor people can buy it. The non-Baladi (nonorganic) products are unhealthy but very expensive because the cost of producing it is higher. Therefore the poor in many cases cannot buy it especially in crisis conditions". The point here is that Baladi products, if available and accessible, provide fair prices, in addition to healthy nutrition to consumers especially the needy people in crisis conditions. If Baladi products find their way to international markets, they also support fair prices and profits for both consumers and producers because the cost of products, in indigenous communities such as in Palestine, is low compared to producing the same products in other countries. In addition, the impacts on the community are positive rather than negative.

In this regard, the fair trade certificate that Bani-Zaid Cooperative won opened the door for dialogue and cooperation between local producers of olive oil and representatives and consumers (importers). They got to talk about what the producer provided to the consumer, the environment in which they produce, and the prices that 
they needed and deserved for the products. This consumer-producer relationship creates what is called fair trade environment and integration of social dimensions with economic dimensions (See the fair trade principles on WFTO 2011). In this regard, Mahmoud AlQadi, describing his experience with Bethlehem University over a two weeks workshop training and learning about fair trade, says that "relationship between consumers and producers in the modern world is based on money, money is always there in trade but it is nice to sense the social dimension with those whom we don't know (consumers) but share with us the same concerns and principles (Al-Qadi 2011).

\section{Indigenous Knowledge Promotes the Integration Process in Sustainable}

Development. The Bani-Zaid Community case represents a successful integration process among the three pillars of sustainable development, economic, social and environmental. "We treat the olive tree as we treat our children." In these words Farid Al-Qadi replied to the question why did he choose to participate in this Organic Olive Oil Project. From an environmental view, the olive tree is the indigenous symbol of local people and natural resources. They mention it in their traditional songs, farmers usually consider olive trees as a wealth; they compete to plant and cultivate them more than any other kind of trees and transfer it to their children and grandchildren. Moreover, "if one cultivate a piece of land in olive trees, he or she turns it into a heaven" (Qadi 2011). Farmers usually start cultivating a new peace of land by gathering rock and stones from the land and using it to build a wall that protects the farm and also for adjusting the level of soil to protect it from erosion. Then they dig a well in a rocky part of it to collect rainfall water. This well is considered the heart of the farm as they use it to irrigate the 
newly planted trees during the summer and water their animals. That is why the BaniZaid Cooperative applied for and later got a grant of $(\$ 25.000)$ from the Spanish government and used it for digging wells (S Al-Qadi 2011, M AlQadi 2011). The wells are not only good for the olive trees but also provide water for wild animals (deer and rabbit), bees and birds.

Indigenous knowledge also provides sustainable and environmentally friendly solutions to agricultural problems. M Al-Qadi indicates that elder farmers in Palestine used to plant a tree called (Carob) Ceratonia Siliqua, a kind of wild tree that has permanent greenness, produces fruit that could be used as a sweet, medicine and soft drink (see also Shtayeh et al 2008). Carob trees, according to Mahmoud Al-Qadi, has some characteristics that " by its smell, dismisses flies that attack olive leaves and crops and at the same time attracts bees by its sweet fruits. This is exactly what olive trees needs. Bees are necessary for pollination but they do not feed on olive oil, other flies, such as the fly that causes Peacock Eye Spot disease, are not desirable” (M Al-Qadi 2011). Some farmers who do not have Carob trees in their farms use a kind of natural trap, a wood board with a sticky material (mixture of corn and sugar) to attract and catch the flies (M Al-Qadi 2011). Compared to chemical treatments, indigenous patterns can not only sustain land and trees productivity but can also save money and effort and on top of that protects human health.

From the economic perspective, the project is providing a sustainable, although seasonal, income to the community. The indigenous patterns that has been used in the 
project reduces the expenses while improving the quality of how olive oil is produced. The patterns used are most likely manual using local labor and less machinery that reflect indigenous practices from many generations past. Although the project has included opening roads into the mountains, still people prefer to use horses in plowing. Using horses according to them is better than tractors because the roots of olive trees are not very deep, so tractors might harm or cut the roots. Farmers also remove undesirable plants from the land and put the trimmings as mulch around olive trees roots so that it can protect it from the sun in the hot summer and reserve rain water in the winter (Zabin 2011, F Al-Qadi 2011). These patterns have been developed by indigenous people long ago and transferred by successful experience that proved its validity and protection to the environment to the current generation. The result of these traditional historically applied patterns is an organic extra virgin olive oil that is competitive in the European market.

From the social perspective, the organic farming project has created recognized social cohesion and family based relationships among the community. Besides the social role of the cooperative in supporting public schools and managing many health care days, the indigenous pattern of "working for share" that has been practiced over generations in Palestinian rural communities creates unique job opportunities and food sources for poor families especially those that do not have land. The tradition enables families, especially needy women, who do not have land to have their whole year needs, and probably more, from olive oil (usually they take a third of the product) by working in harvesting with those who own large farms and need help during the season (see Oxfam 2010, p. 9). If this kind of work is paid in money, families who work will not be able to buy their oil 
needs for the year because labor payments are cheap while olive price might be very expensive for poor people to afford it. This work for share tradition creates a kind of food security and more importantly social connection between families who usually agree on an informal deal that usually applies every year between the owner of the land and families who want to work for share.

\section{Savings and Credit Pattern: It Responds to the Cultural Challenge and Respondes}

to the Needs of the Vulnerable Poor. The saving and credit unit of the Bani-Zaid Cooperative has encouraged farmers to take Halal (interest free) loans as a response to the culturally unacceptable practice of borrowing from regular banks. This idea, according to all respondents, is highly valued in the community. They use loans to start small businesses such as increasing livestock, sheep and cattle, start industrial workshops and minimarkets (M Al- Qadi 2011). In addition to the seasonal intensive jobs, these businesses have created new job opportunities for the young generation such as composting at home, land cultivation and planting, oil filling and labeling, among others. Savings and credit loans have been approved by Islamic Sharia' except for those that charge interest (see for example Al-Qaradawi 2001).

The savings and credit idea is a traditional or indigenous custom named Jamiyya that used to be promoted in community neighborhood by elder women. They used to trust the eldest woman in the group to keep the Jamiyya (a monthly, usually JD 10-20, share of money from each member). Then she would give all the money (say JD 200 if they are 20 women) to a member each month according to her list and also to each 
person's needs. Some women prefer to take the Jamiyya in a month when they need it for special occasion.

From the social view, indigenous knowledge -based patterns are most likely collective patterns where groups of people or family members work together in collecting crops, especially in the hard mountainous pieces of land (See Chapter 2). Women play a key role in the project through their experience in classifying filling and labeling olive oil units. They also play an important role in providing logistic supplies for workers and running their family owned businesses during the olive harvest season (Rizkallah 2011, Masri 2011, Bakir 2011). The profit of the project, however, is also family-based and does not differentiate between men and women. For example Abd Al-Rahman Al-Zabin, a father of eight children, has used the olive oil seasons' savings to repair his house, help his married children to build their own houses, educate his daughters and sons, and pay for their marriage expenses (Al-Zabin 2011).

The project in general and Bani-Zaid Cooperative in particular have played a critical role in improving the health situation in the community. As many rural communities in Palestine, health care in small, remote, and mountainous villages is poor. There is a small public health care unit with one doctor and few medicines. However, the cooperative is now networking with doctors with different specializations, women doctors, mobile labs, and dentists to participate in well organized medical service days that addresses the needs of elders, women, and children (Al-Qadi 2011). Doctors and nurses usually volunteer their time and effort to help poor communities such as the Bani 
Zaid community. Some of these days are organized in a lower cost that covers only basic expenses.

Additionally, the spread of organic farming culture in the community is now very recognizable. People grow many other crops either between olive trees or in other main land and home gardens. People even reject chemically treated vegetables (Zabin 2011, Al-Qadi 2011). Because of the acceptable patterns and decisions implemented and made by the cooperative, it has increased its legitimacy and stature in the community. In particular all participants regarded the committee of Nazaha (accountability) which consists of indigenous leaders and advisors that watches accountability and shares the administrative body of the Cooperative in decision making and planning. However, the Cooperative members trust the indigenous advisors although the advisors are not members in the Cooperative. Probably one of the most important indicators of legitimacy is the creation of the Organic Farmers Union in Ramallah that was expected to expand organic farming practices in rural areas and unify farmers' efforts in promoting sustainable development for local communities.

\section{CONCLUSION}

This case demonstrates strengths and successes of communities in promoting sustainable development, communities that have little resources and are living in crisis conditions. Their strengths and successes are anchored on the use of indigenous knowledge. This case represents a successful example of natural resources management policy implementation at the community level in crisis conditions base on indigenous 
development patterns. This case study described how a small, marginalized and poor community has developed sustainable Baladi farming projects, derived from the local culture of the community, that promoted sustainable living for hundreds of families. The project started by eight compassionate farmers and ended up with a complete sustainable project including an administrative body the (Bani-Zaid Al-Sharkiya Cooperative) that played a critical role in expanding the project. The Cooperative has created a savings and credit unit which responded to a religious challenge of providing Halal loans for farmers to start new businesses and improve their living standards.

More specifically, the analysis of the case provides evidence as to how indigenous knowledge can be used at the community level to achieve progress toward sustainable development in crisis conditions. In this case, indigenous knowledge development is at the heart of success of sustainable development efforts. Traditional cultural patterns have been developed over generations to match successful natural resources management especially in crisis conditions when resources are very few or difficult to reach. Additionally, indigenous knowledge development patterns implemented at the community level helped to build trust and good decisions that serve the immediate needs of the people living under crisis conditions. The effort developed a sense of legitimacy in the community-based organization that grew out of the project. Finally, all participants in the case responded that indigenous knowledge has the power of empowering communities to promote sustainable development, based on the integration process, in crisis conditions. The next case chapter will focus on economic and social empowerment 
of rural women in the West bank, a case that also considers indigenous knowledge based development patterns to be at the heart of sustainable development in crisis conditions. 


\section{CHAPTER 4: SOCIAL AND ECONOMIC EMPOWERMENT OF RURAL WOMEN IN THE WEST BANK WOMEN'S CLUBS, RURAL WOMEN'S DEVELOPMENT ASSOCIATION, AND THE PALESTINIAN AGRICULTURAL RELIEF COMMITTEES}

This case focuses on important issues relating to gender in sustainable development efforts in rural Palestine. The case addresses a program of social and economic empowerment for rural women living in marginalized rural areas in the West Bank Palestine. The program was initially launched and supported by the Palestinian Agricultural Relief Committees (PARC). However, it was later adopted by a new NGO that grew out of PARC that was created in order to focus on rural women's development. That group is known as the Rural Women Development Society (RWDS). Women's clubs that were established in 1996 as part of the program did the actual implementation of the project. The strategy that PARC followed was that rural women should develop their living by their own creative skills and activities. The two NGOs, PARC and RWDS provided professional and administrative training for women leaders at the beginning of the project and continued to advise, facilitate, and network with international donors to sustain the program. The program started by simple social and educational lectures and meetings.

One of the interesting successes was the idea of a savings and credit program, a form of micro-finance, that started from a small rural women's group in the rural community of Maythaloun, drawing from an indigenous tradition called Jamiya that took place in rural Palestinian communities over generations. The chapter will discuss this in more detail later. Serving $(6,722)$ rural women members in 123 women's clubs, the savings and credit units have contributed to changing women's lives by lending them 
interest free loans to start small businesses and projects. The savings and credit finance depends on clubs members but also accept unconditional financial support from national and international NGOs or agencies.

Additionally, the program empowered 26 rural women leaders who succeeded in winning local councils elections organized in 2005 in Palestinian territories, and became involved in decision making in their communities. Moreover, women's clubs have successfully implemented two campaigns that addressed violence in the family and early marriage, two critical and culturally sensitive issues. According to the director of the program, Hanin Zaydan, "the secret of success of this program is driving on indigenous local culture of the targeted communities" (Zaidan 2011).

Traditional culture was embedded in the development patterns that women adopted in their projects, efforts that were environmentally sound, effective social development practices, and supportive of their family's efforts at economic development. Examples include, organic (Baladi) food production, home cooking for public schools, and organic home gardens, and traditional textile design projects. The research team interviewed seven women's clubs leaders and members, in addition to the director and the coordinator of the program, who talked about their successes and the members' experience of empowerment.

From the perspective of feasibility framework of sustainable development (see Cooper and Vargas 2004), choosing women's clubs to implement the program at the community level indicates feasibility in several aspects. However women's clubs leaders were able to overcome many challenges to make the program sustainable. Technically, 
the program depends on traditional cultural patterns and skills of rural women which both provided tools and techniques but of a type that allowed the women to overcome challenges, especially the culturally sensitive ones. Administratively, The PARC and RWDS have provided the necessary administrative training for women's clubs leaders at the beginning, later women's clubs themselves turned into training centers managed by rural women themselves. Additionally, the clubs have obtained legal registration as local community NGOs in the Palestinian Ministry of Interior Affairs. Fiscally, the savings and credit idea, besides external funds, contributed to the financial sustainable situation of women's clubs even in the worst crisis conditions such as the period between 2000 and 2004. Finally, the program represents an ethical commitment of national NGOs towards a very critical and culturally sensitive issue of gender development. Few NGOs in Palestine succeeded to address empowerment of rural women in such very marginalized communities in crisis conditions.

This chapter first presents the story of the program, which reflects the power of rural women's clubs in promoting sustainable development outcomes. It then provides an analysis of the case study to address the core question about the use of traditional indigenous knowledge at the community level in crisis conditions.

\section{RURAL WOMEN'S EMPOWERMENT THROUGH LOCAL WOMEN 'S CLUBS:}

\section{IMPLEMENTATION BY COMMUNITY MEMBERS BRINGS SUCCESS}

The story of this program begins with the start of women's clubs in rural women's houses, establishing formally registered women's clubs, developing the savings and credit idea and its development, and the stories of success of participants. It considers 
how the program expanded and the most important accomplishments that women's clubs achieved, including how women's clubs succeeded in "breaking the taboo" and changed their traditional role in their communities and implementing culturally sensitive projects. The story of women's clubs reflects the power of indigenous knowledge-based development patterns in promoting sustainable development in rural communities in the West Bank Palestine.

Establishment of Women's Clubs: Responding to the Critical Situation of Rural Women

Rural areas in Palestine in general and rural women in particular have suffered from marginalization including lack of access to clean water, health care, education, electricity and other services. From a statistical perspective, rural people in Palestine (West Bank, Gaza and Jerusalem) make up 47\% of the population and live in 666 villages and small towns (less than 10,000 people) (Mtawi and Sharkas 2003, p. 10). The Palestinian Central Bureau of Statistics data (1997) indicates that rural areas, which forms $47 \%$ of Palestinian population, have been marginalized in terms of access to basic services such as clean water, health care, and electricity, especially before the formation of the PNA in 1994 (Mtawi and Sharkas 2003). Gender activists argue that the formation of PNA in 1994 opened the door for NGOs to address this sector, among others, in development programs and projects (Zaidan 2011).

In 1997, a year after the first population census was conducted by Palestinians themselves, literacy rate among people age 15 or over was $13.9 \%$, and $20.1 \%$ for females. However, literacy in rural areas of the country was $17.7 \%, 25.5 \%$ of that rate was females. Literacy among urban women in comparison to rural women was $16.1 \%$ 
(Mtawi and Sharkas 2003, pp. 60-61). Additionally, access to electricity, water nets, and sewer nets are the poorest in rural areas of Palestine. For example, only $1.8 \%$ of the rural population has access to sewer nets compared to $45 \%$ in urban areas (Mtawi and Sharkas 2003 p63).

Breaking the Taboo: The Rise of Rural Women's Voices. In 1996, the Palestinian Agricultural Relief Committees (PARC) was the first national non- governmental organization that paid attention to the need for rural women empowerment. The PARC started sending female agricultural advisors to meet with rural women, listen to their concerns, and collect data about the challenges in these areas. The PARC data indicated that $60 \%$ of agricultural work is done by local rural women (Zaidan 2011). The PARC started exploring the possibility of establishing cooperatives (clubs) for rural women.

The first efforts to engage women and obtain information were very challenging because rural communities, which are often quite conservative, rejected and in some cases even attacked the idea. Hanin Zaidan, the director of Rural Women Empowerment Program describes the cultural challenge at the beginning:

[P]eople did not welcome us at all. In some communities we used to be accused and dismissed from houses because people thought that we brought anti-culture and strange norms. We started the first women groups meetings with some educated women (or those whose husbands are educated) and socially active women. That was in the women's homes. When we started to explain our goals, that we came to help with health issues and educational issues, people started to accept us (Zaidan 2011).

Zidan's statement reflects how important it was to explain carefully the project's goals, especially when approaching culturally sensitive issues such as gender development in rural communities. However, health and education are two areas in 
which Palestinian rural communities usually "welcome" women to participate. Zaidan (2011) states that educated women in rural communities such as school principals and teachers played a key role in explaining the idea of women's clubs and facilitating the formation of these groups. Tahani Jabir, mother of six children and member of Beit Qad community women's club, describes her experience at the beginning when she formed the women's club in her community in 1997:

I am one of the first women who formed the club. At the beginning, we had opposition even from women in our community; not to mention the huge challenge with men. Local women used to describe us opposed to community moral standards and insensitive to community customs. I remember the one who welcomed us in her house was a female teacher in the village. Her husband was a teacher too. They helped to overcome the taboo that women can do things beyond what they used to do. Once women noticed our moral activities in educating about women and children health and education, they started joining us. Now the club has 100 members. However, successful economic projects such as traditional skills training encouraged others, men and women, to accept the idea (Jabir 2011).

Ameera Abu-Dayi, a mother of ten children who has elementary school

education, started the women's club in the Jeeb Community with another five women in the village in 1997. She says:

Originally I worked in traditional clothes sewing and designing tools from natural straw. I heard about the idea of forming women cooperatives from my daughter who heard about it from her teacher. I joined the group, which was four women only, and started volunteering in arranging for lectures given by PARC female advisors which used to take place in my house and other's founders members. My husband didn't like the idea at first. Later I started to train women about traditional designing. My husband accepted it later but I had to struggle to persuade my father in law who lives with us. He opposed the idea of going to the city sometimes for training on administrative skills. Now, I have achieved a lot for my family and myself from my business. I was elected to the village council board in the Palestinian local elections in 2005. I cannot believe it. It is a kind of miracle (Abu-Dayi 2011). 
Breaking the taboo for these women meant allowing somebody who is from outside the community to come and talk with rural women and then having those women organize activities in a new (beyond the traditional) role under women's clubs. The key issue here is that PARC activists started by working in the two acceptable fields, education and health care. The critical lack of these two important services in rural marginalized communities was important to everyone. Additionally, approaching women through agricultural and traditional works was key. The traditional designing of clothes and crafts is one of the careers that rural communities appreciate for females. The fact the PARC started with these activities encouraged people to accept the idea of organizing women's activities. This kind of work usually meets the communities' needs for traditional tools and clothes used by rural people.

Launching the Program of Social Empowerment of Rural Women. In August 1996, PARC adopted some women's groups and supported them to be formally named women's clubs. At the end of 1996, PARC launched the Program of Social Empowerment of Rural Women in the West Bank.

The program focused on educating women and empowering them to be more active and participative in their communities. Most of the activities implemented in the women's clubs were educational, and included professional training (sewing and designing) and child and health care lectures. Zaidan says that their top goal at that time was to "establish a place for women to meet together, express themselves, and discuss their needs and problems. At the same time, establishing women's clubs in new rural communities continued and more training workshops, especially in administrative skills, 
for women continued." (Zaidan 2011). It was also necessary to help build administrative skills for the purpose of empowering women to run the clubs and later manage the projects that they developed.

The establishment of women's clubs indeed opened the door for rural women to be more organized, improve their skills, and participate in their communities' development. At the same time, both PARC and RWDS increased focusing on building long term partnership with rural women's clubs through development programs and activities.

Indigenous Jamiyya: Savings and Credit for Women's Small Projects

In 1999, a group of women members in the Maythaloun community of the women's club, a rural community located in the north of the West Bank, started the idea of a savings and credit program. This idea flows out of an indigenous tradition called Jamiyya that had long been practiced among women in poor Palestinian communities. Savings and credit programs are cooperative arrangements in which members pay an amount of money on which they agree each month. Contributions to Small Jamiyyas could be (20 Jordanian Dinar) while large ones could be (JD100). One member would take the sum each month; usually those with emergency needs take the amount first or they distribute it by lottery.

The PARC immediately adopted the idea and encouraged other women's clubs to establish a savings and credit unit. These units receive funds from PARC and other Palestinian NGOs and from members' fees (usually JD20 per month). The units were designed to be run by members and to encourage them to save money and distribute 
interests free loans to start small businesses and economic projects. Now each women's club has a savings and credit unit (Zaidan 2011).

The New Parallel Economic Empowerment Program: Integration with Social Empowerment and Forming a more Sustainable Program

In 2000/2001, PARC, inspired by the spread of rural Jamiyyas, launched a parallel development program called the Program of Economic Development of Rural Women. This program was designed to meet the goal of building the social empowerment of rural women, but this time connecting and emphasizing the tie to economic development, meeting their need for financial independence, having sustainable sources of income, supporting small businesses run by women, and improving rural families' standard of living (Zaidan 2011). The core purpose of the economic empowerment program was to help rural women sustain their own projects and contribute to development of their communities.

Between 2000 and 2004, as part of the economic development program and because of the success that the savings and credit units achieved, women's clubs leaders decided to unify the savings and credit units under a new organization in each district, formally registered as the Women Savings and Credit Cooperative in (Jenin, Nablus, Hebron and others). This new development and expansion allowed more rural women to participate and benefit from savings and credit activities (Zaidan 2011). At the end of 2001, PARC merged these programs into its Program of Social and Economic Empowerment of Rural Women. The expansion in savings and credit micro-economy 
has grown up and transmitted from women's clubs to other community groups and cooperatives such as farmers' groups.

The Birth of the Savings and Credit Union. In 2005, there were 12 savings and credit organizations in Palestine (11 in the West Bank and 1 in Gaza). The 12 cooperatives have unified under the name of Union of Savings and Credit of Women Cooperatives. The new credit union allowed rural women to receive funds and make partnerships with some international development institutions such as the UNDP, the Islamic Bank for Development, and the International Fund for Agricultural Development (IFAD) (Zaidan 2011). A year later, in 2006, PARC decided to create a separate independent association, the Rural Women Development Society (RWDS), to sponsor women development programs. The Rural Women Empowerment Program was formally attached to RWDS. However, PARC continued to support both the program and the new established RWDS. The simple idea of indigenous Jamiyya that started in the Maythaloun rural community women's club ended up with a women's union that now includes thousands of rural women who used to dream of playing an important role in their communities and now do so. A story provided by one of these women makes the point. The savings and credit cooperatives have provided small loans for women that have changed their lives. Om Sohaib, mother of 7 children, two of whom have gone on to university, and a member of the Dair Gazali women's club since 2005 said:

I live in one of the most conservative communities in Northern West Bank. At the beginning, it was very hard to persuade people with the idea of joining women's clubs. People prejudge them because they do not know about them. When I joined the club and also the savings and credit cooperative, I took some training skills and lectures. Then they offered me an interest free loan $(\$ 5000)$ 
from the savings and credit cooperative. I chose to use the money to start a small productive place for Baladi (organic) diary products. I chose this idea because my community is famous in raising cows and sheep. I solved a problem for farmers who used to send their products to Jenin city; from the project profit, my husband bought a small truck to collect milk from farmers. My children help me during summer vacations to save for their schools (Om Suhaib 2011).

Om Suaib's story exemplifies how women's clubs helped rural women to change the traditional view towards women is role in conservative communities. However, drawing upon indigenous ideas such as Baladi diary products has contributed to the notion of accepting rural women participating in development projects in their communities. Her project has not only solved her economic problems but also helped other community members (farmers) to develop their economies.

It is important to remember that loans, with interest from regular banks, are illegal according to Islamic rules. This fact is critical in rural communities, which are usually religiously and socially conservative. Thus, the need was to find an acceptable way to move forward within that social context. The integration between social empowerment and economic empowerment was very fruitful, especially in very conservative communities such as Om Suhaib's because the way it was done fit the cultural sensitivities of the community, and that was largely because it was based on an indigenous tradition.

As it will be discussed later in this chapter, the economic opportunities created by the program opened the door for family members (husbands and sons) to participate in some of the programs activities. Participation of family members, especially males, gave men in the family a clear idea about the program and reduced their opposition. The key 
idea is that the projects were chosen to be family-based, where husbands and children can also work and benefit from the projects. Making the family part of the economic activities not only reduced unemployment but also reduces men's opposition to women in their family their being active in social and economic development.

\section{$\underline{\text { Surviving under the Worst Crisis Conditions }}$}

The eight women's clubs members who participated in this study, in addition to the director of the program, indicated that the program faced its worst crisis conditions, even more challenging than the ones they faced already, between 2001 and 2004. During this period the program faced serious challenges because of the second Intifada. During this Intifada, closure of cities and villages, military campaigns, and a siege negatively affected the program in terms of lack of communication and lack of funding. However, the program survived and became a resource to help people in need. The program continued to implement simple social and economic activities such as distributing food for needy families and health care days. The purpose during this period was to survive even if those involved could only carry out minimum activities for critical needs (Zaidan 2011, Sabbah 2011, Galudi 2011).

The critical situation that took place between 2001 and 2004 led to a new attitude of strategic thinking among women's club members and also in PARC as umbrella development institution of the clubs (Zaidan 2011). In order to empower women in their communities, the new strategy focused on turning women's clubs in different communities into training and administrative sites that would implement local projects that promote self-reliance and sustainable living for women's clubs' members and their 
families. At the same time the strategy emphasized the importance of continuing to focus on social empowerment in terms of educating rural women to be more active in social and political life (Sabbah 2011, Abu- Dayyi 2011, Jabir 2011).

Like many other crisis spots in the world (see World Bank 2000A, p.146), crisis conditions may, as it did here, unify people and force them to find ways to survive. The groups provided a way to do that in these difficult times. During the second intifada, rural areas suffered more than other areas because they are the poorest in the country. Usually what the rural areas produce depends on access to reach the urban market. The breakdown of access to markets and infrastructure for those in rural areas is common in countries that have been facing crisis conditions (See Cooper and Vargas 2008, pp. 283284). Additionally, rural areas paid the highest price in numbers of killed, injured, and arrested men during the second Intifada (The Palestinian Central Bureau 2009). This fact increased the number of widows and other women family members including children who needed to depend more on themselves and find a way to make a living for their families in a time when the role of the state (PNA) was totally absent. Again, this is a problem that is common to women and their children in many countries that have experienced conflict and are therefore in crisis conditions (Cooper and Vargas 2008, p. 140).

Rawda Ashkar, chair of Shofi community women's club and a mother of two sons who were killed in the second Intifada whose husband was also arrested many times, stated that her situation pushed her to be more independent and creative to feed her nine children. She states that: "My situation pushed me to be more active and creative to help 
myself and other women like me. Besides charitable and voluntary work, my primary interest was educating women who dropped out of schools at an early age through special classes sponsored by PARC and RWDS. My community supported me when I lost my two young sons and I am glad to pay them back with my time and effort (Ashkar 2011)". Later in 2005, Rawda Ashkar was elected to be a member in the village council board. Women in Village Councils for the First Time

Zaidan (2011) argues that women activists lobbied hard to include a women's quota in Law Number 9 adopted by the Palestinian Authority for the 2005 elections (Law Number 9 of 2005 Article (4) of Elections) talks about women representation in the PNA legislative council and local councils. The law states that "each electoral list nominated for the proportional elections (lists) shall include a minimum limit for the representation of women that is not less than one woman among: (1) The first three names in the list; (2) The next four names that follow; (3) each five names that follow (Palestinian Law number 9 of 2005 (4) of Elections). The PARC and RWDS took it as part of their missions to encourage rural women through their clubs to nominate women candidates for the elections (Zaidan 2011). In June 2005, women's clubs decided to participate, as an independent group (not under any political party as it used to be before), in local councils elections. They nominated candidates who were women's clubs' chairs and other active members. The results were that 26 members of women's clubs won and became members in their local councils.

In this regard Rawda Ashkar, member of Shofi local council, states that: "At the beginning, she had criticism from her family, including her university student sons about 
her decision to participate in the elections. The quota encouraged women to think they could win because there was no competition with men; competition was with female candidates from Hamas and Fatah. Because we were active and well known through our women's clubs, we won easily. However, once we passed the elections challenge, the next challenge was to persuade our families that we have to go and participate in the village council meetings and decision-making. That was not easy, but, because the work we had been doing through the women's clubs was very successful, people accepted our role in the village council. Still, sometimes we face criticism (Ashkar 2011)”.

The 2005 elections was the first serious opportunity for rural women to tests their skills and abilities in political life. It was important not only because it resulted in 26 rural women leaders being elected to local councils, but also because it reflected an organized effort from women's clubs to support women candidates, despite traditional opposition from men, and despite the rural customs that used to reject having women participation in decision making with men.

\section{Partnership with the Ministry of Education}

In the middle of 2006, Amal Sabbah, chair of Qafeen community women's club and a mother of 12 children, three of them are university students, created the idea of "cooking for our schools" which meant local women cooking for local schools cafeterias. This idea was first discussed in Qafeen women's club as a suggestion recommended to RWDS to negotiate with the Palestinian Ministry of Education (Sabbah 2011). Zaidan (2011) the director of the Social and Economic Women Empowerment Program discussed the idea with her board and concluded that the idea could be developed to be a 
kind of partnership that could improve not only women's economic situations but also provide quality and healthy food in public schools.

Sabbah started networking among her 68 club members and with other neighboring clubs to collect suggestions about how the project should be implemented and what kind of food would be served. Later Sabbad and other club chairs visited many public schools to look at where the food would be prepared and the environment in the schools “cafeterias" (Sabbah 2011). In Palestinian public schools, there are no indoor cafeterias for students to sit down and eat. There is usually only a small kiosk or food cart for selling food and soft drinks. The final decision that Sabbah and her team reached was that food should be cooked at women's houses and brought to schools (Sabah 2011, Zaidan 2011). With the help of RWDS, women's clubs signed an agreement with the Ministry of Education and later other agreements with public schools. The ministry of education chose 15 schools as a pilot (Sabah 2011). Under the terms of the agreement, women's clubs which participate in this partnership have to pay the rent fees, which was about SH10, 000 (\$2750) per academic year for the school where they supply food (Sabbah 2011). Before this agreement, schools used to use a bid process with the highest price receiving the agreement.

Sabah describes her experience in "cooking for our schools" saying:

The project does not provide good money for women who participated in it but it is better than nothing. It is $\mathrm{SH} 30$ a day (about $\$ 8$ ). We know that it makes a difference for some poor women. Further, we targeted women who have daughters at high school or college so that they could earn some money for their schools. We had a goal to welcome those girls in our clubs in the future. I personally have one of my daughters and my son work with me. More important, the kind of food that we cook is high quality such as traditional meals of Mujadara (mix of Bulgur, rice 
and beans), Maklooba (rice mixed with vegetables), besides cheese and spinach sandwiches, fresh fruits and vegetables and healthy soft drinks. These kinds of meals replaced the junk fast sandwiches that restaurants owners used to provide for schools, such as chips, soda, other processed food, and so on. We take it as if we are cooking for our families, and we really are. Children are paying the same but for better nutrition (Sabbah 2011).

The kind of food women supply for schools reflects women's passion to support schools even if they do not make much money. The agreement with public schools also reflects the mothers' care about education and students health. The partnerships with public schools have created strong and strategic relationships between women's clubs and public schools, especially schools for girls. Women's clubs participate in the schools' annual graduation day and other open house days when families, students and school's staffs gather, play, and eat together, and go on field trips. They also donate food, time, and effort for school activities. Participating in educational events has been important in rural communities that have strengthened women's clubs position in these communities. This also encouraged young girls to appreciate the role of women in society and to become active members of their communities.

One of the top interests of women's club is to improve education for girls and women in their rural communities (Zaidan 2011, Sabbah 2011, Ashkar 2011). The Palestinian Central Bureau of Statistics records indicate that the number of Palestinian females who go to university is increasing gradually. The number has significantly increased between 2000 and 2009. It was 35,339 in (2000/2001) and jumped to 92,763 in (2008/2009). This statistic does not include females who go to study abroad and others who go to community colleges or professional training schools. Also, there is no statistic 
that shows the rate of education for women and girls in rural versus urban areas.

However, all participants in this case indicated their belief that education in rural areas is improving, particularly because of the empowerment program and other social development programs that have been developed alongside the efforts with schools. Rural Women Write their Projects Proposals: Indigenous Knowledge Counts

In 2006, because PARC expanded in working with Palestinian communities in many aspects, RWDS separated from PARC (for the purpose of focusing services) and became an independent NGO specialized in rural women development. Still, partnership and cooperation between the two NGOs continued. In partnership with PARC, RWDS organized a training workshop about how to write a small project proposal. At the end of the workshop, there was a real proposal writing exercise. That exercise asked the women who participated to draft a proposal that included a short description of a proposal idea, how much it costs, tools and facilities needed and benefits and profits. The proposals focused on and reflected participants' local indigenous culture even though some of the participants were well educated in a contemporary sense (Zaidan 2011 and Hamid 2011). Suzan Hamid, a mother of 9 children who joined the club in her community in 2000 , agrees that ideas taken from indigenous culture have influenced the club's activities and also the members' choices of projects. She states that: "Every member usually chooses an idea that reflects her, her family, and her community's needs and interests," such as having cows and sheep, owning a traditional designing shop, producing dairy products, food pickling, bees projects, or home gardens. In 2007, PARC and RWDS, after 
evaluating the women's projects, provided grants for the projects that the women wrote about.

Between 2007 and 2010, the program of empowerment continued to expand, creating more women's clubs in new communities (Zaidan 2011). The integration between social needs and economic needs was a key element in changing the situation of rural women. The economic benefits of these small projects critically affected rural women's lives. Hundreds of rural women became productive in terms of contributing to families needs besides supplying a good standard of living for themselves (Zaidan 2011).

Om Suhaib (2011) described why she chose her project of producing dairy products and what it required. She said:

My family and my husbands' family used to raise cows and sheep. I learned how to make Baladi cheese, butter, and yogurt from my mother since I was a child. What I needed were the tools that enable me to produce big amount and a small truck for my husband to collect the milk and distribute the products. My project encouraged the community to raise more animals, and they prefer my products more than Junaidi [a dairy factory in Nablus city] products...they know the difference in taste. My husband and I now are planning to raise cattle (Om Suhaib 2011).

The difference in quality of these products is not only the taste but also "social" benefits. For example, in a unique indigenous tradition, rural women who produce yogurt usually donate their day's production of yogurt to any woman in the community who has a marriage celebration (for her son or her daughter). They take yogurt and participate in a collective cooking of famous indigenous yogurt soup for the celebration where the whole community will be invited (Om Suhaib 2011, Sabbah 2011, Galudi 2011). Community women, in turn, encourage and support dairy producers by buying 
their products. They prefer them to the commercially produced products as a matter of physical and social taste. This sharing event and the general support for local producers increases social cohesion in these communities.

Care about the Environment. One of the important accomplishments of women's clubs, with respect to the environment, is the project of home gardens sponsored by PARC and RWDS implemented by the women's clubs. The clubs provided complete proposals for each garden to be developed and explained how the proposal would be implemented, while PARC and RWDS sponsored the cost. All gardens were planted and maintained by their owners (Zaidan 2011, Galudi 2011).

The PARC and RWDS have a strategy of promoting food security for poor rural families especially those that do not own large land (Zaidan2011). Through the empowerment program, women's club members have established 270 new home gardens and further developed 580 already existing ones (Zaidan 2011).

The RWDS has trained women's club members how to regularly recycle home trash and change it into useful compost to be used in home gardens. Home gardens were also planned to integrate with bee projects. Every member who gets bee cells (five cells at the beginning) also took funds to improve her home garden or to establish a new one if she did not have one already (Galudi 2011, Abu-Dayi 2011). In this regard, Amera Abu Dayi described her experience with home garden and honey production:

My home garden is two donoms [2000 square meters]. I turned it into a paradise. I grow all kinds of vegetables besides some medical plants. Now I have food sufficiency for my family from the best Baladi (organic) food. I sell vegetables to my neighbors and also for mobile vegetable sellers; I make SH5000 [\$1300] from my garden during the vegetable season. I grew all kinds of flowers around the 
garden as part of the bee project. I got five cells and they are increasing. I also sell honey and of course feed my family.... This reflected on my children's health. They rarely go to the doctor. The empowerment program sustained my family living, enabled me to pay SH300 [\$100] monthly for my asthma medicine out of my own pocket and, more importantly, my husband is proud that I am productive and responsible (Abu Dayi 2011).

Home gardens, integrated with honey production, are important for rural families who usually have many children (the rate of children per family for the seven participants is 8 , the minimum is 4 and the maximum is 12) (See The Palestinian Bureau of Statistics 2000).

Addressing Culturally Sensitive Issues: Indigenous Leadership is the Key

Zaidan (2011) argues that RWDS, as all NGOs, has its own agenda focused on social development that is culturally sensitive and grows out of traditional communities values and concerns. Zaidan believes that in traditional communities "one cannot implement any project or address any problem without paying attention to the indigenous customs and work with the local traditional leadership, including the traditional key role of the mosque. The Imam (mosque leader) can, in one speech, make it easy for you or make it impossible" (Zaidan 2011). Imams of mosques in rural communities usually play a key role in decision making because they are part, if not the most important element, of decision- making councils which usually consists of elders and indigenous leaders. In many cases, Imams have to explain the acceptability of any new decisions from an Islamic perspective. This perspective gives legitimacy to decisions and activities.

In 2010, RWDS launched and provided grant funding for women's clubs to implement two campaigns: one addresses family violence and the other addresses early 
marriage. The two campaigns are in progress at the time of this writing. Zaidan states that it was impossible to address such sensitive issues like violence in the family without discussing it from the Islamic perspective with the Imams. Therefore, the RWDS strategy was for the women to meet with the Imams in all the targeted communities to discuss the issue from the Sharia Law perspective. The meeting took place in village council buildings. Once Imams understood what RWDS was trying to do, they actively supported the effort by focusing on the topic at the next Friday speech in the mosque, under the title of "How Profit Mohammed treated his family" (Zaidan 2011).

In traditional communities, where the education rate is low compared to other communities, rumors are usually troublesome. If somebody, for some reason, does not like an idea such as reducing violence in the family, he or she could make up stories to create opposition against it, especially stirring up religious fears or misunderstandings. One can claim that the group behind this idea has a hidden agenda to attack the communities' customs or even the religion itself. Zaidan (2011) states that they had such troubles with some communities, but once they talked to the Imams and the Imams defended the idea, it became easier.

Moreover, it is very common in traditional communities that people mix what is from custom and what is from religion since custom often incorporates the religious traditions of the community. For example, early marriage is very common in traditional communities. However the debate is whether the pressure for early marriage issue comes from the religion or from other customs. Zaidan argues that it was not hard to challenge people who defended early marriage by demonstrating that there is no Islamic text that 
indicates girl marriage at an early age and the Imams agreed with this important point. One Imam added that: "Islam encourages marriage for the purpose of building a healthy family as part of healthy society.” Healthy family, from an Islamic perspective, means not only physically and psychologically, but also protecting the society from illegal relationships outside marriage and social problems it may cause. Zaidan explains that: "Our role during the primary meetings with Imams and local leaders was to explain the physical and psychological dangers of early marriage supported by evidence from courts about divorce rates caused by early marriage. Women's clubs leaders took the responsibility to make hundreds of home visits and held tens of workshops to address the problem." (Zaidan 2011).

Violence in the family is one of the shortcomings of many male-dominated communities (see chapter 2 of this study). However, the problem is not limited to these kind of communities. For example, in 2005, 1,181 women in the United States were murdered by an intimate partner; that is an average of three women every day (See U.S. Bureau of Justice Statistics 2005). The challenge in Palestine was how to address such a sensitive issue in rural communities. Abu-Dayi who participated in the two campaigns described here states that people at first were very unwilling to address these sensitive issues. She states that "they built on the strengths of the culture such as religious texts that the Imams talked about at Friday prayer. For example the last recommendation that Profit Mohammed told his companions in his last speech was 'I recommend you to treat your women well, they have rights on you and you have rights on them."' (Abu Dayi 2011, see Bukhari, ch. 3 p. 102). Using such language, especially when Imams enforce 
the idea, makes a difference for rural communities who appreciate the role of religion and culture in their life.

The Imams, according to Abu-Dayi, did not address the issue of violence in the family in terms of blaming anybody, but in terms of reminding both men and women about their rights and duties from an Islamic perspective. They also used some positive proverbs from the culture such as: "The one who treat his wife well is the most generous. The one who treats her badly is the most aggressive." Abu-Dayi states that: "Women slowly started to talk about having violence in the family while we were trying to tell them how harmful that is, especially for children. We all discussed together ways to reduce violence in the family" (Abu Dayi 2011).

\section{The Current Situation of the Program: Where it is Going}

Currently the Social and Economic Empowerment of Rural Women Program serves 5,000 rural women who are members in women's clubs and serves another 10,000 women who are not members, but benefit from their activities (Zaidan 2011). The savings and credit programs have benefitted 6,722 rural women, most of them are members in women's clubs but some are not. The small interest free loans given to women so far total 5,336 and the total amount in loans is $\$ 2,232,298$.

Zaidan and many women's clubs leaders and members have an ambition to establish a formal local cooperative that has a formal trade title and brand. Such cooperation is expected to market members' traditional products (clothes, crafts, Baladi food and dairy products) that can compete in the national regional and international market. Amal Sabah, the leading person of this idea states that "besides food, we are 
planning to work on designing traditional Masabeh (prayer beads) using olives to provide for the national market during the Hajj and Omra (Muslims pilgrimage to Mecca). The Palestinian national market imports millions of Masabeh yearly from China, and they are of very low quality. We are thinking about using the olives' hard seeds to make the Masabeh. It is going to be a complementary project with olive pickling; instead of throwing the inner parts we can use it in making good quality Masabeh (Sabah 2011)". The project of making masabeh is another example of building on indigenous culture in promoting sustainable development. The idea is derived from the tradition of giving Masabeh as gifts for people who come to visit in order to congratulate those who go to Hajj and Omra (pilgrimage not during Hajj time) every year.

\section{ANALYSIS OF THE CASE: GROUNDING IN THE CASE TO ANSWER THE RESEARCH QUESTION}

While the previous part of the chapter showed the power of the narrative story of the case, this part of the analysis addresses more directly the research question of interest in this study. How have successful community- level sustainable development efforts undertaken under crisis conditions drawn upon indigenous knowledge to achieve positive outcomes? The following discussion focuses and is grounded on the role of indigenous knowledge in achieving sustainable and positive outcomes in crisis conditions. $\underline{\text { Strengths of Building on Indigenous Knowledge- Based Development Patterns }}$

The advantage of indigenous knowledge based development patterns is that they use indigenous knowledge strengths to respond to cultural challenges that might be obstacles to development. The traditional exclusion of women, among other challenges in 
rural communities, was one of the challenges that the empowerment program targeted using the strengths of indigenous knowledge- based patterns to solve them.

Strengths from the Perspective of Participants. All participants in this case responded about their feeling toward the women's club of which they are members. They emphasized that it is their voice and the place where they express themselves, share their stories and experiences, and plan to solve challenges and have fun. Many participants expressed that before the Rural Women Empowerment Program, there was "zero" participation for women in social and political life because rural communities were not used to women playing any role in political life. For example, comparing women's role in local elections in 1996 with elections in 2005, women in 2005 were more active and advocated for gender issues (Sabbah 2011). In 1996, women's voices (votes) were used to pass political agendas even without knowing what the agenda was. Voting was according to men's opinions who usually know the candidates. For example, if a candidate came to the village, women could not attend the meeting or even know who the candidate was (Abu Dayi 2011, Sabbah 2011, Ashkar 2011). Zaidan (2011) argues that the first step towards developing women participation in public life was carefully addressed to be through activities that belong to the culture such as women's clubs that assures women to practice activities without mixing with men. Starting with organizing social lectures and professional training on skills that are locally acceptable (does not conflict with community culture) was key to achieving positive outcomes (Zaidan 2011). This careful attention to the culture ended up with changing the typical role of women in rural communities. 
In the 2005 elections, women's clubs not only unified women's voice, but also organized their political and social agenda to support their candidates (women's clubs members) who represented their interests. Women's clubs' political agenda has been staying in the middle of the political spectrum in Palestine, neither focused on Hamas nor Fatah, with more emphasis on gender issues such as women's representation in the legislative council (Zaidan 2011, Galudi 2011). In this regard, Zaidan (2011) and Galudi (2011) believe that staying in the middle and avoiding political polarization (a kind of independent position) is better for women's clubs in the current situation to keep the program of empowerment running without problems. However, women's clubs have no exclusion policy. They include women from Hamas, Fatah, and other parties. Part of the success was to decrease political disputes into an environment of "accepting each other" to achieve the general purpose of defending and supporting gender issues (Zaidan 2011, Galudi 2011, Sabbah 2011, Hamid 2011, Abu Dayi 2011).

Zaidan (2011), as a director of the program, believes that having 26 women in their communities' councils participating in decision making was a dream that women's clubs members worked hard to achieve. Some of them have the ambition to win in the coming legislative elections in the future (Sabbah 2011). The case indicates that, in crisis conditions, implementing development programs and projects from an independent position, as women's clubs have been doing, provides fairer results and reaches more people. People under crisis conditions (division and polarization between Hamas and Fatah) have few choices and high level of uncertainty. The programs succeeded in overcoming the challenge of political polarization that often leads to political and social 
exclusion. The independent position facilitated having 26 women's clubs members win the elections. That effectiveness of an independent position is supported by another evidence, which is the expanding number of women's clubs (123 clubs in the West Bank) in rural communities and the high number of rural women (5000 members) who have joined these clubs. From an indigenous knowledge perspective and as women role in rural communities is a little bit sensitive, it is more protective (AbuDayi 2011, Jabir 2011) for women to join an independent group such as women's clubs rather than joining political parties which might require women to do activities that could be culturally rejected such as mixing with men, traveling outside the community, or being engaged in the political conflict between political parties.

The Integration Process. Compared to other programs implemented and sponsored by PARC that usually focus on one dimension (see PARC programs and projects on their website 2010), such as land development program, civil society program among others, Rural Women Empowerment Program integrates the three elements of sustainable development. As the narrative story of the case tells, the program started with a focus on social development and then integrated economic development through environmentally sustainable small projects and activities. As Zaidan (2011) states, in rural communities, there is a "hidden need" for women to express themselves, participate in their communities and feel positive about their role. This need is usually limited by two things (i) the taboo role of women in such marginalized communities, and (ii) the critical economic needs of families that does not leave space for people, even NGOs, to think about the first one (Zaidan 2011). In this program, the examples discussed in the 
narrative part indicate that rural women succeeded in breaking the taboo and changing the tendency of men in the rural communities to reject any new role for women. Regarding breaking the taboo, in many cases, participants indicated that rejection came at first from the family, husband, father in law, sons, but later, and after understanding the nature of activities that did not conflict with the culture, those men and boys supported, and in many cases became part of the activities (for example Sabbah 2011, Om Suhiab 2011). Om Suhiab describes her community (Dair Abu Daif) as one of the most conservative ones in Jenin district. She believes that she accomplished a miracle by persuading her family, especially the husband and men from his side, to agree that she should join the women's club. She states: "at first, I used to go and listen to lectures on health and child care and some professional training about recycling home trash and turning it into compost. When I got the dairy producing project, my husband got involved in driving the small truck and collecting milk from farmers. My son helps him too. Now I am well known. My products are preferred in the community. I am the treasurer of the club. I have many responsibilities and my husband does not oppose anything I do" (Om Suhab 2011).

Launching the economic empowerment part of the program in 2000 has integrated the elements further by connecting the economic carefully with the social part of the program. The economic empowerment was designed (by PARC and RWDS) to be family based small projects that benefit club members and their families. This strategy involved male family members (husbands and sons) in many activities. The men came to 
understand the program's purposes and reduced their opposition to it and, in many cases, supported it (Galudi 2011, Sabbah 2011, Om Suhaib 2011).

The savings and credit part of the program is another example that describes integration. Originally, the idea of Jamiya (savings and credit) is a social cooperative among women to solve their problems. At first, it was not created for profit reasons, such as starting businesses, but to help the needy women to marry their daughters, pay medical expenses such as non-insured surgeries, expand their houses, buy new furniture, or pay for any social occasion (Abu-Dayi 2011, Galudi 2011). The adaptation of the idea and development of it from simple indigenous practice into savings and credit units, then regional cooperatives in each district, and then to a formal savings and credit union shows how an indigenous idea can develop in a modern setting and thrive. The savings and credit union is not only an economic institution but it is also a social institution that plays a political role in lobbying for gender issues. Because the union represents rural women, environmental issues and natural resources management are always present in the union's and of course women's clubs discussions and activities. Women's clubs and the Savings and Credit Union have a preference policy to give loans for environmentally friendly projects (Zaidan 2011, Galudi 2011, Sabbah 2011). It is important to remember here that savings and credit cooperatives now are completely managed by women's clubs members; this was a critical element in improving the administrative feasibility of the Rural Women Empowerment Program.

Additionally, the idea of savings and credit meets with the principles of the World Council of Credit Unions that serves millions of poor members worldwide (see World 
Council of Credit Unions website 2011). The figure below shows the increasing scale of number of credit unions and number of their members in different years.

Figure (1): number of countries that have credit unions, number of unions, and number of its members

\begin{tabular}{|l|l|l|l|}
\hline \multicolumn{2}{l|}{ Year } & \multicolumn{2}{l}{ Countries } \\
\hline 2010 & 100 & 52,945 & $187,986,967$ \\
\hline 2009 & 97 & 49,330 & $183,916,050$ \\
\hline 2008 & 97 & 53,689 & $185,800,237$ \\
\hline 2007 & 96 & 49,134 & $177,383,728$ \\
\hline 2006 & 96 & 46,367 & $172,007,510$ \\
\hline 2005 & 92 & 42,705 & $157,103,072$ \\
\hline 2004 & 82 & 41,042 & $128,338,297$ \\
\hline 2003 & 84 & 40,457 & $123,497,445$ \\
\hline 2002 & 78 & 40,258 & $118,268,624$ \\
\hline 2001 & 93 & 36,901 & $112,274,887$ \\
\hline
\end{tabular}

Source: (The World Council of Credit Unions, 2012, p. 1).

Another example of integration is the partnership between women's clubs and the Ministry of Education and public schools. This partnership integrates the social dimension embedded in cooking and providing healthy food for local schools, the economic dimension of supporting women's clubs' members economically, and the environmental dimension of encouraging establishing and developing home gardens. All food fresh vegetables and fruits were provided from home gardens (Sabbah 2011). The title "Cooking for our Schools" encourages both the community and the Ministry of Education to pay more attention to the issue of school children's nutrition. The Palestinian Central Bureau of Statistics (children nutrition in 2002) indicates that $37.9 \%$ 
of children age (9-59) months are anemic; 34.0\% are in rural areas (Palestinian Central Bureau of Statistics 2002). Therefore, the partnership with women's clubs members who pick organic fresh products from their home gardens to cook "healthy food" for public schools is local, inexpensive, and a more sustainable way to improve health and begin to address issues like the anemia problem.

In this regard, Amal Sabbah, who initiated "Cooking for our Schools", believes that the program is part of the kind of community service to which women's clubs are committed. At the same time, it provides income for members who have suffered from poverty. Sabbah states, "When mothers cook meals rich in protein and vitamins (beans, Mujadara Makluba, fresh fruits and vegetables etc) all picked up from organic home gardens, they do not look for money, they look for health of their children" (Sabbah 2011).

Seed Banks and Renewing Indigenous Crops. There is another indigenous activity among women's clubs members noted earlier that has also been an important integrative effort in sustainable development. That is Baladi (organic) planting and seed production. Members have initiated a Baladi seed bank where they dry, store, and exchange seeds at the planting season. This idea solves the problem of a general lack of Baladi seeds which also cost more, if they can be found and are bought from the commercial market. Moreover, women use their experience (Abu-Dayi 2011, Galudi 2011) in classifying the good kinds of Baladi seeds that are "indigenously known for their resistance to diseases and high productivity" (Abu Dayi 2011, Galudi 2011). Abu Dayi talked about at least 15 
types of vegetable seeds and more types of medical plants that are widely used in the community that might be called in the West "heritage varieties."

Women's clubs in the northern part of the West Bank are working on renewing all kinds of Baladi seeds, particularly watermelon seeds, that were used in farming before the Israeli occupation in 1948. Suher Galudi, the coordinator of the Empowerment Program in the north of the West Bank believes that: "If women's clubs succeed in bringing back the same Baladi watermelon that used to be grown many years a go, this will create a new national income for the Palestinian people, especially the northern districts by exporting to the neighboring countries and of course covering the national market" (Galudi 2011).

It is not strange that rural women rather than men lead this strategic transition to Baladi seeds and crops because they have traditionally had the responsibility of classifying, drying, and choosing the best types before the planting season. This long traditional experience was undermined, after 1948, by importing "genetically improved" seeds from Israel (see Kurzum 2001). The "genetically improved" seeds, for example watermelon seeds, have replaced the Baladi seeds and used intensively during the 1980s. According to Kurzum, this change in seeds and the use of intensive growing techniques with greater use of chemicals and water has damaged the soil and brought new diseases that required new and more toxic pesticides. The result was that the whole watermelon agriculture in the northern plain area was destroyed (Kurzum 2001, p.19).

Special Attention to Social Dimension. From the very beginning of the empowerment program PARC and RWDS have worked to address the need for rural women's 
education. Most rural women left school at an early age (middle school grades) or in some cases did not have formal education enough to be literate. The PARC and RWDS at first depended on sending their staff to lecture in women's clubs in different sites. In 2003, a group of rural women who were interested in catching up with education (for example Galudi 2011, Jabir 2011) suggested that women's clubs establish a special education class for "old" women who wanted to continue their education. At the beginning, the class was run by volunteers. Later, PARC adopted the idea and sponsored the class. Until 2010, there have been 534 women's clubs members who joined the class; $66 \%$ of them passed the high school general certificate (PARC 2010). Three participants in this case benefitted from the special education classes. One of them (Jabir 2011) succeeded in obtaining a middle school certificate, a high school certificate, and she graduated with a BA in social studies from the Open University in Jenin, West Bank.

Tahani Jabir reported her unique story of how she overcame the challenges that she faced and explained how she moved from what had been a $9^{\text {th }}$ grade education to completing her BA in social sciences. She had dropped out from $9^{\text {th }}$ grade after her father died. She got married at an early age because her mother was poor and wanted her to be protected by a man. Jabir said that: "It was my dream to continue my education. I used to cry when people every summer celebrated the results of Tawjihi exam (high school national certificate graduates). I joined the class and finished all the required exams to get ready to do the national Tawjihi. I passed it and immediately joined the Open University. In 2009, I graduated with a BA in social studies. I dream of getting my masters. I am very thankful to the empowerment program and the generous support and 
encouragement from my husband, PARC and RWDS" (Jabir 2011). The lessons learned from the stories of women's clubs members is that solutions without paying attention to peoples' needs and culture and more important engaging people in finding solutions to their problems may end up with non-sustainable results.

Empowerment from the Perspective of Participants. When the research team asked participants how they understand the term empowerment, most of them (seven out of eight) focused on the idea of bringing opportunities (education, health jobs and benefits) to women's communities instead of helping women to go outside the community and get their opportunities. This answer might be due to the nature of rural communities where women have to take care of large families (all participants have between 5-12 children), the household, and the agricultural work. For example, Abu Dayi (2011) states that: “Empowerment for me is helping me to sustain my families' life within my community. I cannot leave my family and run after any opportunity." Jabir (2011) believes that: "Part of her success in rising from $9^{\text {th }}$ grade to BA was the location of the tutoring class, which was in her village women's club. She adds that: "There I could take care of my family and attend the class and get support from the club members... if the class was in Jenin city, it would have been hard for me to attend. Later I joined the Open University for my BA because the schedule is flexible. I went two times a week except for exams" (Jabir 2011). The case teaches a lesson that empowerment depends on the context or at least was highly affected by the context (Cooper and Vargas 2004, ch1).

Sustainable Responses to Critical Problems. Probably the most critical problem that faced the program, especially at the beginning, was the opposition of male family 
members, particularly husbands and sons. Most of the participants indicated that their family members opposed the idea of women's clubs but now in a way or another take part in their spouses projects or at least support and do not oppose their activities (Alyat 201, Sabbah 2011, Om Suhab 2011, Jabir 2011, Abu-Dayi 2011). The projects that women got sponsored by PARC, RWDS and international NGOs, were family-based projects that positively benefitted all the family members including unemployed males (sons and husbands) an indeed involved many of them.

Om Suhaib for example agrees that the dairy project rescued the family from poverty because she, her husband, and her son now work in the project. Her husband and her son, who were unemployed, drive the truck, collect milk from farmers, and deliver dairy products to shops in the village or peoples' houses while she and one of her daughters work on preparing the dairy products (Om Suhaib 2011). Tahani Jabir states that "my husband had some concerns that I joined the women's club in the community at the beginning. Now he appreciates all that I have done and that I am doing. Moreover, he takes care of the cow most of the time, especially when I get sick" (Jabir 2011). The pattern of production in rural communities is collective not individual. Therefore, women's clubs projects were culturally preferred as they involved many family members together in a common effort.

One of the critical problems that members face with their products, such as dairy, Zatar (thyme), traditional clothes, traditional crafts, pickled food, organic seeds and medical plants' flowers, is marketing outside the community when the offer exceeds the demand. Women's club members usually produced more products than the communities 
needs but they did not have access to markets outside their communities. To solve this problem, some women (Abu-Dayi 2011) made contracts with private traders to supply them some of the women's club products. However, RWDS decided to organized a monthly auction in their building to offer women's clubs members' products (Zaidan 2011). Furthermore, RWDS usually networks with food products national auctions and reserve a corner under the name of "Rural Women's Clubs" where rural women can offer their products and sell them for good prices in different communities especially in the city of Ramallah (Zaidan 2011).

In addition, women's clubs in each district usually organize a gathering every two weeks in one club building where other clubs come to visit the community, eat together, exchange experiences, socialize, learn new skills, and market their products (honey, thyme and medical plants, and traditional crafts) (Galudi 2011). This informal meeting is open for all women from all communities to come see what women's clubs do. It is a kind of public relations process drawn upon indigenous culture.

Additionally, the creative idea of planning to establish a new rural women's cooperative with a title and brand (see the narrative section of this chapter, Sabbah 2011) to market women's club's products could be a useful way to market products more effectively outside the local area. If this idea succeeds, their products may be able to reach regional and international markets. Sabbah (2011) believes that they need to think about an attractive title, symbol, drawings and brief descriptions that should be written on their products in a way that reflects the rich culture of Palestinian rural communities and that also pays attention to high quality such as homemade Baladi (organic) products. 
Positive Outcomes for Local Communities. Besides the economic benefits that women's clubs achieved in their communities, their basic focus is still the social dimension, particularly in education and health care. Women's clubs have intentionally decided to add a classroom in their buildings for teaching and training. Zaidan (2011) explains that it was women's clubs policy to have a classroom in each of their club's building to turn them it into training centers and also places for providing community services, like health care outreach. For example, Samar Alyat, chair of Qaffeen women's club, says that "the club is open for all types of community activists. Every academic year we organize tutoring classes for high school students. We welcome doctors and nurses who come to implement check-up days and lecture about women, children and mothers' health. We welcome human rights activists and anyone who wants to benefit the community. Besides that, we turned the club into a training unit for women, so that we save travel money and time instead of going to the mother NGOs in Ramallah. We want others to come and see us (Alyat 2011).” Furthermore, women's clubs now run many childcare centers and at least two public libraries (Galudi 2011). This public service role that women's clubs play is at the core of social networking for the benefit of the community.

Rural people in Palestine are known as good savers (Zaidan 2011). Therefore, it is not strange that the savings and credit idea came from a rural community. The success that savings and credit units and organizations showed encourages more women to be part of this economic cycle in terms of borrowing and starting new businesses. Businesses in turn reflect on improving the communities' standard of living and sustain 
poor families' lives. Jabir $(20110)$ believes that "if she takes a $(\$ 3,000)$ loan from the savings and credit organization in Jenin, she can buy two other cows. This means that the neighborhood, and maybe the community, will keep being able to afford dairy products sold at reasonable prices. It also means an extra (\$300-400) monthly income to her family." Sabbah (2011) explains that: "If the Masabeh (prayer beads) project succeeds, it will open hundreds of new jobs for local women and young girls, and it will activate the local shops and of course save some of the nation's dollars".

The case study emphasizes the importance of micro-enterprises that have indicated significance success in poor communities in countries like Bangladesh and India (Yunis 2003). Yunis argues that in both developing and transition economies, microfinance have increasingly been positioned as one of the most important poverty reduction and local economic and social development policies. Its appeal is based on the widespread assumption that "reaching the poor" with microcredit will establish a sustainable economic and social development route animated by the poor themselves. Probably Palestinian rural communities indicate an advantage to the micro-economy idea; the fact that it is family based where family members produce together and benefit together.

At the end of the road, poor communities, especially in crisis conditions, look forward to having good social services and food security, including good nutrition such as organic vegetables, dairy products, and honey to be available for them at an affordable price. The women's clubs have been very successful in meeting these needs. They also have played an important role in creating positive changes regarding gender issues. This 
key role has contributed to creating a sense of legitimacy for women's clubs in their communities and in a way that does not contradict with local culture.

Community Level Sustainable Development Successes Build Legitimacy. The community as a whole and the family as a basic unit both have been at the core of women's clubs' decisions, as the implementers of the empowerment program. All participants agreed that the projects that came out of the program (bees, cows, traditional designing, home gardens, dairy products and food pickling and pocketing etc.) are family- centered projects. This means that, besides the women's club member, at least two family members work in the project (Sabbah 2011, Abu- Dayi 2011, Zaidan 2011). In terms of legitimacy, the program's family- centered pattern has promoted acceptance and regard for the family and indeed helped in overcoming many challenges such as opposition of males.

The very active social development actions implemented by women's clubs have also promoted their legitimacy in their communities. For example, the tutoring classes that are held in the club buildings have improved success rates for high school students (boys and girls) in English language and math (Sabbah 2011, Zaidan 2011). The health care activities have improved health services in the communities, especially for elders, children and people with disability (Jabir 2011, Sabbah 2011, Alyat 2011). The relationship with the Ministry of Education is a "unique partnership" that serves the purpose of fighting anemia among school children and improving their nutrition. This claim has been supported by community members where it takes place (Sabbah 2011, Zaidan 2011) though those conclusions have not yet been researched by medical 
professionals. Additionally, educational campaigns on social issues such as prevention of early marriage and violence in the family reflect positively on the whole community. The purpose of these campaigns, as Zaidan (2011) describes it, is "to give females more opportunities in life, education, work experience, and a healthy body before marriage, and reduce violence in the family".

Early marriage has been considered the third reason, after low learning capacity and lack of motivation in school, for school drop outs. It is the leading reason for dropouts by girls (Palestinian General Administration for educational Planning 2005, p. 8). The PGAEP studied 1,810 students who dropped out, with 50\% of them girls and $50 \%$ boys. The researchers also conducted interviews with students' parents about the reasons for leaving school. One of the significant findings of the study was the fact that most reasons that led to dropping out are preventable. The family, in cooperation with the school, can prevent it (p. 4). In this regard, Zaidan (2011) states that "in rural communities, because rates of early marriage are high, it is expected that drop out among girls is in most cases because of early marriage... mothers play a critical role in encouraging or preventing this problem because in traditional rural communities, mothers feel committed, responsible and then proud to get her daughters married as soon as she can especially if the family has many daughters" (Zaidan 2011). Therefore, addressing this problem through women is extremely important.

Community Level: No one Can Reach Community Needs Better than Community Members Themselves

This section compares policy implementation from indigenous knowledge- based 
community level versus national level, with respect to the case the empowerment program, from a sustainable development perspective under crisis conditions. The discussion here is not a comprehensive evaluation and comparison between the two levels but it focuses on the case program in terms of how indigenous knowledge- based community level influence policy implementation and which lessons can policy implementers and developers learn.

What Has the Program Done to Communities? All participants in this case responded that women's club's economic, social and environmental activities reflected positively on the community in many aspects such as education and health. They gave examples such as the high demand from community members to implement more specialized medical check up days; dental check up, children's anemia hearing and visual check ups, and vaccination campaigns. Many of them (Abu dayi 2011, Om Suhaib 2011, Jabir 2011, Sabbah 2011, Alyat 2011, Galudi 2011) participated as trainers in free workshops about indigenous craft and clothes desig, managing home gardens, classifying, drying and planting indigenous plants and seeds, recycling home trash and turning it into compost among other skills. These training workshops have transferred indigenous knowledge and skills from the old generation to the younger, and encouraged young generation females, girls who did not finish high school, to join the clubs and improve their professional skills. Many of them had training about how to manufacture traditional soap and traditional food pickling that helped them to produce and contribute to their families living (Sabbah 2011). Interestingly enough, women's clubs members have been creative to solve the challenge of childcare while they go outside the house to have training or 
participate in any event. First, they started by helping each other personally to take care of the children whose mothers leave the house to participate in development activities. After that they succeeded to establish small day care and kindergarten centers that not only solved their problem but also provided living for other women in the community. Now many women's clubs have kindergarten and day care centers.

Community Health. All participants also significantly agreed on the importance of health check up days, mobile clinics and labs, home gardens, bee projects and dairy products. It is important to mention that public health services, especially in rural areas, are essential because they are scares, especially regular check ups. There are few labs and X rays units available in these areas especially in small communities. Health centers in these communities usually have a general medical doctor, an administrative secretary (usually a nurse), a weekly or every- other- week pregnancy services and most likely no labs. Statistics indicate that, in 2003 , only $4.7 \%$ of rural communities had a lab while X ray units were available only in hospitals (see Palestinian Central Bureau of Statistics 2003). In 2010, there are only 40 primary health centers' labs in the West Bank (Palestinian Ministry of Health in West Bank 2010); few of them are located in rural areas. Therefore, women's clubs activities have created alternatives that positively reflected on community health. This alternative embedded in a partnership with the Palestinian Medical Relief(PMR) to send mobile labs and clinics regularly to women's clubs buildings (Galudi 2011, Zaidan 2011). While the PMR sends these clinics and labs, women's clubs have to provide the place in clubs buildings, volunteers to run these activities and other logistic supplies. 
Gender Issue is at the Heart of the Program. All participants agreed that the empowerment program, especially being in the administrative body of women's clubs have increased their self -confidence and created a kind of "identity" and independent status. However this confidence and identity, according to participants do not contradict with indigenous culture. People in rural communities started to get used and encouraged the role of women's clubs in their communities. Before the program, participants stated that they were completely dependant on their husbands while now they contribute to spending on themselves and their families. Being part of the administrative boards of women's clubs reflected positively on their ability to make and share decisions. The point here is that indigenous knowledge based strengths contributed to responding to some traditional limitation about women's role in their communities.

Additionally, six participants out of eight responded that the programs have fostered community confidence and trust in women's abilities to participate in economic and political life. The six participants are the ones who won elections and became members of local councils in 2005 . They believe that, because of community support especially from women, they could compete with other women from Hamas and Fatah on the women's quota seats and actually won the elections. Moreover, all participants, indicated that they had never participated in political life except "voting" in the 1996 elections, and also have never owned a business or ran a project for themselves. This explains that the empowerment program and being members of women's clubs to a high extent positively influenced their position in their communities.

For example, Rawda Ashakar, chair of the Sayda community women's club and 
member of the community council, states that before the program, she now knew and talked to a few people and generally only to women within the family. After the program, she knows the whole community, participates in all voluntary activities, participates in training other women, and attends the village council meetings and participates in decision making. Her main objective is to lobby for the best of gender issues, bring more benefits for rural women, and support poor families in her community (Ashkar 2011).

Zaidan (2011) believes that working with communities requires a special kind of informal relationship with people and local associations especially working on culturally sensitive issues. She raises an important point about the importance of being close to communities with which they have partnerships. She believes that part of their strategy in RWDS is to build a good relationship or maybe friendships with rural women who traditionally appreciate informal relationships and respect cultural norms in building trust. She states: "We usually warmly welcome them in our Organization any time and without appointments, we sit with them eat and drink with them and involve them in our decision making... we answer their telephone calls even if they call our homes or at night, and more importantly, when we visit them in their communities, we dress like them and try to speak like them. This indigenous hospitality counts much for rural people and has built trust between our NGO and rural women, individuals and groups" (Zaidan 2011). This kind of relationship poses some of the participant's statements that "PNA agencies, for example Ministry of Women Affairs and Ministry of Education, has not provided much support for their clubs (for example Sabbah 2011, Abu -Dayi 2011). This statement leads to the question why community level policy implementation in such 
a context might better promote sustainable development compared to the national level.

\section{National Level Versus Community Level, Sustainable Development is the Answer}

Since 1994, PNA has addressed development in Palestinian territories through a specialized national institution called Palestinian Economic Council for Development and Reconstruction (PECDAR) established by P.L.O in 1993 (PECDAR Annual Report 2007). The mission of PECDAR has been to develop a national infrastructure that contributes to economic reform of the Palestinian economy and attracts international investments. PECDAR has been also considered the bridge between PNA and international donors (see PECDAR Activities Report 1996). However, the problem with PECDAR (Galudi 2011) is that it does not pay enough attention to local communities' needs such as empowering females among other social issues. "Sometimes PECDAR representatives do not know anything about the culture of communities who are directly influenced by their projects. Cultural misunderstanding might end up in local people refusing development projects" (Galudi 2011).

The PECDAR, as many economic and reconstruction institutions in the world, focuses on the economic dimension of development and to some extent the environmental dimension from the national level. However, the latest annual report published by PECDAR in (2007) argues that in spite of the huge efforts of the PNA to provide an enabling environment for private sector led growth; the Palestinian economy has stagnated or declined in recent years. The slow and hesitant progress in the peace negotiations has undermined confidence. In addition, many of the actions taken by Israel, especially the policy of closure, have had a devastating impact on the level of economic 
activity (PECDAR Annual Report 2007, pp. 5-6). The PECDAR philosophy of development seems to be tuning with the model of stability and reconstruction (see the problem section in chapter one of this study) that has been implemented in many contemporary crisis conditions from the national level (see also Special Inspector General for Afghanistan Reconstruction 2010). However, economic stability and infrastructure reconstruction, although they are important but does not necessarily mean sustainable development (Cooper and Vargas 2008).

For example, in 2002, PECDAR has launched a program called Integrated Community Development Program (ICDP). The program in definition looks to be designed to address sustainable development with focus on integrating economic, environmental and social purposes through many micro -projects. However, it is a topdown model of national level implementation process that does not necessarily reach community needs especially in crisis conditions.

The Rural Women Empowerment Program in comparison is not a top- down model but bottom -up one based on local people's needs. Women's clubs have successfully implemented ideas that were derived from local indigenous knowledge and created by rural women themselves who belong to the community and understand its needs. The result of this program implementation was more people acceptance and engagement in development activities. Examples of these ideas are savings and credit, partnership with schools, implementing the members personal projects, turning women's clubs building into training units, and creating a cooperatives to compete in the market. All these ideas although they are not sophisticated ideas, they address the core needs of 
local communities in crisis conditions. Empowering marginalized sectors such as rural women does not come by building infrastructure only, but it needs to melt the marginalization taboo by listening to people's stories, engaging them in decision making and implementation through their own local institutions, and on top of that, learning lessons from their experience and indigenous wisdom in natural resources management and sustaining their lives.

Crisis Conditions: How Indigenous Knowledge Based Responses Meet the Challenge

Crisis conditions in this case are not only occupation, war (Intifadas) and political division, but also lack of resources and poverty. In such conditions, each dollar, a simple plan and, small project counts. In this regard, Zaidan (2011) argues that developing or establishing a home garden costs (\$300-500) but it can provide healthy food for big families such as for women's clubs members. Such a project might also provide $\$ 500$ a month for a family during the harvest season. Jabir (2011) argues "our response to crisis conditions is not complicated and does not need much resources but is simple and derived from our culture. With home gardens and a cow, my family's life will be "sustainable", meaning able to face crisis conditions such as closure of markets caused by the Israeli occupation and my husband being unemployed". Of course these arguments are derived from participant's understandings of people's needs in crisis conditions. All participants responded that personal safety and food security are on top of people's need in crisis conditions.

Self -Reliance and Food Security as Cultural Norms. Rural communities in Palestine look at self-reliance, especially in food supplying, as a matter of dignity. All participants 
agreed that the empowerment program have drawn upon indigenous norm of selfreliance. People in rural communities like to raise cows, goats, sheep, chicken, bees, and grow their own gardens including herbs in order to sustain their living. Many participants (Abu Dayi2011, Jabir 2011, Om Suhaib 2011) agreed that "as most rural community people, they like to grow and produce their own food (honey, dairy products meet, chicken, herbs...) as part of living with dignity". However it is not strange in crisis conditions that big rural families need support to buy a cow or start a small bee project or chicken raising.

Women's clubs small projects and activities have improved community self reliance in terms of providing affordable social services and good quality food (usually organic) for local communities. For example Hamid (2011) describes the Bee projects saying that: "the bee projects have influenced all the community. Each bee cell produces, in a good season, about (5kg) of honey. Each kilogram of honey can be sold for SH30-50 (\$8-13). This price is affordable for most people in the community. In Ramallah city, a kilogram of honey may cost SH120 (\$33). Additionally, honey producers usually use honey as a gift for family members and friends who do not produce it” (Hamid 2011). Honey producing is an expensive project for poor people to start out of their own pocket; each bee cell costs (JD200). If the cell is "big and strong", it could be divided into two cells over a year (Hamid 2011), which means an increase in honey production. The point here is that without the women's clubs' projects such as the bees project, rural communities, especially poor families, cannot afford important and nutritious foods like honey. 
Women Networking Improves Social Cohesion. Indigenous Palestinian culture appreciates women's role in building social relations among families, tribes (Hamulas) and communities. The majority of participants including the director of the empowerment program agreed that marriage (getting sons and daughter married) was indirectly present in all women's social activities such as the weekly or monthly meetings, and club-to-club visits, workshops and field trips, and personal visits. Zaidan (2011) believes that by being active in women's clubs, members get to know and build friendships with other people from different tribes (Hamulas) and different communities. This friendship was key to success in addressing culturally sensitive issues such as early marriage and violence in the family.

Moreover, socialization seems to be an important factor in reducing stress and treating trauma in communities under crisis. Some of the participants, besides other community members, have experienced trauma during the two Intifadas such as losing a son, a husband, having members of the family arrested for a long time or losing land or other resources. Women, particularly mothers, indeed the most suffer because the number of victims among males, according to the Palestinian Central Bureau statistics, is bigger than the number of females (Palestinian central Bureau of Statistics 2009).

\section{The Weak Role of the State in Crisis Conditions: Drawing on Indigenous}

Alternatives can Fill the Gap. All participant agreed that the empowerment program empowered rural women, in a way that meets their communities needs and culture. Additionally, the program, according to participants, responded to the lack of the PNA capacity to address the needs of rural communities in sustainable development activities. 
The PNA does not have the capacity or the legal framework or technical or administrative capacity to respond to trauma problems especially gender issues. The UNDP Report about Palestinian territories (2009/2010) indicates that "the current legal framework in the Occupied Palestinian Territories is one of the most significant obstacles to gender equity" (UNDP 2010, p.45). For example, In the West Bank, the law provides for a reduced sentence with respect to a perpetrator who, in a "State of great fury", commits a crime; this also applies to males who kill their female relatives under "suspicious" circumstances (Palestinian National Authority 2002) ${ }^{3}$. Additionally, because of political division, the Palestinian Legislative Council (PLC) failed to change critical legal issues to mandate a penalty against "honor killing". Because the lack of administrative capacity of the PNA in treating trauma conditions (UNDP 2010, p. 47, Zaidan 2011), there are no specialized centers to deal with trauma cases; Palestinian NGOs compensate this role. In some cases, PNA agencies, not only fail to help but also present to obstacles NGOs that want to play a role.

The team asked participants if the PNA through its agencies offer any help for their women's clubs. All of them responded that the only agency that cooperates with women's clubs is villages' councils; this is considered a local institution. Interestingly enough, four of them "complained" that the Palestinian Ministry of Women affairs does not help them or does any thing for them as rural women; the rest of them did not mention anything about the Ministry of Women Affairs. Galudi (2011), the coordinator

\footnotetext{
3 Article 9, All Palestinians are equal under the law and judiciary, without discrimination because of race, sex, color, religion, political views, or disability. Article 10, 1. Basic human rights and freedoms shall be binding and respected. 2. The Palestinian National Authority shall work without delay to join regional and international declarations and covenants which protect human rights.
} 
of the program explains this lack of partnership with the Ministry of Women affairs by two things: First, the Ministry is overwhelmed with "prestigious policy theoretical discussions" about gender issues (women's rights) probably to improve the image of the PNA internationally. Second, the Ministry has very limited implementation tools and capacity to reach people on the ground such as rural women's communities; most of the Ministry's activities take place in the city of Ramallah (Galudi 2011). Lack of partnership with the Ministry of Women raises the question of reaching communities under crisis and also indicates that sustainable development could not be achieved without getting close to peoples needs, listening to their perspectives and helping them to be part of the implementation process.

Amal Sabbah blames the Ministry of Education for not facilitating the women's club partnership with public schools under the "Cook for our Schools" project. She says that "some employers in the Ministry pushed that women's clubs should turn back to the bid system of supplying food for public schools. They want money but do not care about the quality of our work and the value of partnership with women's clubs. We will keep lobbying to keep the partnership as it started and develop it more" (Sabbah 2011).

The important point regarding the lack of role of the state (PNA) in crisis conditions is that indigenous -based institutions and activities respond appropriately to local people's needs and also do not cost and need much resources. Zaidan (2011) states that women's clubs members usually pay attention to cases with special social needs such as widows, women who have "martyrs", women who have family member(s) arrested by Israeli forces, women with special needs or has family member with special needs. "They 
know more than anybody else what are the critical cases in the community" (Zaidan 2011). This attention to cases that are socially traumatized is part of indigenous customs and social life in rural communities that consider paying attention to such cases part of religious rules and social duty.

Finally, the research team asked participants to comment on which model of development implementation they prefer, national level (top down) model or community level (bottom up) model. The researcher described a top -down model as a national agency, in cooperation with the village council, implements activities (distribution of goods and services) while community members receive without participating in the decision- making process. Bottom up model is when community members make all decisions, design activities and implement them while national agencies or NGOs are just supporters and facilitators. All participants, with respect to the empowerment program, agreed that a bottom- up model functions better because it empowers local groups, gives them more experience to improve their capacities, reaches peoples needs better, uses patterns that are derived from the culture and pays attention to sensitive norms in the culture, and tends to be less corrupt. Indigenous Knowledge and Sustainable development

At the very beginning of establishing women's clubs, indigenous culture has played a key role in sustaining their outcomes and their acceptance in the communities. The first members who joined women's clubs were skillful women who used to design traditional clothes from natural wool, design some indigenous crafts (bread containers) from natural wheat strew, design simple furniture pieces from natural cane, and preparing 
traditionally pickled and processed food such as Zatar (thyme) and green olives (AbuDayi 2011, Sabbah 2011). In cooperation with these groups, PARC started sending advisors who used to talk to women in houses about health, education and social life. Zaidan (2011) argues that, if PARC did not pay attention to cultural sensitivity, they would not have established women's clubs.

The opposition that they had at the beginning was because of the assumption that women's clubs may, through "imported "ideas, conflict with the culture of the communities (Zaidan 2011). Conflict with the culture might be something like mixing men with women or participating any anti-religion activity, or taking women to the city to a sleepover training workshop.

Once the picture became clear that women's clubs are helping members to be more organized, more educated, and more productive, the community, particularly males, started to change their view and accepted women's clubs. Part of what Zaidan (2011) calls "breaking the taboo" is that most activities were managed and implemented by members themselves and in the community while PARC and RWDS representatives played the role of facilitators and supporters. Dressing like the community, speaking like them and eating and drinking their food and drinks have also helped in "breaking the taboo" (Zaidan 2011).

The nature of rural communities makes it difficult for their women to leave their families and stay a whole day or sleepover for some days to attend a training activity or meeting. Rural women play a key role in running their families; they run the household, agricultural work, local marketing for the house, preparing children for schools etc. 
Accordingly, choosing to implement activities inside rural communities with special attention to local culture was part of the success. This strategy has resulted in helping women's clubs' leaders to develop themselves administratively and manage and implement all activities and projects inside the community and most likely by community hands.

Indigenous knowledge based norms (traditions, customs, religious norms) count heavily in the process of implementing development activities in Palestinian rural contexts. Such contexts are usually big families living together, everybody knows every body, live from simple economy, care about the environment and natural resources (particularly land and water) because of scarcity, respect religion and culture and led by collective traditional leadership. While young generations in rural communities play an active role in political life, traditional leaders such as Sulha Committees (indigenous conflict resolution pattern) and religious leaders still lead social and cultural life.

In terms of development, if the Imam of the mosque or a group of elders in a rural community decides that some activities are religiously and culturally unacceptable, it will be hard to pass it in the community. People will hesitate to join it. If religious and local leaders agree to support activities, or in some cases lead it, that will be an indicator of legitimacy. Others will accept it and participate. In this regard, Zaidan (2011) states that "sensitive campaigns against family violence and early marriage could not have succeeded without the cooperation of religious leaders who, after involving them with discussions about the topics, gave Friday speeches about the importance of these topics. 
Accordingly, people accepted the idea of talking about the topic and women's clubs members visited many families and raised the issue".

From the participant perspective, all participants agreed that most activities and development patterns implemented through the empowerment program do not conflict with communities' culture, but were at root derived from it. Economic patterns such as Jamiyya (Savings and credit), dairy producing and Baladi (organic) food processing, home gardens, bee raising, are all derived from local culture and integrate with the social and environmental life of rural communities. None of these patterns is harmful to the environment or human health; to the contrary, they provide food security and high quality nutrition to rural communities. In conclusion, indigenous culture based development patterns promote sustainable outcomes based of the integration process between economic, environmental and social dimensions of development.

\section{$\underline{\text { Conclusion }}$}

This case addressed the importance of including gender issues in sustainable development efforts in crisis conditions grounded in traditional knowledge. The rural women empowerment program, including women's clubs as implementers and the PARC and RWDS NGOs as sponsors, have drawn upon indigenous knowledge based activities that led to positive outcome for communities under crisis. Interestingly enough, these activities, because they do not cost much and can be implemented with local available resources, responded well to crisis conditions challenges including lack of resources and the weak role of the state in such conditions. Additionally, because indigenous knowledge based development activities are derived from the local culture, the case 
indicates significant capacity of indigenous knowledge based institutions, leaders and activities to respond to culturally sensitive challenges such as early marriage and violence in the family in rural communities. Finally, the case indicates that indigenous knowledge- based development activities have significantly met sustainable development requirements based on the living triangle. Indigenous knowledge -based development pays attention to both environmental friendly activities that are usually derived from indigenous culture and pays attention to social cohesion. It also sustains communities' living through micro- economic endeavors that look to function well in crisis conditions in terms of supplying food security and a kind of family based self- reliance. 


\section{CHAPTER 5: SULHA COMMITTEES: AN INDIGENOUS PATTERN OF CONFLICT RESOLUTION, THE CASE OF THE CENTRAL SULHA COMMITTEE IN THE DISTRICT OF JENIN IN THE WEST BANK}

This case study deals with conflict resolution in sustainable development in crisis conditions. The case addresses an indigenous knowledge-based conflict resolution process operated by local groups know as Sulha committees (SCs) that have been used in Palestinian communities since at least the time of the Turkish Empire. The core purpose of Sulha committees, besides the day-to-day dispute resolution, is to enforce the rule of law. As it will be discussed later in this section, the rule of law system that Sulha committees support is a hybrid system that borrows from Islamic Sharia law, local traditional customs, and civil law.

Today, this indigenous pattern functions in all Palestinian communities (cities, towns, villages and refugee camps). In particular, this case study focuses on the operation of the Central Sulha Committee of the Jenin District in the West Bank. It provides a variety of lessons on the ways that indigenous knowledge can contribute to successful sustainable development at the community level in crisis conditions.

Building on Christopher Weeramantry's argument, the rule of law is crucial to sustainable development (Weeramantry 2002). Sulha conflict resolution is important to sustainable development because it deals with the three elements of its living triangle: social development, environmental development and economic development. Sulha process through enforcement of the rule of law in crisis conditions, provides social cohesion, protects natural resources that are usually scarce in crisis conditions, and 
protects people's properties and businesses. The process of how the indigenous Sulha committees process promotes sustainable development will be discussed in detail in the descriptive and the analytic sections of the chapter.

Sulha committees consists of 7-10 men and are usually formed by "well known and accepted, honest, respectful, influential and volunteers indigenous leaders", (Sarisi 2011, Turukman 2011) who are usually elders. Over time and experience in the use of Sulha work, the members become known and trusted to dispute communities' conflicts. However, some of Sulha members inherited the responsibility of working on Sulha from their fathers and grandfathers (Turukman 2011, Abu Al-Hayja 2011).

Sulha committees implement their solutions to local problems at the community level. There is no formal, national or local policy on how to organize their work. However, both the justice system and the executive authority in Palestinian territories coordinate with and support Sulha committees (Turukman 2011). The committees are independent and voluntary. They do not charge any fees. They do not follow any policies of governmental agency except for their informal cooperation with the formal legal system (courts, police and governors' offices in districts). However, there have been times when the Palestinian Liberation Organization (P.L.O) and later the Palestinian National Authority (PNA) have tried to contain Sulha committees' work because of the critical influence and strong sense of social authority and legitimacy these committees have in Palestinian communities.

The Sulha committee process for conflict resolution is important because it responds to all kinds of conflicts from serious matters such as intentional killings, thefts, 
and sexual crimes to minor things such as dispute over property, land, and water resources rights, and even marriage and divorce. The Sulha committees begin work immediately after they are approached about a problem to prevent the expansion of these conflicts. They depend on their ability to build social cohesion, encourage tolerance, and bring about forgiveness among people. The evidence in this study is that Sulha has become so important because culturally people prefer it for reasons that will be discussed later in this chapter as compared to the courts and formal legal system, especially in the kinds of crisis conditions that are present in Palestine.

This case study addresses one of the best-known and most widely respected Sulha committees, the Central Sulha Committee in the Jenin District known as (JCSC). The committee was formed in 1987 (during the first Intifada), took the name JCSC in 1993, and is still working until the moment of this writing. Although the committee consists of 7-10 indigenous leaders, the number sometimes increases according to the nature of the particular conflict that is being addressed. The committee is flexible and can add leaders from local communities and tribes that might be part of a critical conflict. This chapter consists of two main parts: the narrative story of JCSC that addresses the start of Sulha idea and the development of the JCSC and the analytic part which investigates how the case answers and explains the way that indigenous knowledge has contributed to sustainable development in crisis conditions.

THE JENIN CENTRAL SULHA COMMITTEE: SUCCESS GROUNDED IN TRADITIONAL KNOWLEDGE 
The story of JCSC begins from the foundations of Sulha as an indigenous process that has been developed over time. It starts with a description of the process and then moves to its origins. The discussions of the origins begins with a description of the foundations of Sulha and next focuses specifically on the way that JCSC has developed and operated as a contemporary case of conflict resolution through Sulha. After that foundation discussion, the next section focuses on the establishment of JCSC in 1987 and its development, how it works, and its relationship with the current Palestinian legal system. The term the committee will be used in many cases to refer to the JCSC. The Sulha Committee Idea: Where Does it Come from and How Does it Work As noted earlier, the Sulha Committee is an indigenous pattern of conflict resolution that is derived from cultural customs, Islamic (Sharia') law, and civil law that has been applied in Palestinian communities for hundreds of years (Turukman 2011, Abu-Al-Haija 2011). Each Sulha committee (SC) usually consists of 7-10 indigenous leaders. They are men who understand and appreciate the culture, community's customs, and are committed to Islamic rules. They are most often elders who are well known and accepted in their communities. However, the number of members serving on a SC can increase if the chair and the members think that they need to add some specific persons who might make a difference in solving a particular local conflict. Today SCs are spread throughout all Palestinian communities, but there is a central SC in each district that leads the resolution of critical cases (such as intentional killings) and coordinates among smaller SCs in different communities within the district. All participants in this case indicated that there are no formal rules or requirements that control who can be a SC 
member. People usually trust them according to their commitment to and care for their communities. They understand the customs of conflict resolution from experience and from the cultural traditions they have learned over time. However, some of them inherited their role as SC members from their fathers (see Abu-Al-Haija 2011, Turukman 2011, Alyat 2011).

The Conflicts and the Purpose. The SCs usually accept any kind of conflict, both civil and criminal, including critical cases such as unintentional killings caused by car accidents, intentional murder committed by individuals, within families, or even as a result of community conflict. They deal with fights that cause injuries, conflicts over property such as land, houses, and businesses, debts and other financial problems, sexual crimes and harassment, and some family problems such as marriage and divorce (Sirisi 2011, Turukman 2011, Alyat 2011). The committees negotiate between conflicting parties not only to solve the conflict but also, and more important, to create an environment of forgiveness, tolerance, and social cohesion that might prevent conflicts in the future (Turukman 2011, Sirisi 2011, Abu-Al-Haija 2011). Turukman (2011) describes the JCSC strategy of resolution in terms of the way that "running water," if it meets obstacles like rocks, does not stop flowing but finds a way to go around them. In the same way SCs do not give up, but maneuver around until they find a way to solve the conflict (Turukman 2011).

The purpose of creating an environment of tolerance and forgiveness in and among communities, especially in crisis conditions, is a key purpose towards promoting sustainable development. In fact such an environment encourages people to live 
peacefully together, protect their properties and businesses, and encourage them to do more. Additionally, forgiveness and tolerance help community leaders and members think together about protecting their resources in crisis conditions where resources are scarce or access to them is limited and the role of the state in managing public resources is weak. In this regard, Fakri Turukman, the chair of the JSCS indicates that this Sulha committee, since its establishment in 1987, succeeded in protecting thousands of properties and businesses (stores, farms, houses, land), public and natural resources (public water resources, grazing areas, public parks and buildings), and most important people's lives during crisis conditions (Turukman 2011). Since enforcing the rule of law is the main purpose of Sulha committees, in details, it addresses the three elements of sustainable development, social development, environmental and natural resources protection and economic development.

The Process at Work. The Sulha members start navigating toward a resolution when one party in a conflict approaches them to help in solving the conflict. However, in some cases, they immediately react by physically standing between the two parties of the conflict. They then begin negotiating with the parties to stop active conflict and give the $\mathrm{SC}$ an opportunity to investigate and find a resolution. For example, in the case of a death resulting from intentional or unintentional actions, the person responsible or a member of his or her family usually approaches the committee, briefly explains the nature of the conflict, and asks them to start the process of Sulha. The committee members, in turn, immediately step into the middle of a fight to prevent more conflict, protect people and property, and start negotiating with the apparently responsible party. 
Then they start collecting primary evidence, which might be listening to witnesses from both sides or talking to injured people (Turukman 2011, Sirisi 2011, Salah 2012, Zaid 2012). The immediate respond of Sulha men to people's needs is the protection of lives and properties and resources which is another example of the key role that SCs play as a sustainable development navigator in crisis conditions. The alternative, if there is no Sulha committees' in existence could be destructive to communities and their resources. In some cases where Sulha men were not able to quickly reach conflict sights, the result was more victims (including deaths), or loss of property, businesses and resources (Sirisi2011, Salah 2012, Turukman 2011).

Turukman (2011), the chair of Jenin SC, states that the Sulha process, after collecting the primary evidence, consists of four steps. First, the person responsible for the injury or conflict or those who represent him or her must accept that they are going to be responsible for the actions that led to the injuries that occurred, agree not to take further action against the other party or expand the tension, be willing to pay all the damages that must be paid and take all required actions that come out of a resolution, and accept the committee's authority to resolve the conflict. The damages can involve monetary obligations or can entail moral obligation such as a public apology and commitment not to do the mistake again, while material damages means all payments of expenses and compensation for losses caused to the victim.

The second step is following the Sulha tradition of doing the first Atwa, also called the searching Atwa. Atwa means: "refraining from violence and affirming calm for 
three days and a third ${ }^{4}$ by asking the victim or those who represent him or her to accept a kind of commitment not to try to take the right by hand and accept the committee to solve the conflict" (Turukman 2011).

In most cases, Atwa is announced in public in the mosque or in the cemetery especially if the case involves a death. A member of the committee stands up and announces that the conflict is under the control of SC. He names the committee members, and explains that the responsible person is admitting the crime and he and his representatives are going to pay all the damages. The speaker reminds people of the Islamic values of forgiveness and protecting the community from taking the matters into their own hands or in some way seeking revenge. During the three days and a third, the committee works hard to identify the boundaries of the conflict and how the resolution should be constructed. If there are some immediate expenses, such as medical bills, the committee asks the responsible party a third of the expenses and a commitment to pay the rest when Sulha completes its process and reaches a decision (Turukman 2011).

The third step is called the second Atwa. After the three days and a third, the committee comes back to the victim or his or her relatives and offers them the kind of resolution, based on the evidence they investigated, that the committee has developed, including all moral and material obligations that should be paid by the person responsible for the injury. In order to meet the victim's damages, it might be necessary, in some cases like sexual crimes for example, a public apology and a commitment that the

\footnotetext{
4 This is the traditional way of calculating the period of time. The Sulha members start contacting the responsible party but not before 10:00 am of the fourth day. During this period, SC members investigate and collect evidence to prove rights and damages and more important, reasons of the conflict.
} 
victimizer will never come to the neighborhood or street where the victim lives. Material rights might include a penalty, compensation for medical bills, property losts, or what is called in Islamic law the Diyya (amount of money that the responsible party must pay to the victim's family in cases of intentional or accidental death). The Diyya in some cases, if the victim has a big family including students who go to school, might reach JD 40 thousand (Turukman 2011, Alyat 2011, Abu- Al-Haija 2011). However, in unintentional fatalities such as car accidents, SC members are likely to negotiate hard to persuade the victims' family not to take the Diyya or to reduce the amount, especially if the person responsible is poor (Turukman 2011, Sirisi 2011, Abu-Al-Hayja 2011). The purpose of negotiating about the Diyya, according to most interviewees, "is to enforce forgiveness and social cohesion, and reduce economic pressure on poor families that may suffer for a long time because of unintentional mistakes". However, Sulha men, in many cases when the responsible party was unable to pay material rights, organize fundraising from the responsible party's tribe, to pay the victim's family especially if he or she left many children in the case of death (Turukman 2011).

In this regard, all participants of the case study agreed that "the purpose of negotiating with the two parties in a dispute, especially in cases involving a killing, is to give and accept forgiveness, even if both parties do not think that the case gave them an

\footnotetext{
5 The Diyya is mentioned in the holy Quran (chapter two, 178, chapter four, 92). Diyya was explained by Sunna (Prophet Mohammed's teachings) as: "it should be collected from the responsible party and his family or tribe and given to the victim's family...the amount is 100 camels. Today, it is about JD30,000 to 100,000"(see Abuzahra 1960). However, Quran (see the same chapters and verses above) encourages the victims family to forgive or at least reduce the Diyya. In another text, Quran explains that a non Muslim person who is living or visiting a Muslim land and is killed intentionally or unintentionally, he or she has the right to take the Diyya the same as a Muslim (see the Quran chapter four 92, see also Abu Zahra 1960, pp. 515-518).
} 
outcome that they think is correct or enough to remedy the impacts of the actions involved". (The relationship of SCs to social justice concerns will be discussed in the analytic section of this chapter.) The committee usually gives the victim party a week or two weeks to reply to them as to whether they accept or refuse the resolution package. During this time, both parties agree on an oral commitment, guaranteed by the elders, not to attack each other or act in a way that might renew the conflict. If the victim or his or her relatives accepts the SC resolution package, the SC asks both parties to prepare themselves for the Sulha event.

If the victim (or their relatives if there is a death) refuses the resolution package, the committee asks for another week. During this week, the SC works hard to identify and persuade those individuals who refuse to accept the settlement. Turukman (2011) explains that "in most cases the committee persuades the victim's party, but in some cases refusal happens because some individuals want to take revenge and some third parties may encourage them to refuse" (Turukman 2011). However if the SC fails to persuade one party or both, they tell both parties that the SC is withdrawing within three days; but during these three days they ask the responsible party to find another committee to start new procedures. All respondents in this research agreed that they keep negotiating hard until they resolve the dispute and persuade all parties. Even if they fail, they informally ask other SCs to help because the result, if no resolution is found, might be more victims and losses. It might mean a cycle of violence in the community that will harm many other people and the peace of the community. 
During the time between the first Atwa and the time of the Sulha (if the SC succeeds), the committee asks the police to keep the person responsible for the injury in jail if it is a matter subject to criminal law until the time of the Sulha unless he or she is committing an intentional killing that needs further court procedures (Turukman 2011). Once the committee solves all points of disagreements, they ask the two parties to sign the Sulha document. The chair of the SC takes the document to the court, if the case is in the court, in order to take the steps necessary to release the responsible person from jail (Turukman 2011).

The fourth step in the process is the Sulha celebration. This celebration is a public event where all community members, including the parties that were in conflict gather in one place, usually the mosque or any open space such as public schools yards. The committee also invites other SCs' members and local leaders from different communities, police representatives, the county governor, Jenin city representatives, and political leaders. The celebration starts by reading some verses from the Quran. Then the chair of the committee gives a short speech thanking the injured party for cooperating to solve the conflict and reaffirms the importance of forgiveness in promoting civil peace. Then he asks the party responsible for the injury to apologize in public for his action and to hug the victim or his family members, declaring that the conflict is over and replaced by forgiveness. Traditional Sada coffee is served for to all who attend (Turukman 2011). In critical cases, such as intentional killing and sexual crimes, the $\mathrm{SC}$ acts fast to protect and remove the alleged perpetrator and his or her family out of the hot spots. They usually send him/her to the nearest police station and resettle his/her family in 
another community far from the conflict spot until the matter is resolved. This action is a protection guarantee for the lives of those responsible for the problem and their families at the time of what is called a Blood Feud (anger reaction) (Turukman 2011, Alyat 2011, Salah 2012, Sirisi 2011, Zaid 2012). Turukman (2011) states that: "In the past, removal used to include, besides the victimizer's family, his father, his brothers, his uncles and relatives up to the third level. Today SCs have reduced removals to include the victimizer and his family only (Turukman 2011). However individuals' removal creates a contradiction between the Palestinian law and the traditional SC actions. (This issue will be discussed later in the analytic section of the chapter).

The previous discussion indicates that Sulha pattern is an indigenous set of activities that lead to supporting the rule of law in a way that takes into account the social, economic and environmental (resources protection) needs of people. From a sustainable development perspective, all activities of the Sulha process, from the time when the Sulha men step in the middle of a conflict to the time when people celebrate the Sulha, has two purposes: A short term purpose of protecting the current generation's needs. It also has a long-term purpose of promoting social cohesion that protects the needs of the future generations. These purposes interestingly agree with the most common definition of sustainable development (the Brundtland Report definition) presented previously in chapter two.

Where did the Idea of SC Come from? There are two perspectives about the origin of the SC method of conflict resolution (Birzeit Institute of Law 2006, p. 40). The first one 
argues that the Sulha process comes from Ashairi $^{6}$ (tribal) justice system which existed in the Arab area at the time of the Turkish Empire. At that time, Palestine was under the jurisdiction of what was known as the State of Damascus (now it is the capital of Syria), which is where the regional central state government and courts used to be.

Supporters of this view argue that three reasons might be behind the forming of the Ashairi justice system in the Arab region, including the use of Sulha committees (see Birzeit Institute of Law 2006, p. 40). First, the geographical expansion of the Turkish Empire, from the Balkan Peninsula to Africa to middle and south Asia, created a lack of central control of the Turkish government over far areas. Second, regional rebellions against the Turkish central government in many places such as Yemen, central Palestine (Nablus and Hebron mountains) pushed people at that time to find an alternative justice system to resolve civil conflicts. Third, the weakness of the Turkish Empire in the aftermath of WWII led to a loss of control by the central government over many regions which encouraged local leaders in the Arab area (especially Palestine and Jordan) to establish their own justice system, depending on indigenous culture that used to play a key role in decision making for tribal leaders (Birzeit Institute of Law 2006, pp. 40-41).

The second perspective considers that the origin of Sulha came from the Bedouin communities that lived in southern Palestine in Hebron and Bir Assabi. Bedouin communities were nomadic and moved around within a large region in the desert that includes what is now Palestine, Jordan, Syria, Egypt, and Iraq. Those communities

\footnotetext{
6 The term Ashair is another term that has the same meaning of the term tribes. Ashair is used in Palestine, Jordan Syria, Lebanon and some parts of Iraq while tribes is used in Yemen, Arabia and the gulf area, Egypt, Sudan and North Africa.
} 
governed themselves by their tribal system, which was led by tribal leaders (Birzeit Institute of Law 2006, p. 41, Turukman 2011). They needed a way to resolve conflicts that was flexible and could operate in different places at different times.

The debate about exactly how these various historical forces brought about the concept of Sulha as it is known in Palestine today continues. Fakri Turukman, chair of the JCSC, accepts that all these reasons noted above might have played a role in the development of Sulha, but what he learned from his father, who was formerly a member of a Sulha committee, the idea came from a Bedouin tradition (Turukman 2011). AbdAl-Razzak Abu- Al- Hayja, member and coordinator of the JCSC, believes that the Sulha pattern existed from the time of the Turkish Empire (Abu-Al Hayja 2011). Most Palestinian communities today are not Bedouin, but they use SC pattern to solve their civil and criminal conflicts. This long term existence and operation in conflict resolution indicates that the SC pattern has power and carries with it a sense of legitimacy based on the that fact that it is grounded in the culture of the region and its people.

In terms of a sustainable development approach, it is important to say that indigenous patterns such as Sulha committees have been functioning well over many generations and are still functioning to meet the needs of the current generation. The key point here is not only sustainable in terms of time but also sustainable because it pays balanced attention to the social dimension, economic dimension and environmental dimension. Turukman (2011) argues that big conflicts such as community- to community or tribe conflicts could cost, besides deaths, millions of dollars if it turns into mass revenge through burning houses, farms, property and businesses. More critically, it 
may destroy non-renewable resources such as water wells, olive trees, farm animals that usually sustain poor communities (chapter three and four addressed cases that indicate how important these resources are to Palestinian communities living in crisis conditions). Additionally, individuals, families, tribes and communities need many years to recover, start normal life, and re-enforce the rule of law after such conflicts.

Development of SC Pattern: From the British Colonialism to the PNA. Though the idea of Sulha has continued to be important over a long history, there have been developments in recent decades. They include the situation during British colonial rule, the period of Jordanian rule, the period from 1967 to the first Intifada in 1987.

The British colonialism authority (1917-1948) that followed the Turkish governance in Palestine after WWII legally authorized the Ashairi (tribal) Sulha System. Organization of the Ashairi Sulha was included in Article 45 of the Executive Order for the Palestinian Constitution of 1922, Article 2 of Origin on Ashairi (tribal) Law of 1937, and Law number 47 for Prevention of Crimes among Ashair (Tribes) 1935 (Al-Wakai AlFAlastenia, 1935, 1944). These laws indicate that the British colonial government at that time respected the practice of the Ashairi system in many parts of Palestine. It was also a way to try to control the Palestinian people through indirect control of tribal leaders by co-opting the existing dispute resolution system.

The situation changed during the period of Jordanian rule from 1948 to 1967. The West Bank was joined to the Hashimic Kingdom of Jordan after the 1948 war and that was formalized in 1950 after the Jericho Conference (Birzeit Institute of Law 2006, p. 42). At that time, the Jordanian justice system included laws that organized the tribal 
justice system such as the Law of Bedouin Affairs of 1929 and Law of Bedouin Affairs of 1936. However, these laws were limited to Bedouin communities in Jordan and not implemented for people of the West Bank.

Birzeit Institute of Law (2006) explains that the Jordanian government controlled the West Bank by active executive deportments of police and courts that had been in use in the rest of the kingdom. The Jordanian authority replaced the laws from the British colonial period with laws that organized Ashairi affairs and instead created the Department of Ashairi Affairs. It was directly connected to the king's office (Birzeit Institute of Law 2006, p. 42).

Turukman (2011), who was a young man during the Jordanian governance, comments on the Sulha system under Jordanian control, saying that "King Hussain wanted to keep good relations with tribal leaders from both the West Bank and the East Bank but without laws that organized their work, it was a matter of containment. That is why he stopped applying laws that were applied before in the West Bank and replaced it with the Department of Ashairi Affairs" (Turukman 2011). The matter of containment of tribal leaders was a political issue rather than a matter of enforcing the law. Containing the West Bank conflict resolution affairs to the Department of Ashairi Affairs was part of the loyalty of Palestinian tribal leaders to King Hussain of Jordan (Turukman 2011, AbAl-Haija 2011). However, in the aftermath of the 1967 War, Israel took over the West Bank and Jerusalem, which led to a very different kind of containment place during the Israeli occupation period. 
With the coming of the occupation and until the first Intifada in 1987, the use of SCs reduced. However, based on security policy considerations, Israel has encouraged and supported any SCs or indigenous leaders who accepted and helped in applying the Israeli policies in the territories. At the same time, those who did not accept or cooperate with Israeli policies were excluded and sometimes arrested (Turukman 2011).

Since the beginning of the Israeli occupation in 1967, the West Bank has been controlled by executive military orders (see for example the Executive Military order number (2) 1967, Executive Military Order number (412) 1970) that gives the West Bank military governor and his assistants the complete power to control the Palestinian affairs in all dimensions, including health care and education. The two orders cited above regulate the jurisdictional system and courts in the West Bank in a way that directs Palestinian people to go to civil court to resolve their civil disputes. Civil courts in Palestinian territories are Palestinian courts, but controlled by Israeli judges and in very limited cases Palestinian judges appointed by the Israeli military governor. This situation caused Palestinians to reject the legitimacy of the courts and avoid approaching the courts, even though some of the judges were Palestinians. More important, this led to the search for what some Palestinians called a "national alternative." That alternative turned out to be the Ashsairi Sulha System.

The attempts to influence the SCs' role by those who were interested in containment (the British, and the Jordanian governance), or interested in rejecting and removing SCs (the Israeli governance), or supporting SCs' role (the Palestinian governance) are evidence that the SCs' role has been key in Palestinian life. It is also an 
evidence of the key relationship between indigenous knowledge and sustainable development as the pattern continued to function despite crisis conditions in attempts at containment or prevention. In this regard, Turukman (2011) states: “I am, and all Palestinians should be proud of the SCs work because what was functioning hundreds of years ago, is still functioning now and will function in the future". The question of the validity of the Sulha pattern for different communities in different stages of time is a matter of actions proved by experience. According to those who inherited it and experienced it on the ground, it indicated positive outcomes.

Birzeit Institute of Law explained that the "Palestinian Liberation Organization (P.L.O.) between 1967 and 1987 supported the role of national Sulha leaders who were known for not being connected to the Israeli occupation and having positive roles in their communities" (Birzeit Institute of Law 2006, p. 46). Additionally, the P.L.O considered the role of SCs as part of Palestinian efforts towards liberation (Birzeit Institute of Law 2006, p.46). Accordingly, Sulha conflict resolution started to expand and took place in almost all Palestinian communities, but they were still not well organized into committees as they are today (Turukman 2011). Turukman adds that the Israeli political pressure and the P.L.O. support for SCs laid the foundation for the "golden period in SCs history" during the first Intifada that started in 1987 and stopped in 1993 (Turukman 2011).

The First Crisis: The First Intifada (1987-1994) and the Establishment of JCSC 
Several historical factors, some of them mentioned above, contributed to the creation of the Jenin Central Sulha Committee, the focus of this case study. The discussion to follow focuses on the development and operation of this SC. This committee exemplifies how indigenous Sulha pattern of conflict resolution enforces the rule of law in crisis conditions and how that promotes sustainable development.

All Sulha committee members interviewed agreed that this period was "the distinguished period" when indigenous leaders organized Sulha patterns through "organized committees," including what became the Jenin Sulha Committee which was established in 1987 (see also Birzeit Institute of Law 2006, p. 46-47). Although the committee was created at that time, it went through a lengthy period of development into the form that it has at the time of this research.

Despite the fact that the period of the first Intifada (1987-1994) was a specific crisis on top of the ongoing crisis in Palestine, where thousands of men and women were killed, arrested, or injured, and houses and businesses were destroyed, there were a number of internal conflicts between tribes or communities within the Palestinian society that called for action by SCs. The JCSC was a very important participant, and probably the only one, in the efforts to address those conflicts and enforce a certain kind of rule of law (based on Sulha rules) during a conflict period. The JCSC was one of the most active and successful SCs. There were disputes in the city of Jenin, in the refugee camp located near the city that housed 15,000 people, and in 20 rural villages in the district. In 1988, JCSC had a challenging time trying to cover the whole Jenin County. The committee started helping local leaders in the city, the refugee camp, and the rural areas to establish 
local SCs. Some had already established their own SCs (Turukman 2011, Sirisi 2011). These minor SCs, although they cooperated with JCSC, took responsibility to solve local conflicts within their areas only. In critical cases involving a death or when one of a conflict parties was from outside Jenin district, cooperation with JCSC was key. The JCSC under the PNA Governance: New Kinds of Challenges. At the end of 1993, Yasir Arafat, the former president of PNA, asked the Jenin Sulha Committee members to expand the committee by adding more members and then to take a lead role in conflict resolution in the West Bank. During 1993, Arafat was interested in preparing a stable civil order before taking over civil responsibilities in the territories (Abu AlHaija 2011, Turukman 2011, Sirisi 2011, Salah 2012). The committee added more indigenous leaders, increasing to 17 formally designated members. The word central was added to the name of the committee when it became the Jenin Central Sulha Committee (JCSC) because of its increased role and importance. The core work of the committee at that time was to resolve critical problems and help other communities' SCs in their effort to address their problems.

All interviewees in this research indicated project that the PNA encouraged Sulha committees which were already established in Palestinian communities and supported their role. In addition, PNA executive agencies, the police and other security forces, have helped to enforce Sulha committees' decisions. In fact, former PNA president Yasir Arafat signed Executive Order number 161 (1994) that directed Palestinian executive agencies to implement Sulha committees' decisions and cooperate with them in all 
aspects (President Yasir Arafat 1995, p.34). The current members of JCSC commented about the exceptional support that PNA offered to SCs.

The PNA support for the JCSC and the other SCs comes in part because of the way that the Palestinian territories are divided up in terms of governance. According to the Oslo Agreement (1993) and the Oslo Implementation Agreement (1995), the Palestinian land in the West Bank is divided into three zones: Zone A has complete civil, administrative, and security control by PNA; Zone B has Palestinian civil and administrative control by PNA but security control by Israel; and Zone $\mathrm{C}$ has complete civil, administrative, and security control by Israel. Palestinian agencies, including the police, have no authority to work in Zone C. The JCSC and other SCs function in those areas where the PNA does not have control (Turukman 2011, Shaik Sirisi 2011, salah2012, Zaid 2012).

During the 1990s JSCS had to face the first test in functioning under Palestinian governance after surviving and functioning well during the extremely critical time of the first intifada. Many JSCS members (Turukman 2011, Salah 2012, Sirisi 2011, Alyat 2011) expected that less people would use the Sulha practic to solve their disputes because of the improvement in the civil peace level during the first period of PNA governance between 1993 and 1998. For the first time, the Palestinian legal system became operational (police, other security forces, courts and judges), although it did not have complete authority, to work in Palestinian jurisdictions. Nevertheless people continued to trust SCs and approach them to solve their conflicts. In this regard, Turukman (2011) argues that "JCSC routine cases did not decreases; people continued to 
come to us rather than going to courts. However, we struggle with new kinds of challenges because some people tried to use their connection to PNA agencies to the influence or even refuse JCSC decisions". As mentioned in the previous two cases of this study, the case of the JCSC emphasizes that trust is a crucial factor in building sustainable development. Trust positively influences community peace and people's readiness to contribute to sustainable development. (The influence of SCs in trust building is discussed in the analytic part of this chapter.)

JCSC Stands Firm against Containment Tries. Even though the respondents discussed the PNA support for the JCSC, they also indicated that one of the most important accomplishments is that it has maintained its independence and resisted any efforts by the PNA to control it. Starting in 1997, there appeared to be efforts by the PNA to do that (Salah 2012).

Also, members of the JCSC indicated in the interviews that the period between 1996 and 2000 was a time in which there was concern about corruption and also about the possibility that there would be efforts to politicize the role of SCs or to have them be completely dependent on the PNA agencies and the Fatah Party in particular. A member of the JCSC states that the committee refused to have a formal office in the Jenin County building because it could have affected the reputation of the JCSC for acting independently and therefore might have affected the way its decisions were perceived in the community. Accordingly, some SC members believe that during this period, people continued to approach SCs such as JCSC because of the accountability and independence 
from other influences that distinguished its members in the community. Other members believe that people during this period decreased approaching SCs was because of the increasingly active role of formal justice system organizations, including courts and executive agencies. Despite these developments, people continued to approach SCs especially those known for their independence in decision-making like the JCSC.

The tendency of JCSC members to keep the committee independent and their concerns about corruption and political exclusion generated by political polarization is evidence of concern as to the ethical feasibility of sustainable development (see Cooper and Vargas 2004, ch. 8). Corruption and political exclusion and discrimination are dangerous factors that interfere with sustainable development efforts. In this regard, most JCSC members argue that the independent status of their committee was a strategic decision that gave the committee more reliability, created and promoted trust among the committee members and people in different communities, protected the committee's decisions from "outside" influence, and resulted in fairer decisions and outcomes.

The Second Crisis: The Period of the Second Intifada (2000-2005). All JCSC members describe this period as the worst in their history because of the Israeli invasion of the PNA zones and the separation of cities and villages from each other, the spread of weapons in the hands of many people, and the complete absence of the rule of law. Courts were shut down and cases accumulated without resolutions. This situation was very challenging for JCSC because the committee had more people approaching it to resolve their conflicts, but the JCSC members had no flexibility to move to and from Palestinian communities or any means to implement their decisions. Turukman (2011) 
states that during this period, committee members had to risk their lives to reach communities and resolve disputes. Sometimes they had to sleep over night in order to finish a case instead of navigating back and forth for many days.

Due to the cooperation between the JCSC and other local SCs in different villages and towns, the Sulha pattern continued to function during the conflictive period. Responding to the security challenge and lack of access to many areas, JCSC expanded, depending on local leaders to help in making Sulha work. They authorized local leaders who were members in local SCs to resolve cases. In many instances, Indigenous leaders had to speak on behalf of the central committee to give the decision-making process more authority. (Turukman 2011, Sirisi 2011, Salah 2012).

On the other hand, during this second Intifada, critical conflicts such as revenge killings between families and members of different tribes and sexual crimes had reduced compared to individual and more routine disputes. Abdel Razak Abu- Al-Haija, the coordinator of JCSC, attributed this difference in the nature and number of disputes to the state of crisis in Palestinian communities at the time. Also, respondents noted that the military campaigns that Israel implemented against Palestinian territories unified people and led them to step back from serious personal conflicts while less serious individual disputes continued (Abo-Al-Haija 2011).

Again the JCSC experience during the second period of extreme crisis conditions (the second Intifada) indicates that trust is a key factor in sustainable development efforts. Trust during this period is exemplified in the relationship between the JCSC and local SCs which had to take responsibility to solve their area's conflicts, even critical ones 
(Turukman 2011). This confidence among SCs enabled Palestinian communities to sustain an acceptable level of rule of law under crisis conditions.

The other aspect of trust that deserves attention during this period is trust between the JCSC and the PNA agencies, especially courts and police departments. The JCSC members (2011) state that because of the destruction that affected courts and police departments,_buildings, security operations, and judicial services were shut down. There were no police departments working. Prisoners were released under warrantees of Sulha men to protect them from Israeli attacks against PNA agencies' buildings. Information about cases was released to Sulha men. Prisoners signed agreements that they would cooperate with Sulha men and listen to their advice in order not to create more conflicts and later, when security conditions improve, would submit to PNA legal decisions (a member of JCSC 2011). The actions of the JCSC during this crisis indicates high level of flexibility and capacity to adapt and respond to critical challenges dependent on trust built in the community which is a key factor to sustainable development.

The JCSC in Recent Years: 2006-2011. According to JCSC members, the period following the second Intifada has been affected by two key events, the internal division between Fatah and Hamas and the arrests and political exclusion that each party (Hamas in Gaza and Fatah in the West Bank) carried out against the other. The other issue was the intention of the PNA to enforce the rule of law as part of its political agenda in the aftermath of the political division and as part of its commitment to the international peace process (see The International Quartet 2002). 
Turukman (2011) argued that Sulha committees stayed away from the political problems (arrests and political exclusion) that resulted from the political division between Hamas and Fatah because these were issues that should have been approached only by PNA security agencies. Neither the JCSC nor the PNA agencies wanted SCs to address political issues (Turukman 2011). However, the PNA continued to support the role of SCs in conflict resolution in other civil issues much more than any time before. Turukman (2011) and Shaik Sirisi (2011) talk about a partnership between the JCSC and the justice system in the district, including the police, the courts, the governor's office and other security agencies. For example, Shaik Sirisi says that "the committee responded to a critical conflict that happened in 2007 in Jaba' Town located to the south of Jenin. There was a murder. We went to the site and evaluated the situation. It was very dangerous. We called the governor and told him to send an emergency police force to protect families and houses as some angry young men were trying to burn the houses after seeing their brother's killed" (Sirisi 2011).

Additionally, in murder cases, there is a policy in the formal justice system that the judge has the flexibility to reduce a sentence to one third of the years of a jail sentence for a criminal offense if SCs can bring about a Sulha agreement between the two parties and prevent revenge. Once the Sulha document is signed, the judge can reduce the sentence (Turukman 2011). Despite partnership and cooperation, some of the JCSC members argue that still there are political challenges especially depending upon who the parties to a conflict are and what type of conflict it is. 
The JCSC is an example of on indigenous conflict resolution pattern that has succeeded in dealing with crisis condition challenges and enforcing the rule of law. Sulha pattern as successfully implemented by JCSC has not only protected lives and created social cohesion and trust within and among communities but also protected people's properties, businesses and resources. The following analytic section discusses the role of indigenous Sulha pattern, exemplified by the JCSC, in promoting sustainable development from the community level in crisis conditions.

THE POWER OF INDIGENOUS KNOWLEDGE FOR BUILDING SUSTAINABLE DEVELOPMENT FROM THE COMMUNITY LEVEL IN CRISIS CONDITIONS: AN ANALYSIS OF THE JCSC CASE

While this case is different in many ways from the previous cases, and has a particularly strong focus on the social dimension of the living triangle of sustainable development, it is also important if sometimes in indirect ways for economic development and protection of the environment. While it is very important to the social order of the community to get resolution to important conflicts, it is equally important to any kind of economic development to be able to resolve important conflicts that in many cases are about property and economic interests. It is also the case that the lack of legal feasibility, especially in crisis conditions, means that care for the environment is undermined. The existence of a rule of law that provides incentives for proper care for the land and its productive capacity as well as other resources is key. The analysis of the case shows how the indigenous knowledge-based conflict resolution process of the JCSC addresses the critical role that SCs represented in building social cohesion and 
forgiveness in communities living under crisis conditions. That social cohesion, in turn, plays an important protective role in providing a foundation for issues affecting the environment and the economy of these communities. This section of the chapter analyzes the JCSC in order to understand the way in which indigenous knowledge has been used in this community level conflict resolution process under crisis conditions to help promote sustainable development.

Strengths of JCSC Conflict Resolution Pattern: Responding to Critical Problems and Promoting Legitimacy for Sustainable Development Efforts

This section discusses four strengths of Sulha committees as promoters of sustainable development in crisis conditions from the community level. First it discusses strengths of the pattern from the perspective of respondents (JCSC members). Second, it addresses the capacity of the pattern to respond sustainably to critical problems. Third, it discusses the capacity of Sulha pattern to integrate the three elements of sustainable development. Finally, it discusses legitimacy of SCs and its capacity to promote legitimacy to sustainable development efforts.

Strengths from the Perspective of the JCSC Members. Most members have lived under four kinds of governance; the British, the Jordanian, the Israeli, and the PNA governance. None of these governances promised anything like sustainable development. They did not lead to economic development, social development, or environmental protection.

The respondents here talked about how the use of the Sulha, which is an indigenous process in which indigenous leaders transmit the pattern from one generation 
to another, has helped communities to move ahead. All participants also agree that the SCs pattern is accepted by all sectors of Palestinian communities, including the poor, the rich, educated, urban, rural, refugees, men, and women. Also important to the success of the Sulha process is the fact that in most cases, the elders in communities play key roles. Elders usually are the ones who approach SC members to start the Sulha process and they (elders) also negotiate to reduce tensions and bring about compromises or resolutions. Turukman (2011), chair of the JCSC, and Abu-Al-Haija (2011), coordinator of the committee, argue that in most of the cases that their committee took in its 22 years of work led to "sustainable peace." No more violence or dispute followed the Sulha solution and conflict parties returned to normal relationships with each other.

Additionally, the parties in only a few cases rejected the committee's proposed resolutions, but later, after going to the court, many of those parties returned to the Sulha committee and accepted its resolutions. Abu-Al-Hayja (2011) explains that people go to the courts because, at the beginning, they think they will get more support or what they think will be fairer resolutions, but soon they discover that the courts take a long time, cost them more, push them indirectly to go back to the Sulha process, and do not promote forgiveness among parties. Pushing conflict parties to do Sulha means that "the judge asks the two parties whether or not they tried to make Sulha.... Some judges ask them directly to try to do Sulha. If they agree, the judge gives them a chance to contact their relatives or for Sulha members do so" (Abu-Al-Haija 2011). Therefore, SCs' resolutions are not only accepted by people, but also accepted by the legal system of the country. From a sustainable development perspective, people's acceptance of the Sulha process is 
not only a sign of strength of this cultural practice but also a sign of supporting the rule of law. The case indicates that enforcing the rule of law in turn leads to integrating the three element of sustainable development.

\section{The Integration Process: A Special Focus on the Social Dimension and a Protective}

Role for the Environment and the Economy. Although it may seem as if the emphasis in Sulha is on social development, there is integration of the elements of sustainable development. Not only does the protective role that JCSC plays protect civil peace and promote social cohesion, but that foundation and ability to resolve disputes also protects the environment and local economies of communities.

The JCSC members believe that civil violence in the past, particularly before the 1987 (the start of the first Intifada), had a high price to communities, besides deaths and injuries, more than the present. Turukman (2011) and Sirisi (2011), the eldest members of the committee, argue that some extreme civil violence cases, especially violence between Ashair (tribes) and communities, used to lead to extreme emotional duress or what is called blood feud revenge. Blood feuds led to killings, burning of houses or sometimes complete neighborhoods, burning farms, killing farm animals, and cutting trees and destroying natural resources such as underground wells. These acts cost millions of dollars and wasted peoples' efforts in addition to the negative influence on the social fabric of communities. The lost efforts included work aimed at building social cohesion, creating a clean environment, and providing sustainable livelihoods for many families and communities. Turukman (2011) states that in hundreds of cases the JCSC have 
rescued olive trees, underground wells, farms, animals, stores, and properties from being destroyed.

For example, in a critical case that happened in a village near Jenin, two brothers were intentionally killed during a huge quarrel between two tribes, the victims family wanted to destroy not only the responsible party's properties and kill his wife and children, but also all his tribe's properties including farms houses and animals. A third party called JCSC; we arrived in 15 minutes to the site, divided ourselves, with the help of other volunteers into small groups and physically rescued families, and animals, and protected properties from being destroyed. We called the police but they came late. In other sites such as Zone $\mathrm{C}$, the Palestinian police cannot come... we have to fill the gap by seeking help from local SCs and local religious and indigenous leaders.

This protective role that the JCSC and other SCs play in their communities not only protects resources and properties, but also promotes social cohesion and builds tolerance in the community necessary for a healthy local economy. If people are not secure and the community lacks social cohesion, neither business properties nor public resources will be safe. According to all JCSC members, the top priority is to rescue people and protect their property and resources, and then to build forgiveness between those involved in the disputes and to enhance social cohesion.

Sustainable Responds for Critical Problems. The JCSC acts fast and collectively to prevent what have sometimes been catastrophic consequences of civil violence and to promote sustainable resolutions to critical problems. Additionally, the committee's members use their social positions to enforce those resolutions. In the past, critical cases, especially those that led to blood feud revenge, cost communities many victims, not to mention loss of property and other resources. 
Many JCSC members explained the success of JCSC in part because the committee is currently more organized and has more influential and strong members than before (for example Alayyat 2011, Turukman 2011, Salah2012, Zaid 2012). A strong SC is the one that is able to respond to conflicts rapidly and reduce the cost of the conflict even if they cannot prevent it. The immediate and physical response of JCSC members to disputes, especially in critical cases, is an important element in reducing the cost of the resolutions that are eventually reached, keeping disputes under control, as much as possible, and ensuring that they last over time. The JCSC success in preventing catastrophic revenge reflects the state of respect and acceptability of the committee among communities. It is important to mention that the committee members are volunteers whose legitimacy comes from their social positions and from their care about civil peace among communities.

\section{Legitimacy of the Sulha Process: The Power of Social Position and the Power of}

Words. Part of the success in reaching and then enforcing Sulha solutions is the fact that JCSC members use their social position as well as their knowledge of local customs, religion, and civil law. Most of JCSC members learned Sulha customs from their fathers (Turukman 2011). Sirisi (2011), one of the JCSC members who inherited Sulha knowledge from his father, points out that Sulha customs are not easy. They connect customs which should not contradict with Islamic (Sharia) law and civil law. In addition, the Sulha process requires patience and a well developed ability to listen as well as an ability to negotiate (Sirisi 2011). Abu-Al-Haija (2011) adds that besides knowledge in 
customs, Sharia' and civil law, SC members have to use their "power of words" to reduce tension in critical moments and start Sulha resolutions. He states that

When we enter physically into the middle of a violence event, we have to make true commitments that we are going to bring victims rights even before we talk to the responsible person. Sometimes if we are not physically there, we ask a third party to declare in the mosque or on the cemetery that JCSC, mentioning our names, gives condolence to the victim party and asks for three days an a third Atwa. Once this commitment is taken on our behalf, we have to make every possible effort to make it turn out right. That is how we created our reputation for truthfulness and legitimacy (Abu-Al-Haija 2011).

Turukman (2011) argues that sometimes, in order to achieve civil peace and prevent critical violence, they face not only physical risk but also thousands of JDs in financial risk. Yet they have to fulfill their commitments to keep the reputation for truthfulness and legitimacy of the JCSC (Turukman 2011). In this regard, it is important to remember that SC members are volunteers who, in many cases, spend weeks or even months of negotiations to accomplish a Sulha settlement. This effort reflects on the legitimacy of the committee. However, JCSC members talked about some other sources of legitimacy, such as age of members, their education level, their material position (richness), their tribe's size, their political background, and their social (career) position. These elements are part of the kinds of values that are important to the indigenous culture of the area and therefore contribute to legitimacy of the process and the increased social cohesion that results from the use of Sulha.

Age of Members. All JCSC members indicated that the age of members of any SC is important. It is not common for young men to join SCs. That is because it is the nature of Palestinian society to respect elders, and respect is part of accepting the Sulha pattern 
and its resolutions. All JCSC members were born before 1940, while three of them were born in the 1930s. Turukman (2011), 78 years old, states that during the 20 years of his serving in JCSC, he has never met a SC member whose ages less than 60 years old. Besides respect, "the age of members is supposed to qualify members to know the customs of Ashairi Sulha and to know the "wisdom and art of negotiations" while dealing with complicated issues such as bloodshed and mass violence" (Turukman 2011). It seems that the wisdom of the Jenin SC is embedded in the patience of its members in the way they deal with very complicated cases and negotiate hard with different people in critical moments. It is the kind of wisdom and patience, Palestinians believe, that comes with age.

Educational Level of Members. Although sometimes SCs have to deal with civil law matters, many SC members have little or no formal education. However, the JCSC members have a diverse range of education. The committee at one time had seventeen members. The eldest of them, those who have died or retired because of sickness and old age, tended to have only elementary education or even no formal education at all. Of the seven current members, four of them have university BA degrees and three of them completed middle school level. However, all JCSC agree that education is not a "big issue" in their work as SC members, but sometimes it is a credit to the SC if the member has other attributes, especially knowledge in traditional customs. The findings in a study by Birzeit Institute of Law (2006) supports the notion that formal education was not an important point and indicated that the most common education among SCs was Islamic studies and education. Their survey included 44 SC members from the Gaza Strip and 
the West Bank of which 14 members responded that they had elementary education, 12 had a university BA in Islamic studies and education while the rest of them had different levels of education (middle school, high school or BA in other fields). Turukman (2011) and Abu-Al-Haija (2001) argue that while in some cases they have to ask the help of experts (engineers, accountants, courts clerks and judges), knowledge in customs, Islamic rules, and civil law comes from experience (Turukman 2011, Abu-Al-Haija 2011). In the end it appears that the legitimacy of the JCSC is partly influenced by the education of members and particularly by their knowledge in traditional customs, Sharia law, and civil law.

Material Position of Members. All respondents agreed that both the "material position" of the members of the SC and their tribes' size is important for the legitimacy of Sulha members. For example, Sirisi (2011) states that poor people cannot be Sulha men because they cannot afford the expenses of this kind of voluntary work. The JCSC members usually pay from their own pockets all expenses needed to work out the Sulha settlement, including travel expenses, communication expenses, food and invitations, and sometimes even a part of a Sulha settlement's most controversial costs (Sirisi 2011). Turukman states that: "Sometimes, I have to write checks for thousands of JDs to prevent a critical violent event. After that, I have to investigate the case. If parties refuse to pay or cannot pay, I have to be committed to my word and pay out of my own pocket. I cannot damage my own reputation because of money" (Turukman 2011). The JCSC members usually have Madafa (a large hall in their houses) where they can invite and welcome hundreds of visitors during Sulha events. If visitors are from the same 
community, coffee is enough to welcome them, but if they are from other communities, coffee and food should be served according to traditional customs. This, of course, adds more expenses that $\mathrm{SC}$ members have to be ready to pay. For most Sulha men, their material position ranges between excellent and good (Turukman 2011, Sirisi 2011, see also Birzeit Institute of Law 2006, p. 85).

Size of Members' Tribes. The size of the Ashirah (tribe) is an important factor in providing social and material support to SC members. For example, "when members have to physically intervene between two conflicting parties to stop fighting, they use strong young men from their tribe to support them and protect families and property." Turukman (2011) argues that small or weak tribes cannot play this role.

The number and social position of men who participate in Sulha negotiations and celebrations is also a critical factor in enforcing resolutions. It is true that Sulha committee members lead negotiations between the two conflict parties, but they do not act alone. Usually they visit conflict parties in what is called in indigenous custom a Jaha; a group of men who are known to be socially acceptable and influential in their communities. Turukman (2011) argues that a "heavy" Jaha a large number of socially influential men means more legitimacy and more likely enforcement to the settlement. This large group of men is considered as a group of witnesses that socially evaluate the behavior of conflict parties in terms of cooperating in promoting forgiveness and tolerance.

Political Background of Members. All JCSC argue that the state of independence of any SC is important for members' work and adds to the acceptability and legitimacy of 
their actions. Even those who have a political background prefer to hide it because they are part of a SC. All JCSC members who participated in this study introduced themselves as independent members and denied any connection to political parties. Birzeit Institute of Law study also found that all Sulha men interviewees denied their political connection to any party and indicated that they are independent social volunteers (Birzeit Institute of Law 2006, p. 84).

Political independence gives SC members more of a reputation for truthfulness and legitimacy in part because of the likelihood of conflicting parties being either politically involved with Hamas or Fatah. Several JCSC members argued that SC members who were clearly holding political positions did not succeed as SC members and left the group. For one thing people would not approach them. Their resolutions are considered biased and other more independent members do not cooperate with them. Professional Position of Members. The professional positions of JCSC members play a key role in increasing the committee's legitimacy. For example, Abd Al-Razak Abu-AlHaija, the coordinator of JCSC, has worked as Jenin camp manager for fifteen years. Now he is an administrator in the department of religious affairs in Jenin County. He states that his position in both jobs increased his "positive social influence in the society and added more respect to his position as a member in JCSC. He uses his relationships as a manager and administrator to serve the purposes of JCSC, not the opposite (Abu -AlHaija 2011). Fakri Turukman, the chair of JCSC, has worked as a school principal for 20 years. He has been socially and politically active. He was elected in 2005 to the Palestinian Legislative Council (PLC). This social position, according to Turukman, 
added more social power to the JCSC in terms of acceptability not only in the Jenin District but also in the West Bank. Turukman states: "When there is a critical problem, I contact more indigenous leaders and PLC members to volunteer with us to overcome the critical moments, especially at the beginning. We focus our efforts to help people overcome difficulties through tolerance and forgiveness because revenge leads to more difficulties.... Our words and visits make a difference in communities" (Turukman 2011).

Legitimacy of the Sulha pattern is derived from indigenous customs that are also enforced by Islamic rules. This legitimacy reinforces and enhances the work of Sulha members, as the case of the JCSC indicates. On the other hand, the indigenous Sulha process provides legitimacy to sustainable development efforts in terms of encouraging people to respect, accept, and support such efforts. In this case, support and regard are represented by enforcing the rule of law that leads to sustainable social, environmental, and economic development.

Positive Outcomes for Local Communities: The Debate over Social Justice. Positive outcomes from the Sulha process for local communities enhance the sense of social justice and contribute to sustainable development. All participants agree that the principle of the SC process is promoting forgiveness and tolerance among communities. The research team asked participants if they believed that SC solutions achieve social justice among communities. Their answers were that the basic point is to get to "forgiveness and civil peace" which, according to them, leads to social justice. Some of JCSC argued that the principle of "forgiveness and civil peace" is more important than 
social justice in crisis conditions (Sirisi 2011, Turukman 2011, Zaid 2012). For example Sirisi (2011) argued that the focus of the SC process on forgiveness in turn leads to social cohesion, and at the end an acceptable level of social justice may be achieved. By Sulha solutions, both parties get some of their rights but the goal is not only rights but also and more important fostering forgiveness and fixing peoples' relations that were negatively influenced because of the conflict (Sirisi 2011). In addition forgiveness and civil peace have positive outcomes on the economies and resources of communities that already suffer because they are living under crisis conditions.

The principle of forgiveness and civil peace is recognized in the findings of Birzeit Institute of Law (2006). The study's data, collected from interviewing many individuals who were part of conflict cases in the West Bank and resolved by SCs, indicate that the SC resolutions of their cases did not necessarily promote justice in the sense that "individuals did not get their rights as they want it," but they agreed on the Sulha to keep civil peace and avoid more catastrophes that might come from revenge (Birzeit Institute of Law 2006, p. 134). The study also presents perspectives of governors, politicians, police heads in different districts, and judges, they all agree that SCs' efforts are key elements in protecting civil peace and building social forgiveness in Palestinian communities (Birzeit Institute of Law 2006, p. 135).

The SCs are not ideal bodies that can provide perfect social justice; rather they provide realistic resolutions that protect communities especially in crisis conditions when alternatives, such as the formal legal system are weak. Additionally, the JCSC case study indicates that SCs are not an alternative to the rule of law, but are supportive and 
protective of the rule of law. The following section discusses the relationship between the SCs as community level "informal" system and the national level formal legal system. Community Level: SCs Support National Efforts in Promoting the Rule of Law

One of the important lessons from this case study about the way that indigenous knowledge can contribute to sustainable development in crisis conditions is that the JCSC and other SCs provide a way to respond where the formal government system has not met a need, but, as stated above, the informal process supports the goals and needs of the formal system. Jurisdictions that governed Palestinian people and land either reinforced SCs role, such as the Turkish Empire and the British colonial power, or tried to organize but contain that role such as the Jordanian kingdom and the PNA. The Israeli occupation is the only jurisdiction that tried to exclude and isolate what was considered "national SCs." The following discussion will analyze the relationship between the JCSC process, as a community level development practice, and the national Palestinian executive and legal system; particularly the JCSC's relationship with legal courts, the police, the Jenin district governor's office, and the political system in the West Bank.

\section{Relationship with the National Legal System: Partnership not Containment. All} members of the JCSC agree that the relationship between their committee, as most SCs, with the Palestinian legal system can be described as a partnership. There is no doubt though that the legal system represented by courts (Sharia courts and civil courts) supports and encourages SCs and their role in promoting forgiveness and tolerance in Palestinian communities. However, this partnership can be analyzed from two angles: 
the effect of SCs on the rule of law or the legal system, and the effect of the legal system on the rule of SCs.

Influence of SCs on the Civil Courts. According to the 1960 Law number (16) applied in the West Bank, the judge, who is looking at any case brought to the court, has the discretion to reduce the punishment after evaluating the circumstances of the crime and the social environment around it (Palestinian Law No. (16) 1960, article 99-100).

Additionally, Articles 52 and 53 of the same law consider the injured party's compromise with the responsible party after the Sulha procedures a possible legal reason to stop the case (Jordanian Laws and National Information system 2012). Turukman (2011), AbuAl-Haija (2011) argue that it is a tradition in Palestinian civil courts that the judges reduce the sentence to the minimum (usually one third of the maximum) after Sulha takes place and the Sulha document is signed by the two parties of the dispute. Turukman, as the chair of the JCSC, describes this procedure:

After completing the Sulha procedure and signing the Sulha document, I usually take the Sulha document to the court. I represent the victimizer while the victim, should be present, represents himself or herself; if it is a killing case, a family member represents the victim. The judge ask for the Sulha document and asks the victim or the representative if they agree on what is in the Sulha document and if they are ready to compromise their personal rights. If they say yes, the judge then has the right to reduce the punishment of the victimizer to a third if the case is intentional crime. If the case is not intentional crime, the judge ask the SC chair to do the legal procedures to release the victimizer; usually by financial warrantee. The Judge takes a copy of the Sulha document and attaches it as a formal document in the case file (Turukman 2011).

The judge in this situation looks at the social benefits (peace and cohesion) that the Sulha process presents to the community as a reason to reduce punishment. 
Additionally, in most minor cases, judges usually ask the parties if they tried to do the Sulha process or if they would like a chance to do Sulha. Most JCSC members mentioned that they had been in a civil court in cases where there was no death involved and asked judges to give them a chance to start the Sulha process between the disputing parties. The judges, according to JCSC members, welcomed and supported their efforts, and in most cases released the dispute parties upon JCSC members' warrantee (for example Turukman 2011, Sirisi 2011, Abu-Al-Haija 2011, Salah 2012, Zaid 2012).

The research team tried to survey judges' opinions about the importance of the Sulha process and the relationship with SCs members. Judges in the Jenin District Court informed the team that they are not allowed to release information for media or researchers about courts "because of the sensitivity of the political situation." Instead the research team could have permission, as ordinary people, to attend four randomly selected cases hearings and take notes. Interestingly enough, the team recorded that the first question that the judge asks disputing parties is whether they tried to complete a Sulha resolution process. In the only case that disputing parties did not make Sulha, the judge ruled 14 days imprisonment as a precaution for both parties. The three other cases that had made Sulha, the judge asked Sulha men and other sponsors to finish the process and asked both parties if they agree on the Sulha process.

Influence of the Legal System on SCs. All JCSC members agree that the influence of civil courts on their committee is very limited, most likely because Sulha solutions in most cases come before the courts' judgments. None of the JCSC members mentioned that their committee decisions are affected by the courts' decision. On the other hand, the 
committee members often decide on a resolution even if it departs from what the formal system says should happen. For example, one of the controversial practices is removing responsible parties and their families from their homes. Removing them at the time of blood feud in killing cases contradicts the Palestinian Amended Basic Law of 2005 Article (20) that guarantees freedom of living for Palestinian individuals and prevents forcing them to be removed from their homes (see Palestinian Nationa Authority 2005). However, SCs still remove families from their communities and resettle them in safer places. Turukman (2011) states that "in order to avoid contradiction with the law we do not write the removal issue in the Sulha document. We have no problem with that as long as we compromise with the two conflicting parties" (Turukman 2011). The most important point here is that the indigenous Sulha system works with the legal system through various devices, but also remains independent of it so that it keeps its legitimacy in the community.

Regarding the relationship with Sharia courts, many JCSC members believe that marriage and divorce, child custody, and inheritance issues need to be solved by Sharia courts (Sirisi 2011, Abu Al-Haija 2011, Turukman 2011, Salah2012, Zaid2012). However, JCSC do not refuse such cases if parties approach the committee to resolve them. If they do take them, the SC has special privacy protections. They limit the discussion as much as possible to some members of the committee and the disputing parties. Turukman (2011) argues that these cases are very limited because the Sharia courts give fast and clear decisions in those cases according to the Islamic law (Turukman 2011). In conclusion, SCs, as a community- level conflict resolution process, 
supports the national legal system and reduces pressure on civil courts. Civil courts and SCs agree on the purpose of promoting civil peace. However, SCs approach this purpose faster than civil courts and with more focus on forgiveness and tolerance. Reducing pressure on civil courts, promoting civil peace and forgiveness counts to the best of sustainable development efforts drawn upon the indigenous Sulha process implemented in crisis conditions at the community level.

Partnership with the Executive Authority, Resisting Attempts at Containment. The relationship with the executive branch of the PNA includes relationships with the police department, the Jenin district governor's office and politicians who work in different agencies especially those who belong to the Fatah party. All JCSC members responded that their committee has a strong and direct relationship with the police department and the Jenin district governor's office. Turukman (2001) states that JCSC has a continuous coordination with police department heads in Jenin district. The chair of the committee and the coordinator have a "hot line" to call the police heads and in some cases the governor when there is a need to do so. In many critical cases, Turukman or Abu-AlHaija calls the police heads to request police forces to help in controlling violence. In other cases the committee members evaluate the event on the ground and might ask the police to withdraw and give the committee a chance to fix the problem. The committee can also ask the police to arrest criminals who refuse to cooperate with the committee, facilitate members visiting criminals in jails to persuade them agree and sign the Sulha document, and in some cases provide personal protections for the committee members in case of threats (Turukman 2011). 
The relationship with the governor's office is important for JCSC. The governor is the highest political and administrative position in a Palestinian district. Governors usually have wide executive responsibilities. The relationship between Jenin governor and JCSC members has been very strong and there has been almost coordination with the governors' office (Zaid 2012, Turukman 2011). Turukman (2011) states that "the governor of Jenin always appreciates JCSC efforts to promote civil order and peace and he provides the committee with all facilities it needs; sometimes he participate with the committee members in negotiations between conflicting parties when needed. The committee, in turn, respects and appreciates the governor's role and usually coordinates with his office and invites him or his representatives to Sulha celebrations" (Turukman 2011).

The JCSC case indicates the power of community level development patterns not only in contributing to sustainable development in a variety of ways, but especially by supporting civil peace and order as well as by promoting social cohesion based on respect through an indigenous process at a time when the government's ability to resolve some of the problems is limited and there is political stress. At the same time, the indigenous process is flexible enough both to work alongside the government where possible and still maintain its independence, which is necessary.

$\underline{\text { Sustainable Development Efforts under Intifada Challenges: JCSC Responds to Crisis }}$ $\underline{\text { Conditions }}$

The JCSC members believe that crisis conditions, particularly the first Intifada, gave birth to their committee as was true of many other SCs in different districts in 
Palestine. Most of the members of JCSC said of the period of the first Intifada that, although it was a serious crisis, was the "best" stage in JCSC life. Best in this case means fewer conflicts, more independence, and more enforcement of the committee's decisions and solutions (for example Turukman 2011, Sirisi 2011, Abu- Al-Haija 2011, Zaid 2012, Alyyat 2011). This section focuses on three stages of crisis that happened during JCSC life within the general crisis of the occupation: The first Intifada, the second Intifada and the internal division between Hamas and Fatah that led to the division into two political authorities, Hamas in Gaza and Fatah in the West Bank. The focus of this session is about how this indigenous process was able to work under crisis conditions to provide the foundational support for sustainable development in terms of social cohesion, legitimacy, and peace and order, even while it helped to resolve important conflicts that affect all three elements of sustainable development.

The Crisis of the First Intifada. During the first Intifada, Palestinian communities had to create what were called "national alternatives" to fill in the gap on the aftermath of the collective boycotting of the Israeli economic, administrative and political agencies working in the Palestinian territories. The first stage of boycotting started in 1987 by encouraging Palestinian people not to work or make business with the Israeli market. Then people were encouraged not to approach courts, police departments and other administrative departments and to use instead "national alternatives" to fill in the gap; a key alternative was SCs (fore example Turukman 2011, Zaid 2012, Sirisi 2011, Alyyat 2011). However, one of the critical challenges that the Intifada leadership as well as the P.L.O. leadership had to deal with was criminal justice (Muhsin Saleh 2001). 
Turukman (2011) and Abu-Al-Haija (2011) argue that criminal justice and building social tolerance and forgiveness was a key need for Palestinian communities during the Intifada but it was also easy to meet this need through SCs. Turukman and Abu-Al-Haija agree that "a month after the start of the Intifada, indigenous leaders and Sulha men, who used to do Sulha before the Intifada but individually (not in committees), found themselves forced to volunteer and address all kinds of civil problems because of the complete absence of courts and police forces. Although dispute cases were reduced in numbers, especially intentional killing crimes" (Turukman 2011, and Abu-Al-Haija 2011), the serious challenge that faced the JSC at that time was enforcing the committees' agreements and requirements, including bringing responsible parties to sessions, collecting fines, and removing responsible parties from communities where they committed crimes. The challenge of enforcing the SC resolutions was solved by the unified Leadership of the Intifada who formed special groups that applied and enforced SCs decisions and solutions.

During the seven years of the first intifada, JCSC, as many other SCs, responded to all kinds of disputes in a way that "strengthened social cohesion in Palestinian communities living under that crisis conditions" (Alyat 2011). Sulha committees had to balance between supporting Palestinian communities, through the Sulha process, as part of supporting the Intifada as a political event, and avoiding direct opposition with the Israeli occupation which rejected their role. Turukman (2011) argues that this balance was possible because SCs stayed as much as possible away from clear political positions 
and more important because of the "indigenous wisdom" that carefully and patiently cared about people's needs of social cohesion under such conditions.

The Crisis of the Second Intifada. The second Intifada, started in 2000, which was the second crisis condition that stormed the Palestinian territories after six years of security and stability between 1994 (the establishment of the PNA) and 2000, the start of the second Intifada. The second Intifada was more challenging for the Palestinian communities than the first Intifada, as it started as a military and not civil resistance by Palestinian armed resistance groups and formal security forces against the Israeli forces. As a result of using weapons against the Israeli forces in Palestinian territories, Israel responded by a comprehensive military campaign and destroyed most of the PNA infrastructure, including Police stations and logistic tools, courts, jails, security forces buildings, in addition to killing and arresting thousands of people, including Police officers (see the Palestinian Central Bureau of Statistics 2007).

The challenge was not only the loss of criminal justice infrastructure in the Palestinian territories but also the spread of weapons into many hands. All JSCS respondents argue that the number of crimes, including critical cases reduced during the second Intifada, however the spread of weapons complicated SCs job and created new challenges for Sulha men. Some armed groups started to use weapons to threaten civil peace (Sirisi 2011, Zaid 2011). The spread of weapons also affected Israeli forces behavior in that they started to suspect and threaten individuals who tried to move between communities, especially at night. Most JCSC members describe this period as the most difficult of all. 
The JCSC responded to the second Intifada challenge by establishing more local SCs in different communities that could coordinate with the central committee to resolve local conflicts. Turukman (2011) and Sirisi (2011) argue that Palestinian communities led by indigenous leaders became more unified against civil disorder caused by armed individuals or groups, more cooperative with local SCs, and more tolerant towards each others. The challenge caused by the Israeli military campaign unified people and probably caused people to forget or delay their internal disputes.

Since police stations and civil courts were either destroyed or shut down, people increasingly came to local SCs and the JCSC to resolve their problems. This action was appreciated and encouraged by the PNA political leadership that was trying to keep peoples' support. The JCSC was able to enforce most of its decisions and resolutions except arresting perpetrators in cases of intentional killing. This condition continued until the end of 2007 when PNA started to rebuild security forces with international help and probably an Israeli compromise. This compromise came on the aftermath of the political division between Hamas and Fatah that led to the division of the Palestinian territories into two authorities, Fatah in the West Bank and Hamas in Gaza. The political division issue has been another challenging crisis condition for the JCSC.

The Challenge of Political Division: Political Polarization versus Independence. In the aftermath of the political division that happened in 2006 when Hamas took over the Gaza Strip, JCSC found itself forced to deal with a new kind of challenge besides normal civil conflict disputes. These were internal political problems caused by political polarization. This crisis condition mixed between civil disputes and political disputes 
because Fatah individuals in the West Bank, like Hamas individuals in Gaza, started to target individuals from the other party in many civil disputes but for political hidden reasons (JCSC member 2011). Many JCSC believe that the political situation in the aftermath of the 2006 division has been very sensitive.

On the one hand, JCSC members cannot refuse people's requests to solve disputes regardless of their political background. On the other, if they judge in favor of individuals from Hamas, that might create difficulties with the Fatah party and PNA security agencies that have been implementing a "security campaign" against Hamas in the West Bank and with Hamas which has similar conflicts with Fatah in Gaza. (JCSC member 2011).

All JCSC respondents agree that these tensions make it important for the committee to stand firm about its independence. This state has been the key to success during the internal division situation. Many JCSC respondents stated that they were able to solve many disputes the same way they had before only by keeping the same distance from all political parties. However, political polarization caused by the division in governance has limited the JCSC in particular and SCs in general. Some JCSC members mentioned that the committee and other central committees will keep trying to persuade both parties to achieve reconciliation or at least reduce tension in media that often harms the public from both sides. Members who give speeches in Sulha celebrations use this occasion to talk about reconciliation and tolerance as a strategic purpose for SCs (JCSC members 2011). The UNDP report about Palestinian territories (2009/2010) addresses the internal division as a critical crisis condition that challenges development in the 
Palestinian territories and interestingly suggests the indigenous Sulha process, based on tolerance and forgiveness what they call a "realistic" solution for the internal division. The next section of this chapter focuses on the indigenous power of the Sulha process. Indigenous knowledge Power: The Power of Action and Words

All JCSC respondents argue that SCs are not limited to a certain sector in the Palestinian Society. To the contrary, all sectors approach SCs in their communities, especially central committees because they (central committees) are more powerful and influential than local committees (Salah 2011). Mohammed Salah, an Imam and a manager in the Ifta' department ${ }^{7}$ and a member of the JCSC, states that even ministers and heads of security agencies approached JCSC when they had problems. This section tries to answer the question why people prefer SCs than any other solutions and focuses particularly on the importance and the power of the indigenous foundations of Sulha actions that SCs (JCSC) implement. And it is this legitimacy and ability to increase social cohesion that makes it possible to support the three elements of sustainable development even in these crisis conditions.

The Power of Indigenous Actions. JCSC members are convinced that SCs members' presence in any community makes an important difference, especially when disputes arise. The fact that SC members are elders who volunteer their time, effort, and sometimes money to resolve people's problems is at the core of this impact and that comes from the indigenous tradition. Salah (2012) Sirisi (2011) argue that Palestinian

\footnotetext{
7 This is a governmental department that follows the Ministry of Religious Affairs. The department is responsible for explaining the Sharia law to people and giving answers (Fatwas) for issues that needs explanations from an Islamic perspective, particularly contemporary issues such as human organs transplants, etc.
} 
communities have indigenous customs that give elders a unique role in their communities, especially dealing with conflict resolution. For example, when a conflict starts, elders in that location, whether they are SC men or not, try to solve the conflict. Their presence reduces the tension and helps younger generations to calm down. If elders from both conflict parties cannot solve the problem, they immediately approach a local SC or JCSC if the conflict gets to be critical such as a killing. Turukman (2011) argues that the presence of JCSC members, as elders, who have reputations for being truthful, for caring about civil peace, for understanding local culture and customs, for understanding Sharia law and civil law, and who are known to be ready to act to stop existing conflicts and prevent further conflict are critical qualities and all flow from the indigenous roots of Sulha. In local customs, "individuals who try to refuse to respect or cooperate with Sulha committee members or who ignore committee members learn that their behavior means that they "do not belong" to the community", according to Turukman (2011).

In this regard, Salah (2012) states that "when we (JCSC members) physically act to stop a violent event, it is not our strong bodies that force people to stop, but two other things. First, it is the indigenous customs (respect of elders, respect of the social position of Sulha men) that legitimize our actions and push the parties to stop. Second, the trust that JCSC has built with communities over time so that community members know that we come to help, to support those injured, and to resolve the conflict" Salah (2012). However, many JCSC members believe that SCs members have legitimacy not only from communities that respect and appreciate their role, but also from the justice and executive 
authorities who support their role and accept their solutions. Moreover, according to the indigenous Palestinian culture, it is a "serious offense" if an individual attacks or insults a SC member (Turukman 2011). The JCSC usually use this custom to protect families and properties of responsible parties during a conflict when the those who were injured are tempted to respond with a blood feud. Turukman states that some JCSC members had to step inside perpetrators' houses during or immediately after a killing crime in order to protect the responsible party's family and property from the victim's family who may try to kill, burn, or destroy them (Turukman 2011, Also Sirisi 2011, and Salah 2012).

\section{The Power of Atwa and Jaha: SCs Members' Words and Promises are the}

Guarantee. The Jaha is the number and social position, "quality," of men who participate in the Sulha, especially when visiting dispute parties to negotiate solutions. In Palestinian traditions, as noted earlier, a large number of men who are socially respected and of influential means shows that the SC is strong enough to solve the conflict and achieve justice. Turukman (2011) states that JCSC chooses the Jaha that helps in solving the conflict carefully, but also with regard to the "size of the conflict". "Conflicts involving a death, conflicts between two communities, and conflicts with parties from outside the district usually require a stronger Jaha" (Turukman 2011). However, sexual crimes are usually treated with privacy and very limited number of Sulha men (usually one member who is usually an Imam or specialized in Islamic studies). Generally speaking, Palestinian communities, especially traditional ones, prefer a strong Jaha. A strong Jaha means not only guarantee of "rights and justice" but also, and more important, respect for the injured party. This respect plays an important role in 
persuading them to accept the Sulha. Therefore, JCSC usually avoids including individuals who might not be acceptable to a conflict party or both parties (Turukman 2011, Zaid 2012).

Refusing the Jaha is culturally unacceptable unless there is a reason that should be discussed with the SC members. Abu-Al-Haija (2011) states that "refusing the Jaha means disregarding the culture, the local customs, and Islamic values of forgiveness and tolerance. In many cases the injured party dos not refuse, but may seek to negotiate the Jaha and present their conditions for the Sulha men. If JCSC members notice that there are unreasonable conditions, they enforce the Jaha with more influential people in the next visit to practice more pressure on individuals who complicate the resolution" (Abu Al-.Haija 2011). The Jaha, therefore, is a social traditional power that aims to reduces tension, enforce the SC's resolutions, guarantees disputing parties rights and enforces forgiveness in communities.

Atwa: the Power of Words and Promises. Atwa represents the power of words and promises in indigenous SCs' pattern of conflict resolution. It is the second step, after stopping the violent event that SC members need to do. Atwa means a promise that the responsible party confesses to the transgression and shows a readiness to pay all required damages to the injured party of those who represent her or him. This promise comes from one of SC members who at this moment represent the $\mathrm{SC}$ and the responsible party. $\mathrm{He}$ asks the injured party to accept that promise for three days and a third. He also requests that there be no retribution from the injured party or their relatives, and asks that they accept the SC to solve the conflict (for example Turukman 2011, Zaid 2012). The 
important point here is that the foundation for relying on promises and taking a series of important actions on the word of SC members is all grounded in indigenous tradition. Words and promises in Sulha practice are used to protect lives, guarantee rights, and promote justice and forgiveness.

Without indigenous knowledge experience, the commitments would not be accepted and could not be fulfilled. These are communities where indigenous customs are important. For example, when the JCSC decides the Diyya in cases involving a death (money paid by the responsible party to the victim's representatives according to the Sharia law and local customs), they take into consideration whether the victim has children and how many persons he was financially supporting. At the same time, if the victim is poor, especially in unintentional cases, the committee negotiates with the victim's relatives to reduce the Diyya or return it to the responsible party. In many cases people respect the committee's efforts and actually do return the Diyya (Tutkman 2011).

The Power of Solutions: Integrating local Customs, Sharia Law and Civil Law. All JCSC members agree that Sulha solutions are derived from three sources: traditional customs, Sharia law, and civil law. They also argue that integration among the three sources is at the core of enforcing the committee's solutions. Customs are used to enforce community values of generosity, tolerance, respect etc. Sharia rules are implemented to enforce forgiveness and justice. Civil law addresses the rights of people according to the Palestinian Constitution.

Indigenous attention to the collective rights of communities as compared to simply focusing on individual rights is one way that some authors in sustainable 
development have seen successful examples driven by indigenous practices (see Weeramantry 2002, Pye-Smith et al 1994). Christopher Weeramantry criticizes modern law because, besides focusing only on individuals rights, it has failed to recognize "traditional wisdom of humanity" that considers rights of the individual, rights of the group, right of the village and rights of the environment (Weeramantry 2002, p. 4). PyeSmith et al. (1994) describe a number of successful indigenous groups and communities who collectively worked to solve their problems and sustain their lives. This is a case study that shows how indigenous knowledge can be used to resolve some of the most difficult problems in a society with which it must deal if any of the three elements of sustainable development is going to be achieved in an integrated manner.

The Power of Sulha Celebration. The Sulha Celebration is the last stage of the Sulha process. This event is called a celebration because it declares that the conflicting is over and replaced by peace and tolerance between the conflict parties, and it is open to the public. During the Sulha celebration, huge Jahas come to appreciate and thank the victim's party for their forgiveness and accepting the Sulha and also thank the victimizer party for their cooperation with the SC. Besides Jahas, many indigenous leaders (elders, Imams and local leaders), the district governor, the district police head, and members of other SC witness the signing the Sulha document and congratulate the community for achieving the Sulha. After signing the document, both conflicting parties shake hands and greet each other (Turukman 2011, Sirisi 2011, Salah 2012).

As noted earlier in the chapter, the purpose of the Sulha celebration is not only to declare that the conflict is over, but also to send a massage to the community and to those 
attending about the importance of tolerance and forgiveness. In this regard, Sirisi (2011) states that "the Sulha celebration is a great opportunity for public forgiveness. We intentionally invite indigenous (tribal) leaders as well as younger generation leaders so that we all learn from what happened ... we ask the parties to the dispute to shake hands and hug each other in public to show that any conflict could end peacefully if people choose forgiveness" (Sirisi 2011). In addition, a Sulha celebration reinforces the traditional solutions (stages of the Sulha process) by celebrating its happy end. As Salah (2012) puts it, "If the Sulha process ends by signing the Sulha document without declaring it publicly as it is in the celebration, probably, both conflict parties and the public would not feel the taste of forgiveness".

The Sulha celebration is where the power of culture, action and words are put together to promote sustainable social cohesion and civil peace. These resolutions are important not only in disputes about personal matters, but also in many cases about business matters or issues dealing with property like land and water rights. In this way, the process supports all three elements of sustainable development.

\section{CONCLUSION}

Conflict resolution is a critical policy domain in crisis conditions. The ability to address conflict is key to all three elements of sustainable development. Without that sense of some kind of rule of law and a sense of social cohesion that allows even very serious disputes to be resolved, little progress would be possible on any side. It is critical to business and financial development. It is critical to protect land and water rights that 
are at the core of environmental issues in Palestine. It is essential for social cohesion that can support social development.

Addressing this policy domain from the community level makes even more of a difference in crisis conditions when the role of the state is absent or weak such as the two long -term occupations in the West bank of Palestinian territories. However, this case study points out that JCSC as an indigenous knowledge-based conflict resolution process that has promoted resolutions of very serious disputes in Palestinian communities. The Sulha process depends on the local traditions and values of tolerance and forgiveness driven from traditional customs and Islamic rules. The Sulha pattern integrates three approaches to conflict resolutions: local customs, Islamic rules, and civil law rules. At the core of the JCSC success is the power and large acceptance of indigenous leaders, values and traditions by communities in addition to both the formal justice system and the executive authority. The members of the JCSC consider themselves as supporters to the rule of law, not alternatives to the rule of law.

This case, as the previous two cases, emphasized the importance of the role of indigenous knowledge in sustainable development and incorporates all three elements. In this case, there is particular attention to the social component, but this process is necessary to economic development and environmental protection in Palestine. The following chapter provides a cross-case analysis in order to learn lessons about the way that indigenous knowledge can support sustainable development in crisis conditions. 


\section{CHAPTER 6: CROSS CASE ANALISIS: LESSONS ON THE USE OF INDIGENOUS KNOWLEDGE IN SUSTAINABLE DEVELOPMENT}

The previous three chapters presented three different case studies that discussed how indigenous knowledge used in each case contributed to sustainable development outcomes in crisis conditions. All were about work at the community level. This chapter is a cross-case analysis that explains what those case studies contribute to understanding the ways in which indigenous knowledge can support sustainable development, even in very difficult conditions.

The chapter first considers similarities and differences among the three cases with particular attention to factors that appear to shape behaviors in positive ways. It provides a discussion of findings and lessons that can be learned from them. The chapter then presents a number of testable propositions about the role of indigenous knowledge in promoting sustainable development in crisis conditions that can contribute to building theory and improving practice in this important area. Then the chapter presents a number of lessons for practice which come from the propositions and from other observations from the cases. Finally the chapter presents some suggestions of further research that could be conducted in the future to test these propositions.

\section{INDIGENOUS KNOWLEDGE AS A DRIVER TOWARD SUSTAINABLE}

\section{DEVELOPMENT: COMMON FEATURES IN THREE CASES}

There are a number of similarities and differences among the three cases that can help researchers and practitioners to understand the influence of indigenous knowledge in promoting sustainable development in crisis conditions. They provide evidence from the 
three cases that supports propositions for later testing and illustrate lessons that can be learned for practice. The following discussion demonstrates a set of themes that grew up from similarities and differences of features across the three cases.

Indigenous Knowledge Can Adapt to New Conditions Through Cultural Processing Indigenous knowledge-based patterns of behavior and ideas have the capacity to be more flexible than many might think. They can be adapted to contemporary sustainable development needs through cultural processing. At the same time, the projects themselves become cultural processors that find indigenous ways to meet current problems. In this regard, cultural processing means that any development activity needs three operations before applying it in a new context. First, it needs language interpretation so that words, terms and norms make sense in the new context. Second, Cultural mediation (see Vargas 2000) that deals with removing cultural boundaries and helps developers and stakeholders to create better communication and understanding about development activities. Third, cultural adaptation that deals with the question of how the new cultural context can adapt and apply the new development activity. Cultural processing is essential when borrowing development norms and activities from another culture and also when developing new activities and norms within the same culture.

Case one indicates that the Bani Zaid Cooperative was originally established to manage traditional practices of producing Baladi olive oil. Later the cooperative leadership had to adapt the way they handled and processed the olives as well as their administrative skills to enable the cooperative to get the required organic farming and fair trade certificates that meet with the international market requirements. Farmers in the 
Bani-Zaid community needed to move from the individual grower focus to a cooperative one in order to do what they needed to do both to get the certification and also to make it affordable. They have adapted collective practices for organic olive producing farms, using collective techniques of harvesting the product, and more important collective pressing. As many farmers from the Bani-Zaid Cooperative reported, at the beginning they did not know what the term organic meant and why they had to follow special procedures to get their product certified. Later they discovered that organic has a similar understanding in the culture, which was the term Baladi.

Administratively, the Bani-Zaid Cooperative leadership had to do cultural processing too. Although the cooperative functions in a traditional community and led by local farmers, its leadership practices contemporary skills such as the democratic elections that they arrange every two years to choose the administrative body (M Al-Qadi 2011). The cooperative's history also indicates a recognized level of accountability. The administrative body meets every two weeks to discuss members' needs and the cooperative's tasks, and prepare administrative and financial reports to discuss with the members in their monthly meetings (M Al-Qadi 2011). Both electing the administrative body and accountability are requirements for approving the cooperative as an organic olive oil producer, and also requirements for the Fair Trade Certificate that the cooperative later achieved.

The administrative leadership also reports to the indigenous committee of advisors as a kind of "locally important moral commitment to cooperation with local leaders" (M Al-Qadi 2011). This integration between what is indigenous and what is 
contemporary has indeed contributed to sustainable development in Bani Zaid community.

In the second case, the word "club" is a contemporary name that replaced the traditional name Jamiyya. The term club has been culturally processed by the people involved in the project to overcome many challenges to local acceptance and also to provide a foundation for changing rural women's role in local communities. The word club is literally interpreted in Arabic as Nadi. The word Nadi means a place for practicing sports, but more importantly a place where men and women can mix together, which is culturally unacceptable. Therefore, the term had to pass through a stage of reinterpretation that was culturally sensitive and then mediation to clarify goals through acceptable communication (see Vargas 2000). Then it was able to reach the last stage of adapting the term to the required social norms.

The women's clubs were launched to meet the needs of local women based upon working together on indigenous activities such as crafting, indigenous designing, in addition to their health care needs. Traditional practices play a critical role in attracting even the new generation of local girls to join women's clubs, especially girls who do not have educational opportunities.

Women's clubs also got their legitimacy from meeting and paying attention to local communities' needs, especially for rural women and their families. Through this local legitimacy which was strengthened by the work they did as was explained in the case, women's clubs now are considered key organizations in lobbying and leading change in gender issues, even culturally sensitive ones, such as family violence and early 
marriage, as well as increasing women's participation in political and social life. The coordination between women's clubs and the local indigenous leadership, particularly elders and Imams, played a key role in promoting more acceptance and regard for women's clubs in their communities. Besides their social role and care about the environment and human health, women's clubs are working hard to produce products for sale under a unified title that allows their traditional products to compete in regional and international markets.

Cultural processing was a key factor in the case of the Rural Women Empowerment Program. The women's clubs, as implementers of the program, focused on building carefully from indigenous work and concerns about family and community allowed them to build legitimacy through the culture and that allowed them to bring the idea of women's clubs in the current environment, including the ability to be active in controversial discussions and to do business in a modern way. Clearly the women's clubs have contributed to sustainable development in their communities.

The JCSC in case three similarly integrates traditional practices and the contemporary purposes of promoting the rule of law. Enforcing the rule of law is a contemporary purpose for the PNA as well as for many developers and international donors who support many Palestinian NGOs that work to enforce it in Palestinian territories. Although very few institutions and people pay attention to the role of traditional practices, the Sulha pattern of conflict resolution is an example of successful traditional practice that has made it possible to meet a current need when other options 
were not available or not working well. However, the SCs have also had to adapt to the new conditions.

The Sulha process in the past was a very simple process that takes place in communities when there was no court, no police, and even, in some stages, there was no legal system. Currently, the SCs have adapted new procedures to deal with a complex contemporary situation with many parts that include conflicting parties, courts, judges, civil law shortcomings and challenges, Sharia law, and customs, and to do that with very limited resources under crisis conditions. For example, as part of spreading forgiveness and peace, the Sulha process stories have to be published in formal newspapers (usually Al-Quds newspaper) to inform as many people as they can about the importance of Sulha and about the peaceful ends of critical conflicts.

Additionally, the JCSC has succeeded in managing networks and partnerships with local leaders, SCs in other districts, the police department, the governor's office, courts, and local communities. The philosophy of the Sulha process is supporting the rule of law, but also promoting and sustaining social cohesion, civil peace, and more important forgiveness and tolerance in crisis conditions. They are both mediators in the usual sense of that word, but they are also cultural mediators. The JCSC, like many SCs, practices the role of mediator between many complex situations and in many cases, contradictory elements common in crisis conditions; this role contributes thoroughly to sustainable development and especially focuses on the social dimension. In doing that, 
the SCs both adapt their indigenous process to new problems and culturally process new problems to find a way to deal with them using on indigenous process.

Indigenous Knowledge Can Address Crisis Conditions' Challenges: Political Polarization and Social Exclusion are Critical Examples

Social exclusion is one of the crucial problems that take place in communities under crisis, very often because of political conflicts. In the three cases of the study, indigenous knowledge was used in a way that showed a capacity to manage political polarization and decrease social exclusion. The things that were important in this regard were that they were seen as legitimate in the community and they were used in a way that kept them independent of politics. The three cases have indicated that the state of independence is a key dimension in functioning in crisis conditions when political polarization is usually a sensitive issue.

In case one, the Bani-Zaid Cooperative could keep its state of independence from local and national politics that helped the leadership keep the focus on peoples' need. Even when the cooperative sometimes had to be involved in politics, such as lobbying with PNA agencies and the local council, the Bani Zaid Cooperative leadership kept a balanced relationship with political parties (both Hamas and Fatah) by accepting members and delivering services and benefits without political exclusion and with the focus on the community's needs.

The indigenous knowledge background of the cooperative, Baladi olive oil cultivation, has strengthened the cooperative's state of independence. That foundation increased the cooperative's legitimacy in the community. As Al-Qadi (2011) put it, 
"indigenous leadership believes in community needs more than anything else. In fact indigenous leaders have kept a similar distance from all political parties when political disputes happened. They used their influence as independent local leaders to get parties together and help them work together".

In case two, women's clubs also kept their independence and avoided political relationships that would have excluded anyone. For the first time in rural communities, rural women were able to be active in the community and in politics through the women's clubs. Women's clubs also have welcomed all local women regardless of their political background. If women's clubs were not able to carefully manage their independence and open access, men in their families would likely have used their political influence to direct and probably dominate women's opinions, especially during political elections.

The focus on culturally accepted indigenous activities increased the women's clubs' legitimacy and accordingly increased their influence in local communities. Paying attention to the local culture roles such as the role of Imams and elders leaders enabled women's clubs to successfully address change in culturally sensitive issues such as early marriage and violence in the family. Such issues were for many years taboo, especially if addressed by institutions that were thought to have a political agenda (Zaidan 2011). Inclusion and exclusion are extremely critical issues in sustainable development efforts in crisis conditions.

In case three, the JCSC not only had to keep its state of independence in terms of how the community saw it and its members, but, as explained in the case narrative, it also 
had to resist attempts by political officials to contain the SCs. The case indicates that Sulha pattern of conflict resolution could not function well under political influence, especially from government executive agencies or political parties. The need for independence of the Sulha process is in some ways like the state of independence of the formal judicial system. However, the JCSC case indicates that the indigenous Sulha process, supported by the power of local customs, religious norms, and the strong independent social position of Sulha leaders, can do more even than courts in terms of building social cohesion, civil peace as well as fostering forgiveness in crisis conditions. In this regard, Radi Zaid (2012) states that "legal courts address facts (evidence) but Sulha committees, besides facts and evidence, address feelings and social relations". The Feasibility of Indigenous Knowledge-Based Development in Crisis Conditions

Cooper and Vargas (2004) present the feasibility framework for understanding implementation of sustainable development and they discuss some of challenges of meeting these requirements particularly in crisis conditions presented in (Cooper and Vargas 2008).

The feasibility framework looks for technical, legal, fiscal, administrative, political, ethical, and cultural feasibility in order to implement sustainable development (Cooper and Vargas, 2004). The three cases indicate that indigenous knowledge-based development patterns are feasible ways of doing sustainable development in crisis conditions. The respondents in this study explain that indigenous knowledge-based processes are easy to apply, familiar to the culture, relatively simple, and inexpensive. They meet the needs of individuals, families, and communities effectively and at a time 
when they need them most. They are socially equitable and do not need complicated administrative or legal procedures. These conclusions were true about the Baladi olive oil production and indeed all Baladi farming skills and treatment that are grounded in local peoples' long experiences. It is also true about traditional designing and crafting, traditional ways of food processing, traditional ways of producing Masabeh (prayer beads), patterns of raising and treating bees, and cultivating home gardens in the empowerment program case.

Case three indicates a clear preference for the Sulha process by all sectors of Palestinian communities because of its legal, cultural, ethical, political, administrative, and fiscal feasibility. Respondents point out that approaching civil courts for conflict resolution costs a great deal of money, time, and effort. In comparison, the Sulha process responds to conflicts immediately and saves people's lives, businesses, and properties in a way that is highly regarded in the culture and does not cost money. It also avoids political problems. Communities under crisis conditions indeed need these kinds of development characteristics at a time when the role of the state is either weak or absent and the local and national resources are scarce or inaccessible.

Empowering Local Communities and Promoting their Self-Reliance through Indigenous Ideas

The three cases indicate the many connections between their success and the fact that they were implemented from the community level. At the same time, they also show that the communities grew stronger and more self-reliant because of those successes. 
The Bani-Zaid Cooperative case shows that the cooperative led a significant change in attitudes toward organic farming in the Bani-Zaid community as well as neighboring communities. Encouraging local farmers to turn back to organic farming, however in a new way, was also positive in improving marketing opportunities, increasing olive oil prices, cultivating more land and protecting it from being illegally taken, and protecting the limited remaining natural resources of the community. Moreover, the cooperative, by following the strategy of implementing by local hands, has empowered the local community to manage its organic olive oil production and development, has built new partnerships with other communities, and also has worked more effectively with local, national, and international NGOs. Accordingly, the cooperative has been turned into a training center for farmers and a well-known address for visitors who want to learn from and provide learning to the community. The cooperative has brought and implemented many development projects and workshops for the benefit of the local community.

In case two, the implementation of the Rural Women Social and Economic Empowerment Program through local rural women's clubs is a unique example of empowering communities, especially the inclusion of rural women who in turn have helped to strengthen the community. Women's clubs, in partnership with two leading national NGOs whose work focuses on gender issues, RWDA and PARC, have improved community empowerment through creating and managing family-based micro-enterprise projects to build their families' food security through supporting home gardens. The influence of these projects on these women has motivated them to run for office in local 
councils wining the elections in 2005 . The empowerment program indeed positively changed the role of women in rural communities, including changing what had been considered taboos, such as having women in rural village councils or addressing sensitive issues like early marriage and violence in the family.

In case three, the JCSC is a different kind of community empowerment. It is a kind of self-reliance on the Sulha conflict resolution process to solve problems in their own communities in a way that strengthened social cohesion even in times of conflict. This process has played the role of a safety valve that provides protection for community lives and resources, but goes beyond that to strengthen the community. The philosophy of SCs is promoting forgiveness and social cohesion in addition to providing what JCSC members call "a realistic level of social justice under crisis conditions." Additionally, the case indicates that indigenous leaders who use indigenous knowledge are the key negotiators of conflict resolution in communities under crisis.

Indigenous Knowledge-Based Development Patterns Promote the Integration Process of Sustainable Development

The three cases indicate that local culture is a way of addressing problems and needs that very naturally pays attention to the three elements of sustainable development: environmental protection, social development and economic development. As Weeramantry (2002) explains, many indigenous communities have operated effectively for many generations because their ways of living, evolved incorporated all three elements. 
The organic farming process in cases one and two are examples of how indigenous skills almost always pay attention to natural resources management, such as methods of planting and crop choice, use of manual sustainable methods of soil protection, effective use of rain water reservation, and safe and natural pest protection and diseases treatment. Additionally, indigenous farming patterns provide a safe environment for wildlife species such as wild plants and flowers that are necessary for bee reproduction, birds, deer, and rabbits that usually live in mountainous areas of Palestine. The Sulha process is a way to resolve disputes and protect land and water rights which are both essential to environmental protection and sustainable development.

Economically, besides the seasonal several types of jobs that organic farming projects create, the projects encourage farmers to cultivate more land so that it will be protected from being taken by Israeli illegal settlers and forces and remain as a national wealth for future generations. The business that has been brought in by exports of oil also promises future resources. Moreover, the savings and credit unit of the cooperative creates an additional opportunity for the Bani-Zaid community to access micro-finance investments in the community by encouraging local people to borrow and start microenterprises, or small businesses and projects. The case indicates that micro-enterprises seem to be safer and more sustainable than large businesses in crisis conditions (See Vargas 2000 and Cooper and Vargas 2008, Ch. 5). This is an important subject for the author's future research.

All three cases show important contributions to social development and integration with the other parts of sustainable development. The organic farming project 
and the Bani -Zaid Cooperative have promoted social cohesion among the community and between the Bani-Zaid community and other communities. The successful decisions and the positive attitudes toward organic farming and the cooperative that the leadership created over time have increased the cooperative's legitimacy in the community. The various partnerships with local institutions such as the village council, women's clubs, schools, and health care centers are examples of these decisions. Additionally, achieving fair trade certification in organic farming has afforded fairer prices for producers and consumers and promoted self-confidence in the community's capacities. They have seen that they can depend on their own strengths and achieve more successes.

Case two similarly indicates that indigenous patterns and norms have the capacity to integrate the three elements of sustainable development. Women's clubs were originally established as social groups that could pay attention to rural women's needs in health and education. By using traditional skills in producing products and crops, which are typically environmentally friendly and culturally accepted, rural women members in women's clubs came to be seen as productive members of the community who are able to provide a living for themselves and their families. They had reached out, become more active in the community, and came to be seen as community leaders. The family-based projects that women's clubs implemented have helped to address not only economic problems, but also social problems caused by long-term unemployment among men in poor communities.

However, the idea of women's clubs for those early and relatively simple purposes has developed into having women's clubs members in local councils, and 
having sustainable micro-enterprises that grew as from small projects and businesses sponsored by the savings and credit institutions created from women's clubs.

Furthermore, the strong partnerships between women's clubs and local schools and health care providers have reflected positively on the local communities' health, especially for women and children. Examples include the "Cooking for our Schools Project" which was integrated with the bees project, the home organic gardens development, the health care days, and other activities managed by volunteer from women's club's.

Although case three has a special focus on social development, it is important in the other two areas of sustainable development as well. As discussed earlier, it deals with conflict resolution and social cohesion, but the fact that it supports the rule of law also makes it possible to move ahead on economic development and environmental protection.

The indigenous Sulha process of conflict resolution plays a protective role for individuals and the community in crisis conditions. It is a successful example of not only solving conflicts but more important promoting civil peace and forgiveness in crisis conditions when the role of the state cannot function well or may not even exist at all. The case indicates an active role of the indigenous Sulha process during the two Palestinian Intifadas when people have very limited resources to protect their lives and resources. The protective role that the Sulha process can play is providing resolutions, based on forgiveness, protects not only people's life but also property, businesses, and resources such as land and water rights. The Sulha resolutions not only are protective 
because they address conflicts directly, but also because they prevent violence and destruction from revenge or from those who would take things into their own hands.

The fact that the Sulha process is available in the community through the committees lets people know they can do business and make personal decisions without fear. They also know that they can call on the Sulha committees if they need to do so. As mentioned in chapter five, people who approach Sulha committees are not limited to any class or group. They could be poor, rich, people in formal positions such as leaders of security agencies, and even people who hold high positions in the government. However, JCSC interviewees reported that the business class is the most that uses the SCs to solve many routine disputes over businesses' ownership debts, among other disputes.

Crisis Conditions Retard Development, but Indigenous Knowledge Can Still Work

Clearly, war and other crisis conditions retard development (Cooper and Vargas 2008, p. 1). This statement is defended in many studies in the field of development in crisis conditions (see for example World Bank 2003, The Special Inspector General for Afghanistan Reconstruction 2010, UNDP 2003, 2004, 2007). However, the three cases in this study indicate that leadership grounded in indigenous culture and the use of indigenous ideas and ways of living can be successful even in those conditions and can move a community toward sustainable development. The indigenous ideas are important, but the respect for the role of indigenous leadership is particularly important in crisis conditions in part because of the lack of alternatives, including the weak role of the state (see also Mortenson 2006, Mortenson 2009). Indigenous leaders are not just elders, 
although they are important indigenous leaders, but it also means that the leadership is local rather than from outsiders or people from the national government.

The organic farming project and the establishment of the Bani-Zaid Cooperative came as a respose to the worst depression in olive oil prices, the only resource for the Bani-Zaid community. The eight farmers who started the idea of producing Baladi olive oil have built on Baladi farming practices and indigenous norms of regarding olive trees as a valuable cultural symbol. Accordingly, many farmers, including young generation farmers, joined the cooperative, returned to the land, and renewed the traditional Baladi farming that has now successfully reached the international market. Cultivating more land has eventually protected it from being taken by Israeli illegal actions. In the same respect, Bani-Zaid community increased its trust in the cooperative's leadership who led efforts voluntary that enabled them to win a fair trade certificate.

In case two, rural women's clubs leaders have achieved significant development in managing their clubs' activities. These activities have always paid attention to the strengths and limitations of local culture and drew on local leaders like the Imams and elders for assistance in dealing with taboo issues. Consequently they achieved an important change in rural women's view of themselves and the local communities' view of the role of women. Indicators of this desirable change is having 25 rural women leaders, for the first time, in local decision making councils after wining elections in 2005. Additionally, women's clubs leaders were able, through coordination with local religious leaders, to address culturally sensitive issues such as early marriage and violence in the family. Moreover, rural women in many cases succeeded to manage 
family based small projects that provided job opportunities for their husbands and sons who at the beginning rejected the idea of women's clubs. Similar to case one, case two indicates that development reduces the negative impacts of crisis conditions.

In case three, the interviews showed that Palestinian communities, even during the extreme crisis conditions such as the two Intifadas, have cooperated with SCs in conflict resolution. Implementing the Sulha process by all sectors and the resolutions it negotiated indicates that indigenous Sulha leaders (SCs members) were able to bring and maintain reasonable levels of civil peace and forgiveness in crisis conditions. Part of that comes from the special way that SC members are chosen and the kinds of people who are members that were described in the case study narrative.

The forgiveness and acceptance brought by Sulha are considered very important social resources that SCs could draw on from communities during extreme crisis conditions especially, when the rule of law is weak or absent. Most JCSC members consider the Sulha practice as a "safety valve" of communities. Additionally, as the Sulha pattern positively affects social cohesion in local communities, this social environment it fosters also positively affects the economic environment and promotes trust. People feel safe on themselves and with respect to their resources allowing them to focus on their businesses and develop them. All of this clearly dependence not only on the process of Sulha, but also on the respect for the indigenous leaders who are the members of the JCSC.

Community Level Action Using Indigenous Ideas Succeeds Where Weak Governments Often Cannot 
National or even regional governments in crisis conditions are often not strong enough to help address the many kinds of problems typical of conflict resolutions. Respondents in the three cases indicate that their projects and programs did not receive much formal support from PNA agencies, except in case three and even there it was more the Sulha committees contributing to the state and the state to the SCs. This study emphasizes the argument of other studies that the weak role of the state is common in crisis conditions because of the many pressures that the state faces especially political and economic pressure (see Cooper and Vargas 2008, Ch. 5 and World Bank 2003).

In case one, respondents agreed that neither the organic olive oil project nor BaniZaid Cooperative received any formal support in the form of funds, logistical assistance, or technical advice from the PNA. The only cooperation that respondents indicated was at the local level with the village council which sometimes facilitated and coordinated with the cooperative. The Ministry of Agriculture, according to participants, did not support the project (see Dager 2011, M Al-Qadi 2011, Rihi 2011). To the contrary, the Ministry of Agriculture continues to support unsustainable intensive farming that destroys the soil with chemicals and often produces unhealthy and relatively expensive products compared to organic products (Dager 2011). Under such conditions, the only alternative seems to be community level efforts such as those of Bani-Zaid Cooperative to persuade and attract more community members to support organic farming.

In case two, women's club's leaders made it clear that the Ministry of Women's Affairs and, to some extent, the Ministry of Education did not provide support for rural 
women in general or the empowerment program in particular. Some women's club leaders in fact state that empowering communities might be impossible if it is not implemented at the community level (Jarodi 2011, Ashkar 2011). The data also indicated that where there was some cooperation with PNA agencies, such as the partnership between women's clubs and the Ministry of Education, the women's clubs in the community were the ones who started working toward creating the partnership and tried their best to develop it. Additionally, several participants consider that the relationship between women's clubs and local councils is mostly the result of local customs of cooperation between community members and community institutions for the benefit of the community. As the data indicates, 24 women's club members became members of the local councils.

The Sulha case study discussed the many ways in which this indigenous institution provided a successful alternative to the lack of action in crisis conditions. The role of the JCSC during the two Intifadas in sustaining reasonable levels of civil peace and conflict resolution is clear evidence of the assumption that indigenous knowledge can support or sometimes substitute the role of the state in crisis conditions. It is for this reason that the PNA agencies provided some support to SCs during its various historical stages. Different from case one and two, PNA agencies strongly and formally supported and facilitated the role of SCs most likely because of two reasons: (i) the weak position of PMA agencies (courts, police, other security agencies) under occupation and (ii) because of the successful model, based on forgiveness, that SCs apply. As the case study narrative indicated, some high level PNA employees, including ministers, leaders of 
security agencies, and top public administrators used the Sulha committees to resolve problems. Finally, as the data in the three cases indicate, being part of the local culture has accumulated legitimacy for the Bani-Zaid Cooperative, women's clubs and the JCSC that is less visible during complex political times at other governance levels. Trust in Local Institutions and the Increase in People's Participation in Development $\underline{\text { Activities }}$

One of the important findings of this study is that trust plays a key role in traditional communities in a variety of ways. The study emphasized that trust in indigenous leadership who implement development activities through practices derived from local indigenous culture, from the community level, increases people's participation and support for sustainable development activities. The connection between the local community focus and the level of trust is key, especially in crisis conditions. All three cases provided evidence for this point.

In case one, the idea of organic farming was both derived from local culture and implemented at the community level with an emphasis on building trust and cooperation so that everyone would benefit. The cooperative's leaders emphasized that their priority was to implement all activities by community hands and in local community -based businesses. They also emphasized that they discuss all decisions and activities with members and also ask advice from the committee of local advisors. That consultation and the success of the cooperative's decisions and activities increased people's trust in the cooperative and its leadership and, accordingly, increased their participation in the 
project. As the only condition to join the cooperative was commitment to the organic production conditions, more farmers returned to Baladi (organic) farming or cultivated new mountainous land to be able to join the cooperative and benefit from its projects and activities. The cooperative the cooperative was also successful in creating partnerships with local institutions, national NGOs, international NGOs, and other communities in the area.

Women's clubs in case two also implemented the Social and Economic Empowerment Program at the community level and by rural community hands especially poor women and women with special needs. The implementation strategy of women's clubs has been to pay careful attention to local cultures, "both to work from its strengths and to pay attention to its limitations" (Zaidan 2011). That was clear in supporting rural women's micro-enterprise projects and community acceptance of the campaign against early marriage campaign and the campaign against violence in the family. The result of this strategy was strengthening community trust in women's clubs in the community, including men, and increase the number of women's clubs, and in membership in these women's clubs which led to an increase in rural women's participation in social and political life.

The JCSC in case three has been implementing the Sulha process at the community level since 1987. Although some members were individually practicing Sulha even before 1987. The recognizable truthfulness and legitimacy that the JCSC demonstrated over time have increased the communities' trust in the Sulha process and encouraged many local communities to establish their own community SCs to participate 
in promoting conflict resolution and forgiveness. The case indicates that, because people all over Palestinian communities trust them as indigenous leaders, JCSC members can be effective. They add to that level of trust by volunteering their time, money, and effort, sometimes even at risk to themselves, to keep the Sulha process functioning to protect civil peace in communities when it is lacking in the world around them.

\section{Local Culture is a Strength to be Used as a Resource and not a Burden}

As Chapter 1 recognized, there can be situations in which local culture can be a challenge to sustainable development. However, in these case studies, it was clear that the local leaders knew that culture is a resource that can support sustainable development and should not be seen as a burden. Local leaders know local culture well and they are able to benefit from its strengths.

In case one, leaders of the Bani-Zaid community saw Baladi farming as a clean and healthy way to grow crops that could get a fair price at a reasonable cost for production and these things were important to the local culture. Accordingly, they invested well in people's knowledge of this kind of farming and established the BaniZaid Cooperative that gave Baladi farming a new face that can meet the requirements of the current international market.

As Dager (2011) puts it, people now leave chemically-based farming and turn to Baladi farming because Baladi farming is part of their culture, but historically they did not pay attention to its importance. At a time when officials in the Palestinian Ministry of Agriculture considered organic farming a "straw man argument," something that was 
not realistic for development, people used indigenous knowledge for successful sustainable development policy from which officials can learn (Dager 2011).

Indigenous patterns of olive trees cultivation could benefit from everything in the land to increase its productivity. They could benefit from stones and rocks spread in the land to build walls that protect spoil erosion. They could use undesirable plants, besides animals' remains, to make compost. They could use indigenous trees such as Ceratonia Siliqua trees to treat diseases. They could use savings and credit models to solve the problem of borrowing from regular banks as an illegal act according to religious texts of Islam.

Similarly, indigenous leaders in case three use indigenous cultural norms as resources with which to address crisis conditions. The JCSC members, like other Sulha committee members, understand the weight of customs in their communities. Therefore, they use these customs along with their own actions, such as their physical presence in the scene of conflict, their words, and their promises along with Atwas, Jahas, Madafas, and other Sulha activities and norms to reduce conflict and build community peace. The case of the JCSC indicates that the Sulha process has a significant legitimacy to the extent that the formal Palestinian legal system partners with SCs, and consider and appreciate their solutions. Even those who might otherwise take a different approach understand the strength of the foundations of the Sulha process.

\section{Indigenous Knowledge-Based Action and Social Cohesion}

The cases studied here show how indigenous knowledge-based development patterns use both formal and informal activities to reinforce traditional customs and 
practices to achieve social cohesion, something that is difficult in crisis conditions but important to sustainable development. Case one indicates that the informal relationship and friendships between the Bani-Zaid Cooperative's members had existed before the cooperative and have become stronger after the cooperative. Members of the Bani- Zaid Cooperative emphasized that the informal visits, meetings over meals, greeting in occasions, and voluntary work together strengthened social cohesion in the community. This strong relationship helped the cooperative to overcome the challenge of collective pressing that was a key factor in sustaining the olive oil production project. Additionally, trusting the indigenous elders committee, who are not members of the cooperation but advise its administrative leadership, has created a kind of community satisfaction and acceptance of the cooperative's position in the community. Respecting elders is culturally considered respecting the whole community and therefore contributes to promoting social cohesion. In terms of the formal use of farming methods, the cooperative reinforced the historic foundations of the community.

In case two, the women's clubs followed a tradition of weekly informal meeting of the members of each club that usually takes place in the club building or when the whole group is invited to one member's house. The group usually cooks and eats a famous traditional meal (Mansaf, Makloba, Musakkan) together as a social activity. Such traditional meals are symbols of respect, sincerity, and love in local traditions. This tradition is repeated every month, but among different communities' women's clubs. As many women's club members describe it, such informal visits also promote social cohesion by developing new marriage bond that counts for a great deal in rural 
communities. Additionally, the groups and individuals exchange experience and knowledge through a friendly informal environment.

The groups leaders also invite RWDA and PARC members, who dress like indigenous people do, to these meeting. This, according to (Zaidan 2011), the director of the Empowerment Project, plays a critical role in building healthy environment for rural women's empowerment as a development objective. Several participants in this case mentioned that such gatherings are important for them to express themselves, discuss problems and solutions, and to socialize. Further, many of them also mentioned that "such informal occasions, which are open to all community women, encouraged new members to join women's clubs especially the new generation".

The activities of the group which draw on indigenous traditions such as making local products and gardening helps to support the family and others in the community. All of these reinforce social cohesion.

The discussion in Chapter 5 of the Sulha process explained in detail how it is designed to promote social cohesion. All JCSC members indicate that traditionally, the houses (Madafas) of Sulha committee members' are open for all community members any time to sit down, drink coffee, or ask the members help to solve a problem. Although SC members participate in conflict resolution, they also participate actively in happy occasions such as marriage parties, Eid festival, and national festivals. The most important procedure in the Sulha process that addresses the purpose of promoting social cohesion is the Sulha celebration once the celebrations have agreed with the proposed 
resolution of the dispute. It is usually carefully planned. This celebration takes place in public and is open to the public to encourage forgiveness and social cohesion.

Given these commonalities across cases, it is possible to develop a series of propositions that are supported by those lessons which can be tested in other places in the

country, in other countries in the region, and in other parts of the world. That knowledge should then be a starting point to develop theory concerning the ways that indigenous knowledge can contribute to sustainable development and particularly in crisis conditions.

LESSONS LEARNED AND TESTABLE PROPOSITIONS FOR FUTURE RESEARCH AND THEORY BUILDING.

The premise of this study is to develop a set of testable propositions derived from lessons learned from the three cases and could be applied in different contexts. These propositions are expected to contribute to building theory that explains the role of indigenous knowledge in promoting sustainable development in crisis conditions. This section discusses these theoretical propositions, the lessons learned from the cases, and finally suggested topics for further research that the researcher is interested to do in the future.

Proposition one: Indigenous knowledge- based patterns can adapt to contemporary development needs through cultural processing of these techniques.

The cases in this study indicate that indigenous knowledge development patterns are neither rigid nor anti-development, but have the capacity to adapt to contemporary needs and can fit with newer tools of development such as administrative tools, new 
technology techniques, and contemporary civil law rules. However, it is important to adapt the indigenous knowledge patterns to the current context and current techniques to match with the indigenous culture. Cultural processing means that local culture does not reject contemporary development tools, but that it is important to take time to find places where the new and the old can fit together. It is also important then to make the language of the new and the old work together. Both the practice and the language can be adapted but they need to be built on similar values in the local culture.

As discussed in the previous section, cultural processing includes three subprocesses which Professor Vargas (2000) has discussed: (i) cultural interpretation, which is the first step to understand what does a certain development activity mean (ii) cultural mediation is the second step as mediation removes cultural boundaries to understanding and supports better communication about the development activity; and (iii) cultural adaptation which is the stage when a development activity becomes culturally acceptable and applicable or adaptable in the new context. Cultural mediation (Vargas 2000) is a key factor in this cultural processing because, as the cases indicate, careful communication with indigenous leadership and institutions is key to overcoming cultural challenges. It is important to note that this is a mutual adaptation process.

Proposition Two: Paying greater attention to the local indigenous culture of communities decreases the complexity of sustainable development challenges in crisis conditions.

Looking at the complexity of challenge of crisis conditions, the three cases indicate significant evidence that indigenous knowledge integration in community based 
development patterns are relatively simple and require less outside resources, which is especially important in crisis conditions. This research shows that they also tend to reduce political polarization, respond fast to critical problems, do not cost much money, effort and time, and are culturally understandable and acceptable. Additionally, depending on these patterns may not require complex operations and high levels of administrative training. Local people know what they are doing. They also and can learn quickly from elders and neighbors how to use the indigenous techniques in ways that fit their needs. All three case studies showed this to be the case. In the case of organic farming, it took some research to relearn old techniques, but it was not difficult to do that. Proposition Three: Efforts grounded in indigenous knowledge increase fiscal feasibility which enhances the likelihood of successful implementation of sustainable development activities.

In crisis conditions, fiscal feasibility is crucial to the implementation process of sustainable development activities. Part of the selection criteria of the three cases of the study is to meet the feasibility framework (Cooper and Vargas 2004) including fiscal feasibility. In fact, these cases suggest that the use of indigenous techniques improves all of the feasibility elements including the technical, legal, fiscal, administrative, political, ethical, and culture. At least though, these case studies show that indigenous approaches tend to take less resources to implement than other approaches and that is key to success particularly in crisis conditions. In those conditions there is often poverty and a lack of systems and infrastructure (See Cooper and Vargas 2008, Ch. 5, World Bank 2003). 
The methods used in all three of the case studies were less expensive and required less outside support than the alternatives that were advocated by others outside the community. The three cases of the study indicate that indigenous community- based patterns are capable of managing scarce resources and finding local alternative solutions when resource problems arise.

Proposition Four: The use of techniques grounded in indigenous knowledge increases cultural feasibility which enhances the likelihood of successful implementation of sustainable development activities.

As noted above, the cases appear to be feasible in all dimensions of the feasibility framework, but particularly cultural feasibility. The cases show that indigenous approaches respond to some culturally sensitive issues which are considered a crucial challenge for implementing sustainable development in crisis conditions. Additionally, indigenous patterns include many key sustainable development principles (Cooper and Vargas 2004) such as the poverty eradication principle, family based principle, equity principle, the principle of balance and integration, the livable community principle and protecting the environment principle, among others.

The use of these kinds of approaches also reduces the dangers come from trying to apply techniques from very different cultures or contexts. These things can work if they go through cultural processing as explained above, but there is always a danger that they will not fit.

Proposition Five: Indigenous knowledge- based development patterns are particularly likely to be successful when implemented from the community level. 
Compared to national level development patterns, Indigenous knowledge- based development patterns are derived from community culture and indeed get legitimacy from community support. Additionally, the community level indigenous knowledgebased patterns provide sustainable outcomes to targeted communities. For example, the Bani-Zaid Cooperative as well as the women's clubs had the tendency to implement all development projects and activities depending on community hands. This strategy has supported the local economies of all community members and also strengthened social cohesion. However, the increased number of people who joined the Bani-Zaid Cooperative and the women's clubs and the increased number of cooperatives that adapted organic farming, and the increase in number of women's clubs are indicators of success for implementing sustainable development from the community level.

The Sulha process case is a significant example of successful indigenous knowledge- based development implemented from the community level. In fact the pattern is hard, if not impossible, to implement except from the community level and by community leaders of Sulha committees. The large spread of Sulha committees in all Palestinian communities and the large number of people who use it resolve conflicts show how successful and powerful is this indigenous process. Sulha committees also get their legitimacy from community support and regard. This fact enabled Sulha committees to stand firm against all attempts of state containment. As mentioned in previous discussions, communities know what they are doing and how to do it.

Proposition Six: Indigenous knowledge- based patterns promote communities' selfreliance and therefore increase capacity for future action. 
Self- reliance here means confidence derived from successful experiences and from local knowledge. Also, the participation of indigenous leaders are mostly volunteers who care about their communities and have patience in teaching, negotiating, and building on approaches to sustainable development for their communities.

According to the data collected from the three cases, indigenous knowledge community patterns have caused local people, including the young men and women who have not been historically included, to have confidence in their ability to implement sustainable development activities with few available resources. Several respondents from the three cases mentioned that because indigenous patterns are familiar to the culture, the level of uncertainty in implementation reduces. Indigenous leaders, based on extensive experience, know what to do and how to do it (M Al-Qadi 2011, Zaid 2012).

Proposition Seven: Engaging local leadership, who are empowered by traditional authority, in sustainable development activities increases communities' empowerment.

Indigenous leaders are not only decision makers but also public relations and social cohesion builders. Because they are empowered by traditional authority that strongly influences their communities, elders and others such as Imams, in these cases, can play important roles. At the same time, the cases suggest that ignoring indigenous leadership, might lead to failure in sustainable development policy implementation.

Also, engaging indigenous leadership in sustainable development activities can increase the capacity of communities in terms of empowering more people to be active in their communities. The three case studies clearly indicate that indigenous leadership is a key component of traditional communities and accordingly a key component in 
community empowerment programs. The example of the women's clubs' efforts to address early marriage and domestic abuse are clear examples.

Proposition Eight: Engaging indigenous leadership encourages voluntary contribution of resources by community members to achieve positive outcomes for their communities. Indigenous leaders lead by example. They physically show up to solve problems as in the case of Sulha pattern. The three cases, significantly the case on rural women's empowerment, indicate that a new generation of men and women started or continued to volunteer in their communities because of their experience with the Bani-Zaid Cooperative and the women's clubs' activities. Additionally, the active voluntary work that indigenous leaders do encourages state agencies, as in the third case study, local and national NGOs and businesses, as in case one and two, to partner with indigenous institutions to implement sustainable development projects and programs. Many development programs and projects, for example the fair trade certificate in case one, require local communities to contribute to voluntary social, environmental and economic activities as part of their commitment to sustainable development.

Proposition Nine: Engaging indigenous leadership increases legitimacy in terms of people's acceptance, regard, and support for sustainable development activities. Indigenous leadership obtains its legitimacy from the culture that usually appreciates its role as a foundation for community life. Additionally, successful decisions, activities and outcomes accomplished by indigenous leadership, add legitimacy to sustainable development activities. The three case studies indicate that legitimacy was key to success, while at the same time successful decisions and activities 
made by indigenous community -based leadership added legitimacy to sustainable development activities. Like the idea of trust, the concept of legitimacy came through over and over again in the interviews and in the explanations as to why programs and projects worked.

Propositions Ten: Indigenous knowledge-based development practices promote the integration process of sustainable development.

The study began by reviewing the literature in which there were continuous problems with making sure all three parts of sustainable development are integrated. It pointed out particularly how social development has often been left out. These case studies show how the use of indigenous knowledge in sustainable development programs and projects can help make sure that integration happens. That is especially interesting and important in these cases because they were implemented under crisis conditions.

Unlike other patterns of development, indigenous culture based patterns do not show the lack of integration that commonly has been a problem so many times. Instead even under crisis conditions, the use of indigenous approaches seems to promote integrated solutions that respond to very serious challenges. The reason behind this success is probably, as Weeramantry (2002) indicates, the fact that indigenous wisdom does not look at sustainable development from a materialistic (cost benefit) and individualistic perspective, but approaches it from a comprehensive perspective that pays attention to the group rights of the community and not just to individuals rights. As he also points out, it looks beyond the present to future generations. 
The patterns examined in this study indicate significant evidence that indigenous knowledge-based sustainable development can successfully integrate the three elements of sustainable development including making the social development part an important factor. Indigenous patterns are by nature caring of the environment (Dager 2011), pay attention to social cohesion (Turukman 2011), and are concerned with the ability of families and the community to provide an acceptable standard of living (Zaidan 2011). Proposition Eleven: Given that states in crisis conditions are relatively weak, implementing sustainable development from the community level using indigenous knowledge can reduce dependence on and stress for state agencies.

The study indicates that the state (PNA) has been overwhelmed with challenging politics, lack of resources, or lack of accessibility to reach resources if available, and even in the best conditions focused on stability and security rather than sustainable development. The fact that the community groups used indigenous knowledge that did not require much if any support from the state and could rely on local resources meant that the programs could succeed and the state did not have to face demands for resources that it could not meet. In fact, in the Sulha case, the indigenous knowledge- based program provided support for the state by supporting the rule of law and promoting social cohesion and tolerance in Palestinian communities. This reduces stress on the Palestinian police and the judicial system.

In case one and two, the organic olive oil and the social and economic empowerment program for women compensate for the lack of support for sustainable development actions that address rural poor communities. The cases indicate that both 
the Palestinian the Ministry of Agriculture and Ministry of Women Affairs do not provide enough support to these communities. Probably the strong partnership between state agencies and Sulha committees in case three gave some support, but not to the women's clubs or the Bani-Zaid Cooperative. Therefore, community level process based on indigenous knowledge can help the state and help the community without getting involved in political problems or fights over resources.

Proposition Twelve: Implementing sustainable development from the community level increases communities' trust in local institutions and accordingly increases people's participation in development activities.

The cases in this study suggest that increased levels of trust come from the use of indigenous knowledge-based programs that are implemented in local communities and that the increase in trust results in an increase in participation in community programs. The three cases indicate that local institutions are the key components of building partnerships necessary for sustainable development in large part because of that level of trust. That seems to be especially the case in crisis conditions when there is so little trust in many institutions or actors. That lack of trust can even extend to outside NGOs that have their own political agendas.

In this regard, having local institutions led by indigenous leaders, who already have high levels of trust from their communities, increases peoples' participation in development activities, as the three cases indicate. As respondents in the three cases indicate, the unique informal relationships, based on local customs, among local 
institutions encouraged local people to join these institutions and increase their participation in sustainable development activities implemented by these institutions.

Proposition Thirteen: Indigenous leadership builds on strengths of local culture and looks at the culture as a resource that leads to sustainable development, not as a set of problems.

One of the important findings of this study that was discussed earlier in this chapter is that the base of local culture that comes with the use of indigenous knowledge was seen and used by the leaders of the three programs studied as a resource for sustainable development and not as a set of problems. The three cases indicate that indigenous leaders, like Imams, elders, and Sulha committee members, and younger local leaders used local culture strengths to resolve development problems and in ways that were acceptable in their communities.

In many cases, the indigenous leaders have successfully built on communities' strengths to solve critical challenges. For example, the Bani-Zaid Cooperative involved indigenous leaders committee (committee of advisors) in reviewing the cooperative's reports and decisions in order to benefit from their experience and position in the community. Sulha leaders also choose their Jahas carefully to reduce opposition of some conflicting parties to their solutions. Similarly, women's club leaders involved Imams and male family members in their activities as part of resolving problems. Additionally, directors and coordinators of the Organic Olive Oil Project (M Al-Qadi 2011, Dager 2011) and the Empowerment Program (Zaidan 2011, Galudi 2011) agree that indigenous 
leaders who know the strengths of local communities were the key factors to sustainable development success.

Proposition Fourteen: Indigenous knowledge-based efforts at sustainable development implemented from the community level promote social cohesion.

Again, the cross-case comparison at the beginning of the chapter explained at length the ways that social cohesion was built in all three cases based on the use of indigenous knowledge. And as was mentioned several time, the problem of the lack of sufficient attention to the social dimension of sustainable development was not a problem here. The three cases of the study indicate how important this social dimension was. The discussions kept coming back to the idea of social cohesion. The three cases suggest that most indigenous knowledge-based development efforts are likely to include social cohesion as an important element, that may in part be related to the points made by Weeramantry (2002) discussed earlier.

Proposition Fifteen: If outside organizations advocating sustainable development actions understand and ground their work in community's culture, this will increase trust among them and facilitate successful program implementation.

If outside groups seek to work with indigenous culture and knowledge, they are much more likely to succeed because they can build trust. If they try to bring in something that does not fit in the indigenous culture, it will unlikely work. That may seem clear, but some may need to learn how the local groups, like the ones in this study, succeeded. 
Additionally, communities living under crisis are likely not to trust outsiders easily because of the critical experience of warfare. Therefore, understanding the culture might break the barriers, increase trust, and, accordingly, facilitate reaching people's needs.

Proposition Sixteen: Given that political and social exclusion is a serious challenge in crisis conditions, sustainable development efforts grounded in indigenous customs as practiced in local communities tend to enhance inclusion and therefore contribute to ethical feasibility.

Inclusion of all sectors of people, especially the needy, is an important principle of sustainable development (Cooper and Vargas 2004, Ch. 8). The three cases indicate that, because of the political situation caused by both the occupation and the internal division, political and social exclusion is a serious challenge when talking about sustainable development in Palestine. The targeted communities of this study are not only marginalized and socially excluded because of they are rural communities or rural women but also because of political polarization that have critically increased in the aftermath of the division between Gaza and the West Bank.

However, sustainable development efforts grounded in indigenous knowledge that were explored in the three cases indicated a significant success in overcoming social and political exclusion by reaching out to marginalized people and communities that had not been included. The projects kept their independence from politics and focused on the local community and all of its people. There is significant evidence that the independence of the Bani-Zaid Cooperative, the women's clubs, and the JCSC promoted 
inclusion of people who might be otherwise socially or politically excluded. Examples of this proposition are rural women, people with certain political and religious belief (Hamas versus Fatah debate) and the poor. Including these groups in sustainable development projects and programs indeed contributes to ethical feasibility (Cooper and Vargas 2004p. 163).

Proposition Seventeen: Indigenous knowledge-based community sustainable development enhances the likelihood that equity challenges will be addressed.

Equity is one of sustainable development principles (Cooper and Vargas 2004,pp. 37-38). Indigenous knowledge community-based development practices examined in the three cases indicate commitment to fair and equitable outcomes for community members regardless of their race, religion, gender, physical condition, or age.

Additionally, indigenous knowledge-based patterns used in cases one and three indicated a moral commitment towards including needy people in development activities such as including poor women (especially widows), poor families that have large numbers of children or children with special needs, and university students (especially girls). In case three, equity is present in reducing Diyas in unintentional death cases, when the responsible party's family is poor, and increasing the Diya when the responsible party is rich but the victim or the victims surviving family is poor.

Proposition Eighteen: Indigenous based sustainable development efforts at the community level tend to reinforce local cultural strength and cohesion.

The three cases indicate that local culture cannot only be a source of sustainable development patterns but also these patterns can reinforce cultural strengths and protect 
cultural identity. This supports the cultural sensitivity principle of sustainable development (Cooper and Vargas 2004, pp. 55-57).

Case one has reinforced Baladi olive farming that used to be a cultural symbol for Palestinian communities. Case two also reinforced many traditional crafting, food processing, savings and credit (Jamiyyas), and other social programs that not only improve the quality of living for hundreds of families but also sustained the cultural traditions of communities. Case three has significantly represented cultural cohesion enforced by Sulha process that has been successfully functioning over many generations.

\section{LESSONS FOR SUSTAINABLE DEVELOPMENT PRACTICE IN CRISIS}

\section{CONDITIONS}

The propositions explained to this point are important for theory development and for practice. There are some additional lessons for sustainable development practice in crisis conditions that come from the study. This discussion is part of the author's effort to make sure that this work becomes action research. At the beginning, one of the purposes of the study was to function as a basis for the author, the respondents in the case studies, relevant decision makers, relevant policy implementers, and development practitioners to share the results and apply the lessons learned from the study to existing and new sustainable development programs in Palestine. This section identifies and briefly discusses the most important lessons that the study generates for practice. Some of these lessons are common among the three cases and some are derived from the special findings of certain cases.

The Importance of Cultural Processing 
Sustainable development policy implementers need to pay enough attention to indigenous knowledge capacity of adaptation. Processing contemporary ways of doing work through indigenous knowledge is possible and helpful in sustainable development. Cultural mediation is necessary at all points in that process (Vargas 2000). This lesson is generated from the three cases, however, case two significantly evidence that IK patterns can adapt solutions even for questions that are culturally considered sensitive such as having rural women in decision making councils through democratic elections. Indigenous Knowledge is Valid in its Context

It is important to start from the fact that indigenous knowledge patterns' validity tends to be high and the fact that these are accepted locally is important to remember in sustainable development efforts. Sustainable development policy implementers and students need to look at indigenous knowledge with that in mind and with an understanding of the local context. In sustainable development efforts, context always counts (Cooper and Vargas 2004). In many cases, indigenous knowledge was treated as anti-development because some researchers evaluate it from a modern scientific knowledge perspective. The three cases of the study point out that indigenous knowledge tends to be successful even in crisis conditions context.

\section{Collective Perspectives versus Individual Perspectives}

Collective interest, interest of the group, the community, the village, and collective will are key factors in traditional pattern as compared to individual interests and perspectives as is often true in modern actions. Traditional leadership takes into consideration the interest of individuals through the interest of the group. This lesson is 
significantly important for sustainable development projects that address natural resources such as water, land, and planting, but it also true for economic development and social development. Case two explains the way this worked out with the women's empowerment program and case three explains why it was important not only to resolve conflicts between individual parties but also to involve the community in order to build civil peace and social cohesion especially in crisis conditions.

\section{$\underline{\text { Religion Counts in Traditional Communities }}$}

Religion is a key element of traditional communities' culture. In many cases, religion is misunderstood to play a negative role in sustainable development. The three cases indicate the opposite; religion can facilitate and support sustainable development.

In this regard, what policy implementers need is careful attention to and coordination with religious leaders when necessary and careful mediation and understanding to religious texts. That does not mean that there will always be agreement, but if those leaders or the importance of religion is not considered, there will probably be problems.

Implementer Should Appreciate Traditional Actions and Words

In traditional communities where people have high regard for indigenous patterns, every action and word counts and might make a difference. Implementers should pay attention to this fact.

Case three has indicated clearly that the power of indigenous leaders' words could make a difference in solving critical problem. In case two, the women's club members' careful actions that were in tune with the local culture could break down what 
used to be social taboos such as participation of rural women in local councils and addressing sensitive issues such as early marriage and violence in the family among many other examples.

\section{Understanding the Culture Helps in Reaching People's Needs}

Sustainable development policy implementers need to understand and act upon local communities' culture which is a critical part of reaching people's needs in crisis conditions.

Understanding local culture of communities does not mean only reading about this culture or meeting with some decision makers; but more important learning from ordinary people, eating with them, talking to them, asking them questions, answering their questions and concerns, and respecting their customs. While local leaders who live the culture can easily use the cultural norms, partners from outside the culture, such as national and international NGOs need to share these norms with local people in order to earn their trust and increase their acceptance and participation in development activities. As proposed above, understanding the culture and acting upon it increases trust in implementers and increases people's participation in development activities. While this may seem obvious, it does not happen as often as it should.

\section{Community Level Implementation Reduces Political Exclusion}

In crisis conditions, political exclusion is a serious challenge to sustainable development implementers. Political exclusion is likely reduced when implementing sustainable development from the community level and in partnership with local institutions. 
Local leaders in the three cases evidence that they succeeded in keeping their institutions in a state of independence and carefully balance political polarization. The balanced management of political issues (including members regardless of political background) allowed sustainable development efforts to reach more people and therefore increased the Bani-Zaid Cooperative's, Women's Clubs', and JCSC's legitimacy. $\underline{\text { Social Cohesion is Core to Sustainable Development }}$

Social cohesion positively affects security and stability, and accordingly affects economic development and environmental protection as well as social development. Social cohesion and civic peace are practical preconditions for better schools, safer streets, safer environment, faster economic growth, more effective government, and healthier lives. The three cases showed that social cohesion is a critical component that indigenous knowledge-based patterns promote especially case three.

\section{Crisis Conditions Challenge People to Extract Resources and Manage them Well}

Crisis conditions can under some conditions seem to unify communities' efforts and push communities to carefully extract and manage their resources. Sustainable development implementers could build on indigenous knowledge-based process that facilitate successful management of resources and get people's support for development activities. The stories of success told in the three cases indicate that local leadership could sustain and indeed develop their institutions with few available resources (Bani Zaid Cooperative, women's clubs and the JCSC) during crisis conditions especially in case three. The JCSC not only survived during the two Intifadas but also replaced the absent or insufficient role of the state in criminal justice management. Indeed the Bani- 
Zaid Cooperative and many women's clubs were born as a response to crisis conditions and succeeded and developed during the most critical crisis conditions, the two Intifadas. Indigenous Knowledge-Based Practices Contribute Effectively to Food Security and

\section{Personal Security of Communities}

Personal security and food security are priorities in crisis conditions. The familybased solutions developed according to indigenous knowledge are likely to function effectively in terms of providing personal security and food security for local communities.

Family-based development concerns fit with sustainable development principles (Cooper and Vargas 2004) as it includes economic needs, educational needs, health needs, food security, poverty reduction among other needs. In fact the family principle is one of the principles in the international common commitments to sustainable development explained in Cooper and Vargas (2004, pp. 43-44). Development activities implemented in the Organic Farming Project and the Rural Women Economic and Social Empowerment Program are focused on family-based activities where the whole family can participate and benefit from development. In case three, family issues play a very critical role in sustaining justice through the Sulha process. In most cases, family members have to negotiate to resolve the problem on behalf of either the victim or the victimizer. In this regard, it is important to say that the role of elders in local communities is significantly important in accepting Sulha patterns solutions and indeed protecting families, tribes and communities from possible disorder during crisis conditions. 
Informal Relationships and Activities Encourage People's Participation in Development $\underline{\text { Activities }}$

Social norms and informal relationships are very necessary in community level policy implementation. As many respondents in the three cases indicated, informal meetings and activities in houses, Madafas, mosques, streets, over food and coffee chatting and celebrating local occasions have played an important role in expanding communities' acceptance of sustainable development activities. That was especially true for rural women who had very few chances of socializing before the women's clubs establishment. Respondents affirmed that community level sustainable development activities expand social networks.

Trust Building is a Key Factor When Implementing Sustainable Development in Crisis $\underline{\text { Conditions }}$

Because of the traumatic conditions that people under crisis (especially wars and civil conflicts) live, trust becomes a critical issue to be considered in accepting and participating in development activities. Indigenous knowledge-based patterns implemented from the community level, where local people and leaders lead and participate in decision making and action, seem to be a trusted alternative to other politicized alternatives such as occupiers, war agents, political parties and political agendas, and even national and international NGOs who may not understand the need to culture sensitivity. However, building trust with traditional communities, although it is challenging, is possible when implementers show real commitment to learn from and 
partner with local leadership and build on these communities' strengths instead of the typically used approach of focusing on weaknesses.

The Importance of Decentralization and Authorizing Communities

Decentralization and recognizing the authority and legitimacy of communities is key for sustainable development, especially in crisis conditions. The Community level is not always an alternative to the role of the state; rather it often supports the state and fills in what the state cannot do. The more the state and donors support and facilitate community level sustainable development, the less pressure there is likely to be on the state agencies. In the first two cases of the study, the PNA had few resources and capacity to reach the targeted communities and many similar communities through sustainable development projects and programs. However, the PNA, although it authorized the Bani-Zaid and the women's clubs to implement development in partnership with NGOs, it did not work to provide much support even though these projects build strong communities that helped the state.

In the third case, partnership between PNA agencies and Sulha Committees was needed by both parties. On the one hand, despite the social power that Sulha committees have in the Palestinian culture, still they needed formal support from PNA agencies, especially the police and courts. On the other hand, because of Oslo agreements limitations, PNA agencies cannot reach all zones in the West Bank and Jerusalem. Additionally, in critical crisis conditions such as Israeli military campaigns and Palestinian Intifadas, PNA agencies lose their role in terms of implementing criminal justice and security. Therefore, supporting the authority and legitimacy of community 
level programs and processes such as Sulha committees enforces social justice and stability in crisis conditions.

\section{FURTHER RESEARCH NEEDED ON INDIGENOUS KNOWLEDGE IN}

\section{SUSTAINABLE DEVELOPMENT}

This study is the first step in the effort of building a theoretical framework that explains the role of indigenous knowledge in sustainable development in crisis

conditions. As the study, through the three cases, developed these propositions about the role of indigenous knowledge in the Palestinian context, there is the need to address, through further research, this role in different contexts using different cases. Addressing the role of indigenous patterns in building sustainable development in other crisis conditions contexts will enrich the literature and help in building the theoretical framework that the author of this study is interested to see. The following discussion discusses seven topics that the author or any other author can address.

\section{$\underline{\text { Suggested Further Research }}$}

First: How can Arabic Spring countries build on indigenous knowledge to address social cohesion on the aftermath of removing dictatorships?

The Arab countries' public uprising against dictatorships or what is now called in the media "the Arabic Spring" is an interesting field of study. Unfortunately, in some of the Arabic Spring countries, such as Libya and Syria, the conflict has created a huge negative impact on both countries' economies, their environment, and more importantly on the social fabric of their societies. Unfortunately, the efforts so far in Libya again emphasizes the model of "reconstructing Libya" with almost no focus or at least 
mentioning the media anything about sustainable development (Cooper and Vargas 2008, pp. 28-35). Therefore, in tribal communities like the Arab Spring countries, addressing the role of indigenous knowledge patterns in building sustainable development will be extremely interesting for research. This suggestion focuses on social cohesion as a critical component, as this study emphasized, for sustainable development in crisis conditions.

Second: It is important to compare top- down power-based national level policy implementation versus legitimacy-grounded leadership at the community level and indigenous knowledge: Selected cases from the Palestinian context. As an additional and complementary effort to this study, the author is interested in testing more relevant topics in the Palestinian context. The concept of legitimacy is one of the concepts that this study emphasized to be important in modeling sustainable development in crisis conditions. Legitimacy grounded in leadership at the community level and indigenous knowledge first need to be refined and specified by comparison with top-down powerbased national level models.

Third: Conflict resolution indigenous knowledge-based patterns grounded in the Libyan culture requires more attention. How can Indigenous knowledge contribute to reconciliation in the new Libya and other countries as well?

After the significant findings that case three showed about the important role that Sulha committees play in resolving disputes in the Palestinian context, it is interesting to test the role of indigenous patterns used in Libya in building reconciliation on the aftermath of the recent war in Libya and moving forward to sustainable development. Such 
research needs support from the new governors in Libya and probably from the some international institutions like the United Nations because the Libyan context is more complex. Libya, its over 40 years of dictatorship, has never experienced civil institutions or civil law. All power was centralized in one hand through what was called Public Rebellion Committees that used the tribal nature of the society to serve the regimes purpose of staying in power. Not to mention the impacts of the latest war.

Fourth: More research is needed that focuses on rural women's role in promoting sustainable development in crisis conditions. Examples might include the task of making a sustainable living from the community level, selected successful cases from Yemen, Libya and Egypt.

Interestingly, women in the three countries, with differences from one country to another, have played a critical role in demonstrations against dictatorships. That role was significantly recognized in Yemen although the Yemeni society is considered one of the most conservative and armed societies in the world. As Tawakul Karman, a Yemeni female activist who won the noble prize for peace in 2011, put it addressing the Yemeni women "you are the real power in the society and in the street. You Yemeni women, whom the dictatorship regime wanted you to stay in ignorance, are the ones who put the dictatorship down and you are the ones who led me to stand here. You are the ones who won the noble prize not me" (Karman 2011). Indeed other group activists and organizers who are not as popular as Karman and others will be addressed from the community level by this suggested comparative research. This suggested research can be an exploratory 
research that can examine what women groups can do in building sustainable development from the community level in the three countries.

Fifth: It is important to understand more about the value of trust in indigenous knowledge- based sustainable development effort in crisis conditions: Why do or do not communities trust developers?

The concept of trust is proved to be significantly important to sustainable development in this study. However, the concept needs further testing in different crisis context to see when communities do or do not trust development activities and why. Testing the trust concept in different crisis conditions contexts will be a key component in the theoretical framework about the role of indigenous knowledge in building sustainable development in crisis conditions. However, the findings of such research will be interesting to developers.

\section{CONCLUSION}

The study began by the effort to learn lessons about sustainable development in crisis conditions. It focused on the use of traditional knowledge and presented the question: How have successful community-level sustainable development efforts undertaken under crisis conditions drawn upon indigenous knowledge to achieve positive outcomes? The three cases addressed in this study have explained some of the ways that indigenous knowledge has played significant positive roles in promoting sustainable development for communities living under crisis conditions in Palestine. Indigenous knowledge community based process indicated significant focus on the strengths of local culture, social cohesion, the integration process, and special advantages for policy 
implementation from the community level as key components of sustainable development in crisis conditions.

The study contributes to theory by analyzing common elements from the case studies and providing a set of testable propositions, grounded in those successful experiences that can be a starting point for building theory. It is now important to test them in other programs and places. Indigenous knowledge community based programs studied here show strengths of local culture, social cohesion, the integration process, and special advantages for policy implementation from the community level as key components of sustainable development in crisis conditions. Additionally, these propositions could be used to build up, through further research, a theoretical body for sustainable development in crisis conditions. Practically, the study has generated lessons that sustainable development policy implementers and decision makers can learn from when addressing sustainable development in different crisis conditions contexts. 


\section{References}

Abu Zahra, Mohammed (1960). Crime and Punishment in Islamic Feqh. Cairo, Egypt: Dar Al-Fikr Al-Arabi.

Al-Omari, Hussain (2006). E- Government Architecture in Jordan: A Comparative Analysis. Journal of Computer Science 2 (11), 846-852. Retrieved May /22/2011 from http://findarticles.com/p/articles/mi_m0VVT/is_11_2/ai_n24997999/

Al-Qaradawi, Yousif (2001). Banks Interests: It is Haram. Cairo Egypt: Al-Risala Publications.

Arab Center for Policy Studies (2005). Arab Policy Report. Cairo Egypt.

Battiste, Marie and James, Henderson (2000). Protecting Indigenous Knowledge and Heritage: A Global Challenge. Saskatoon, Canada: Purich's Aboriginal.

Bardach, Eugene (1977). The Implementation Game: What Happens after a Bill Becomes a Law. Chicago: University of Chicago Press.

Berg, Bruce L. (2007). Qualitative Research Methods for Social Sciences. New York: Pearson Education.

Breidlid, Anders (2009). Culture, Indigenous Knowledge System and Sustainable Development: A Critical View of Education in an African Context. International journal of Education Development. 29 (2), 140-148.

British Colonial Governance in Palestine (1935). Al-waqai' Al-Falasteniya 577. Retrieved December/10/11 from http://muqtafi.birzeit.edu/pg/.

British Colonial Governance in Palestine (1944), Al-waqai' Al-Falasteniya 1380. Retrieved December/10/11 from http://muqtafi.birzeit.edu/pg/.

Brown, Lester (2009). Plan B 4.0: Mobilizing to Save Civilization. U.S.A.: Earth Policy Institute.

Brynard, Petrus (2005). Policy Implementation: Lessons for Service Delivery, Paper Presented at African Association for Public Administration and Management, AAPAM Annual Roundtable Conference, Zambia. Retrieved April/15/2011 from http:/unpan1.un.org/intradoc/groups/public/documents/AAPAM/UNPAN025756.pdf.

Central Asian Institute (2011). August 26, 2011 - Cherry-Picked, Manipulated, and Misrepresented. Retrieved on May/13/2011 from http://www.ikat.org/. 
Cooper, Phillip J. and Vargas Claudia Maria, (2004). Implementing Sustainable Development: from Global Policy to Local Actions. U.S.A.: Rowman and Littlefield Publishers. (2008). Sustainable Development in Crisis Conditions: Challenges of War, Terrorism and Civil Disorder. U.S.A.: Rowman and Littlefield Publishers.

Creswell, John W. (2007). Qualitative Inquiry, Research Design: Choosing Among Five Approaches. London: Sage publication.

Dahl, Robert A. (1971). Polyarchy: Participation and Opposition. New Haven: Yale University Press.

Diesendorf, Mark (2000). Sustainability and Sustainable Development. Australia: Sustainability Centre PTY LTD. Retrieved April /2012 from: http://www.isf.uts.edu.au/publications/CorpSust.pdf.

Easton, David (1965). A Framework for Political Analysis. Englewood Cliffs: Prentice Hall.

Friedkin, Noah E. (2004). Social Cohesion, Annual Review Sociology (30) 409- 425. Retrieved June/10/2011 from http://www.soc.ucsb.edu/faculty/friedkin/Reprints/ARSCohesion.pdf.

Erving, Goffman (1986). Stigma: Notes on the Management of Spoiled Identity. New York: Touchstone publications.

Gambetta, Diego (1998). Trust Making and Breaking Cooperative Relations. Oxford: Basil Black Well Ltd.

Glaser, Barney G. and Strauss, Anselm L. (1967). The Discovery of Grounded Theory: Strategies for Qualitative Research. Chicago: Aldine Publishing Company.

Government of Israel and Palestinian National Authority (2002). The Four International Committee: The Road Map to Peace. Retrieved February/22/12 from http://www.cfr.org/middle-east/middle-east-road-map-peace/p7738\#p1.

Government of Israel and Palestinian Liberation Organization (1995a). The Wye River Memorandum. Retrieved February /22/12 from: http://www.state.gov/www/regions/nea/981023 interim_agmt.html.

Government of Israel and Palestinian Liberation organization (1995b). The IsraeliPalestinian Interim Agreement (Oslo II). Retrieved February /22/12 from: http://www.acpr.org.il/publications/books/44-Zero-isr-pal-interim-agreement.pdf. 
Institute of Law in Birzeit University (2006). The Informal Justice System In Palestine, Palestine Ramallah: Institute of Law Publications. Retrieved April/10/2011 fromhttp://www.freewebs.com/plhr/Kefah\%20Hamed.pdf.

Jordanian Laws and National Information System (2012). Jordanian Criminal Law N. 71 (1954). Retrieved on December 10/11 from http://www.lob.gov.jo/ui/laws/index.jsp.

Jordanian Laws and Nations Information System (2012). Jordanian Criminal Law N. 19 (1960). Retrieved on December 10/2011 from http://www.lob.gov.jo/ui/laws/index.jsp.

Kurzom, George (2001). Towards Alternative Self-Reliance Agricultural Development. Palestine Ramallah: Ma'an Development Center Publications.

Lijphart, Arend (1975 ). The Comparative Case Strategy in Comparative Research. Comparative Political Studies 8(2) 158-177.

Ma'an Development Center (2009). Ma'an Development Report. Ramallah, Palestine. Retrieved May/12/2011 from http://www.maan-ctr.org/pdfs/AnnualReport2009Final.pdf.

Mazmanian, Daniel and Sabatier, Paul (1983). Implementation and Public Policy. Glenview, III.: Scott Foresman.

Mortenson, Greg (2006). Three Cups of Tea. New York: Penguin Books Ltd.

Mortenson, Greg (2009). Stones into Schools. New York: Penguin Books Ltd.

Mtawi, Khaleel and Sharkas, Othman (2003). Characteristics of Rural and Urban Areas in Palestine. Palestinian Central Bureau of Statistics, Ramallah, Palestine. Retrieved November 24/ 2011 from:

http://www.pcbs.gov.ps/Portals/_PCBS/Downloads/book961.pdf

Nakamura, Robert T. and Smallwood, Frank (1980). The Politics of Policy

Implementation. New York: St. Martin's Press.

Oweiweih, Mohammed (2011). Details of Honor Killing Shocking. Ma'an News, Ramallah Palestine. Retrieved 5/9/2011 from:

http://www.maannews.net/eng/ViewDetails.aspx?ID=385727.

Palestinian Agricultural Relief Committees Website (2010). Women Economic Empowerment Program. Retrieved 11/30/11 from: http://www.palarc.org/programs/program7.html.

(2010). Women Social Empowerment Program. Retrieved on 11/30/11 from: http://www.pal-arc.org/programs/program2.html. 
Palestinian Economic Council for Development and Reconstruction PECDAR (2007). Annual Report. Retrieved on 12/1/11 from:

http://www.pecdar.ps/userfiles/file/activity2007.pdf.

Palestinian General Administration of Educational Planning (2005). Drop out

Phenomenon in Palestinian Schools: Causes and Prevention Procedures. Ramallah

Palestine. Retrieved on 11/30/11 from:

https://docs.google.com/viewer?a=v\&q=cache:wmbCesxJW2sJ:www.mohe.gov.ps/Uplo ads/admin/tasarob.doc $+\& \mathrm{hl}=\mathrm{en} \& \mathrm{gl}=$ us\&pid=bl\&srcid=ADGEESjgiMCLhvPtNejTg3f8d X6m4zSFM-XwApBRVy8bhoqtzvUIQ7BcS7gVW9PDVhGdw9hhFPkmquifnQ-cN7ZDFS0fTQaBVSZEA-

98fuX9Aj2eRKjLsa4QEbNdE34EHt0SC1Qp9kq\&sig=AHIEtbSTC-

txwSIvfEh17BC5FQPUn4gzYg.

Palestinian National Authority (2002). Palestinian Basic Law of (2005). Retrieved on December 10/2011 from http://www.palestinianbasiclaw.org/basic-law/2005-basic-law.

President Yasir Arafat (2003). Executive Order No. 161. Ramallah Palestine: Alwaqai Alfalasteeniya. Retrieved on October/6/2011 from http://muqtafi.birzeit.edu/pg/.

Pressman Jeffrey, and Wildavsky, Aaron (1983). Implementation: the Oakland Project, Third Ed, expanded. London England: University of California Press.

Pye-Smith, Charlie, Grazia Feyerabend, and Richard Sandbrook (1994). The Wealth of Communities: Stories of Success in Local Environmental Management. West Hartford, CT: Kumarian Press.

Sabatier Paul P. (1999). Theories of the Policy Process. U.S.A.: West View Press.

(1986). Top-Down and Bottom-Up Approaches of Implementation Research: a Critical Analysis and Suggested Synthesis. Journal of Public Policy. Vol.6 (1) 21-48. and Jenkin-Smith Hank (1993). Policy Change and Learning: An Advocacy Coalition Approach. U.S.A.: West View press.

Saleh, Muhsin (2001). The Palestinian Problem: its Background and Development until 2001. Gaza Palestine: Palestinian Media Center Publications.

Sen, Amartya (1999). Development as Freedom. New York: Anchor Books.

Shtayeh, Ali et al (2008). Traditional Knowledge of Wild Edible Plants Used in Palestine (Northern West Bank): A Comparative Study. Journal of Ethno-biology and EthnoMedicine (4) 13 1-13. Retrieved November/17/11 from http://www.ethnobiomed.com/content/4/1/13.

Stake, Robert E. (2006). Multiple Case Study Analysis. New York: The Golford Press. 
(1995). The Art of Case Study Research. New York: Sage Publication.

Stone, Deborah (2002). Policy Paradox: The Art of Political Decision Making. New York: Rev.. Ed. W.W. Norton

Thahir, Azeza (2010). Organic Farming: A Palestinian Promising Dimension Towards Producing Healthy Food. Afaq Al-Tanmiyah, (21) 1-3. Retrieved May /18/2011 from http://www.maan-ctr.org/magazine/Archive/issue21/topic3.php.

The Palestinian Central Bureau of Statistics (2010). Statistics of Education. Ramallah Palestine. Retrieved 11/28/11 from:

http://www.pcbs.gov.ps/DesktopDefault.aspx?tabID=4111\&lang=ar-JO.

The Palestinian Central Bureau of Statistics (2002). Statistics of Children's Nutrition. Ramallah Palestine. Retrieved November /29/11 from:

http://www.pcbs.gov.ps/DesktopModules/Articles/ArticlesView.aspx?tabID=0\&lang=en \&ItemID $=403 \& \mathrm{mid}=11128$.

The Special Inspector General for Afghanistan Reconstruction (2010). Quarterly Report to the United States Congress. Retrieved April/13/2011 from http://www.sigar.mil/pdf/quarterlyreports/jan2010/pdf/SIGAR_Jan2010.pdf.

The World Commission on Environment and Development (1987). Our Common Future. New York, United Nations: Oxford Press. Retrieved April/13/2011 from: http://www.un.org/documents/ga/res/42/ares42-187.htm.

The World Council of Credit Unions (2012). International Credit Union System. Retrieved on 11/24/11 from: http://www.woccu.org/memberserv/intlcusystem.

Trudy, Govier (1997). Trust and Human Communities. Canada: McGill-Queen's University Press.

United Nations (1992). United Nations Conference of Environment and Development: Agenda 21, Reo De Janerio Brazil. Retrieved April /13/ 2011 from: http://www.un.org/esa/sustdev/documents/agenda21/english/Agenda21.pdf.

(1995a). Copenhagen Declarations and Program of Action. New York: United Nations. Retrieved April/13/2011 from http://www.un.org/esa/earthsummit/. (1995b), World Summit for Social Development. Copenhagen Denmark. (1997). United Nations Earth Summit+5 Report: Special Session of the General Assembly to Review and Appraise the Implementation of Agenda 21. New York, USA. Retrieved May/18/ from: http://www.un.org/esa/earthsummit/.pdf.

(2005). Millennium Goals Progress Report. Retrieved May/20/2011 from http://www.un.org/millenniumgoals/reports.shtml. 
(2008). Resource Kit on Indigenous Peoples' Issues. New York: United Nations Publications.

(2009/2010). Human Development Report about Occupied Palestinian Territories: Investing in Human Security for a Future State. Retrieved May/12/2011 from http://hdr.undp.org/xmlsearch/reportSearch? $=* \& c=n \% 3$ AOccupied+Palestinian+Territo ry $\& \mathrm{t}=*$ \&lang $=$ en $\& \mathrm{k}=\&$.

(2010). The Millennium Goals Progress Report. Retrieved May/20/2011 from

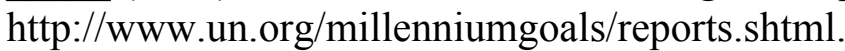

(2012). Millennium Goals Reports Website. Annual Reports. Retrieved

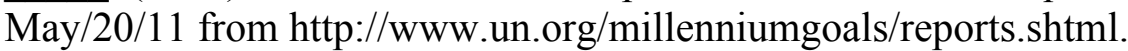

United Nations Development Program UNDP (1999). Human Development Report in Rwanda. Retrieved March/10/2011 from: http://hdr.undp.org/en/reports/.

(2004a). Afghanistan Human Development Report: Security with a Human Face Challenges and Responsibilities. New York, United Nations. Retrieved April 15/2011 from http://hdr.undp.org/en/reports/nationalreports/asiathepacific/afghanistan/Afghanistan 200 4 en.

(2004b). Arab Human Development Report: Towards Freedom in the Arab World. Retrieved May/11/2011 from http://www.arabhdr.org/publications/other/ahdr/ahdr2004e.pdf.

(2005). Arab Human Development Report: Towards the Rise of Women in the

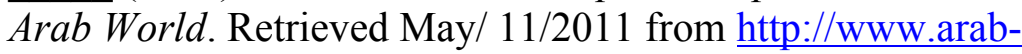
hdr.org/publications/other/ahdr/ahdr2005e.pdf.

(2009). Arab Human Development Report: Challenges to Human development in Arab Countries. Retrieved on May /11/2011 from http://www.arab-hdr.org/.

United Nations Document Gathering: a Body of Global Agreements (2011). Nairobi Declaration 1982. Retrieved December/8/11 from: http://www.un-documents.net/nairdec.htm.

United Nations Environment Program UNEP (1972). "United Nations Conference on Human Environment". Retrieved May/11/2011 from:

http://www.unep.org/Documents.Multilingual/Default.asp?documentid=97\&articleid=15 03.

(2003). Afghanistan: Post-conflict Environmental Assessment. Nairobi, Kenya.

First published in Switzerland. Retrieved May/19/2011 from

http://postconflict.unep.ch/publications/afghanistanpcajanuary2003.pdf. 
(2007). UN-Iraq Reconstruction and Development Report. Retrieved

$\overline{\mathrm{March}} / 10 / 2011$ from

ttp://www.uniraq.org/documents/UN_Iraq\%20Reconstruction\%20\&\%20Development\%2 0Update\%20June\%202007.pdf.

U.S. Bureau of Justice Statistics (2005). Intimate Homicide Victims by Gender.

Retrieved November /27/2011 from:

http://bjs.ojp.usdoj.gov//homicide/tables/intimatestab.htm.

Uslaner, Eric M. (2001). The Moral Foundation of Trust. New York: Cambridge University Press.

Van Meter, Donald and Van Horn, Carl (1975). The Policy Implementation Process: A Conceptual Framework. Administration and Society (6), 445-488.

Vargas Claudia Maria (1998). Ethical Challenges in Refugee Research: Troublesome Questions, Difficult Answers. Refuge, 17 (3) 33-41. Retrieved March/16/2011 from http://pi.library.yorku.ca/ojs/index.php/refuge/index.

(2000). Community Development and Micro-Enterprises: Fostering Sustainable Development. Sustainable Development 8 (1) 11-26.

(2002). Bridging Solitudes: Partnership Challenges in Canadian Refugee Service Delivery. Refuge, 18 (6) 1-6. Retrieved March/15/2011 from https://pi.library.yorku.ca/ojs/index.php/refuge/article/viewFile/22054/20722.

Warren, D. M. (1991). Using Indigenous Knowledge in Agricultural Development. World Bank Discussion Paper No.127. Washington, D.C.: The World Bank. Retrieved March/13/2011 from http://www.worldbank.org/afr/ik/ikpaper_0102.pdf.

Weeramantry Christopher (2002). Sustainable Development: An Ancient Concept Recently Revived, Presentation at the Global Judge's Symposium on Sustainable Development and the Role of Law. Universalizing International Law, pp. 431-437. Johannesburg, South Africa. Retrieved on May/20/2011 from http://www.google.com/search?client $=$ safari\&rls=en\&q=Weeramantry + Christopher $++(2$ 000), + sustainable + Development: + An + Ancient + Concept ++ recently + Revived\&ie $=$ UTF$\underline{8 \& o e=U T F-8}$.

World Bank (1993). "Traditional Knowledge and Sustainable Development Conference" Washington DC. Retrieved December/14/11 from: http://collections.infocollections.org/ukedu/uk/d/Jwb43te/4.1.html.

(1998). Indigenous Knowledge for Development: A Framework for Action. World Bank Publications. Retrieved December/15/11 from http://www.worldbank.org/afr/ik/ikrept.pdf. 
Press.

(2000a), Voices of the Poor Report: Crying out For Change. Oxford University

(2000b), Voices of the Poor Report: Can Anyone Hear us? Oxford University

Press.

(2000c), Voices of the Poor Report: From Many Lands. Oxford University Press.

(2003). Breaking the Conflict Trap, Civil War and Development Policy. The World Bank and Oxford University Press. Retrieved May/18/2011 from http://hdr.undp.org/en/reports/. (2009). International Reconstruction Fund Facility for Iraq: World Bank-Iraq

Trust Fund, Report For Donors. Retrieved on March/10/2011 from http://hdr.undp.org/en/reports/.

World Fair Trade Organization (2011). About Fair Trade. Retrieved November/10/11 from: http://www.wfto.com/.

Yin, Robert K. (2009). Case Study Research: Design and Methods, $4^{\text {th }}$ edition. London: The Sage publication.

Yunus, Muhammad (2003) Banker to the Poor: Micro-lending and the Battle against World Poverty, New York: Public Affairs.

\section{Interviews}

Abu Alayya Rajih (2011 December 14). Personal interview

Abu Al-Hayja Abd Alrazik (2011 December 14) Personal interview

Abu Dayi S. Amera (2011 September 18) Personal interview

Al-Qadi Farid (2011 September 14). Personal interview

Al-Qadi Mahmoud (2011 October 8). Personal interview

Al-Qadi M. Saleem (2011 September 12). Personal interview

Alzabin Abd Alrahman (2011 September 12). Personal interview

Alyat M. Samar (2011 September 17). Personal interview

Ashkar Rawda (2011 September 18). Personal interview

Bakir Ribhi (2011 December 1). Personal interview

Dager Said (2011 October 6). Personal interview 
Galudi Suher (2011 December 13). Personal interview

Hamad N. Susan (2011 September 17). Personal interview Jabir Tahani (2011 December 7). Personal interview

Masri A. Ali (2011 September 12). Personal interview

Om Suhayb (2011 December 7). Personal interview

Rizkallah Farid (2011 September 15). Personal interview

Sabah J. Amal (2011 September 18). Personal interview

Salah M. Said (2012 January 4). Personal interview

Sirisi M. Sulayman (2011 September 29). Personal interview

Turukman F. Fakri (2011 September 29). Personal interview

Zabin H. Saleem (2011 September 12). Personal interview

Zaid Radi (2012 January 29). Personal interview

Zaidan Hanin (2011 October 13). Personal interview 


\section{Appendices}

Appendix A- Interview questions of case one: Organic (Baladi), Extra Virgin Olive Oil Producing Project in Bani-Zaid Al-Sharkiya Community: "We Treat the Olive Tree As We Treat Our Children."

I am (the interviewer).........................Member of research team studying "Building on the Strengths of Indigenous Knowledge to Promote Sustainable Development in Crisis Conditions from the Community Level: The Case of Palestine". This study is conducted by Jehad Alayasa; PhD student in Portland State University. Your community is part of this study. Thank you for participating in this study, we appreciate your time.

Please feel free to interrupt, for any reason, and ask any question. Also you have the right to stop the interview at any time you want. The information you provide will be treated confidentially and only for the purpose of research and knowledge. You might choose that your name will not be mentioned in the study report.

\section{Personal Questions}

Can you please introduce your self (your name, age, marital status, level of education, and number of children if any, and role in the Bani-Zaid Cooperative) and how long have you been practicing organic farming?

How do you define organic (baladi) farming, what are the characteristics of this type of farming and how it is distinguished from other types (non- organic)?

How did you know and learn how to practice Baladi farming?

Which Baladi farming do you grow?

Why do you choose these kinds of crops particularly?

Which indigenous practices (kinds of seeds, plants, fertilizers, treating diseases etc) do you use in your farms?

\section{Common Questions}

Community level

How common is the Baladi farming pattern in your community?

Does your co-operation collaborate with other co-operations in other committees? 
How regarded is your cooperation in other communities?

What are the social benefits that your Baladi farming project achieved to your community?

How do you think your Baladi farming project contributes to strengthening social cohesion in your community?

Are there any economic problems that Baladi farming contributes to solve or economic benefits Baladi farming brings to your community? (Think about if it doesn't exist)

Are there any environmental problems that Baladi farming contributes to solve or environmental benefits that it brings to the community? (Think about if it doesn't exist)

\section{Strengths and Success}

Among many Baladi farming co-operatives in your district and other districts, do you think your cooperation is a successful one?

What are the indicators of success?

How acceptable is the idea of Baladi farming (crops) in your community?

Are Baladi Products preferable in your community?

Why do people prefer Baladi products (if they do) among other alternatives.

Baladi farming is rooted in the Palestinian culture, do you think this fact has helped your project success?

Which other organizations (official, NGOs) or community groups or individuals support Baladi farming patterns in your community?

\section{Crisis Conditions}

Crisis conditions, for the purpose of this study, defined as conditions crated because of the long term occupation and conflict that, in many cases, disable or weaken the government (PNA) to function well, economic crisis and economic siege, and political division between Gaza and West Bank.

What are the most important needs for communities living under crisis conditions such as yours?

What are the challenges that face Baladi farming in such crisis conditions? 
How do co-operatives like yours contribute to overcome these challenges?

Who are the partners (local, national and international) who help your cooperation to overcome challenges?

From a sustainable development perspective, sustainable solutions are the ones that integrate or (brings integrated solutions) between social, environmental and economic dimensions:

Does Baladi farming as an indigenous based development project integrate between social development, economic development and environmental development?

\section{Indigenous Knowledge and Sustainable development}

Baladi farming pattern is classified to be derived from Palestinian indigenous (traditional) culture, how have Baladi farming pattern historically developed over generations?

Thinking about any Baladi product you know, can you describe some indigenous (traditional) solutions that have been developed over time?

What are the advantages of such solutions say over modern solutions?

Who are the people who prefer to use Baladi farming patterns: for example, elders, religious, poor people, rich people, people living in urban/rural areas, etc?

Who are influenced (directly or indirectly) by your Baladi project in your community?

If people do not choose Baladi farming, what are the other alternatives?

What are the advantages of other alternatives?

What are the disadvantages (harms) of other alternatives?

Why do people choose indigenous knowledge based (derived from the local culture) patterns among other alternatives?

Does being indigenous knowledge based pattern increase/decrease acceptability of Baladi farming role in your community?

Does the fact that Baladi farming is an indigenous knowledge based pattern improve social cohesion in your community? How?

Considering the definition of SD that we talked about, and the characteristics of crisis conditions your community is living, Do you think IK based patterns such as Baladi farming can support sustainable development? 
Do you think indigenous knowledge (culture) serves/obstacles the purposes of the sustainable development in crisis conditions?

Do you think Baladi farming serve Palestinian self -reliance capabilities as people living under crisis?

What are the challenges that face traditional pattern such as Baladi farming in you community?

What do you do/suggest to overcome these challenges?

\section{Particular question}

What is the role of the women in your Baladi farming project?

According to your experience, what are the economic impacts (job opportunity, improve in your income, etc) of Baladi farming projects implemented in your community on your life and family?

What are the social impacts (for example poverty radicaction, family unity, educating children, social cohesion) of Baladi farming projects implemented in your community on your life and family?

Organic (Baladi) farming is considered to have good impacts on both human health and the environment. From your experience, how does Baladi farming: protect the environment and natural resources:

Protect peoples' health (diseases):

Produce healthy nutrition to Palestinian people:

Do you think people in your community appreciate and regard the Baladi farming impacts discussed above? Why? Why not?

Do you have any suggestion about how to improve Baladi farming implementation in Palestinian communities in the future?

Why do you think members in your community support, regard, and participate in development activities implemented by your cooperative? 
Appendix B- Interview questions of case two: Social and Economic Empowerment of Rural Women in the West Bank Women's Clubs, Rural Women's Development Society, and the Palestinian Agricultural Relief Committees.

I am (the interviewer)..........................ember of research team studying "Building on the Strengths of Indigenous Knowledge to Promote Sustainable Development in Crisis Conditions from the Community Level: The Case of Palestine". This study is conducted by Jehad Alayasa; PhD student in Portland State University. Your community is part of this study. Thank you for participating in this study, we appreciate your time.

Please feel free to interrupt, for any reason, and ask any question. Also you have the right to stop the interview at any time you want. The information you provide will be treated confidentially and only for the purpose of research and knowledge. You might choose that your name will not be mentioned in the study report.

\section{Personal Questions}

Can you please introduce your self (your name, age, marital status, level of education, number of children if any, and your position in the your women's club?

Please describe, what is your role in you women's club and how long have you been part of the project?

Can you please give us an idea about the project? What is Rural Women Empowerment project doing?

Who benefit from this project? Are there any conditions of beneficiary?

How many members are there in your women's clubs?

How many women's clubs are there now?

How did you know about the project?

How did you become a member in your women's club?

What are the conditions of membership?

What are the challenges that you faced at first?

How do members choose the club's administrative leaders?

The Rural Women Empowerment Project is interested in traditional culture basedactivities, can you please describe these activities? 


\section{Common Questions}

Community level

How acceptable/common are the traditional activities that members of women's clubs practice in your community?

Does your women's club collaborate with other clubss in other committees?

How regarded are your products in other communities, for example urban communities?

What are the social purposes of rural women's clubs in general?

What are the key social achievements (empowerment) that your club has offered for members?

On the family level (with your husband, children, family and community), how does the empowerment program influence your life?

How do you define, look at women social empowerment and its importance in your community?

How do you think your Rural Empowerment Project contributes to strengthening social cohesion in your community?

Comparing before and after the empowerment program, how does your community look at the role of women in the society?

With more focus on your community, what are the impacts of the Empowerment Project on:

Education

Healthcare

Voluntary work

Political life 
What are the economic achievements of your women's clubs for members in general?

Personally, what are your benefits from the club?

Comparing you economic situation before and after being a member, how did the project of rural women empowerment and being a member in your club economically changed your life, for example improved your income, supported you to start a business etc?

With respect to the environment (indigenous patterns of natural resources management, planting, home gardens, community cleanness, recycling etc), which of these (or others) are addressed by the empowerment project?

Describe in details the environmental activities your women's club implemented in your community?

\section{Strengths and Success}

Among many projects that address women in your district and other districts, do you think your Rural Women Empowerment Project is a successful one?

What are the indicators of success?

How accepted is the idea of social empowerment (social and political participation) of women in your community?

How accepted is the idea of economic empowerment (participating in the business market, managing their own businesses) of women in your community?

Many of your project's activities such as (crafting, food preparing, caning and reserving, raising animals and poultry etc) s are rooted and practiced in the Palestinian traditional culture, do you think this fact has helped your project success?

Which other organizations (official, NGOs) or community groups or individuals support the project?

\section{Crisis Conditions}

Crisis conditions, for the purpose of this study, is defined as conditions created because of the long term occupation and conflict that, in many cases, disable or weaken the government (PNA) to function well, economic crisis and economic siege, and political division between Gaza and West Bank.

What are the most important needs for communities living under crisis conditions such as yours? 
What are the challenges that face your project as a leading women empowerment one in such crisis conditions?

How do women's clubs like yours contribute to overcome these challenges?

Who are the partners (local, national and international) who help your club to overcome challenges?

From a sustainable development perspective, sustainable solutions are the ones that integrate or (brings integrated solutions) between social, environmental and economic dimensions:

Do you think your project brings sustainable responds to your community problems under crisis conditions?

More specifically, does you project, as an indigenous based development project, integrate between social development, economic development and environmental development?

\section{Indigenous Knowledge and Sustainable Development}

Development pattern implemented in your project is classified to be derived from Palestinian indigenous (traditional) culture, how have these patterns historically developed over generations?

Thinking about any activities and patterns that you practice, can you describe some indigenous (traditional) solutions that have been developed over time?

What are the advantages of such solutions say over modern solutions?

Who are the people who prefer to use traditional patterns, for example, elders, religious, poor people, rich people, people living in urban/rural areas, etc?

Who are the clients of (people who buy) your products?

Who are influenced (directly or indirectly) by your project in your community?

Thinking about one example, if women do not use traditional patterns like the ones you use, what are the other alternatives they may use?

What are the advantages of these other alternatives?

What are the disadvantages (harms) of these other alternatives?

Why do people choose indigenous knowledge based (derived from the local culture) patterns among other alternatives? 
Does being indigenous knowledge based pattern increase/decrease acceptability of your project's role in your community?

Does the fact that Rural Women Empowerment Project is an indigenous knowledge based pattern improve social cohesion in your community? How?

Considering the definition of SD that we talked about, and the characteristics of crisis conditions your community is living, Do you think IK based patterns such as patterns used in your project can provide sustainable development?

In Particular, do you think traditional patterns implemented in your project integrate the three pillars of sustainable development, the social, the economic and the environmental?

Do you think indigenous knowledge (culture) serves/obstacles the purposes of the sustainable development?

Do the patterns implemented in your project serve Palestinian self -reliance capabilities as people living under crisis?

What are the challenges that face traditional pattern of development such as these implemented in your project?

What do you do/suggest to overcome these challenges?

\section{Particular question}

Does Rural Women empowerment Project improve the role of women in the Palestinian society? How?

Do men in your direct family support/obstacle women participation in the Empowerment Project?

Do men in your community support/obstacle women participation in the Empowerment Project?

What are the economic impacts (job opportunity, improve in your income, etc) of the project on your life and family?

What are the social impacts (Poverty reduction, family unity, improving in you educational level, educating children, socialization etc) of the project on your life and family?

Does being part of the Rural Women Empowerment Project have good impacts on your and your family's health?

What are the impacts of the home garden supported by the project on your family? 
Why do you think your community support and participate in development activities implemented by your club?

Why do your community trust your club in terms of implementing sustainable development activities?

Why do you trust PARC and RWDA among national NGOs who support development in Palestine?

Do you have any suggestions about how to improve the function of the project in the future? 
Appendix C- Interview questions of case three: Sulha Committees: An Indigenous Pattern of Conflict Resolution, The Case of the Central Sulha Committee in Jenin District

I am (the interviewer) Member of research team studying "Building on the Strengths of Indigenous Knowledge to Promote Sustainable Development in Crisis Conditions from the Community Level: The Case of Palestine". This study is conducted by Jehad Alayasa; PhD student in Portland State University. Your community is part of this study. Thank you for participating in this study, we appreciate your time.

Please feel free to interrupt, for any reason, and ask any question. Also you have the right to stop the interview at any time you want. The information you provide will be treated confidentially and only for the purpose of research and knowledge. You might choose that your name will not be mentioned in the study report.

\section{Personal}

As a Sulha Committee member, introduce your self (name, age, marital status, level of education, and place of living).

How did you become a member in Jenin Central Sulha Committee (JCSC)? Were you invited by other members of the committee, elected, appointed by someone, or did it come about in another way?

Please describe your role in the committee (if identified)

What does the committee do?

Could you mention the most common kinds of problems that the committee addresses?

What is the most interesting or unusual problem that your committee has resolved? How does it work when someone brings a problem to you?

\section{Common Questions}

Community level

How acceptable is JCSC as a conflict dispute pattern in your community?

Does your Sulha Committee cooperate with other committees in other communities?

How regarded is your Sulha Committee in other communities? 
How do you think your Sulha committee contributes to strengthening social cohesion in your community?

What are the most critical social problems that your Sulha committee responds to?

Are there any economic problems that JCSC contributes to solve or economic benefits SC brings to your community? (Think about if it doesn't exist)

Are there any environmental problems that SC contributes to solve or environmental benefits that it brings to the community? (Think about if it doesn't exist)

\section{Strengths and Success}

Among many SCs in your district and other districts, do you think your SC is a successful one?

What are the indicators of success?

Do the dispute parties in your community usually accept/reject your committee solutions?

Why do you think people in your community accept your committee's solutions?

What Happens when people rejects Sulha Solutions

Do you remember any cases that rejected your solutions? Why did people rejected?

Why do people prefer Sulha Solutions among other alternatives, for example going to a court?

Which other organizations (official, NGOs) or community groups or individuals support SCs patterns

\section{Crisis Conditions}

Crisis conditions, for the purpose of this study, defined as conditions crated because of the long term occupation and conflict that, in many cases, disable or weaken the government (PNA) to function well, economic crisis and economic siege, and political division between Gaza and West Bank.

What are the most important needs for communities living under crisis conditions such as yours?

What are the challenges that face SC work in such crisis conditions?

How does your SC contribute to overcome these challenges? 
Who are the partners (local, national and international) who help your SC to overcome challenges?

What is the role of these partners? What do they do?

From a sustainable development perspective, sustainable solutions are the ones that integrate or (brings integrated solutions) between social, environmental and economic dimensions:

Do you think your SC brings sustainable solutions to your community problems under crisis conditions?

Indigenous Knowledge and Sustainable Development

SC pattern is classified to be derived from Palestinian indigenous (traditional) culture, how have SC pattern historically developed over generations?

Who are the clients of (people who seek solutions from) SC pattern: for example, elders, religious, poor people, rich people, people living in urban/rural areas, etc?

Who are influenced (directly or indirectly) by SC solutions?

If people do not choose SC to solve their problems, what are the other alternatives?

Why do people choose (trust) indigenous knowledge based (derived from the local culture) patterns among other alternatives?

Does being indigenous knowledge based pattern increase/decrease acceptability of $\mathrm{SC}$ role in your community?

Does the fact that SC is an indigenous knowledge based pattern improve social cohesion in your community?

Do you think indigenous knowledge (culture) serves/obstacles the objectives of the sustainable development in crisis conditions?

Do you think SC pattern of conflict resolution serve building self-reliance model of living for people living under crisis conditions such as your community?

What are the challenges that face traditional pattern such as SCs in you community?

\section{Specific Questions about the Case}

What are the criteria of "justice" Sulha committees consider in solving conflicts in your community? 
Do you have an example(s) in mind about a case that your indigenous pattern failed to solve a conflict and what were the reasons?

How do you evaluate the role of Sulha Committee (consider your committee and other committees) in the role of law in the Palestinian society?

SC pattern of conflict resolution is recognized to play a protective role in Palestinian communities, which kind of protection does your SC provide to your community?

Is there any kind of collaboration between your SC and the PNA institutions such as the governor, the police?

Describe your committee's relationship with the PNA?

If you are to compare between the role of Sulha committees in your community before the PNA (1993) at the intefada 1987-1993) time and after the PNA (1993now), what are the differences and similarities?

Do you have suggestions how to improve the role of SCs in Palestinian communities in the future? 
Appendix D- Interview Questions for Directors of Case one and two

I am (the interviewer)...........................ember of research team studying "Building on the Strengths of Indigenous Knowledge to Promote Sustainable Development in Crisis Conditions from the Community Level: The Case of Palestine". This study is conducted by Jehad Alayasa; PhD student in Portland State University. The project (name of the project) that you are the director of is part of this study. Thank you for participating in this study, we appreciate your time.

Please feel free to interrupt, for any reason, and ask any question. Also you have the right to stop the interview at any time you want. The information you provide will be treated confidentially and only for the purpose of research and knowledge. You might choose that your name will not be mentioned in the study report.

Please introduce your self (your name, age, level of education position)

What is your role in this project and how long have you been interested in and working with Baladi farming projects?

Could you please describe how do you work with the community, what do you do?

Your organization has been working on Baladi farming for a long time, how did the idea of organic come to the interest of your organization?

What are the other development interests of your organization?

\section{Common Questions}

\section{Community level}

You project is recognized and certified to be successful in the development field, what is special about this community that made the project success?

How did you choose this community for this project of organic farming?

Organic farming has been implemented in different communities in Palestine, what are your criteria of selecting these communities?

What are you association's social objectives from implementing Baladi farming in Palestinian communities?

What are the key social achievements that your association accomplished from this project?

With more focus on community level, what are the impacts of the Project on: 


\section{Education}

Healthcare

Voluntary work

Empowerment of farmers' communities

What are the economic achievements of the project for participants?

With respect to the environment (indigenous patterns of natural resources management, planting, home gardens, community cleanness, recycling etc): Which of these (or others) are addressed by the Baladi farming project?

\section{Strengths and Success}

Among many projects that your association implements in the Palestinian society, do you think your Baladi farming project is a successful one?

What are the indicators of success?

Baladi farming is rooted in the Palestinian traditional culture, do you think this fact has helped the project success?

Who are the project's partners; organizations (official, NGOs) or community groups or individuals that support the project?

\section{Crisis Conditions}

Crisis conditions, for the purpose of this study, is defined as conditions created because of the long term occupation and conflict that, in many cases, disable or weaken the government (PNA) to function well, economic crisis and economic siege, and political division between Gaza and West Bank.

What are the most important needs for communities living under crisis conditions such as Baladi farming project community?

What are the challenges that face your project as a leading Baladi farming one in such crisis conditions?

How do cooperatives like Bani Zaid cooperation contribute to overcome these challenges?

Who are the partners (local, national and international) who help your association to overcome challenges? 
From a sustainable development perspective, sustainable solutions are the ones that integrate or (brings integrated solutions) between social, environmental and economic dimensions:

Do you think your project brings sustainable solutions to Palestinian communities under crisis conditions?

More specifically, does you project, as an indigenous based development project, integrate between social development, economic development and environmental development?

\section{Indigenous Knowledge and Sustainable Development}

Development pattern implemented in your project is classified to be derived from Palestinian indigenous (traditional) culture, how have these patterns historically developed over generations?

Thinking about any activities and patterns that participants in the project practice, can you describe some indigenous (traditional) solutions that have been developed over time?

What are the advantages of such solutions say over modern solutions?

Who are the people who prefer to use traditional patterns, for example, elders, religious, poor people, rich people, people living in urban/rural areas, etc?

Does your association help in marketing Baladi products nationally?

Does it help in marketing internationally?

Who are the clients of (people who buy) Baladi products?

Besides the co-operation members, who are influenced (directly or indirectly) by your project?

Thinking about one example, if farmers do not use traditional patterns like the ones they use, what are the other alternatives they may use?

What are the advantages of these other alternatives?

What are the disadvantages (harms) of these other alternatives?

Why do people choose indigenous knowledge based (derived from the local culture) patterns among other alternatives?

Does being indigenous knowledge based pattern increase/decrease acceptability of your project's role in the community? 
Does the fact that Baladi farming project is an indigenous knowledge based pattern improve social cohesion in the community? How?

Considering the definition of sustainable development that we talked about, and the characteristics of crisis conditions your community is living, Do you think IK based patterns such as patterns used in your project can provide sustainable development?

In Particular, do you think traditional patterns implemented in your project integrate the three pillars of sustainable development, the social, the economic and the environmental?

Do you think indigenous knowledge (culture) serves/obstacles the purposes of sustainable development?

Do the patterns implemented in your project serve Palestinian self -reliance capabilities as people living under crisis?

What are the challenges that face traditional pattern of development such as these implemented in your Baladi farming project?

What do you do/suggest to overcome these challenges?

\section{Specific Questions}

Do you have any plans to target other communities in developing Baladi farming?

Can Palestine build on Baladi farming (as it used to be in the past) policy? What are the advantages and disadvantages of such policy?

Baladi farming is based on indigenous practices, what did you as a director, and your organization as a developer learned from these indigenous patterns?

What are the reasons that communities trust developers, and how can developers build on this trust to achieve sustainable development in crisis conditions? 